Uma abordagem híbrida relacional para a desambiguação lexical de sentido na tradução automática

\author{
Lucia Specia
}





\title{
Uma abordagem híbrida relacional para a desambiguação lexical de sentido na tradução automática
}

\author{
Lucia Specia
}

Orientadores: Profa. Dra. Maria das Graças Volpe Nunes e Prof. Dr. Mark Stevenson

Tese apresentada ao Instituto de Ciências Matemáticas e de Computação - ICMC-USP, como parte dos requisitos para obtenção do título de Doutor em Ciências - Ciências de Computação e Matemática Computacional.

\section{"VERSÃO REVISADA APÓS A DEFESA"}

Data da Defesa:

$28 / 09 / 2007$

Visto do Orientador:

USP - São Carlos

Novembro de 2007 



\section{AGRADECIMENTOS}

Agradeço à Maria das Graças Volpe Nunes pela orientação, apoio e incentivo nesses 4.5 anos de trabalho. Lembro ainda com alegria do dia em que a Graça decidiu me aceitar como aluna de doutorado. Essa aceitação foi decisiva para a minha formação acadêmica. Sua confiança e apoio incondicionais, desde o início e mesmo nos períodos mais críticos deste trabalho, foram extremamente relevantes. Admiro a sua segurança como orientadora, o que permite que nós, alunos, tenhamos a liberdade para o desenvolvimento do nosso trabalho, o que é tão importante para o nosso crescimento e formação plena como pesquisadores.

I thank my co-supervisor in the UK, Mark Stevenson, for his supervision during my one-year internship at the University of Sheffield. Besides all the technical help, Mark was always very supportive and encouraging and I really appreciate the effort he made to put me in contact with so many other researchers from Europe and all over the world. I also thank my colleagues over there for making my life more enjoyable in my first ever year abroad, especially Vitaveska Lanfranchi.

I am very grateful to my manager at the Knowledge Media Institute (Open University), Enrico Motta, for giving the opportunity to start working on a new and exciting area, the Semantic Web, while still allowing me to develop my PhD work. I also thank my colleagues and office mates Marta Sabou and Dnyanesh Rajpathak.

I am very thankful to Ashwin Srinivasan, who supervised me during my internship at IBM Research in New Delhi. In only one month, Ashwin not only helped me with all my issues related to Inductive Logic Programming, but also brought innovative ideas to my $\mathrm{PhD}$, and encouraged me to further develop these ideas in future work, in a collaboration that has been very successful. I also thank our third collaborator, Ganesh Ramakrishnan, for all his help with Machine Learning issues.

I thank my managers at Microsoft Research India, A. Kumaran and Baskaran Sankaran. Working for Microsoft gave me the chance to evaluate my $\mathrm{PhD}$ proposal in a real application and also allowed me to learn a lot about Statistical Machine Translation.

Agradeço aos colaboradores de partes do trabalho descrito nesta tese, Gabriela Castelo Branco Ribeiro e Syllas Freitas Oliveira-Neto, pelo esforço e motivação para realizar experimentos sob a minha supervisão.

Agradeço aos amigos e colegas do NILC pelo apoio constante, em especial, à amiga Helena de Medeiros Caseli e aos colegas que me auxiliaram em experimentos diversos: Marcela Franco Fossey, Mônica S. Martins e Carmen Dayrell. Agradeço também ao NILC pelo apoio financeiro para a participação em muitos eventos científicos. 
Agradeço ao ICMC-USP pelas instalações e auxílio financeiro para a participação em eventos, bem como a todos os funcionários pelos seus serviços.

Agradeço à CAPES pela bolsa de doutorando sanduíche em Sheffield, que me propiciou tantas oportunidades de crescimento e amadurecimento como pesquisadora.

Agradeço aos meus amigos queridos, Valéria Feltrim, Jorge M. Pelizzoni e Marcela F. Fossey, dos quais sinto muita falta.

Agradeço muito à minha grande e fantástica família, pelo incentivo constante nesses anos todos, apesar da distância.

Por fim, agradeço infinitamente ao meu parceiro para a vida toda, Teo, por tudo de maravilhoso que nos tem acontecido nos últimos dois anos - incluindo a conclusão dessa tese. Seu companheirismo, apoio, paciência, motivação e carinho foram imprescindíveis. 


\section{RESUMO}

A comunicação multilíngue é uma tarefa cada vez mais imperativa no cenário atual de grande disseminação de informações em diversas línguas. Nesse contexto, são de grande relevância os sistemas de tradução automática, que auxiliam tal comunicação, automatizando-a. Apesar de ser uma área de pesquisa bastante antiga, a Tradução Automática ainda apresenta muitos problemas. Um dos principais problemas é a ambigüidade lexical, ou seja, a necessidade de escolha de uma palavra, na língua alvo, para traduzir uma palavra da língua fonte quando há várias opções de tradução. Esse problema se mostra ainda mais complexo quando são identificadas apenas variações de sentido nas opções de tradução. Ele é denominado, nesse caso, "ambigüidade lexical de sentido". Várias abordagens têm sido propostas para a desambiguação lexical de sentido, mas elas são, em geral, monolíngues (para o inglês) e independentes de aplicação. Além disso, apresentam limitações no que diz respeito às fontes de conhecimento que podem ser exploradas. Em se tratando da língua portuguesa, em especial, não há pesquisas significativas voltadas para a resolução desse problema. O objetivo deste trabalho é a proposta e desenvolvimento de uma nova abordagem de desambiguação lexical de sentido, voltada especificamente para a tradução automática, que segue uma metodologia híbrida (baseada em conhecimento e em córpus) e utiliza um formalismo relacional para a representação de vários tipos de conhecimentos e de exemplos de desambiguação, por meio da técnica de Programação Lógica Indutiva. Experimentos diversos mostraram que a abordagem proposta supera abordagens alternativas para a desambiguação multilíngue e apresenta desempenho superior ou comparável ao do estado da arte em desambiguação monolíngue. Adicionalmente, tal abordagem se mostrou efetiva como mecanismo auxiliar para a escolha lexical na tradução automática estatística.

Palavras-chave: Tradução Automática, Ambigüidade Lexical de Sentido, Desambiguação Lexical de Sentido, Programação Lógica Indutiva 



\begin{abstract}
Crosslingual communication has become a very imperative task in the current scenario with the increasing amount of information dissemination in several languages. In this context, machine translation systems, which can facilitate such communication by providing automatic translations, are of great importance. Although research in Machine Translation dates back to the 1950 's, the area still has many problems. One of the main problems is that of lexical ambiguity, that is, the need for lexical choice when translating a source language word that has several translation options in the target language. This problem is even more complex when only sense variations are found in the translation options, a problem named "sense ambiguity". Several approaches have been proposed for word sense disambiguation, but they are in general monolingual (for English) and application-independent. Moreover, they have limitations regarding the types of knowledge sources that can be exploited. Particularly, there is no significant research aiming to word sense disambiguation involving Portuguese. The goal of this $\mathrm{PhD}$ work is the proposal and development of a novel approach for word sense disambiguation which is specifically designed for machine translation, follows a hybrid methodology (knowledge and corpus-based), and employs a relational formalism to represent various kinds of knowledge sources and disambiguation examples, by using Inductive Logic Programming. Several experiments have shown that the proposed approach overcomes alternative approaches in multilingual disambiguation and achieves higher or comparable results to the state of the art in monolingual disambiguation. Additionally, the approach has shown to effectively assist lexical choice in a statistical machine translation system.
\end{abstract}

Keywords: Machine Translation, Lexical Semantic Ambiguity, Word Sense Disambiguation, Inductive Logic Programming 



\section{LISTA DE FIGURAS}

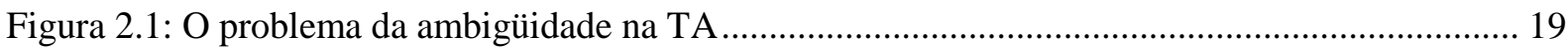

Figura 3.1: Modos e tarefas de aprendizado em AM (Monard \& Baranauskas, 2003, p. 91).............. 85

Figura 4.1: Processo de identificação e anotação da tradução de cada ocorrência (ocorrência ${ }_{x}$ ) do verbo $\left(\right.$ verbo $_{\mathrm{v}}$ ) em uma unidade paralela (EUi e PUi) de um dado córpus C ....................................... 138

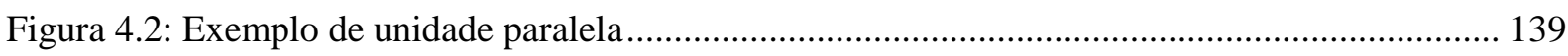

Figura 4.3: Traduções candidatas para a unidade paralela na Figura 4.2 …...................................... 139

Figura 4.4: Exemplos de anotações produzidas para sentenças dos verbos come, get e take ............. 140

Figura 5.1: Representação utilizando-se vetores de atributos ........................................................... 148

Figura 5.2: Vetor atributo-valor para a representação de relações sintáticas ....................................... 151

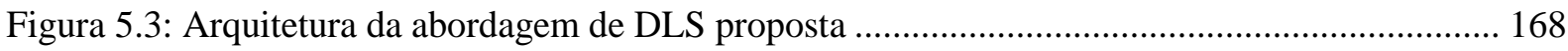

Figura 5.4: Exemplos de regras produzidas pelo Aleph para a desambiguação do verbo come .......... 175

Figura 5.5: PLI para o aprendizado de atributos proposicionais ....................................................... 177

Figura 5.6: Exemplo de atributo binário construído a partir de uma cláusula que identifica o sentido do verbo come como "voltar" caso os predicados has_expression e has_pos sejam verdadeiros... 179 Figura 6.1: Exemplos de regras produzidas para o verbo come no Experimento 1 ............................ 188

Figura 6.2: Exemplos de regras produzidas no Experimento 4 para a desambiguação do verbo ask 197

Figura 6.3: Exemplos de regras produzidas no Experimento 5 para o verbo appear.......................... 199

Figura 6.4: Exemplos de regras produzidas no Experimento 7 para o verbo expect........................... 205

Figura 6.5: Exemplo de definição de sentido no SemEval-2007 contendo expressões verbais ........... 207

Figura 6.6: Exemplo de definição de sentido no SemEval-2007 específica para expressões verbais. 208

Figura 6.7: Exemplos de regras produzidas no Experimento 8 para o substantivo authority ............. 208

Figura 6.8: Técnica $n$-best reranking para a adição de funções a um sistema básico de TA.............. 217 



\section{LISTA DE TABELAS}

Tabela 2.1: Exemplos de traduções dos três sistemas de TA 30

Tabela 2.2: Compilação da análise da ambigüidade dos verbos 33

Tabela 2.3: Exemplos de sentenças do BNC com verbos problemáticos.............................................. 33

Tabela 2.4: Sentenças do New York Times com ambigüidade lexical ................................................... 34

Tabela 2.5: Verbos e substantivos ambíguos do New York Times........................................................ 35

Tabela 2.6: Exemplos de sentenças do NYT com ambigüidade lexical de sentido nos verbos ............ 35

Tabela 2.7: Exemplos de sentenças com ambigüidade lexical de sentido de Oliveira et al. (2000) ..... 36

Tabela 2.8: Ocorrências dos verbos isoladamente e em expressões verbais .......................................... 40

Tabela 2.9: Distribuição das sentenças selecionadas entre os cinco tradutores ..................................... 42

Tabela 2.10: Possíveis sentidos e traduções dos verbos em consideração .............................................. 42

Tabela 2.11: Resultados da análise das traduções do primeiro grupo ...................................................... 45

Tabela 3.1: Exemplo de escores atribuídos por diferentes critérios de avaliação no sistema scorer .... 55

Tabela 3.2: Lista dos trabalhos de DLS baseadas em conhecimento manualmente codificado........... 65

Tabela 3.3: Lista dos trabalhos de DLS baseados em conhecimento pré-codificado............................ 82

Tabela 3.4: Lista dos trabalhos de DLS baseados em córpus............................................................. 115

Tabela 3.5: Acurácias dos melhores sistemas na tarefa Lexical Sample do Senseval-2 ..................... 120

Tabela 3.6: Acurácias dos melhores sistemas na tarefa Lexical Sample do Senseval-3 .................... 121

Tabela 3.7: Acurácias dos melhores sistemas na tarefa Lexical Sample do Senseval-4 .................... 122

Tabela 4.1: Verbos e suas possíveis traduções, de acordo com dicionários bilíngües ......................... 131

Tabela 4.2: Número de unidades e palavras nos córpus paralelos ...................................................... 132

Tabela 4.3: Probabilidades de traduções para give no córpus Compara ……………........................... 136

Tabela 4.4: Precisão do processo de anotação das traduções.................................................................. 141

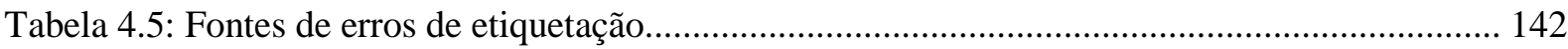

Tabela 4.6: Precisão de uma versão preliminar do processo de etiquetação de traduções, baseada

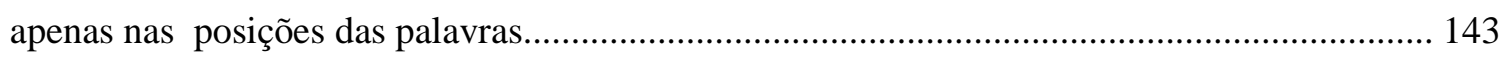

Tabela 4.7: Distribuição da origem das sentenças no novo córpus ................................................... 144

Tabela 4.8: Precisão média do sistema de alinhamento de palavras GIZA++ nos córpus ................... 145

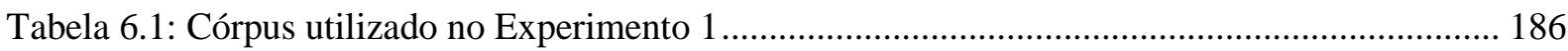

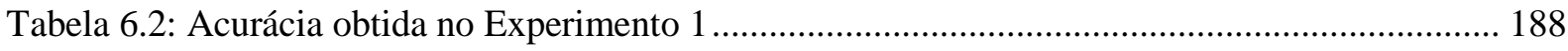

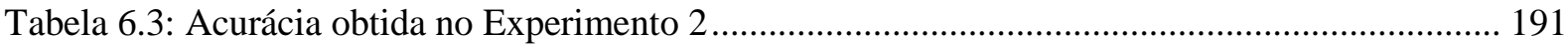

Tabela 6.4: Acurácia obtida no Experimento 3 …............................................................................. 193

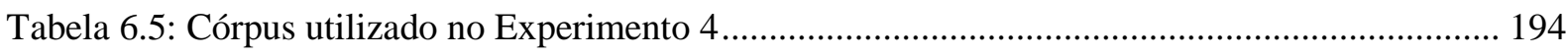

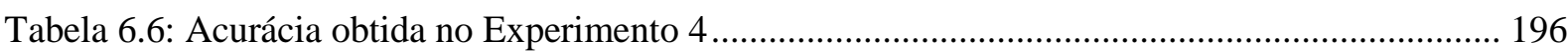

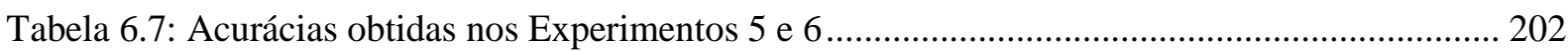


Tabela 6.8: Acurácias médias dos Experimentos 5 e 6 e de outros participantes do Senseval-3 ......... 203

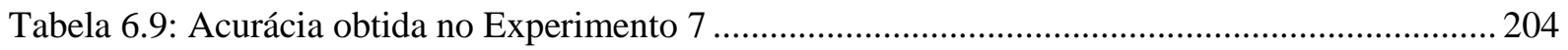

Tabela 6.10: Acurácias obtidas para os 65 verbos dos Experimentos 8 e 9 ........................................ 209

Tabela 6.11: Acurácias obtidas para os 35 substantivos dos Experimentos 8 e 9 ................................ 211

Tabela 6.12: Acurácias dos sistemas participantes da tarefa Lexical Sample no SemEval-2007 ........ 212

Tabela 6.13: Acurácia do algoritmo LibSVM com fontes de conhecimento simplificadas para os 10

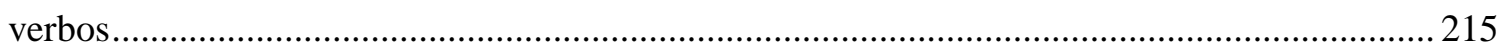

Tabela 6.14: Escores BLEU para os dois métodos de integração e variações de modelos de DLS .... 220

Tabela 6.15: Pesos de todas as funções no modelo linear de TA antes e depois da inclusão da função

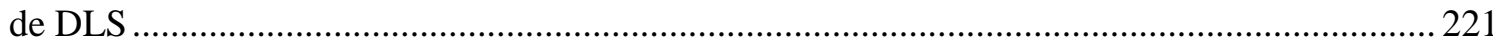




\section{SUMÁRIO}

1. INTRODUÇÃO ................................................................................................................1

1.1 O PROBLEMA DA AMBIGÜIDADE LEXICAL DE SENTIDO NA TRADUÇÃO AUTOMÁTICA ................ 1

1.2 ABORDAGENS PARA A DESAMBIGUAÇÃO LEXICAL DE SENTIDO ..........................................

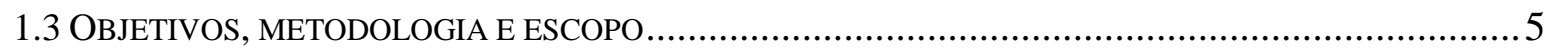

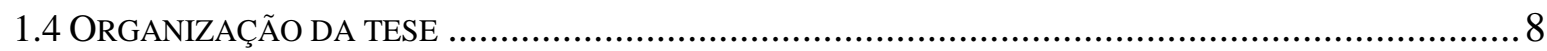

2. O PROBLEMA DA AMBIGÜIDADE LEXICAL NA TRADUÇÃO AUTOMÁTICA ...........11

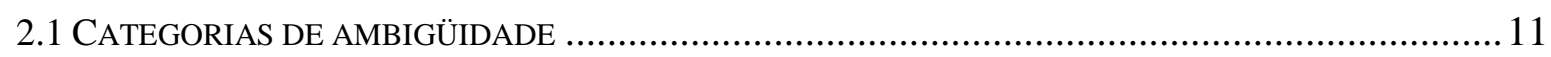

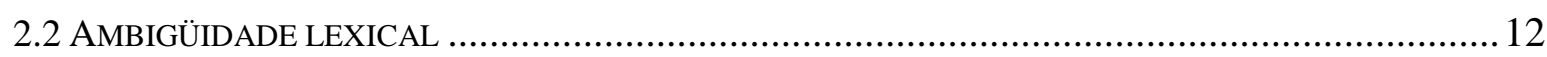

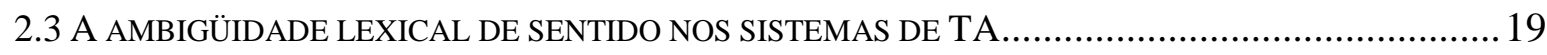

2.4 A AMBIGÜIDADE LEXICAL DE SENTIDO NOS SISTEMAS DE TA INGLÊS-PORTUGUÊS - UM ESTUDO

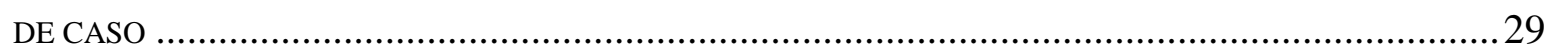

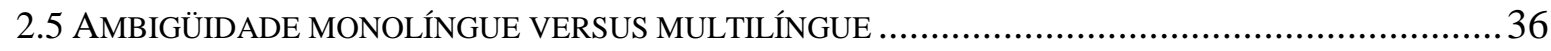

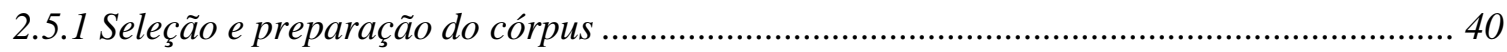

2.5.2 Repositórios de sentidos do inglês e de traduções do português .......................................... 42

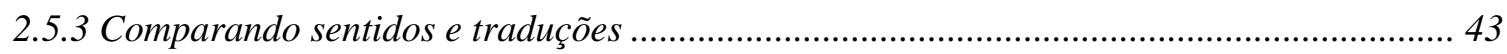

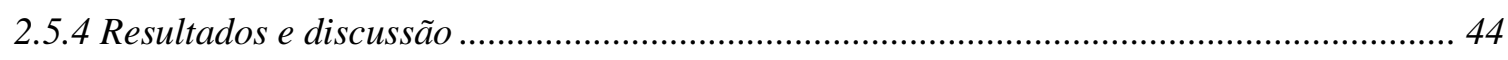

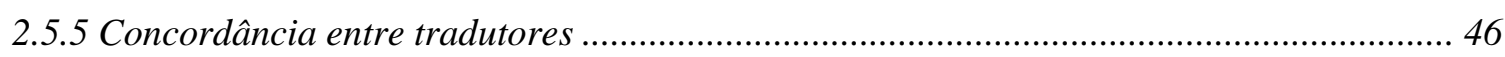

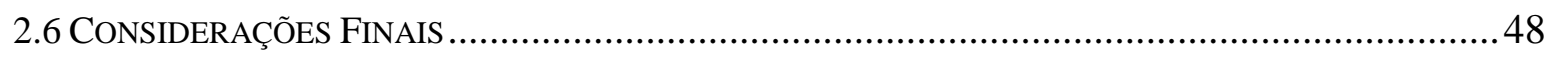

3. ABORDAGENS PARA A DESAMBIGUAÇÃO LEXICAL DE SENTIDO..............................49

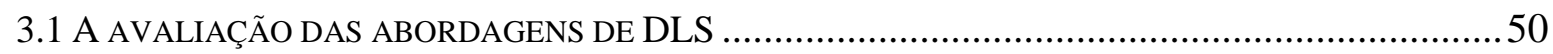

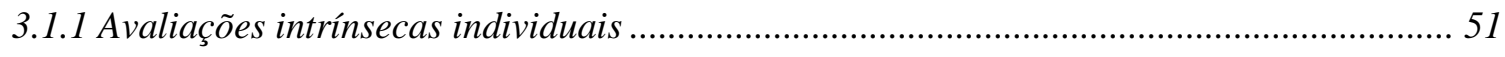

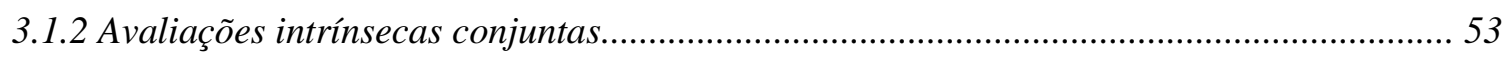

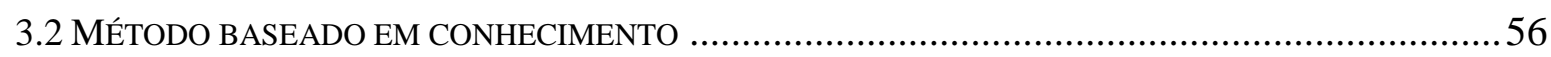

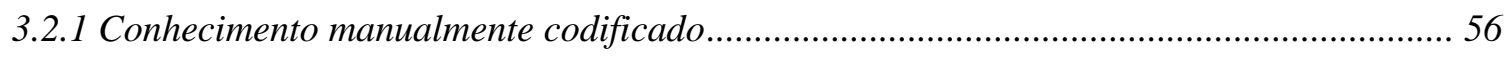

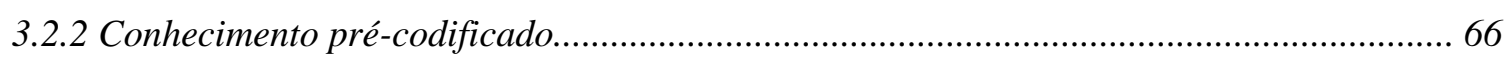

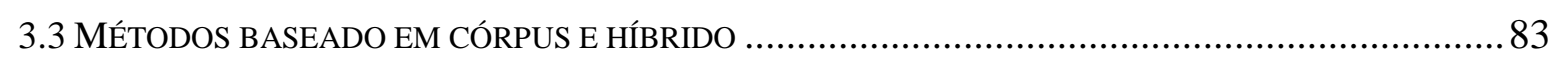

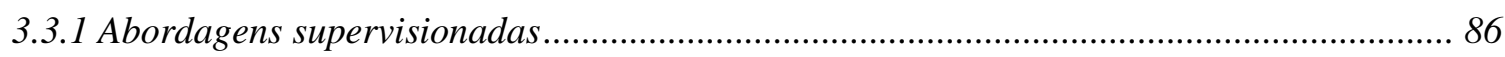

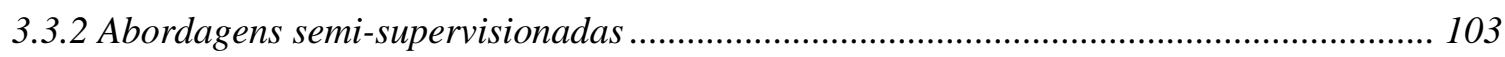

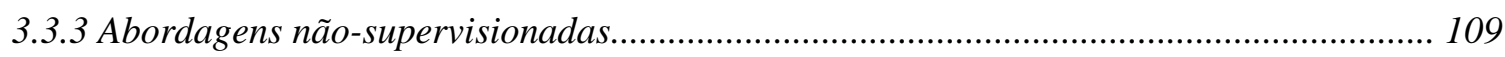

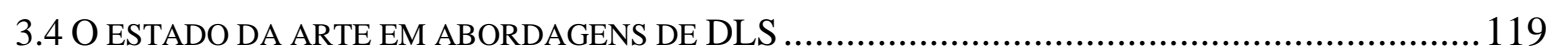

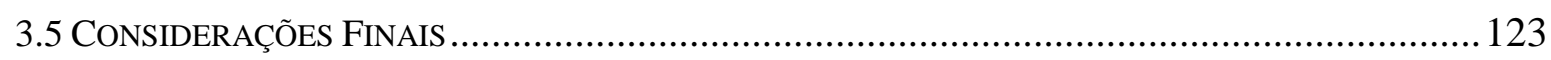

4. A CRIAÇÃO DE CÓRPUS DE EXEMPLOS DE DLS.......................................................125 
4.1 CÓRPUS ETIQUETADOS MANUALMENTE

4.3 A ABORDAGEM PROPOSTA PARA A CONSTRUÇÃO AUTOMÁTICA DE CÓRPUS ETIQUETADOS COM SENTIDOS MULTILÍNGUES

4.3.1 Escopo.

4.3.2 Córpus paralelos.

4.3.3 Pré-processamento do córpus.

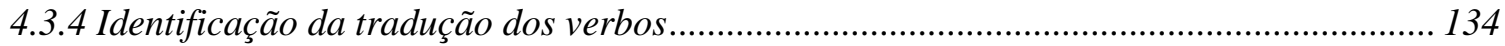

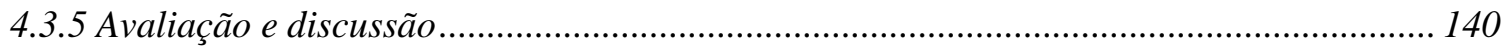

4.3.6 Comparação com abordagem alternativa ……............................................................... 144

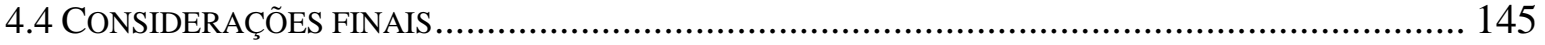

5. UMA ABORDAGEM HÍBRIDA RELACIONAL PARA A DESAMBIGUAÇÃO LEXICAL

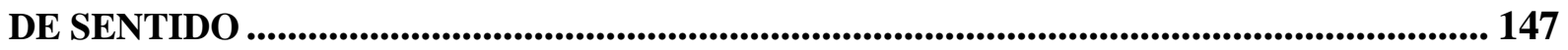

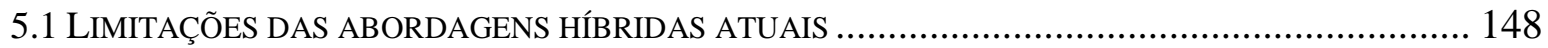

5.2 APRENDIZADO RELACIONAL E PROGRAMAÇÃo LÓGICA INDUTIVA ....................................... 152

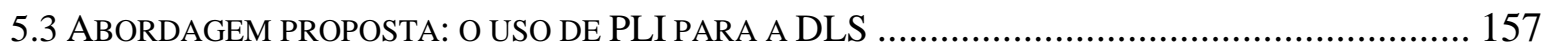

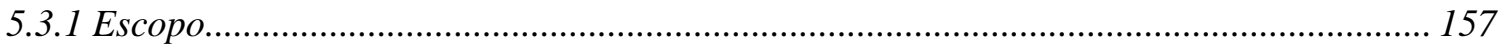

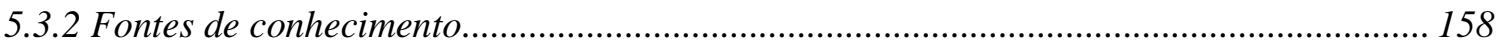

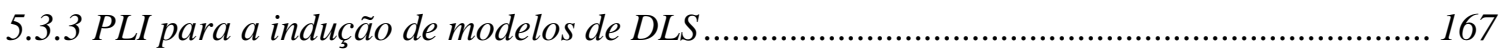

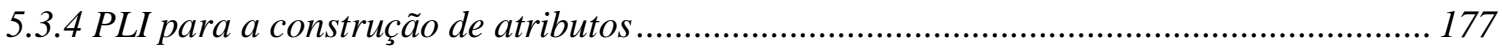

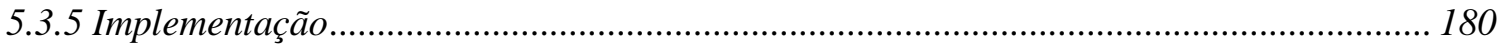

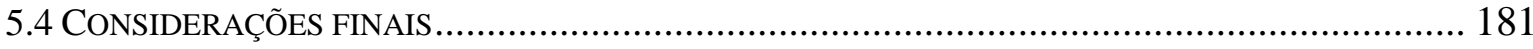

6. AVALIAÇÃO DA ABORDAGEM DE DLS PROPOSTA................................................. 183

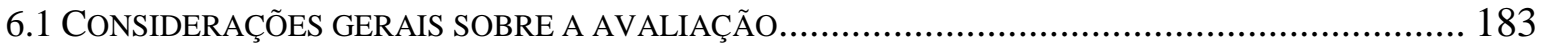

6.2 AVALIAÇÃO INTRÍNSECA - TAREFAS MULTILÍNGUES....................................................... 185

6.2.1 Experimento 1 - Modelos de PLI para a desambiguação de 7 verbos................................ 185

6.2.2 Experimento 2 - Modelos de PLI otimizados para a desambiguação de 7 verbos ........... 189

6.2.3 Experimento 3 - Modelos SVM com atributos PLI para a desambiguação de 7 verbos... 191

6.2.4 Experimento 4 - Modelos de PLI para a desambiguação de 10 verbos............................. 193

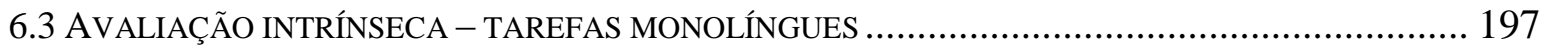

6.3.1 Experimento 5 - Modelos de PLI para a desambiguação de 32 verbos do Senseval-3 .... 198 6.3.2 Experimento 6 - Modelos SVM com atributos PLI para a desambiguação de 32 verbos do

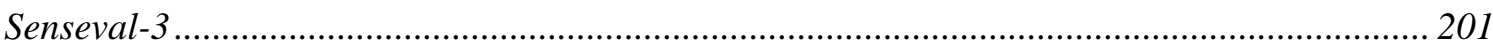

6.3.3 Experimento 7 - Modelos otimizados de PLI para a desambiguação de 32 verbos do Senseval-3.....

6.3.4 Experimento 8-Modelos de PLI para a desambiguação de 100 palavras do SemEval .. 205 
6.3.5 Experimento 9-Modelos SVM com atributos PLI para a desambiguação de 100 palavras

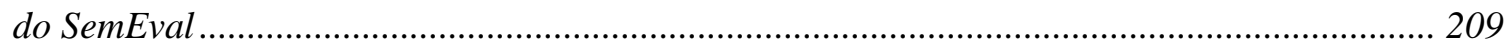

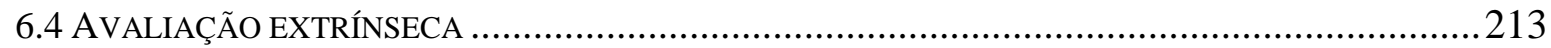

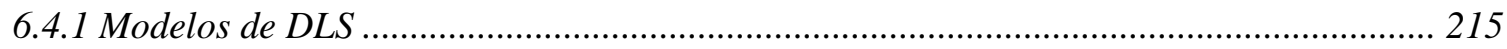

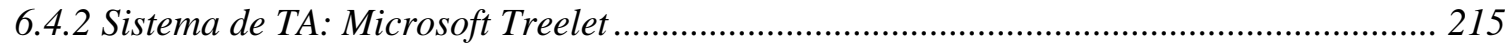

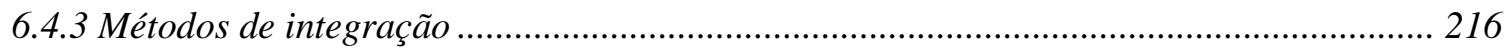

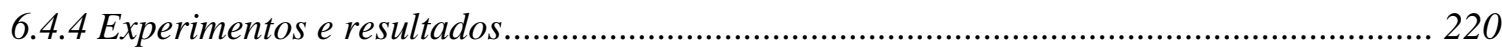

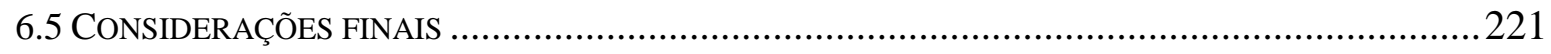

7. CONCLUSÕES, CONTRIBUIÇÕES E TRABALHOS FUTUROS .................................223

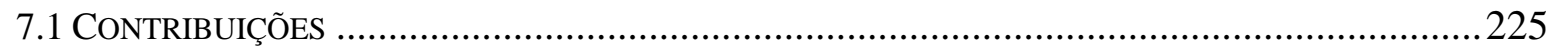

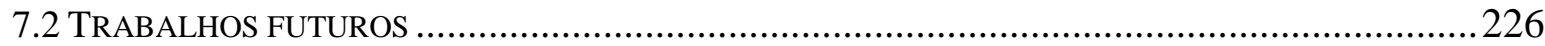

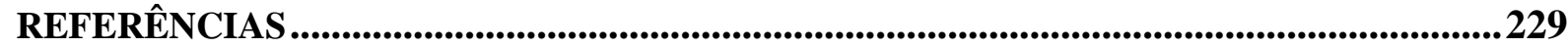





\section{INTRODUÇÃO}

Aplicações voltadas para o processamento das línguas naturais (PLN) vêm sendo investigadas antes mesmo da década de 1950. Uma das primeiras aplicações propostas para os então recém lançados computadores visava à tradução automática (TA), ou seja, à tradução por computador de textos de uma língua natural (língua fonte) para outra (língua alvo) (Weaver, 1949). Uma vez que computadores haviam se mostrado mais eficientes que humanos para desempenhar certas tarefas matemáticas complexas, assumiu-se que eles poderiam realizar de maneira igualmente eficiente a tradução entre línguas, bem como outras atividades de interpretação e geração de línguas naturais. Após experimentos com alguns protótipos de sistemas de tradução para pequenos subconjuntos das línguas, aplicações mais abrangentes e robustas começaram a ser desenvolvidas no início da Guerra Fria, financiadas pelo governo americano. Estas visavam gerar traduções que, mesmo com qualidade inferior, permitissem identificar se textos em russo veiculados na imprensa referiam-se a assuntos de segurança (Dostert, 1955)

\subsection{O PROBLEMA DA AMBIGÜIDADE LEXICAL DE SENTIDO NA TRADU- ÇÃO AUTOMÁTICA}

Já nos primeiros protótipos de sistemas de TA percebeu-se que seriam inúmeros os obstáculos para a produção de traduções com qualidade satisfatória e que tais obstáculos eram decorrentes não apenas das limitações da tecnologia da época, mas também da complexidade do sistema lingüístico humano. Em 1960, Bar-Hillel, ao elencar diversos problemas no estado da arte em tradução automática, destacou, em particular, o problema da ambigüidade semântica, utilizando como exemplo a sentença (1.1) para levantar a questão "Is 'pen' a writing instrument or an enclosure where children play?" (Bar-Hillel, 1960).

(1.1) "Little John was looking for his toy box. Finally, he found it. The box was in the pen. John was very happy."

Bar-Hillel declarou tal problema insolúvel e, como conseqüência, em 1966, cientistas da ALPAC (Automatic Language Processing Advisory Committee) responsáveis por avaliar o progresso e revisar os investimentos destinados à pesquisa nessa área, concluíram que a tradução realizada por computadores jamais atingiria a qualidade da tradução humana, devido a aspectos inerentes à língua natural (Pierce \& Carroll, 1966; ALPAC, 1966). Com isso, as 
pesquisas em TA foram drasticamente reduzidas e somente a partir da década de 1970 foram retomadas em larga escala.

Após cinco décadas de pesquisa, apesar dos grandes avanços alcançados na área de TA e em PLN de modo geral, alguns problemas ainda representam grandes barreiras para o desenvolvimento de aplicações visando traduções de qualidade. Uma das principais dificuldades diz respeito à ambigüidade semântica das línguas, ou seja, à possibilidade de múltiplas interpretações para uma dada proposição. Conforme enfatizado desde o relatório da ALPAC, esse problema é causado, em grande parte, por ambigüidades semânticas no nível lexical, ou seja, pelo emprego de palavras com diversos significados. Nesta tese, esse problema é designado Ambigüidade Lexical de Sentido e a área que se ocupa do seu tratamento, Desambiguação Lexical de Sentido (DLS) ${ }^{1}$.

A ambigüidade lexical de sentido na TA caracteriza a necessidade de escolha lexical durante a tradução, ou seja, a escolha pela palavra mais adequada, na língua alvo, para traduzir uma palavra da língua fonte. Ela é consequiência, fundamentalmente, das diversas caracterizações de mundo adotadas por diferentes línguas, que dão origem a certas relações semânticas interlexicais entre essas línguas, principalmente a homonímia e a polissemia. Tais relações fazem com que a uma palavra da língua fonte correspondam várias palavras da língua alvo, com diferentes significados, que podem ser relacionados entre si (caso de polissemia, por exemplo, know, que pode ser traduzida para o português como "saber" ou “conhecer") ou não relacionados (caso de homonímia, por exemplo, light, que pode ser traduzida como "leve" ou "luz").

A proeminência do problema de ambigüidade lexical de sentido na TA e, como conseqüência, a necessidade de mecanismos de desambiguação, pode ser ilustrada pela sentença (1.2), extraída do córpus BNC (British National Corpus) (Burnard, 2000). No exemplo, são indicados os números de possíveis traduções para o português de cada uma das palavras de conteúdo, dadas as suas categorias gramaticais, com base no dicionário eletrônico DTS DIC Prático Michaelis® ${ }^{\circledR}$.1.

(1.2) "I expect-7 some-3 take-110 the veil-8 to hide-5 a flat-24 chest-11".

A tradução completa da sentença (1.2) resulta num o número muito alto de possíveis combinações de traduções: 24.393.600. Muito embora algumas das opções de tradução para cada palavra sejam sinônimas, essa sentença relativamente simples e curta, com palavras de

\footnotetext{
${ }^{1}$ Do inglês, Word Sense Disambiguation (WSD).
} 
uso comum, ilustra a necessidade de um mecanismo para a escolha lexical nos sistemas de TA.

\subsection{ABORDAGENS PARA A DESAMBIGUAÇÃO LEXICAL DE SENTIDO}

Mecanismos de desambiguação lexical de sentido podem ser úteis não apenas para a TA, mas para aplicações monolíngues como Recuperação de Informações (por exemplo, uma busca incluindo a palavra-chave cricket pode retornar documentos sobre o esporte ou o animal), Extração de Informações (por exemplo, na sentença "Herb Bergson is the mayor of Duluth", Duluth pode referir-se à cidade em Minnesota ou a subúrbio em Geórgia), entre outras.

Fundamentalmente, a tarefa de DLS consiste da identificação do sentido mais adequado de uma palavra dado o seu contexto, em função de uma lista pré-definida de sentidos, a qual pode variar de acordo com a aplicação. Várias abordagens têm sido propostas para essa tarefa, especialmente em contextos monolíngues, independentemente de aplicação. Tais abordagens podem ser categorizadas em três principais grupos: abordagens baseadas em conhecimento lingüístico (e, possivelmente, extralingüístico) manualmente ou semiautomaticamente especificado (Small, 1980; Hirst, 1987; Wilks et al., 1990; Agirre \& Rigau, 1996; Wilks \& Stevenson, 1996; etc.); abordagens baseadas em córpus, ou seja, baseadas em conhecimento superficial extraído de córpus de exemplos por meio de técnicas estatísticas ou de aprendizado de máquina para gerar modelos de desambiguação (Yarowsky, 1995; Schütze, 1998; etc.); e abordagens híbridas, que combinam características das outras duas abordagens para gerar automaticamente modelos de desambiguação a partir de córpus de exemplos e de conhecimento lingüístico / extra-lingüístico ( $\mathrm{Ng}$ \& Lee 1996; Stevenson \& Wilks, 2001; etc.).

Abordagens baseadas em conhecimento podem ser bastante precisas, já que regras para casos particulares de ambigüidade são manualmente especificadas, podendo fazer uso de conhecimento lingüístico profundo. Contudo, a necessidade de codificação manual limita sua aplicação a cenários restritos. Abordagens baseadas em córpus, por outro lado, são mais abrangentes, uma vez que os modelos de desambiguação são automaticamente adquiridos. Porém, os resultados são em geral menos precisos, dada a quantidade limitada de conhecimento que pode ser extraída de córpus. Por fim, abordagens híbridas têm o potencial para levar a resultados precisos e abrangentes, uma vez que prevêem o aprendizado automático de modelos a partir de conhecimento disponível no córpus e fornecido por recursos externos. 
De fato, como a DLS é uma tarefa semanticamente motivada, intuitivamente acreditase que abordagens profundas, que façam uso de conhecimento lingüístico substancial e, idealmente, conhecimento extra-lingüístico, possam levar a melhores resultados. Atualmente, uma quantidade considerável de conhecimento lingüístico está disponível na forma de recursos eletrônicos apropriados para uso prático, como a WordNet (Fellbaum, 1998), dicionários eletrônicos, parsers, etc. No entanto, a maioria das abordagens híbridas existentes restringe-se à representação de conhecimento lingüístico superficial, por exemplo, categorias morfossintáticas das palavras. Isso se deve à dificuldade para integrar conhecimento lingüístico profundo com os algoritmos de aprendizado de máquina tradicionalmente utilizados para DLS. Para representar exemplos de desambiguação, tais algoritmos assumem como entrada vetores de atributos e seus valores. Vetores do tipo atributo-valor têm o mesmo poder de expressividade da lógica proposicional, ou seja, somente constantes e proposições atômicas são permitidas. Isso torna inviável a representação de conhecimento profundo, principalmente relacional, sobre a língua, como as relações sintáticas e semânticas entre as palavras de uma sentença. Em geral, nas abordagens híbridas atuais, conhecimento lingüístico profundo, como preferências de seleção, quando explorado, é pré-processado para ser transformado em vetores atributo-valor, ou é utilizado em etapas prévias ao processo de aprendizado, para refinar ou atribuir diferentes pesos às opções de desambiguação (e.x., Stevenson \& Wilks, 2001). Como consequiência, o conhecimento é parcialmente perdido nessa transformação e não pode interagir com outras fontes de conhecimento durante o processo de aprendizado. Além disso, os modelos produzidos são capazes de refletir apenas o conhecimento superficial que é fornecido ao algoritmo de aprendizado. Outras limitações de tal formalismo incluem a necessidade de uma estrutura única e extensional, em termos de atributos, para todos os exemplos, o que requer que todos os possíveis atributos a serem testados sejam conhecidos a priori, dificulta a generalização dos exemplos e pode resultar numa representação altamente esparsa dos dados.

Considerando-se não apenas abordagens híbridas, mas também as baseadas em córpus e em conhecimento, são poucos os trabalhos propostos especificamente para aplicações multilíngues como a TA. Em geral, os sistemas de TA realizam a DLS de forma implícita ou utilizam outras estratégias para contornar o problema da ambigüidade lexical, por exemplo, por meio de linguagens controladas, sublinguagens, micro-glossários para minimizar as possibilidades de ambigüidades, ou mecanismos de interação ou pós-edição humana (e.g., KANT - Baker et al., 1994; Mitamura, 1999). Alguns poucos sistemas consideram a representação de conhecimento profundo e de regras de desambiguação para a tradução em 
domínios específicos (e.g., Goodman \& Nirenburg, 1991; Beale, 1997). Sistemas comerciais de TA irrestrita e completamente automatizada baseiam-se em critérios muito simples para a escolha lexical, tais como a tradução mais freqüente em geral ou em determinadas colocações (e.g., Power Translator®). Os sistemas estatísticos de TA, bastante recentes, realizam a desambiguação lexical implicitamente, uma vez que as palavras utilizadas nas traduções de treinamento são levadas em consideração quando do aprendizado dos modelos de tradução. No entanto, em tais sistemas, conhecimento contextual é inexistente ou limitado a uma vizinhança bastante pequena na sentença (e.g., Och \& Ney, 2003; Koehn et al., 2003) e o conhecimento lingüístico, quando explorado, restringe-se ao nível sintático (Lin, 2004).

Apesar da reconhecida necessidade de um módulo de desambiguação em sistemas de TA, a utilidade de módulos dessa natureza em aplicações práticas têm sido motivo de debate, particularmente no contexto de sistemas estatísticos de TA. Por exemplo, Carpuat \& Wu (2005a) argumentam que o uso de DLS não acarreta benefícios para a qualidade de sistemas estatísticos de TA. Contudo, são questionáveis vários aspectos dos experimentos realizados em tal trabalho. Em particular, um módulo de DLS monolíngue (chinês) para a TA do chinês para o inglês, de modo que é realizada a desambiguação da língua fonte, seguida do mapeamento dos sentidos dessa língua para traduções na língua alvo. Contudo, esse mapeamento é bastante problemático, uma vez que não há uma correspondência unívoca entre sentidos monolíngues e suas traduções na língua alvo. Já Vickrey et al. (2005), Carpuat \& Wu (2006; 2007) e Chan et al. (2007) mostram que, se designado especificamente para a TA estatística, utilizando-se, por exemplo, de repositórios de sentido multilíngües, um módulo de DLS pode melhorar significativamente a qualidade de sistemas dessa natureza. De fato, como ressaltam Wilks \& Stevenson (1996), Kilgarriff (1997a) e Resnik \& Yarowsky (1997b), a DLS é uma tarefa intermediária e, portanto, acredita-se que a definição de um módulo de DLS depende, essencialmente, da aplicação para a qual ele será usado, já que certos aspectos, tais como o repositório de sentidos, fontes de conhecimento e estratégias de desambiguação, podem variar de acordo com a aplicação.

\subsection{OBJETIVOS, METODOLOGIA E ESCOPO}

O principal objetivo deste trabalho de doutorado é a proposta e desenvolvimento de uma nova abordagem de desambiguação lexical de sentido capaz de superar as limitações identificadas nas abordagens atuais, tais como a representação limitada de conhecimento profundo, a qual possa ser incorporada em um sistema de tradução de modo a auxiliar no processo de escolha 
lexical nos casos de ambigüidade e, com isso, melhorar a qualidade dos sistemas de TA inglês-português atuais. Tal abordagem possui três características principais:

(1) É destinada especialmente para a tradução automática, uma vez que considera um repositório de sentidos, fontes de conhecimento e estratégias específicos para essa aplicação;

(2) É híbrida, pois explora o aprendizado de máquina juntamente com um conjunto bastante rico de fontes de conhecimento; e

(3) Utiliza um formalismo relacional para a representação das fontes de conhecimento sobre os exemplos, o qual permite a representação de conhecimento profundo e a utilização desse conhecimento durante o aprendizado de modelos de desambiguação.

Para a implementação de tal abordagem, utiliza-se a técnica de Programação Lógica Indutiva (PLI) (Muggleton, 1991), que combina características de Aprendizado de Máquina e Programação Lógica para fornecer mecanismos para o aprendizado supervisionado de modelos simbólicos (conjuntos de regras) a partir de exemplos de desambiguação e de conhecimento de fundo de qualquer forma, incluindo conhecimento relacional. Isso é possível porque a linguagem de representação utilizada possui poder de expressividade equivalente ao da lógica de primeira ordem, permitindo a representação de predicados n-ários e variáveis, possibilitando capturar relacionamentos contextuais.

Não se tem conhecimento de outras abordagens genuinamente híbridas que explorem formalismos relacionais de aprendizado para a tarefa de DLS, seja ela monolíngue ou multilíngue. A hipótese deste trabalho é, portanto, de que com a definição e extração automática de um arcabouço substancial de conhecimento lingüístico e sua formalização por meio da técnica de Programação Lógica Indutiva, é possível gerar automaticamente modelos efetivos de DLS, em termos de precisão e abrangência. Por se tratar de uma abordagem de extração automática de conhecimento, esta pode ser facilmente generalizada não apenas para um conjunto maior de casos de ambigüidade, mas também para novas aplicações (monolíngues e multilíngues).

O trabalho apresentado nesta tese concentra-se na tradução do inglês para o português. São relatados experimentos com a abordagem proposta para a desambiguação de verbos, casos reconhecidamente complexos para a tradução, uma vez que são em geral bastante ambíguos e que podem influenciar a desambiguação de outras palavras em seu contexto na sentença. A partir do estudo do comportamento dos tradutores mais comumente utilizados para a tradução inglês-português de um conjunto de verbos freqüentes na língua inglesa, o 
escopo de investigação foi definido como um conjunto de sete verbos altamente ambíguos e problemáticos para a tradução nesses sistemas (come, get, give, go, look, make e take) e foi posteriormente estendido com três outros verbos menos ambíguos (ask, live e tell) para que se pudesse analisar o efeito do nível de ambigüidade na abordagem proposta.

Para realizar experimentos com esses verbos, são criados diferentes córpus de exemplos de sentenças contendo tais verbos, extraídos de fontes de diversos gêneros e domínios, sendo a tradução de cada verbo automaticamente anotada por um sistema de etiquetação de sentidos também desenvolvido neste trabalho. Esse sistema é baseado em dicionários bilíngües, no alinhamento sentencial de córpus paralelos, em informações estatísticas extraídas desses córpus e em um conjunto de heurísticas.

Como fontes de conhecimento, são utilizadas fontes superficiais, automaticamente extraídas do córpus de treinamento, juntamente com fontes profundas, automaticamente extraídas de recursos lexicais. Ao todo, os diversos experimentos exploram subconjuntos de doze fontes distintas: (a) bag-of-words de cinco palavras à direita e esquerda do verbo; (b) lemas de cinco palavras de conteúdo à direita e esquerda do verbo; (c) categorias gramaticais (morfossintáticas) das cinco palavras à direita e esquerda do verbo; (d) relações sintáticas de sujeito e objeto com relação ao verbo; (e) 12 colocações com relação ao verbo, por exemplo, a primeira preposição à direita do verbo; (f) bigramas freqüentes consistindo de pares de palavras adjacentes na sentença; (g) pares de palavras freqüentemente relacionadas sintaticamente; (h) restrições de seleção do verbo, definidas com relação aos traços semânticos de seus argumentos; (i) sobreposição entre as palavras no contexto do verbo na sentença e nas definições de cada tradução do verbo em dicionários; (j) potencial existência de phrasal verbs na sentença; (k) bag-of-words de 10 palavras já traduzidas na sentença alvo, que formarão a vizinhança do verbo a ser desambiguado; e, por fim, (l) colocações de 10 palavras já traduzidas na sentença alvo, de acordo com suas posições.

Para a indução dos modelos de desambiguação é utilizado o sistema de Programação Lógica Indutiva Aleph (Srinivasan, 2000). Tais modelos gerados são então avaliados com relação à sua acurácia (que engloba ambas as medidas precision e recall) e os resultados são comparados aos obtidos por técnicas proposicionais de aprendizado tradicionalmente empregadas para a DLS, a saber, Naive Bayes, árvores de decisão e Support Vector Machines. Experimentos comparativos também são realizados considerando-se dois córpus padrão para a desambiguação monolíngue de verbos e substantivos do inglês. Adicionalmente, experimentos são realizados com um uso alternativo da técnica de Programação Lógica Indutiva para a DLS: a indução de uma forma proposicional de atributos relevantes a partir da 
representação relacional das fontes de conhecimento, os quais são então usados para a geração de modelos de desambiguação por meio de técnicas proposicionais de aprendizado. Experimentos preliminares para a avaliação da contribuição dos modelos de DLS para um sistema estatístico de TA são também realizados.

\subsection{ORGANIZAÇÃO DA TESE}

O conteúdo desta tese está organizado da seguinte forma:

No Capítulo 2, o problema da ambigüidade na tradução automática é discutido, focalizando-se na ambigüidade lexical de sentido e no tratamento dispensado a esse problema por parte dos sistemas de TA. Adicionalmente, é apresentado um estudo de caso analisando o problema da ambigüidade lexical de sentido em três dos principais sistemas de TA baseados em regras disponíveis para o par de línguas inglês-português. Este estudo serviu para definir o escopo deste trabalho e para mostrar a necessidade de um módulo de desambiguação em sistemas dessa natureza. Por fim, é apresentado um estudo de caso que evidencia as diferenças entre a desambiguação monolíngue e multilíngue, visando justificar o desenvolvimento de uma abordagem específica para a TA.

Uma revisão da literatura sobre as abordagens mais relevantes para a desambiguação lexical de sentido (monolíngue e multilíngue) é apresentada no Capítulo 3, seguindo-se a classificação mencionada anteriormente: abordagens baseadas em conhecimento, abordagens baseadas em córpus e abordagens híbridas. Considerações sobre a avaliação de abordagem de DLS, incluindo-se o exercício Senseval, são também discutidos nesse Capítulo.

No Capítulo 4 são descritos os córpus de exemplos de desambiguação tradicionalmente utilizados para a avaliação e / ou treinamento de abordagens supervisionadas. São também descritas as principais abordagens existentes para a criação automática de córpus dessa natureza. Por fim, é apresentada a estratégia proposta neste trabalho para a etiquetação do córpus de exemplos multilíngue e a avaliação do sistema resultante considerando-se diferentes córpus de exemplos.

No Capítulo 5, as diferenças entre aprendizado baseado em formalismos proposicionais e relacionais são discutidas, de modo a enfatizar as vantagens do uso de formalismos relacionais. A técnica de Programação Lógica Indutiva é apresentada e exemplos do seu uso para outras aplicações de processamento de língua natural são dados. A abordagem híbrida relacional de desambiguação proposta neste trabalho é então introduzida, incluindo-se a arquitetura geral do sistema e detalhes sobre a definição, extração e formalização das fontes 
de conhecimento no sistema de Programação Lógica Indutiva utilizado, Aleph. A investigação do uso alternativo da técnica de Programação Lógica Indutiva para a tarefa de desambiguação lexical de sentido é também apresentada nesse capítulo: o aprendizado de atributos "interessantes", que são então usados por um algoritmo proposicional tradicionalmente empregado para essa tarefa.

No Capítulo 6, após uma breve discussão sobre metodologias e critérios de avaliação intrínseca e extrínseca comumente empregados para a DLS, são apresentados diversos experimentos de avaliação da abordagem proposta, incluindo-se detalhes sobre o seu escopo, ou seja, o subconjunto de palavras e os córpus de exemplos de desambiguação, as combinações de fontes de conhecimento, as configurações e parâmetros do sistema Aleph, etc. Os resultados obtidos são comparados a baselines, a resultados de algoritmos proposicionais e a resultados de outras abordagens independentes deste trabalho, testadas sob as mesmas condições, nos mesmos conjuntos de exemplos. Um experimento de avaliação extrínseca no contexto da tradução automática estatística também é apresentado.

Finalmente, no Capítulo 7 são discutidas as conclusões desta tese, suas principais contribuições e os aspectos que podem ser endereçados em trabalhos futuros. 





\section{O PROBLEMA DA AMBIGÜIDADE LEXICAL NA TRADUÇÃO AU- TOMÁTICA}

Neste capítulo são apresentados os principais problemas causados por diferentes categorias de ambigüidade (Seção 2.1), de modo a contextualizar a ambigüidade lexical de sentido (Seção 2.2). É apresentado também o quadro geral, do ponto de vista histórico, do tratamento dispensado a esse tipo de ambigüidade por parte dos sistemas de TA (Seção 2.3). Na Seção 2.4 é descrito um estudo de caso que analisa esse problema em três dos principais sistemas disponíveis atualmente para a TA do inglês para o português, visando motivar a escolha da TA entre essas línguas e também selecionar um conjunto de palavras para constituir o escopo inicial deste trabalho. Para ilustrar a necessidade de estratégias específicas para a desambiguação em aplicações multilíngues e, em particular, aplicações para o par de línguas inglês-português, é apresentado um estudo contrastando o problema da ambigüidade em contextos monolíngues e multilíngues, com ênfase nas diferenças nos repositórios de sentidos (Seção 2.5).

\subsection{CATEGORIAS DE AMBIGÜIDADE}

No processamento de textos escritos, a ambigüidade entre as línguas pode ocorrer em diversos níveis, entre eles, o lexical, sintático, semântico, contextual e pragmático. No nível lexical, a ambigüidade ocorre quando da multiplicidade de opções, durante a seleção de uma palavra ${ }^{2}$ da língua alvo para traduzir uma palavra da língua fonte. Diz respeito, portanto, a escolhas lexicais, considerando o léxico como um recurso que faz a correspondência de palavras entre as línguas fonte e alvo. Por exemplo, o português possui várias traduções para o termo seal do inglês: "selo", "escudo", "lacre", "foca", etc.

No nível sintático ou estrutural, a ambigüidade ocorre porque as línguas utilizam diferentes estruturas para o mesmo propósito, e também a mesma estrutura para diferentes propósitos. Dessa maneira, a estrutura sintática de uma sentença na língua fonte pode ter mais de uma correspondente na língua alvo, a exemplo da sentença "I saw the man in the hill with a telescope", na qual é necessário determinar se "with a telescope" modifica " $P$ " ou "the man".

\footnotetext{
${ }^{2} \mathrm{O}$ termo "palavra", aqui, designa a unidade mínima de significado a ser traduzida, já na sua forma básica (lema ou canônica), que poderia incluir palavras-compostas, mas não outras unidades multipalavras. Assume-se, contudo, que a delimitação dessa unidade e a identificação da sua forma básica são realizadas em uma etapa prévia ao processo de tratamento da ambigüidade lexical.
} 
A ambigüidade no nível semântico ocorre quando há mais de uma interpretação para o relacionamento semântico entre os elementos da sentença e, portanto, várias traduções que levam a diferentes proposições. Ela pode ser causada por ambigüidades lexicais, sintáticas ou contextuais. Por exemplo, a interpretação da sentença "I saw the man in the hill with a telescope" muda de acordo com a escolha sintática que indica quem estava com o telescópio, "the man" ou " $P$ ".

A ambigüidade no nível contextual ou referencial ocorre quando um termo pode retomar a referência de outros diferentes termos anteriormente utilizados, que são traduzidos de maneira diferente. Portanto, é preciso determinar qual o termo antecedente mais apropriado. Por exemplo, na sentença "The printer outputs the paper; it is fast", é preciso identificar que "fast" refere-se à "the printer" e não à "the paper", para traduzir o pronome it corretamente.

Em um nível mais abstrato de representação, a ambigüidade pragmática ocorre quando as diferentes proposições que correspondem às possíveis traduções de um enunciado podem ser usadas com diferentes funções comunicativas. Por exemplo, "Copy it", que pode representar um pedido (“Copie, por favor”), uma ordem (“Copie, agora!”), entre outros.

A ambigüidade no nível pragmático é bastante subjetiva, de tratamento demasiadamente complexo, mesmo em aplicações monolíngues. Como conseqüência, o tratamento desse tipo de ambigüidade é geralmente negligenciado. As ambigüidades estrutural e referencial, em alguns casos, podem ser mantidas na TA, gerando traduções igualmente ambíguas, nos níveis sintático ou referencial e, como conseqüência, semântico, mas sem prejuízo para a tradução. Esse é o caso, por exemplo, da sentença "I saw the man in the hill with a telescope". A ambigüidade lexical, por sua vez, caracteriza sempre uma escolha imprescindível e cujos efeitos podem ser extremamente prejudiciais à tradução, uma vez que ela dá origem a proposições semanticamente muito distintas.

\subsection{AMBIGÜIDADE LEXICAL}

Grande parte dos problemas da tradução, seja ela humana ou automática, está relacionada às diferenças lexicais entre as línguas, ou seja, aos diferentes modos pelos quais as línguas caracterizam o mundo, quais palavras elas escolhem para expressar conceitos, e quais conceitos não são utilizados. As diferenças lexicais entre as línguas são normalmente denominadas divergências lexicais. 
Entre os aspectos de divergência lexical estão os diferentes níveis de granularidade das distinções feitas pelas línguas e também as bases para essas distinções. Por exemplo, o francês faz três distinções para o termo único do inglês, leg (perna), quais sejam, jambe (perna de um humano), patte (perna de um animal) e pied (perna de uma mesa). Sobre a base das distinções, um exemplo é que o inglês escolhe diferentes verbos para a ação "vestir" (putting on) e o estado "usar" (wearing), uma distinção diferente da realizada pelo japonês, que escolhe diferentes verbos de acordo com o objeto sendo vestido (sapatos, óculos, chapéu, blusa, etc.). Em termos práticos, esses aspectos dão origem a uma das principais manifestações da divergência lexical: a ambigüidade lexical de sentido na tradução.

O problema da ambigüidade lexical na tradução, também denominada ambigüidade interlingüística, ocorre, segundo Hutchins \& Somers (1992), quando a multiplicidade de significados de um termo não pode ser simetricamente transposta de uma língua para outra. De fato, essa multiplicidade de significados é, na maioria das vezes, decorrente de ambigüidades na língua fonte que se realizam por diferentes palavras na sua tradução para a língua alvo. Há casos, contudo, em que a palavra não é ambígua na língua fonte e a sua ambigüidade só se manifesta na tradução. Por exemplo, a palavra "neve" possui diversas traduções para o esquimó, de acordo com as características da neve (fina, grossa, clara, etc.). Assim, é importante ressaltar que o problema endereçado nesta tese refere-se à ambigüidade que ocorre entre as palavras das duas línguas, ou seja, da língua fonte em relação à língua alvo, pois a sua existência isolada nas duas línguas não implica, necessariamente, um problema para a tradução.

A ambigüidade lexical na tradução é causada, então, por relações interlexicais como a homonímia, a sinonímia, a polissemia e a vagueza, que se manifestam na tradução de uma língua para outra. A polissemia é a propriedade que uma palavra possui de apresentar diferentes sentidos que não são opostos nem excludentes. Os diferentes sentidos podem se relacionar em maior ou menor grau em um mesmo sentido básico, geral. Segundo a abordagem diacrônica do estudo do significado, a polissemia abrange os casos de alternância de sentidos semântica e etimologicamente relacionados. Na tradução, a polissemia faz com que a uma palavra da língua fonte correspondam duas ou mais palavras da língua alvo, com diferentes significados, mas relacionados entre si. Por exemplo, à palavra do inglês board podem corresponder as palavras semanticamente relacionadas no português "tábua", “tabuleiro", "mesa", "quadro (negro)", etc. 
A homonímia é a propriedade que uma palavra possui de apresentar dois significados distintos que possuem a mesma forma gráfica (homografia) e/ou fonológica (homofonia) ${ }^{3}$. Segundo a abordagem diacrônica do estudo do significado, a homonímia distingue-se da polissemia pelo critério etimológico: palavras homônimas são etimologicamente sem relação, ou seja, a mesma forma gráfica ou fonológica ocorre acidentalmente, não havendo relação entre os significados, que são mutuamente excludentes. Assim, não é possível estabelecer um sentido base, no caso da homonímia, pois os sentidos são incompatíveis, contrastantes. A homonímia entre duas línguas faz com que a uma palavra da língua fonte correspondam duas ou mais palavras da língua alvo, de diferentes significados, não relacionados. Por exemplo, a palavra do inglês run pode ser traduzida como "executar (programa)" ou "correr".

A sinonímia ocorre quando da existência de palavras de sentido idêntico, ou quase idêntico. Os sinônimos idênticos, chamados de sinônimos perfeitos, não representam problemas para a tradução, uma vez que qualquer um dos sinônimos pode ser escolhido como correspondente para uma dada palavra. No entanto, casos de sinônimos perfeitos são praticamente inexistentes, geralmente, os significados dos sinônimos diferem entre si, ainda que sutilmente. Portanto, eles não são permutáveis em todos os enunciados possíveis. Assim, a diferença entre polissemia e sinonímia, em muitos casos, não é muito clara. Por exemplo, “pai” e "papai” são considerados sinônimos, mas não é comum dizer "João é "papai’ de três filhos". Na tradução, esse problema ocorre quando a uma palavra na língua fonte podem corresponder vários sinônimos na língua alvo. Por exemplo, para traduzir $d o g$, em inglês, é preciso escolher entre "cachorro" e "cão". Decisões como essa envolvem, em maior grau de importância que as diferenças de significado, questões estilísticas.

A vagueza (ou subespecificação) ocorre quando não é possível - apenas com as informações fornecidas por uma palavra no léxico - recuperar seu referente ou sentido com precisão. Este é, por exemplo, o caso da palavra bom, exemplificada por Alves (2002). Em função de uma multiplicidade de critérios de definição - bom x ruim -, podem ser geradas diferentes interpretações (e traduções): o que é bom em um contexto pode ser ruim em outros contextos. Outro exemplo são as palavras que podem ter diferentes níveis em uma escala de aplicação, como os adjetivos escalares, por exemplo, "pobre”, "rico", “alto", "baixo". Os conceitos que se têm sobre as qualidades identificadas por adjetivos como esses variam de acordo com experiências pessoais.

\footnotetext{
${ }^{3}$ Neste trabalho, somente os homônimos homógrafos são de interesse, uma vez que a preocupação é apenas com o processamento da língua escrita, e não falada. Portanto, o termo "homonímia" indica, sempre, a homonímia homográfica, a qual pode ou não ser acompanhada de homonímia homofônica (por exemplo: apelo - verbo e apelo - substantivo).
} 
Nem sempre é possível separar a polissemia da vagueza. Por exemplo, conforme citado por Alves (2002), o referente da palavra "criança”" pode ser considerado ambíguo em relação à diferença de gênero, já que pode se referir a um ser "feminino" ou "masculino". Se o sentido da palavra varia entre "feminino" e "masculino", ela é polissêmica. Por outro lado, a palavra também pode ser considerada não-polissêmica, mas vaga, havendo apenas uma falta de determinação referencial.

O significado das palavras vagas inicia no léxico, porém, elas só têm seu significado completo se a elas forem somados elementos do contexto e / ou extralingüísticos. Portanto, apesar de este tipo de ambigüidade ter sido considerada lexical, é importante destacar que as palavras vagas apresentam fortes influências de elementos extralingüísticos. Kilgarriff (1997a), ao procurar diferenciar vagueza de ambigüidade, afirma que a diferença básica entre esses fenômenos é que a ambigüidade ocorre no léxico, enquanto a vagueza ocorre no texto. Por exemplo, a sentença "The man was here" pode parecer ambígua para o ouvinte se houver mais de um homem a quem o locutor possa se referir, contudo, não há ambigüidade lexical, mas apenas vagueza. O mesmo valeria para a palavra hand, que é vaga entre os conceitos de right hand e left hand. $\mathrm{O}$ autor cita alguns critérios para distinguir a vagueza da ambigüidade, incluindo o teste de substituição considerando-se a tradução para uma segunda língua: se a palavra da língua fonte for traduzida por diferentes palavras na língua alvo, ela é ambígua; caso contrário, é apenas vaga. Contudo, dependendo das línguas envolvidas, esse critério não se aplica. Por exemplo, se alguma língua considerar diferentes traduções para a palavra hand, em inglês, dependendo do seu modificador (left ou right), segundo esse critério, a palavra deixa de ser vaga e passa a ser ambígua.

Há ainda outros fenômenos considerados por alguns autores, como Leffa (1995), como causas da ambigüidade lexical, por exemplo, a metáfora e a metonímia. Contudo, neste trabalho, é adotada a visão de Ullmann (1964), segundo a qual todas as mudanças de aplicação de uma palavra que fazem com que ela adquira um novo sentido, incluindo a metáfora e a metonímia, são fatores causadores da polissemia, e não outros fenômenos independentes. Mais especificamente, neste trabalho, serão essencialmente abordados os casos de homonímia e polissemia, excluindo-se a vagueza, pela sua dependência de elementos referencias, e a sinonímia, por referir-se a problemas estilísticos, menos graves para a tradução. Contudo, como existe uma interseção entre os fenômenos polissemia-sinonímia e polissemia-vagueza, e como a distinção entre eles é bastante difusa, alguns casos tratados como polissemia podem ser eventualmente interpretados como casos de vagueza ou sinonímia. 
A homonímia e a polissemia são reportadas por muitos outros autores como os fenômenos mais relevantes no contexto da ambigüidade lexical. Segundo Ullmann (1964), por exemplo, a polissemia é um fenômeno naturalmente presente na língua natural; é um fator de economia e de flexibilidade para a eficiência do sistema lingüístico. Além disso, a frequiência de uma palavra está relacionada com a sua polissemia: quanto mais freqüente uma palavra, mais sentidos é possível que ela tenha. Ainda segundo o autor, a homonímia é menos comum e complexa que a polissemia, mas seus efeitos podem ser tão graves ou até mesmo mais contundentes que os da polissemia.

De fato, esses dois fenômenos são os mais referenciados no contexto da ambigüidade lexical. Contudo, a diferenciação entre eles não é consensual. A distinção descrita acima, adotada neste trabalho, é similar à de Ullmann e Lyons (1977) e também à de trabalhos específicos para a DLS, como os de Krovetz (1998), Kilgarriff (1997a) e Leffa (1995). Kilgarriff, em especial, afirma que é muito difícil fazer essa diferenciação, na prática, uma vez que identificar se os sentidos são ou não relacionados é uma tarefa complexa. Segundo o autor, o critério da etimologia comumente utilizado para essa identificação não é adequado: questões sincrônicas sobre a estrutura dos significados das palavras não podem ser resolvidas usando critérios diacrônicos.

Para Zavaglia (2002), a distinção entre os fenômenos da homonímia e da polissemia é importante, por exemplo, para a construção de dicionários. Isso ocorre porque, normalmente, nos dicionários, as palavras homônimas são descritas por entradas distintas, enquanto que as polissêmicas são descritas como subdivisões (de sentido) em uma mesma entrada. Contudo, ainda que o fator "existência ou não de significado entre as palavras" seja aceito para distinguir homonímia de polissemia, a autora afirma não haver consenso sobre como designar a existência ou não de relação entre os significados de uma palavra. Mesmo entre os lexicógrafos que adotam o critério etimológico, há diferenças na classificação de determinadas palavras.

Apesar de essa distinção ser importante em áreas como a Lexicografia, na área de DLS a maior parte dos trabalhos não diferencia polissemia de homonímia. Hirst (1987), por exemplo, concorda que existe distinção entre esses dois fenômenos, mas afirma que tal distinção é desnecessária no tratamento automático da língua natural. Em geral, os trabalhos utilizam o termo "word sense disambiguation" em um sentido amplo, abrangendo tanto polissemia quanto homonímia. Como menciona Zavaglia, “(...) esses sistemas (de DLS) trabalham com qualquer tipo de forma ambígua, tanto as polissêmicas quanto as homônimas, de forma indiscriminada, ou seja, formas homônimas e polissêmicas são vistas sob o mesmo 
nível de ambigüidade (...)” (Zavaglia, 2002, p. 127). Nas recomendações do grupo EAGLES (EAGLES, 1998) para trabalhos de DLS, consta que a resolução de qualquer ambigüidade semântica no nível lexical é denominada "word sense disambiguation": as palavras podem ter mais de um significado, em alguns casos, muito próximos; em outros, completamente distintos.

Essa visão indiscriminada é comum porque, para o propósito de implementação de mecanismos de DLS, o tratamento para ambos os problemas (polissemia e homonímia), em essência, é o mesmo: uma palavra pode ter vários sentidos, sendo que, dado o seu contexto, o sentido mais apropriado deverá ser selecionado. Entretanto, uma distinção normalmente é feita entre os trabalhos no que se refere ao nível de refinamento da divisão dos sentidos. Certos trabalhos realizam a desambiguação apenas entre sentidos muito distintos, como as entradas (homógrafos) distintas em um dicionário, que, em alguns casos, correspondem a distinções em nível de homonímia. Outros se preocupam com distinções mais refinadas, incluindo variações muito sutis de significado, que, em alguns casos, correspondem a distinções em nível de polissemia. Outros, ainda, tratam ambos os níveis de refinamento, mas relatam os resultados separadamente, de acordo com o nível. Contudo, vale notar que as chamadas "distinções refinadas" nem sempre correspondem à polissemia, e que o mesmo vale para as "distinções entre sentidos muito diferentes", que nem sempre correspondem à homonímia.

Outra característica importante na definição desses fenômenos é a noção de categoria gramatical. Ullmann (1964) afirma que tanto a polissemia quanto a homonímia podem ser acompanhadas por diferenças sintáticas, que ocorrem quando os sentidos da palavra polissêmica possuem categorias gramaticais ${ }^{4}$ diferentes ou quando as palavras homônimas pertencem a categorias gramaticais diferentes. Considerando-se também essa variante, são possíveis quatro tipos principais de ambigüidade lexical: homonímia e polissemia entre palavras da mesma categoria gramatical ou de categorias distintas.

O termo homonímia categorial indica a homonímia constituída de palavras de classes gramaticais distintas. Analogamente, o termo polissemia categorial é usado para denominar a polissemia entre palavras de categorias gramaticais distintas. Assim, o problema da ambigüidade lexical pode ainda ser classificado como ambigüidade categorial ou ambigüidade de sentido (ou semântica) (Jurafsky \& Martin, 2000). Na tradução, a

\footnotetext{
4 "Categoria gramatical” refere-se, neste trabalho, à classificação da palavra por sua categoria ou classe morfossintática (do inglês, part-of-speech), por exemplo, substantivo, verbo ou advérbio. Algumas variações dessa denominação incluem "classe/categoria sintática" e "classe/categoria morfossintática".
} 
ambigüidade categorial ocorre quando as duas ou mais opções de tradução de uma dada palavra da língua fonte têm diferentes categorias gramaticais na língua alvo. Um exemplo de ambigüidade categorial na forma de homonímia é a palavra do inglês field, que pode ser traduzida para as palavras "campo" (substantivo) ou "interceptar" (verbo), no português. Já um exemplo de ambigüidade categorial na forma de polissemia é a palavra do inglês eats, que pode ser traduzida no português como "mantimentos, víveres, gêneros alimentícios" (substantivos) ou "come" (verbo "comer" conjugado na terceira pessoa singular, presente do indicativo). Na ambigüidade de sentido, por sua vez, as duas ou mais opções de tradução de uma dada palavra da língua fonte têm a mesma categoria gramatical na língua alvo. Nesse caso, valem os exemplos já mencionados para polissemia e homonímia.

A ambigüidade categorial é, em geral, muito mais simples que a de sentido, uma vez que pode ser resolvida, na maioria das vezes, pela análise das características sintáticas das palavras (realizada por procedimentos de etiquetação morfossintática ou análise sintática). De fato, segundo Towell \& Voorhess (1998), a precisão dos etiquetadores morfossintáticos disponíveis atualmente mostra que esse é um problema mais simples.

A resolução da ambigüidade de sentido, por outro lado, exige uma análise mais aprofundada das palavras e dos seus usos nas línguas fonte e alvo. Segundo Maegaard (2001), sem algum nível de representação semântica, como a semântica lexical ou as ontologias, os sistemas de TA não são capazes de resolver, de forma eficaz, os problemas de ambigüidade de sentido.

Vale notar que alguns autores não consideram a possibilidade de existência do fenômeno da polissemia entre palavras de classes gramaticais distintas. Por exemplo, para Zavaglia (2002) e Rehfeldt (1980), a polissemia é sempre unicategorial: “a partir do momento que a uma forma são atribuídas duas ou mais categorias gramaticais, ela se torna integrante do fenômeno da homonímia" (Zavaglia, 2002, p. 89). Já segundo Dias-da-Silva (1996), as ambigüidades lexicais podem se manifestar por meio de três fenômenos: polissemia, homonímia e categorização gramatical, sendo que apenas as ambigüidades de categorização ocorrem quando uma mesma forma lexical pertence a classes gramaticais distintas. De acordo com Kilgarriff (1997a), formas iguais, mas com categorias gramaticais distintas, não são consideradas lexemas polissêmicos, tampouco homônimos.

Como afirmam Wilks \& Stevenson (1998), não há consenso sobre a decisão de considerar ou não a ambigüidade categorial como um tipo de ambigüidade de sentido e, portanto, se ela deve ou não ser tratada pelas abordagens de DLS. Os autores, em seus vários trabalhos, consideram a ambigüidade entre palavras de categorias gramaticais distintas, mas 
utilizam um etiquetador morfossintático em uma etapa prévia ao processo de DLS. As etiquetas gramaticais servem, assim, como filtro para a DLS.

Neste trabalho, apenas a ambigüidade lexical de sentido será focalizada, partindo-se do princípio que as palavras já estão identificadas com relação às suas categorias gramaticais. Essa mesma posição é adotada pela grande maioria dos trabalhos de DLS. Segundo Ide \& Véronis (1998), a área de DLS deve, de fato, focalizar somente a ambigüidade lexical de homógrafos com a mesma categoria gramatical. De maneira gráfica, a Figura 2.1 destaca o problema da ambigüidade de sentido que será endereçado neste trabalho (isto é, polissemia e homonímia) no quadro geral dos principais casos de ambigüidade na TA discutidos anteriormente. Na seqüência, esse problema é descrito no contexto dos sistemas atuais de TA.

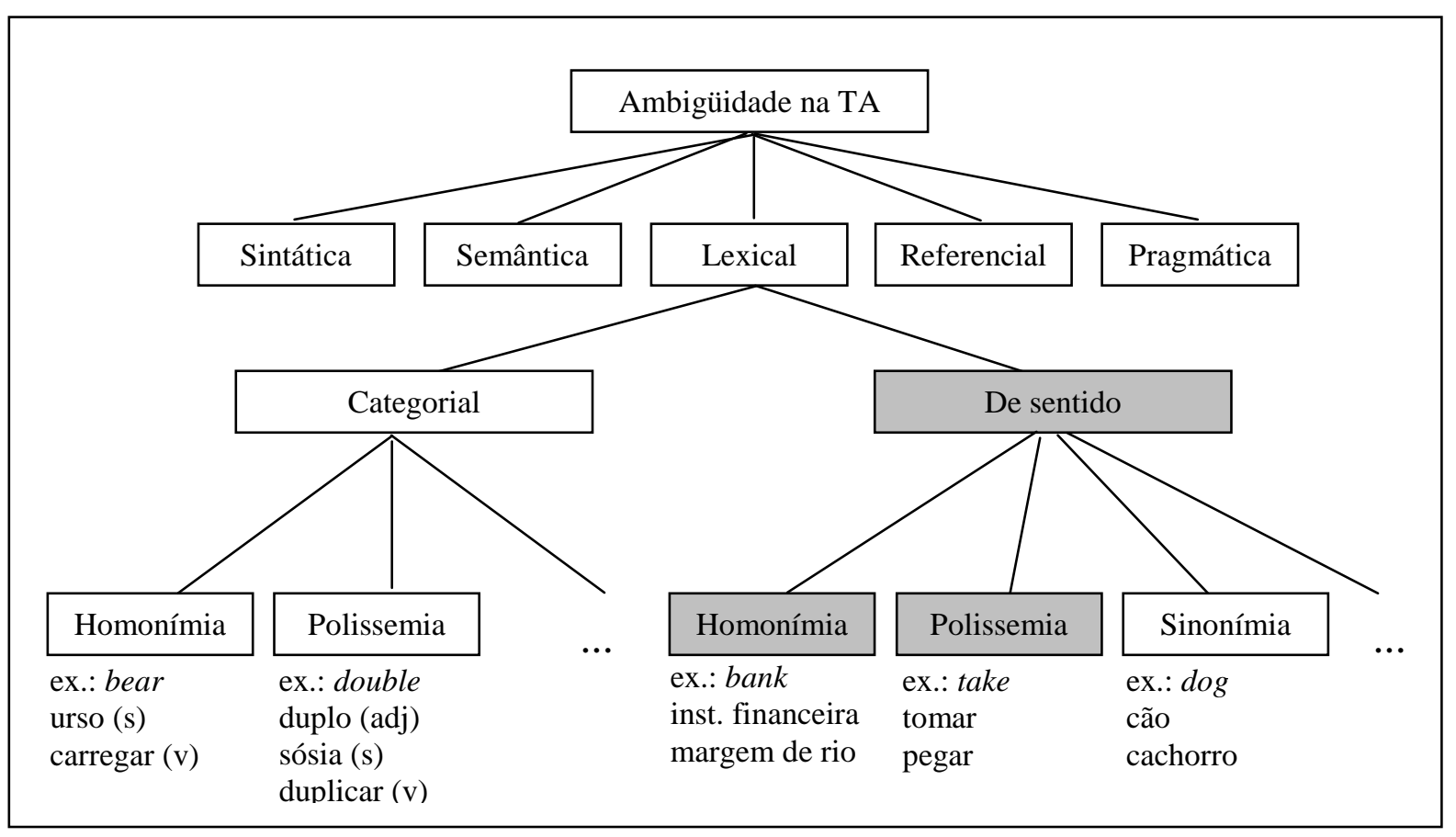

Figura 2.1: O problema da ambigüidade na TA

\subsection{A AMBIGÜIDADE LEXICAL DE SENTIDO NOS SISTEMAS DE TA}

Conforme mencionado, em função das diferenças lexicais entre as línguas, raramente há correspondência unívoca entre os seus vocabulários. A identificação dos diferentes tipos de correspondências entre vocabulários é um processo complexo mesmo para humanos (Cole et al., 1996). A incorporação de tais capacidades em sistemas de TA vem sendo abordada de diferentes formas desde as primeiras aplicações nessa área, na década de 50.

Intuitivamente sempre se julgou que a resolução do problema de ambigüidade lexical poderia melhorar a qualidade da TA. Segundo Arnold et al. (1993), por exemplo, as reflexões 
do problema da ambigüidade de sentido na TA são grandes, pois as implicações locais, causadas pela escolha incorreta na tradução de um item, podem ser propagadas, causando a escolha incorreta de outros elementos na sentença. Kilgarriff (1997b) afirma que, em outras aplicações da DLS, como a Recuperação de Informações, dificilmente pode-se atribuir o desempenho insatisfatório do sistema à inexistência ou ineficiência de um módulo de DLS. $\mathrm{Na} \mathrm{TA}$, por outro lado, é reconhecidamente claro que a ambigüidade lexical de sentido é um grande problema e, portanto, que módulos efetivos de DLS podem melhorar significativamente sua qualidade. Kilgarriff, bem como Resnik \& Yarowsky (1997a), afirma que dentre as várias aplicações em que a DLS pode ser empregada, a TA é a que mais pode se beneficiar, pois é para essa aplicação que a ambigüidade lexical de sentido representa o maior problema. Também segundo Ide \& Véronis, apesar da DLS ser necessária, em diferentes níveis, para a realização de muitas tarefas de PLN, na TA ela é essencial para obter traduções adequadas.

Inicialmente, o objetivo era conseguir representar e utilizar conhecimento de mundo sobre as línguas, já que se acreditava que somente por meio desse tipo de conhecimento seria possível resolver as ambigüidades. Contudo, conforme relatado por Bar-Hillel (1960), não se dispunha, na época, de meios para codificar e utilizar o conhecimento de mundo e isso tornava impossível escolher o sentido adequado na TA em muitos casos, o que seria uma grande e intransponível barreira para o desenvolvimento da TA. Por muitos anos, assumiu-se então a desambiguação como um problema insolúvel, o que resultou em uma grande redução nos investimentos e pesquisas em TA.

Dessa forma, os primeiros trabalhos em TA procuravam, na verdade, evitar a ambigüidade lexical, delimitando os dicionários a uma única tradução para cada palavra. A partir da década de 1970, todavia, os avanços em várias áreas da Inteligência Artificial, tais como a representação de conhecimento, resultaram na retomada das pesquisas em TA, mas com o objetivo mais modesto de tentar traduzir corretamente pequenos conjuntos de palavras, restritos a determinados domínios. Nessas aplicações, geralmente acadêmicas, representavamse apenas as palavras (e seus significados) necessários para a criação de protótipos para processar pequenos subconjuntos da língua que o sistema se propunha a manipular, o que muito raramente incluía casos de ambigüidade lexical. Esses casos eram, por sua vez, tratados isoladamente. Estratégias comuns para minimizar as possibilidades de descrições das palavras nos recursos lexicais incluíam os micro-glossários (dicionários que registram apenas uma tradução para cada palavra), linguagens controladas (linguagens restritas a alguns padrões gramaticais e de vocabulário) ou sub-linguagens (linguagens com gramática e vocabulário 
especializados segundo algum domínio e objetivo comunicativo), ou, ainda, mecanismos de interação ou pós-edição humana, em geral por meio da enumeração de todas as possibilidades de tradução, para que o usuário escolhesse pela tradução mais adequada. Essas estratégias são exploradas mesmo por sistemas mais recentes. Por exemplo, o sistema KANT (Baker et al., 1994; Mitamura, 1999) restringe tanto a linguagem, que é controlada de acordo com um domínio técnico, quanto o léxico, que permite a representação de uma única tradução para cada entrada, sempre que possível. Quando é necessário representar mais de uma tradução e isso acarreta uma ambigüidade lexical, o sistema exibe todas as possíveis traduções e a escolha é feita por meio da pós-edição manual. Mais recentemente, para minimizar as limitações das aplicações resultantes, passou-se a investigar alternativas para resolver o problema.

Alguns poucos sistemas de TA baseados em regras consideram a representação de conhecimento profundo e de regras para a desambiguação para a tradução em domínios específicos. Por exemplo, nos sistemas de TA por interlíngua baseados em conhecimento lingüístico KBMT (Goodman \& Nirenburg, 1991) e Mikrokosmos (Beale, 1997), a DLS é realizada durante a interpretação da língua fonte, implicitamente, por meio dos módulos de análise semântica. Ambos os sistemas focalizam domínios específicos: manuais técnicos (sobre computadores) e aquisição e fusão entre corporações, respectivamente. São definidos, em cada um, uma ontologia e um léxico semântico cujas entradas estão relacionadas aos conceitos da ontologia. No léxico, o significado dos termos de entrada é definido por informações lingüísticas de diversas naturezas (morfológicas, sintáticas, semânticas, etc.). Nesses sistemas, a ambigüidade lexical de sentido é resolvida pelo analisador semântico, que combina o conhecimento disponível na ontologia e no léxico, aplicando-o à sentença de entrada, para produzir as representações semânticas. Basicamente, o processo de DLS consiste em, a partir de todas as entradas do léxico para uma palavra ambígua (isto é, todos os seus sentidos), que satisfazem as restrições sintáticas da sentença atual, verificar se as características semânticas da entrada de cada sentido satisfazem uma série de restrições para o seu mapeamento em conceitos da ontologia, considerando também os possíveis mapeamentos das palavras vizinhas na sentença em conceitos da ontologia. Todas as possíveis combinações entre todos os sentidos das palavras da sentença de entrada são verificadas e um escore é calculado de acordo com a satisfação mútua das restrições em cada combinação. A representação semântica com o maior escore é então escolhida. O uso dessa abordagem de DLS permite desambiguações precisas, porém, limitadas aos gêneros e/ou domínios específicos de cada sistema. 
O sistema UNITRAN, de tradução automática por interlíngua entre o inglês, o espanhol e o francês (Dorr, 1993), também não dispõe de um mecanismo específico para esse problema. Esse sistema utiliza uma adaptação das estruturas conceituais lexicais (Lexical Conceptual Structures - LCS) de Jackendoff (1990), para a representação tanto dos itens lexicais quanto das estruturas conceituais compostas por vários itens. A interlíngua do sistema corresponde à composição de várias dessas estruturas para a representação de sentenças específicas, de acordo com as palavras da sentença. No UNITRAN, a ambigüidade lexical é considerada um problema de divergência lexical e é tratada na realização das estruturas conceituais para a língua alvo. A seleção é feita por meio da verificação das estruturas lexicais que satisfazem as restrições de seleção sintáticas e semânticas presentes na estrutura conceitual composta, por meio de um processo similar ao de unificação. Tais restrições incluem vários níveis da teoria de Jackendoff: primitivas, tipos, campos e traços das estruturas conceituais lexicais devem combinar com os mesmos itens da estrutura conceitual composta. Várias estruturas lexicais podem combinar com a estrutura sendo composta em todos esses níveis, de modo que, em alguns casos, o sistema retorna mais de uma realização lexical. Um problema dessa estratégia é que as restrições utilizadas não capturam distinções que não sejam caracterizadas por propriedades puramente sintáticas, por exemplo, por distinções que dependem de conhecimento do discurso, de domínio ou de mundo, conhecimento de usos idiomáticos, etc. Essa limitação nos tipos de conhecimento considerados no sistema, bem como o fato de o sistema poder retornar várias realizações lexicais, implica, certamente, que muitos casos de ambigüidade não são resolvidos. De fato, segundo a autora, um tratamento mais explícito a esse problema, considerando-se, por exemplo, restrições contextuais e colocações, poderia melhorar o processo de escolha lexical do sistema.

O sistema TA por transferência entre coreano e o inglês descrito em (Egedi et al., 1994), também acadêmico, possui um módulo específico de DLS para tratar da ambigüidade de alguns verbos. O tratamento é feito com base na unificação de restrições de seleção semânticas definidas na estrutura argumental desses verbos com os traços semânticos definidos para os substantivos que podem ser utilizados como seus argumentos. As regras de transferência, incluindo as restrições de seleção e os traços semânticos, são manualmente especificadas. A DLS ocorre no processo de transferência lexical, com base nas possíveis traduções especificadas em um dicionário bilíngüe e nas restrições de seleção e traços semânticos especificados na língua alvo. A desambiguação dos verbos depende da tradução correta dos seus argumentos, que precisam ser primeiramente traduzidos. Os autores justificam a especificação desse conhecimento na língua alvo porque, segundo eles, a seleção 
lexical normalmente depende da existência de traços semânticos nos elementos da língua alvo que são completamente irrelevantes para a língua fonte. Eles citam, como exemplo, a tradução do verbo wear, do inglês para o coreano. No coreano, a tradução depende do complemento do verbo: "wear clothes" e "wear socks" são traduzidos por verbos completamente diferentes. No inglês, no entanto, não há distinção.

Sistemas de TA como o EUROTRA (Copeland, 1991) e o METAL (Gajek, 1991), que também seguem o método por transferência, empregam procedimentos mais simples de DLS que os das abordagens baseadas em interlíngua. Eles procuram tratar a ambigüidade lexical por meio da definição de estruturas argumentais e de restrições ou preferências de seleção sobre essas estruturas, na língua fonte. No sistema EUROTRA, em particular, uma hierarquia simples de tipos semânticos (entidade, humano, não-humano, etc.) é utilizada para tratar os casos de desambiguação mais refinada, também com base em preferências de seleção. $O$ sistema aplica a noção de distância semântica entre os nós dessa hierarquia. Contudo, de modo geral, como afirma Pedersen (1997), essas restrições são simples e limitadas, de modo que resolvem apenas alguns casos mais básicos de ambigüidade.

Sistemas de TA irrestrita e completamente automatizada, normalmente comerciais, em especial aqueles que incluem o português, não consideram conhecimento lingüístico aprofundado para a desambiguação lexical. Em geral, baseiam-se em critérios muito simples para a escolha lexical, como a tradução mais freqüente, que é utilizada na maioria das ocorrências da palavra, excetuando-se alguns casos do uso da palavra em expressões comuns ou phrasal verbs, por exemplo. O Systran $\AA^{5}$, um dos sistemas de TA mais antigos e mais utilizados atualmente, adota uma visão bastante prática do processo de DLS (cf. Flanagan \& McClure, 2002): procura identificar o domínio do texto sendo traduzido para acessar dicionários específicos de cada domínio. Isso é feito com base na análise de traços sintáticosemânticos (objeto concreto, sujeito humano, etc.) e das categorias semânticas (dispositivo, propriedade, etc.) das palavras do contexto, armazenadas nos dicionários do sistema. Contudo, nem todas as entradas possuem essas informações e o seu uso não é efetivo, na maior parte dos casos. Além disso, dependendo do tamanho do texto a ser traduzido e da sua natureza, a identificação do domínio não é possível. Para os casos mais simples, o Systran também possui entradas específicas para algumas expressões idiomáticas, locuções comuns e termos técnicos de diversas áreas.

\footnotetext{
${ }^{5}$ http://www.systransoft.com
} 
Mais recentemente, os sistemas estatísticos de TA realizam a desambiguação lexical implicitamente, uma vez que as palavras utilizadas nas traduções de treinamento são levadas em consideração quando do aprendizado dos modelos de tradução. No entanto, em tais sistemas, conhecimento contextual da língua fonte é inexistente, no caso de traduções diretas palavra a palavra (e.g., Tillmann et al., 1997; Germann et al., 2001; Och \& Ney, 2003) ou limitado a uma vizinhança bastante pequena na sentença, em sistemas de tradução por frases ou blocos de palavras (e.g., Koehn et al., 2003; Vogel et al., 2000; Vogel et al., 2003). Conhecimento lingüístico, quando explorado, restringe-se ao nível sintático, por meio da representação dos exemplos como estruturas sintáticas (e.g., Wu, 1997; Yamada \& Knight, 2001; Lin, 2004; Quirk et al., 2005). O conhecimento da língua alvo é também limitado à análise de n-gramas (geralmente trigramas) no módulo estatístico denominado modelo da língua. Além disso, a grande maioria dos sistemas estatísticos atuais é otimizada com relação à medida BLEU (Bilingual Evaluation Understudy) (Papineni et al., 2002), que dá preferência à fluência, em detrimento da adequação, uma vez que analisa a qualidade das traduções contrastando n-gramas traduzidos àqueles nas traduções de referência.

Nos últimos anos, tem sido motivo de debate a utilidade de módulos de DLS em sistemas estatísticos de TA, muito embora o primeiro trabalho a realizar a integração de um módulo de DLS na TA estatística tenha apresentado resultados positivos (Brown et al., 1991). Brown et al. empregam um modelo estatístico da Teoria da Informação baseado em informação mútua para a seleção lexical de itens ambíguos na TA do francês para o inglês. O modelo é treinado no córpus paralelo do parlamento canadense (Canadian Hansard). São extraídas desse córpus as possíveis traduções das palavras do francês para o inglês que apresentam um alinhamento direto (um para um), as quais representam os sentidos de tais palavras. Somente a desambiguação binária, ou seja, a escolha entre apenas duas possíveis traduções de uma palavra ambígua, é considerada. O algoritmo flip-flop (Nadas et al., 1991), baseado na teoria de ganho de informação, é utilizado para encontrar, para cada palavra ambígua, um único atributo que indica, com um alto nível de confiabilidade, qual a sua tradução. Definido esse atributo, os exemplos (em francês) são divididos em dois grupos, para as duas traduções possíveis, de acordo com o valor que apresentam para esse atributo. $\mathrm{O}$ modelo foi treinado para a desambiguação das 500 palavras mais comuns do inglês e as 200 mais comuns do francês e as regras resultantes foram incorporadas a um sistema de TA estatístico, na fase de análise. Na tradução de 100 sentenças aleatoriamente selecionadas com essas palavras, os autores relatam uma diminuição de $13 \%$ na taxa de erro das traduções 
resultantes do sistema. $45 \%$ das sentenças traduzidas foram consideradas aceitáveis, contra apenas $37 \%$, sem o uso do módulo de DLS.

Apesar de bastante representativo, o trabalho de Brown et al. limita-se a distinções binárias de sentidos, enquanto que, claramente, o nível de ambigüidade de grande parte das palavras é maior. Recentemente, porém, outros pesquisadores voltaram a avaliar a influência de um módulo de DLS na TA. Por exemplo, Carpuat \& Wu (2005a) argumentam que a DLS não acarreta benefícios para a qualidade de sistemas estatísticos de TA. Os autores procuram integrar os resultados de um sistema de tradução por palavras do chinês para o inglês com a desambiguação realizada por um módulo de DLS para o chinês, cujos sentidos são manualmente mapeados para traduções no inglês. A incorporação da melhor opção de desambiguação resultante do sistema de DLS é feita na etapa de decodificação do sistema de TA, forçando a escolha de tal opção como a tradução da palavra, ou como pós-processamento, substituindo a escolha do sistema de TA pela escolha do sistema de DLS. Em ambos os casos, não houve melhoria na qualidade da tradução, que foi medida de acordo com a métrica BLEU. Contudo, tais resultados são certamente influenciados por uma série de limitações da abordagem: (1) o módulo de desambiguação foi desenvolvido para a língua fonte e, portanto, não considera nenhuma informação sobre a língua alvo; (2) os atributos utilizados para o treinamento do sistema de DLS são bastante superficiais, tais como colocações; (3) as traduções fornecidas pelo sistema de DLS simplesmente substituem as opções do sistema de TA, em vez de interagirem com as demais informações estatísticas disponíveis no sistema; (4) a medida BLEU não reflete apropriadamente modificações no nível lexical resultantes de desambiguações corretas.

Por outro lado, os mesmos autores mostram posteriormente que sistemas de TA não apresentam a mesma qualidade na resolução do problema da ambigüidade lexical isoladamente, fora do contexto da TA (Carpuat \& Wu, 2005b). Experimentos comparando a escolha lexical do mesmo sistema de TA do chinês para o inglês e de diversos sistemas de DLS para um conjunto de 20 palavras ambíguas mostraram que o sistema de TA não atinge a precisão de sistemas de DLS, nem mesmo daqueles não supervisionados, que são os que apresentam a precisão mais baixa entre todos os sistemas de DLS testados. Isso mostrou que, de fato, a DLS pode contribuir para a TA e motivou os autores a investigarem uma maneira mais apropriada de integrar as duas aplicações. Em (Carpuat et al., 2006) são apresentados os resultados de experimentos preliminares com um sistema estatístico de TA baseado em frases e o mesmo sistema de DLS, com os mesmos atributos, mas dessa vez considerando-se como sentidos as traduções candidatas identificadas de acordo com o mesmo método de 
alinhamento de palavras utilizado pelo sistema de TA, em vez do conjunto de todos os sentidos da língua fonte mapeados para traduções na língua alvo. Além disso, ambos os sistemas são treinados utilizando-se o mesmo córpus. A integração dos dois sistemas foi também modificada: as possíveis traduções identificadas pelo sistema de DLS são fornecidas como candidatas adicionais ao módulo de decodificação no sistema de TA, e tal módulo então procede com a escolha lexical. Os resultados, computados em termos da métrica BLEU em quatro conjuntos de teste distintos, mostraram que o módulo de DLS permite melhorias, ainda que bastante pequenas, mas consistentes. Os autores enfatizam que o principal motivo para os resultados positivos é o uso de um sistema de DLS projetado especificamente para a tarefa de TA.

Vicrey et al. (2005) e Cabezas \& Resnik (2005) também procuraram integrar a DLS a um sistema estatístico de TA e reportaram resultados promissores, em sistemas para os pares de línguas inglês-espanhol e inglês-francês, respectivamente. Em ambos os casos, o sistema de DLS é supervisionado e utiliza como sentidos as traduções automaticamente identificadas no córpus paralelo por meio de um sistema de alinhamento por palavras e apenas fontes de conhecimento superficiais, fornecidas pelo córpus, são utilizadas. A integração com o sistema de TA é feita de maneira similar a (Carpuat et al., 2006), ou seja, a lista de possíveis traduções é fornecida ao sistema de TA, que pode combinar tais sugestões com outras informações para realizar a escolha. Cabezas \& Resnik fornecessem as traduções apontadas pelo sistema de DLS como opções adicionais àquelas encontradas pelo sistema de TA, para que o decodificador possa escolher a tradução mais adequada. Vicrey et al., por não disporem de um sistema de TA, simulam tal integração numa tarefa de tradução.

Mais recentemente, dois trabalhos com metodologias alternativas similares para a integração de DLS e TA estatística foram propostos: Chan et al. (2007) e Carpuat \& Wu (2007). Ambos os trabalhos visam à tradução do chinês para o inglês, mas enquanto Chan et al. utilizam um sistema sintático hierárquico de TA estatística, Carpuat \& Wu utilizam um sistema baseado em frases. Em Chan et al., os exemplos para o treinamento do sistema de DLS são obtidos durante o treinamento do sistema de TA: todas as regras de tradução para subfrases de uma ou duas palavras extraídas do córpus paralelo são considerados exemplos. Adicionalmente, a sentença contendo aquela subfrase e duas sentenças vizinhas são extraídas para fornecer o contexto para o sistema de DLS. Assim, as possíveis traduções são dadas pelo córpus de TA juntamente com o método de alinhamento de palavras GIZA++ (Och \& Ney, 2003). Para cada subfrase ocorrendo pelo menos 10 vezes, um modelo de desambiguação é gerado, utilizando-se o algoritmo SVM (Support Vector Machines) e atributos superficiais: 
colocações, categorias gramaticais e bag-of-words. A integração da DLS ocorre na fase de decodificação: para cada regra de tradução de uma subfrase (ou palavra), primeiramente identifica-se se existe uma regra de DLS correspondente àquela subfrase (ou palavra). Em caso positivo, a tradução sugerida pelo sistema de DLS é comparada à tradução sugerida pelo sistema de TA. Caso a primeira seja uma subcadeia da segunda e pelo menos uma das palavras da primeira corresponda a um alinhamento com a subfrase na língua fonte, são calculados dois atributos referentes ao conhecimento adicionado pelo módulo de DLS: (1) a soma de todas as probabilidades para todas as traduções sugeridas que combinam com as traduções indicadas pelo sistema de TA; (2) a soma do comprimento de todas essas traduções. Esses atributos são então adicionados ao modelo do sistema de tradução, que é retreinado para estimar os pesos destes e de todos os outros atributos, por meio de uma técnica chamada de Minimum Error Rate Training (MERT) (Och, 2003). Experimentos com essa abordagem levaram a uma melhoria significativa no escore BLEU.

Carpuat \& $\mathrm{Wu}$, em seus experimentos mais recentes, também focalizam no desenvolvimento de uma abordagem de desambiguação de subfrases voltada especificamente para a TA estatística. Os "sentidos" são também obtidos a partir córpus de treinamento do sistema de TA, também por meio do método de alinhamento de palavra GIZA++. No entanto, neste caso, são extraídas subfrases de qualquer tamanho: todas as subfrases geradas pelo método de alinhamento são consideradas exemplos de desambiguação. O módulo de DLS é baseado na combinação de quatro algoritmos de aprendizado e utiliza atributos bastante superficiais, como colocações e bag-of-words. A integração de DLS com SMT é feita durante a decodificação, por meio da adição ao modelo de tradução de um atributo correspondendo à probabilidade da tradução em questão ser indicada pelo módulo de DLS. A técnica chamada de Minimum Error Rate Training é utilizada para estimar o peso do novo e dos demais atributos. Detalhes sobre como as subfrases resultantes dos dois sistemas são comparadas não são fornecidos. Experimentos com diversas bases de dados usando oito medidas de avaliação de TA mostraram que, consistentemente, o módulo de DLS melhora a qualidade do sistema de TA.

Os diversos trabalhos citados mostram o potencial de mecanismos de DLS para a TA estatística. Os dois trabalhos mais recentes, no entanto, não abordam a DLS no sentido tradicional: não se define o repositório de sentidos previamente e conjuntos de palavras (subfrases) constituem a unidade básica de desambiguação. Apesar de comprovadamente úteis para a TA, tais soluções exigem a simplificação da tarefa de DLS, principalmente no que diz respeito às fontes de conhecimento que podem ser exploradas. Como as unidades de 
desambiguação são subfrases constituídas, em princípio, de qualquer combinação e número de palavras, muitas das fontes tradicionalmente utilizadas para a DLS não podem ser extraídas. Por exemplo, torna-se complexa ou impossível a representação de relações sintáticas ou semânticas entre a subfrase ambígua e os demais elementos da sentença. Basicamente, somente fontes de conhecimento superficiais, extraídas por córpus, podem ser utilizadas, por exemplo, bag-of-words. Além disso, a complexidade do processo de tradução como um todo aumenta consideravelmente, já que se considera como casos ambíguos todas as subfrases geradas pelo sistema de TA (ou todas as subfrases de até duas palavras, no caso de (Chan et al., 2007). Certamente, muitas das subfrases consideradas não serão ambíguas e, portanto, não necessitariam de modelos de desambiguação, por exemplo, preposições e outras palavras de classe fechada. Outro problema, especialmente no método de Carpuat \& Wu, diz respeito à esparsidade dos dados. Como modelos de desambiguação são gerados para subfrases de qualquer tamanho, é necessário que se disponha de uma grande quantidade de dados de treinamento para que se tenha exemplos suficientes de cada caso. Por fim, as traduções indicadas pelo módulo de DLS são limitadas àquelas para as quais haja exemplos suficientes de treinamento, ou seja, nenhum recurso adicional, como um dicionário bilíngüe, é utilizado para fornecer possíveis traduções.

Em geral, o desenvolvimento de sistemas de DLS e de TA de maneira totalmente automatizada com o uso de técnicas estatísticas e de aprendizado de máquina têm permitido a investigação de maneiras de integrar as duas áreas. Contudo, os recentes e ainda poucos esforços para a incorporação de mecanismos dedicados de DLS em sistemas de TA têm sido voltados para aplicações acadêmicas, e pares de línguas específicos. Nenhum estudo foi ainda realizado envolvendo o par de línguas inglês-português. Além disso, os sistemas de DLS empregados ainda são resultado de pesquisas em DLS para a língua fonte, de modo que o conjunto de atributos utilizado não inclui informações sobre a língua alvo.

$\mathrm{Na}$ próxima seção é descrito um estudo de caso realizado para analisar o comportamento dos sistemas acadêmicos e comerciais de TA inglês-português no que se diz respeito ao problema da ambigüidade lexical de sentido, visando motivar o desenvolvimento de módulos de DLS para a TA entre essas duas línguas. 


\subsection{A AMBIGÜIDADE LEXICAL DE SENTIDO NOS SISTEMAS DE TA INGLÊS-PORTUGUÊS - UM ESTUDO DE CASO}

O problema da ambigüidade lexical de sentido na tradução do inglês para o português foi analisado, neste trabalho, em um estudo de caso cujo objetivo era investigar as consequiências dessa ambigüidade em traduções automáticas de textos reais, a fim de motivar este projeto de doutorado, bem como de delimitar a proposta aos casos mais problemáticos de ambigüidade. Esse estudo é apresentado com detalhes em (Specia \& Nunes, 2004a).

O estudo consistiu de um experimento com o córpus BNC (Burnard, 2000) e três sistemas de TA inglês-português comumente utilizados, a saber, Systran ${ }^{6}$, FreeTranslation ${ }^{7}$ e Globalink Power Translator Pro®, todos independentes de gênero e domínio. Os dois primeiros estão disponíveis para uso gratuito na web, enquanto o último é um sistema comercial. Todos os sistemas são baseados em regras; nenhum sistema estatístico foi utilizado porque na época em que o estudo foi realizado não se dispunha de sistemas dessa natureza treinados para o par inglês-português. Adicionalmente, a idéia inicial era a de propor uma abordagem simbólica de DLS, a qual poderia, portanto, ser diretamente integrada a sistemas baseados em regras.

Foram considerados para análise somente os verbos das sentenças, mais especificamente, um subconjunto de verbos freqüentes no BNC. Conforme foi discutido anteriormente, a escolha da categoria gramatical deve-se ao fato de verbos serem casos bastante complexos de desambiguação, que podem determinar o sentido correto de outros elementos na sentença. Estudos como o de Klavans \& Kan (1998), por exemplo, comprovam a relevância da desambiguação dos verbos. Os autores analisam o papel dos verbos na análise de documentos e relatam que a identificação correta do sentido do verbo provê uma indicação confiável do conteúdo do documento.

Foram selecionados os verbos com mais de 100 mil ocorrências no córpus, a partir de uma lista de freqüência lematizada levantada por Adam Kilgarriff ${ }^{8}$. Esse critério resultou na seleção dos seguintes 15 verbos: to be, to have, to do, to say, to go, to get, to make, to see, to know, to take, to think, to come, to give, to look e to use.

Antes de analisar a ambigüidade dos verbos pré-selecionados, procurou-se verificar se tais verbos eram potencialmente ambíguos, isto é, se eles possuíam mais de uma tradução, com diferentes sentidos (denotativos), mas da mesma categoria gramatical (verbo, neste caso).

\footnotetext{
${ }^{6} \mathrm{http}: / / \mathrm{www}$. systransoft.com

${ }^{7}$ http://www.freetranslation.com

${ }^{8} \mathrm{ftp}: / /$ ftp.itri.bton.ac.uk/pub/bnc.
} 
De acordo com o dicionário eletrônico DTS DIC Prático Michaelis® 5.1, todos os verbos podem apresentar diferentes traduções, com significados relacionados ou totalmente distintos. Assim, considerou-se que todos os 15 verbos pré-selecionados são potencialmente ambíguos na tradução.

Para a análise de tais verbos, foram selecionadas, aleatoriamente, cerca de 35 sentenças com cada verbo, no Córpus Central do BNC, uma porção do córpus cuja etiquetação gramatical foi revisada manualmente. Na seleção, foram consideradas amostras de cada verbo com diferentes etiquetas verbais (VVD - passado simples, VVI - infinitivo, etc.), representando variações, por exemplo, no modo e no tempo do verbo. Ao todo, foram selecionadas 531 sentenças englobando os 15 verbos.

As sentenças foram então submetidas aos três tradutores automáticos e as suas respectivas traduções foram esquematizadas em tabelas para uma análise posterior. Exemplos de traduções dos sistemas para algumas sentenças de diferentes verbos são apresentados na Tabela 2.1.

Tabela 2.1: Exemplos de traduções dos três sistemas de TA

\begin{tabular}{|c|c|}
\hline \multicolumn{2}{|c|}{ Be ready to stake any which show signs of flopping. } \\
\hline FreeTranslation & Esteja pronto a estaca qualquer que mostra sinais de cair. \\
\hline Systran & Esteja pronto para estacar alguns que mostrarem sinais de flopping. \\
\hline TranslatorPro & Esteja pronto para apostar qualquer que sinais de espetáculo de baquear. \\
\hline \multicolumn{2}{|c|}{ Well he came into the garage the other day and told me his wife had kicked him out! } \\
\hline FreeTranslation & Bem veio em garagem o outro dia e me contou sua esposa tinha chutado-o para fora! \\
\hline Systran & Poço veio na garagem o outro dia e dito me sua esposa tinha-o retrocedido para fora! \\
\hline TranslatorPro & Bem ele entrou em garagem o outro dia e me falou para a esposa dele tinha o expulsado! \\
\hline \multicolumn{2}{|c|}{ "This city has suddenly came alive," said her husband, an off-duty border guard. } \\
\hline FreeTranslation & $\begin{array}{l}\text { "Esta cidade repentinamente veio vivo," disse seu marido, um guarda de fronteira de fora- } \\
\text { dever. }\end{array}$ \\
\hline Systran & "esta cidade tem vivo de repente vindo," dito seu marido, um protetor off-duty da beira. \\
\hline TranslatorPro & "Esta cidade veio viva" de repente, disse o marido dela, um guarda de borda de fora-dever. \\
\hline \multicolumn{2}{|c|}{ It's best to be alone when the noises get this loud. } \\
\hline FreeTranslation & Está melhor estar só quando os barulhos recebem este alto. \\
\hline Systran & É o mais melhor estar sozinho quando os ruídos começam este alto. \\
\hline TranslatorPro & É melhor para estar só quando os barulhos adquirirem este alto. \\
\hline \multicolumn{2}{|c|}{ "You get three clear benefits out of this," he explained. } \\
\hline FreeTranslation & "Recebe três remover benefícios de isto," explicou \\
\hline Systran & "Você começa três benefícios desobstruídos fora deste, "ele explicou \\
\hline TranslatorPro & " Você sai três benefícios claros disto, " ele explicou. \\
\hline \multicolumn{2}{|c|}{$\begin{array}{l}\text { He arrived late yesterday afternoon, it seems, and he has offered to give a little recital to anyone on the island } \\
\text { who wishes to attend. }\end{array}$} \\
\hline FreeTranslation & $\begin{array}{l}\text { Chegou tarde ontem tarde, parece, e ofereceu dar um recital pequeno a ela na ilha que deseja } \\
\text { assistir. }\end{array}$ \\
\hline Systran & $\begin{array}{l}\text { Chegou tarde atrasada do ontem, parece, e ofereceu dar um recital pequeno a qualquer um } \\
\text { no console que deseja atender. }\end{array}$ \\
\hline TranslatorPro & $\begin{array}{l}\text { Ele chegou ontem tarde tarde, parece, e ele ofereceu a dar um pequeno recital a qualquer um } \\
\text { na ilha que deseja assistir. }\end{array}$ \\
\hline \multicolumn{2}{|c|}{ But I suppose you're right: the public isn't going to notice and those who know me. } \\
\hline FreeTranslation & Mas eu o suponho são direito: o público não notará e esses quem me sabem. \\
\hline Systran & Mas eu suponho que você é direito: o público não está indo observar e aqueles que me \\
\hline
\end{tabular}




\begin{tabular}{|l|l|}
\hline & conhecem. \\
\hline TranslatorPro & Mas eu suponho você tem razão: o público não vai notar e esses que me conhecem. \\
\hline
\end{tabular}

Cada tabela com as sentenças de origem de um verbo, juntamente com suas traduções nos sistemas, foi então analisada manualmente, com o auxílio de dicionários bilíngües e de outros recursos como a WordNet, por uma tradutora humana. Nessa análise, a tradutora acrescentou, para cada sentença, a tradução mais adequada (considerada ideal) do verbo em questão, a indicação dos sistemas que levavam a essa tradução ou a traduções alternativas, e comentários gerais, quando julgados importantes. Vale ressaltar que essa análise focalizou apenas a tradução do verbo em questão, e não da sentença completa. Assim, desde que fosse possível identificar o sentido do verbo, a tradução dos demais elementos na sentença, problemas de fluência, concordância, tempo, modo, entre outros, não foram considerados.

A análise realizada pela tradutora humana permitiu identificar as possíveis traduções de cada verbo, considerando-se a amostra de sentenças selecionada. Vale notar que foram consideradas traduções possíveis aquelas relativas ao uso do verbo em phrasal verbs (por exemplo, "get up") ou em construções e expressões nas quais o verbo não pode ser traduzido independentemente das demais palavras da expressão, uma vez que, isoladamente, não possui sentido algum. Por outro lado, não foram consideradas acepções possíveis aquelas provenientes de expressões de sentido figurado ou do uso dos verbos na função de auxiliares, como to be, to do, e to have. No caso do uso de verbos como auxiliares, foi analisada somente a capacidade do sistema de diferenciar o uso do verbo como principal ou auxiliar (somente nos casos em que é o verbo principal, verificou-se sua habilidade em traduzi-lo adequadamente).

Além das diversas traduções de cada verbo na amostra, a análise permitiu verificar principalmente se os sistemas eram capazes de identificar tais traduções nas diferentes sentenças. Com base nos resultados dessa análise, foram definidos os seguintes critérios para identificação de um subconjunto de verbos mais problemáticos com relação à ocorrência de ambigüidade lexical de sentido e à ineficiência no tratamento dispensado a ela pelos sistemas de TA:

- Verbos com mais de uma possível tradução identificada pela tradutora humana no conjunto de sentenças da amostra do córpus BNC foram considerados potencialmente problemáticos. Apesar de constarem diversas traduções para todos os verbos em dicionários bilíngües, nem todas elas foram verificadas na amostra. 
Isso provavelmente se deve à quantidade relativamente pequena de sentenças da amostra ou ao uso pouco freqüente do verbo em certos sentidos.

- Para cada ocorrência do verbo, assumiu-se que sua ambigüidade não era tratada adequadamente pelos sistemas nas sentenças para as quais pelo menos dois sistemas não haviam sido capazes de traduzir corretamente o verbo, de acordo com a tradução identificada ou considerada como uma alternativa aceitável pela tradutora humana.

- Sentenças originais cuja tradução adequada para o verbo em foco não pôde ser identificada pela tradutora humana foram desconsideradas da análise. Algumas sentenças em inglês apresentavam problemas na sua construção, inviabilizando a identificação da acepção do verbo. Em outras sentenças a identificação não foi possível em função da vagueza dessas sentenças, observadas isoladamente do seu contexto.

- Sentenças originais cujo verbo em foco era utilizado com sentido figurado foram desconsideradas da análise.

- Um verbo foi considerado de fato problemático, sob o aspecto da ambigüidade lexical de sentido, caso essa ambigüidade não recebesse tratamento adequado na sua tradução na maioria das sentenças da amostra contendo tal verbo, ou seja, caso a maioria das suas ocorrências (sentenças) tivesse sido considerada problemática.

Com base nesses critérios, os números da Tabela 2.2 foram levantados a partir da análise das traduções das sentenças contendo os 15 verbos. Nela, pode-se perceber que seis verbos são mais problemáticos: to go, to get, to make, to take, to come e to look. Entretanto, em alguns casos, apesar do verbo ter sido considerado problemático em uma parcela menor que $50 \%$ das sentenças, foi possível verificar que a influência das traduções utilizando sentidos inadequados na qualidade da tradução da sentença era bastante negativa. Por essa razão, foi realizada uma análise mais aprofundada para cada verbo, considerando, além dos critérios citados, os efeitos das escolhas incorretas para a compreensão das sentenças traduzidas. Além dos seis verbos inicialmente selecionados com base nos critérios citados e, também, na confirmação da influência negativa das suas traduções inadequadas nas sentenças, o verbo to give também foi considerado problemático. Ao todo, foram selecionados, portanto, sete verbos: to go, to get, to make, to take, to come, to look e to give. Alguns exemplos de casos de 
ambigüidade lexical de sentido encontrados no uso desses verbos e não manipulados adequadamente pelos tradutores avaliados são ilustrados na Tabela 2.3.

Tabela 2.2: Compilação da análise da ambigüidade dos verbos

\begin{tabular}{|c|c|c|c|c|}
\hline Verbo & $\begin{array}{c}\text { \# sentenças } \\
\text { da amostra }\end{array}$ & $\begin{array}{c}\text { \# sentenças } \\
\text { desconsideradas }\end{array}$ & $\begin{array}{c}\text { \# acepções } \\
\text { na amostra }\end{array}$ & $\begin{array}{c}\text { \# sentenças } \\
\text { problemáticas }\end{array}$ \\
\hline be & 51 & 1 & 8 & $7(14 \%)$ \\
\hline have & 39 & 1 & 3 & $3(7.9 \%)$ \\
\hline do & 31 & 2 & 4 & $5(17.2 \%)$ \\
\hline say & 30 & 0 & 1 & $1(3.3 \%)$ \\
\hline go & 37 & 0 & 22 & $23(62.2 \%)$ \\
\hline get & 30 & 0 & 18 & $29(96.7 \%)$ \\
\hline make & 31 & 0 & 10 & $19(61.3 \%)$ \\
\hline see & 41 & 4 & 1 & 0 \\
\hline know & 30 & 0 & 2 & $3(10 \%)$ \\
\hline take & 40 & 0 & 19 & $33(82.5 \%)$ \\
\hline think & 30 & 0 & 3 & $19(30 \%)$ \\
\hline come & 42 & 4 & 15 & $11(33.3 \%)$ \\
\hline give & 33 & 0 & 11 & $15(50 \%)$ \\
\hline look & 30 & 1 & 8 & $7(19.4 \%)$ \\
\hline use & 36 & 0 & 3 & \\
\hline
\end{tabular}

Tabela 2.3: Exemplos de sentenças do BNC com verbos problemáticos

\begin{tabular}{|c|c|c|c|c|}
\hline \multirow[t]{2}{*}{ Sentença } & \multirow{2}{*}{$\begin{array}{l}\text { Acepção } \\
\text { correta }\end{array}$} & \multicolumn{3}{|c|}{ TA } \\
\hline & & Systran & $\begin{array}{c}\text { Free- } \\
\text { Translation }\end{array}$ & $\begin{array}{c}\text { Power } \\
\text { Translator }\end{array}$ \\
\hline The war may well just go on and on. & continuar & ir & vai & ir \\
\hline $\begin{array}{l}\text { Stand in a French village when the Tour de } \\
\text { France goes by and you are participating in } \\
\text { an event which is unambiguously French. }\end{array}$ & $\begin{array}{l}\text { passa } \\
\text { (passar) }\end{array}$ & vai & vai & passa \\
\hline $\begin{array}{l}\text { It's best to be alone when the noises get } \\
\text { this loud. }\end{array}$ & ficam (ficar) & recebem & começam & adquirem \\
\hline $\begin{array}{l}\text { A lot of international help will be needed } \\
\text { to get things moving. }\end{array}$ & fazer & receber & começar & adquirir \\
\hline They take more foreign holidays. & têm (ter) & tomam & $\begin{array}{l}\text { fazem } \\
\text { exame }\end{array}$ & levam \\
\hline $\begin{array}{l}\text { "Take that money out of your mouth!" } \\
\text { said her mother. }\end{array}$ & tire (tirar) & $\begin{array}{l}\text { toma } \ldots \\
\text { fora }\end{array}$ & $\begin{array}{l}\text { faça exame } \\
\ldots \text { fora }\end{array}$ & $\begin{array}{l}\text { objeto pega- } \\
\text { do ... fora }\end{array}$ \\
\hline $\begin{array}{l}\text { Now eat your supper, both o' ye, afore it } \\
\text { takes cold. }\end{array}$ & fique (ficar) & toma & faz exame & leva \\
\hline $\begin{array}{l}\text { "This city has suddenly come alive," said } \\
\text { her husband, an off-duty border guard. }\end{array}$ & $\begin{array}{l}\text { renasceu } \\
\text { (renascer) }\end{array}$ & veio vivo & $\begin{array}{l}\text { vivo } \ldots \\
\text { vindo }\end{array}$ & veio viva \\
\hline $\begin{array}{l}\text { "Yes, I'm coming, but I've one or two } \\
\text { things to attend to first," she explained. }\end{array}$ & indo (ir) & venho & vindo & vindo \\
\hline $\begin{array}{l}\text { Mr Gonzalez has also come in for criticism } \\
\text { from within his own party. }\end{array}$ & $\begin{array}{l}\text { recebeu } \\
\text { (receber) }\end{array}$ & entrou & entrou & entrou \\
\hline
\end{tabular}

\footnotetext{
${ }^{9}$ Sentenças nas quais não foi possível para a tradutora humana identificar a acepção adequada ou cuja acepção derivava de uma expressão de sentido figurado.

${ }^{10}$ Excluindo-se as diferentes acepções provenientes do uso do verbo como auxiliar (todas as ocorrências são consideradas como uma única acepção - auxiliar).
} 
Esses resultados mostram que os sistemas estudados, de uso expressivo atualmente, não incorporam métodos eficientes de DLS. Normalmente, eles escolhem uma das possíveis acepções de um verbo, provavelmente a mais freqüente, e esta acepção é utilizada na tradução da maioria das suas ocorrências, excetuando-se alguns casos do uso do verbo em phrasal verbs ou em expressões comuns.

Outros estudos recentemente realizados sobre a TA envolvendo essas duas línguas corroboram os resultados aqui apresentados. Por exemplo, Fossey et al. (2004), visando a uma avaliação comparativa com o sistema de TA inglês-português EPT-Web ${ }^{11}$, analisam vários problemas na TA inglês-português, incluindo a ambigüidade lexical. Nessa análise, foram considerados textos do jornal New York Times (NYT) on-line e quatro ferramentas de tradução disponíveis na web: Linguatec E-Translation Server, Intertran, Systran e FreeTranslation. Esse estudo considerou indistintamente ambos os tipos de ambigüidade lexical, isto é, categorial e de sentido (homonímia e polissemia). Foram avaliadas as traduções de todas as palavras de conteúdo de 515 sentenças, nos quatro sistemas. Uma sentença foi considerada problemática em um sistema se apresentasse pelo menos uma palavra ambígua inadequadamente traduzida por ele. Os números de sentenças problemáticas em cada tradutor são apresentados na Tabela 2.4.

Tabela 2.4: Sentenças do New York Times com ambigüidade lexical

\begin{tabular}{|l|c|c|}
\hline \multicolumn{1}{|c|}{ Sistema } & $\begin{array}{c}\text { \# sentenças cuja acepção não foi } \\
\text { corretamente identificada }\end{array}$ & $\begin{array}{c}\text { \% sentenças cuja acepção não foi } \\
\text { corretamente identificada }\end{array}$ \\
\hline E-Translation & 279 & 54,1 \\
\hline Intertran & 361 & 70,1 \\
\hline Systran & 272 & 52,8 \\
\hline FreeTranslation & 271 & 52,6 \\
\hline
\end{tabular}

Nesse estudo também foram apresentados os percentuais de palavras ambíguas cuja acepção não foi corretamente identificada pelos tradutores, agrupadas de acordo com a sua categoria gramatical, com relação ao total de palavras ambíguas. Nos quatro sistemas avaliados, a maioria das palavras ambíguas se distribuía entre substantivos e verbos, conforme ilustrado na Tabela 2.5. Exemplos de sentenças com problemas de tradução causados pela ambigüidade lexical de sentido apenas dos verbos em alguns dos sistemas são ilustrados na Tabela 2.6.

Pela Tabela 2.4, pode-se observar que os quatro sistemas apresentaram um porcentual maior que $50 \%$ de sentenças com problemas específicos de ambigüidade lexical, em uma ou mais palavras. Em outra análise realizada ainda nesse estudo sobre a gramaticalidade das sentenças, foi verificado que a maior parte de sentenças problemáticas corresponde a

\footnotetext{
${ }^{11}$ http://www.nilc.icmc.usp.br/nilc/projects/ept-web.htm
} 
sentenças agramaticais ou gramaticais com tradução incorreta. Os autores perceberam que, em grande parte dos casos, uma vez resolvido o problema da ambigüidade, as sentenças poderiam tornar-se semanticamente corretas. Assim, segundo os autores, fica evidente que a ambigüidade lexical compromete profundamente a qualidade das traduções produzidas automaticamente e que a solução das questões envolvendo esse problema se revela como um dos passos necessários para a obtenção de resultados mais satisfatórios nas ferramentas de TA.

Tabela 2.5: Verbos e substantivos ambíguos do New York Times

\begin{tabular}{|l|c|c|}
\hline \multicolumn{1}{|c|}{ Sistema } & $\begin{array}{c}\text { \% substantivos cuja acepção não foi } \\
\text { corretamente identificada }\end{array}$ & $\begin{array}{c}\text { \% verbos cuja acepção não foi } \\
\text { corretamente identificada }\end{array}$ \\
\hline E-Translation & 36,7 & 29,8 \\
\hline Intertran & 38,7 & 32,3 \\
\hline Systran & 39,6 & 24,1 \\
\hline FreeTranslation & 40,0 & 31,4 \\
\hline
\end{tabular}

Tabela 2.6: Exemplos de sentenças do NYT com ambigüidade lexical de sentido nos verbos

\begin{tabular}{|c|c|c|c|}
\hline Sentença & $\begin{array}{l}\text { Acepção } \\
\text { correta }\end{array}$ & TA & Sistema de TA \\
\hline $\begin{array}{l}\text { With an Organic Sensor, a Food Wrapper Sniffs } \\
\text { Out Trouble. }\end{array}$ & $\begin{array}{l}\text { descobre } \\
\text { (descobrir) }\end{array}$ & funga fora & E-Translation \\
\hline Bush Sending Powell to Middle East. & $\begin{array}{l}\text { enviando } \\
\text { (enviar) }\end{array}$ & emite & Systran \\
\hline $\begin{array}{l}\text { Click Here to Receive } 50 \% \text { Off Home Delivery of } \\
\text { The New York Times Newspaper. }\end{array}$ & clique (clicar) & estale & Systran \\
\hline Check them out, or post any wine-related topics. & $\begin{array}{l}\text { dê baixa (dar } \\
\text { baixa) }\end{array}$ & $\begin{array}{l}\text { verifique-os } \\
\text { para fora }\end{array}$ & FreeTranslation \\
\hline
\end{tabular}

Em um terceiro estudo, realizado por Oliveira et al. (2000), os autores analisaram, comparativamente, vários sistemas de TA entre inglês e português, comerciais ou disponíveis na web, avaliando ambas as direções da tradução. Para testar o desempenho dos sistemas na direção inglês-português, 10 passagens de textos do jornal New York Times (com uma ou mais sentenças, totalizando 530 itens lexicais) foram submetidos a cinco sistemas: Globalink Power Translator Pro®, Alta Vista, Intertran, Tradunet e Linguatec E-Translation Server. As traduções foram analisadas para identificar problemas em três níveis de interpretação: lexical, sintático e semântico-pragmático.

No nível lexical, o desempenho dos sistemas foi testado em quatro situações: dicionarização, ambigüidade, conotação e expressões idiomáticas. Como ambigüidades lexicais, foram consideradas, indistintamente, as ambigüidades categorial e de sentido (polissemia ou homonímia). Alguns exemplos de problemas causados pela ambigüidade lexical de sentido na tradução são ilustrados na Tabela 2.7. 
Tabela 2.7: Exemplos de sentenças com ambigüidade lexical de sentido de Oliveira et al. (2000)

\begin{tabular}{|l|c|c|c|}
\hline \multicolumn{1}{|c|}{ Sentença } & $\begin{array}{c}\text { Acepção } \\
\text { correta }\end{array}$ & TA & Sistema de TA \\
\hline $\begin{array}{l}\text { (...) Hungary has ceded more sovereignty than } \\
\text { many other nations - including the United States - } \\
\text { would ever consider (...) }\end{array}$ & sempre & jamais & Translator Pro \\
\hline $\begin{array}{l}\text { To paraphrase a celebrated epitaph, prosperity left } \\
\text { scarcely any of our industries untouched, and } \\
\text { touched nothing it did not enrich. }\end{array}$ & mal & $\begin{array}{c}\text { quase } \\
\text { nenhuma }\end{array}$ & E-Translation \\
\hline
\end{tabular}

Segundo os autores, a presença da ambigüidade lexical na TA entre o inglês e o português é bastante freqüente, justificando a necessidade de estratégias de desambiguação nas ferramentas de tradução. A qualidade das escolhas lexicais afeta o processo de tradução em vários graus, principalmente se a escolha incorreta ocorrer em itens lexicais em posições de núcleo, como verbos em um predicado verbal ou substantivos em um sujeito. Nesses casos, a ambigüidade lexical pode prejudicar a coerência local e global da sentença, freqüentemente tornando-a incompreensível.

Nesse estudo, os autores também concluem que as ferramentas de tradução não empregam mecanismos adequados para procurar resolver o problema da ambigüidade lexical. Em vez disso, apostam em decisões baseadas em critérios muito simples, como a freqüência da ocorrência de cada acepção em traduções reais. A maioria dos erros encontrados, segundo os autores, diz respeito a expressões com grupos de palavras que podem assumir significados diferentes da composição do significado que elas possuem individualmente, como ocorre, por exemplo, em phrasal verbs. A conclusão geral dos autores é que a qualidade das traduções poderia ser consideravelmente aprimorada se fosse assumida uma perspectiva diferente com relação às idiossincrasias de cada língua, ou seja, se fossem empregados esforços de caráter mais efetivo para o tratamento dessas idiossincrasias.

De modo geral, apesar de terem objetivos distintos, os três estudos citados apresentam resultados que mostram que a ambigüidade lexical de sentido é um problema bastante comum, proeminente e prejudicial para a tradução inglês-português. Mostram, também, que esse problema não recebe, ainda, tratamento adequado nas principais ferramentas de TA disponíveis, comprovando a necessidade e utilidade de mecanismos de DLS para essa tarefa.

\subsection{AMBIGÜIDADE MONOLÍNGUE VERSUS MULTILÍNGUE}

Conforme mencionado anteriormente, apesar de ser geralmente reconhecido que a DLS é uma tarefa intermediária (Wilks \& Stevenson, 1998; Kilgarriff, 1997a; Resnik \& Yarowsky, 
1997b), a grande maioria dos trabalhos não considera nenhuma aplicação específica. Tais trabalhos geralmente focalizam na DLS do inglês e utilizam repositórios de sentido padrão, tais como a WordNet (Fellbaum, 1998). Para aplicações multilíngues, uma abordagem comum é a realização da desambiguação na língua fonte, seguida do mapeamento dos sentidos na língua fonte para suas correspondentes traduções na língua alvo. Essa estratégia mostra-se relativamente viável para pares de línguas que possuem um repositório multilíngue comum de sentidos, por exemplo, a EuroWordNet (Vossen, 1998). No entanto, são muito poucos os pares de língua cobertos por tais repositórios como esse e as abordagens desenvolvidas (e.g., Montoyo et al., 2002) não foram testadas em aplicações reais, como sistemas de TA. Nas demais línguas, o mapeamento de sentidos na DLS constitui uma tarefa complexa por si só, o que leva a resultados insatisfatórios quando do uso dos resultados de módulos de DLS em sistemas multilíngues reais (e.g., Carpuat \& Wu, 2005a).

Muitos aspectos da DLS dependem da aplicação à qual deverá ser integrada. O principal fator é o repositório de sentidos. Como enfatizado por Kilgarriff (1997a), não há um único repositório que seja apropriado para todas as aplicações. Mesmo para a mesma aplicação, há geralmente pouco consenso sobre o repositório mais apropriado. Por exemplo, o uso da WordNet, embora muito freqüente, tem sido criticado devido ao nível de refinamento das distinções de sentido e os critérios abstratos usados para definir tais distinções (e.g., Palmer, 1998). Em particular, é consenso que a granularidade dos sentidos na WordNet é muito refinada para a TA.

Além de diferentes repositórios de sentidos, as fontes de conhecimento empregadas e o processo de desambiguação, propriamente dito, podem ser mais apropriadamente definidos de acordo com as necessidades de cada aplicação. Por exemplo, na DLS monolíngue, a principal fonte de conhecimento é o contexto da palavra ambígua, ou seja, as palavras na vizinhança da palavra ambígua na sentença ou parágrafo, na língua fonte. No caso de aplicações multilíngues como a TA, no entanto, pode-se utilizar também o contexto da palavra na língua alvo, ou seja, as palavras não ambíguas ou já traduzidas para a língua alvo.

O estudo realizado neste trabalho, descrito com detalhes em (Specia et al., 2006a), focaliza nas diferenças no repositório de sentidos. Para tanto, compara-se o repositório de sentidos da WordNet para a desambiguação do inglês com as traduções em português atribuídas a um conjunto de seis dos sete verbos ambíguos descritos na Seção 2.4, juntamente com três outros verbos, também freqüentes, mas menos ambíguos, que foram selecionados depois do estudo apresentado na Seção 2.4, visando permitir identificar a influência do nível de ambigüidade nas divergências entre as distinções das duas línguas: ask, live e tell. $\mathrm{O}$ 
principal objetivo é mostrar que a relação entre o número de sentidos do inglês para tais verbos e de traduções não é unívoca, e que isso não é devido simplesmente ao alto nível de refinamento da WordNet. Com isso, pretende-se confirmar que a desambiguação multilíngue difere da monolíngue e argumentar em favor da necessidade de métodos específicos para a TA, já que o emprego de abordagens de DLS monolíngues não é apropriado.

Recentemente, outros estudos levantaram as diferenças entre repositórios de sentidos para outros pares de línguas, embora com diferentes objetivos. Por exemplo, Chatterjee et al. (2005) investigam a ambigüidade na tradução do verbo inglês to have para o híndi. Os autores identificaram 11 padrões sintático-semânticos distintos de tradução para representar 19 sentidos do verbo, de acordo com a WordNet. Esses padrões incluem diferentes estruturas sintáticas e traduções para o verbo, os quais não estão diretamente relacionados com o sentido monolíngue do verbo, ou seja, o mesmo sentido pode necessitar de estruturas sintáticas e / ou palavras diferentes para ser expresso em híndi. De fato, dos 14 sentidos que foram analisados, seis possuíam múltiplos padrões com diferentes traduções (2-5 cada).

Visando explorar o mapeamento de sentidos entre línguas, Bentivogli et al. (2004) investigam a criação de um córpus do italiano etiquetado com sentidos (chamado MultiSemCor) com base na transferência de anotações do córpus SemCor (Miller et al., 1994), anotado com os sentidos do inglês, utilizando-se de métodos de alinhamento de palavras. Quando da criação manual de um córpus de referência por meio da transferência dos sentidos do SemCor para as palavras em italiano de uma versão traduzida do córpus, os autores reportaram que de 1.054 palavras anotadas no inglês, 155 anotações foram consideradas não-transferíveis para suas palavras correspondentes no italiano, devido à falta de sinonímia no nível lexical, ou seja, ao fato de que os sentidos em tais anotações não são utilizados em italiano.

Miháltz (2005) também investiga o mapeamento manual de sentidos entre línguas, neste caso, de sentidos do inglês em um córpus anotado com sentidos para suas traduções em húngaro, visando utilizar tais anotações para treinar um sistema de DLS para a TA. De 43 substantivos ambíguos analisados, 38 tiveram todos ou a grande maioria dos seus sentidos mapeados em uma única tradução no húngaro. Por outro lado, alguns sentidos dos demais substantivos tiveram de ser traduzidos por diferentes palavras. Na média, com o mapeamento de sentidos o nível de ambigüidade diminuiu de 3.97 sentidos do inglês para 2.49 traduções em húngaro.

É importante mencionar também outra linha de investigação relacionada a este estudo, na qual informação multilíngue, especialmente na forma de córpus paralelos, é empregada 
para auxiliar na criação de recursos para a DLS monolíngue, como córpus anotados com sentidos monolíngues. Essa linha de investigação é motivada pelo argumento defendido por Resnik \& Yarowsky (1997b) de que os sentidos de uma palavra devem ser determinados com base nas distinções que são lexicalizadas em uma segunda língua. Ide (1999), por exemplo, analisa traduções de palavras do inglês em quarto línguas diferentes visando identificar os sentidos de uma dada palavra do inglês que são lexicalizados por diferentes palavras em todas as outras línguas. Um córpus paralelo alinhado por palavras é utilizado e as diferentes traduções de palavras com múltiplos sentidos são manualmente mapeadas em sentidos da WordNet. O conjunto de sentidos do inglês obtido a partir da análise nas quatro línguas é então considerado um conjunto de distinções de sentido potencialmente útil para diversas aplicações monolíngues. Em um trabalho subseqüente (Ide et al., 2002), sete línguas e técnicas de clustering são utilizadas para criar grupos se sentidos com base nas suas traduções.

Diab \& Resnik (2002) utilizam informação multilíngue para criar um córpus monolíngue anotado com sentidos para treinar uma abordagem também monolíngue de DLS. Um repositório de sentidos do inglês (língua alvo), bem como um córpus paralelo automaticamente produzido por um sistema de TA (entre o francês e o inglês) são utilizados. Adicionalmente, um sistema de alinhamento de palavras é empregado para determinar as correspondências lexicais entre as duas línguas. Todas as palavras do inglês que correspondem a traduções de uma única palavra do francês são agrupadas e os possíveis sentidos monolíngues (em inglês) de cada uma dessas palavras são considerados candidatos. O sentido que maximiza a similaridade semântica entre todas as palavras do grupo é então escolhido e projetado para a palavra correspondente na língua fonte, utilizando-se a informação fornecida pelo alinhamento de palavras.

De maneira similar, $\mathrm{Ng}$ et al. (2003) utilizam um córpus paralelo inglês-chinês alinhado por palavras para identificar um repositório de sentidos do inglês. Os sentidos do inglês são manualmente definidos utilizando-se a WordNet e então revisados com base nas traduções para o chinês. Se duas ou mais ocorrências de uma palavra expressando diferentes sentidos de acordo com a WordNet são traduzidas por uma única palavra do chinês, considera-se que as ocorrências possuem um único sentido no inglês.

Em geral, essas investigações permitem a criação de recursos para a DLS monolíngue e confirmam a suposição de que, em muitos casos, os sentidos de uma palavra numa língua podem ser determinados com base nas distinções feitas por uma segunda língua. Contudo, 
como se pretende mostrar com esse estudo, essa suposição não pode ser generalizada para a direção oposta, ou seja, o uso de informação monolíngue para a desambiguação multilíngue.

\subsubsection{Seleção e preparação do córpus}

O conjunto de 10 verbos ambíguos mencionado anteriormente foi inicialmente definido para a realização dos experimentos, ou seja: to ask, to come, to get, to give, to go, to live, to look, to make, to take e to tell. No entanto, to take não foi analisado por razões práticas: dependia-se de tradutores humanos, os quais não puderam concluir suas traduções para tal verbo, que foi o último a ser distribuído. Assim, apenas os verbos ilustrados na Tabela 2.8 foram considerados no estudo.

O córpus utilizado para os experimentos consiste de sentenças contendo os nove verbos, extraídas de três córpus tradicionalmente utilizados para tarefas de análise semântica, especialmente DLS: SemCor (Miller et al., 1994), Senseval-2 e Senseval-3 ${ }^{12}$. Os verbos são anotados, nos três córpus, com sentidos da WordNet (versão 2.0). O número de sentenças selecionadas para cada um dos verbos, bem como o adicional número de sentenças nas quais tais verbos são utilizados em expressões verbais, ou seja, phrasal verbs, são ilustrados na Tabela 2.8. Expressões verbais incluem construções do tipo "verbo + partícula", por exemplo, "give up", e também expressões multi-palavras, por exemplo, "get in touch with", "make up for", "come to mind", etc.

Tabela 2.8: Ocorrências dos verbos isoladamente e em expressões verbais

\begin{tabular}{|c|r|r|r|r|r|r|r|r|r|}
\cline { 2 - 10 } & ask & come & get & give & go & live & look & make & tell \\
\hline $\begin{array}{c}\text { \# ocorrências do } \\
\text { verbo }\end{array}$ & 414 & 674 & 683 & 740 & 489 & 242 & 370 & 1463 & 509 \\
\hline $\begin{array}{c}\text { \# ocorrências do } \\
\text { verbo em expressões }\end{array}$ & 8 & 330 & 267 & 79 & 456 & 5 & 213 & 105 & 3 \\
\hline
\end{tabular}

Para evitar comprometer o experimento devido a possíveis desentendimentos dos usos dos verbos, bem como para reduzir o número de sentenças a serem analisadas e com isso tornar o experimento possível, subconjuntos dos números de sentenças ilustrados na Tabela 2.8 foram selecionados e distribuídos entre cinco tradutores inglês-português profissionais (T1, T2, T3, T4, T5), de acordo com os seguintes critérios:

(1) O significado do verbo / expressão no contexto da sentença deve ser compreensível, não-ambíguo e não-metafórico (para um tradutor humano).

\footnotetext{
${ }^{12}$ Os três córpus estão disponíveis em http://www.cs.unt.edu/ rada/downloads.html.
} 
(2) O experimento deve abranger o maior número de sentidos possível para cada verbo / expressão, desde que o critério (1) seja respeitado.

(3) Cada tradutor humano deve receber duas ocorrências, quando disponíveis, de todos os sentidos distintos de cada verbo / expressão, de modo que possa contrastar os diferentes usos do verbo.

(4) Os tradutores não devem receber nenhuma informação além da sentença em que o verbo / expressão ocorre.

Um tradutor profissional, que não foi envolvido na tarefa de tradução, analisou as sentenças pré-selecionadas (Tabela 2.9) para filtrá-las de acordo com os critérios definidos acima. Esse processo foi diferente para verbos ocorrendo em expressões verbais, uma vez que havia um número muito grande de expressões diferentes, mas poucas ocorrências de cada expressão. No caso das ocorrências de verbos em contextos que não expressões verbais, o tradutor analisou as sentenças pré-selecionadas visando selecionar 10 ocorrências distintas de cada sentido (duas para cada tradutor). O filtro mencionado no passo (1), acima, para eliminar sentenças complexas e ambíguas, não resultou na eliminação de nenhum sentido dos verbos e, portanto, não reduziu a abrangência do experimento. Quando havia menos de 10 sentenças para um determinado sentido, as sentenças foram repetidas entre os tradutores de modo a garantir que cada tradutor receberia exemplos de todos os sentidos do verbo. Por exemplo, no caso de um sentido de um dado verbo com apenas quatro ocorrências, as duas primeiras foram repetidas para os tradutores T1, T3 e T5, enquanto as demais foram dadas a T2 e T4. Sentidos ocorrendo apenas uma vez foram repetidos para os cinco tradutores. Para verbos em expressões verbais, o mesmo procedimento foi usado para eliminar sentenças complexas ou ambíguas. No entanto, apenas duas ocorrências (quando disponíveis) de cada sentido de cada expressão verbal foram selecionadas, em vez de 10. Cada tradutor recebeu, dessa forma, um subconjunto de ocorrências de todas as expressões.

As sentenças foram então distribuídas entre os cinco tradutores de modo que cada tradutor recebesse um número similar de casos, como mostrado na Tabela 2.9. Como havia, em muitos casos, um grande número de possíveis expressões verbais para um dado verbo, as expressões foram distribuídas entre múltiplos tradutores, ou seja, cada tradutor recebeu ocorrências de apenas algumas das expressões da cada verbo. Manteve-se, no entanto, todos os possíveis sentidos de uma dada expressão para o mesmo tradutor. 
O número total de sentenças distribuídas para cada tradutor variou entre 289 e 309 . As anotações originais de sentido foram removidas e as ocorrências de sentenças para cada verbo e suas expressões verbais foram aleatoriamente ordenadas.

Tabela 2.9: Distribuição das sentenças selecionadas entre os cinco tradutores

\begin{tabular}{|l|c|c|c|c|c|c|c|c|c|}
\cline { 2 - 10 } \multicolumn{1}{c|}{} & ask & come & get & give & go & live & look & make & tell \\
\hline \# sentenças por tradutor & $\sim 12$ & $\sim 51$ & $\sim 58$ & $\sim 48$ & $\sim 47$ & $\sim 13$ & $\sim 17$ & $\sim 45$ & $\sim 13$ \\
\hline
\end{tabular}

\subsubsection{Repositórios de sentidos do inglês e de traduções do português}

Conforme mencionado, os córpus usados são anotados com sentidos da WordNet. Muito embora esse repositório não seja o ideal para muitos propósitos, é a melhor opção em termos de disponibilidade e abrangência. Além disso, é o repositório mais freqüentemente utilizado para sistemas monolíngues de DLS, o que torna possível relacionar os resultados obtidos à maioria dos trabalhos monolíngues. Na Tabela 2.10 são ilustrados os números de sentidos fornecidos pela WordNet 2.0 para os verbos estudados (incluindo-se os sentidos das suas expressões verbais), juntamente com os números de possíveis traduções para cada verbo (e expressões), de acordo com um conjunto de dicionários bilíngües, incluindo DIC Pratico Michaelis ${ }^{\circledR}$, versão 5.1 .

Tabela 2.10: Possíveis sentidos e traduções dos verbos em consideração

\begin{tabular}{|c|r|r|r|r|r|r|r|r|r|}
\cline { 2 - 11 } \multicolumn{1}{c|}{} & ask & come & \multicolumn{1}{c|}{ get } & give & \multicolumn{1}{c|}{ go } & live & look & make & \multicolumn{1}{c|}{ tell } \\
\hline \# sentidos & 15 & 125 & 179 & 104 & 143 & 16 & 37 & 104 & 13 \\
\hline \# traduções & 16 & 226 & 242 & 128 & 197 & 15 & 63 & 239 & 28 \\
\hline
\end{tabular}

Como se pode perceber na Tabela 2.10, o número de possíveis traduções difere do número de possíveis sentidos, o que já mostra que não há uma correspondência direta, um-para-um, entre sentidos e traduções (apesar de haver uma correlação entre o número de sentidos e traduções: Correlação Pearson $=0.955)$. Em geral, o número de possíveis traduções é maior que o número de possíveis sentidos, o que em parte se deve ao fato de sinônimos serem considerados diferentes traduções, aqui, já que não é possível agrupar tais sinônimos sem considerar seus contextos de ocorrências. No entanto, como será ilustrado na próxima seção, traduções sinônimas utilizadas pelos tradutores nas ocorrências selecionadas dos verbos são identificadas e agrupadas. 


\subsubsection{Comparando sentidos e traduções}

Para comparar os sentidos do inglês às traduções em português, as sentenças selecionadas foram submetidas a dois grupos de cinco tradutores (T1, T2, T3, T4 e T5), todos falantes nativos do português, de acordo com a divisão feita anteriormente. O mesmo conjunto de sentenças foi submetido a dois grupos de tradutores para que se pudesse verificar a confiabilidade do experimento por meio da análise da concordância entre os dois grupos de tradutores.

Os tradutores foram instruídos para atribuir a tradução que julgassem adequada para cada ocorrência dos verbos, mas não foram informados para que as suas traduções seriam utilizadas. Eles receberam as sentenças inteiras, mas por razões práticas foram solicitadas apenas as traduções dos verbos em questão. Quaisquer dicionários ou outros recursos bilíngües à escolha do tradutor poderiam ser utilizados, se necessário. Eles deveriam identificar uma única tradução para cada ocorrência, utilizando, preferencialmente, verbos como traduções, e evitando considerar traduções sinônimas como diferentes traduções.

Uma vez obtidas as traduções de cada um dos dois grupos de cinco tradutores, o seguinte procedimento foi seguido para analisar manualmente tais traduções, separadamente para cada verbo e suas expressões, em cada um dos grupos:

1) Dadas todas as ocorrências de cada sentido do verbo em inglês, suas traduções foram analisadas para identificar traduções sinônimas (naqueles usos específicos), utilizandose para tanto um dicionário do Português (Dicionário Eletrônico Houaiss $®$, versão 1.0). Apesar de ter sido solicitado aos tradutores que evitassem utilizar palavras distintas com o mesmo significado para traduzir diversas ocorrências, sinônimos foram utilizadas por tradutores diferentes. Tais traduções sinônimas foram consideradas uma única tradução.

2) As sentenças que haviam sido repetidas para múltiplos tradutores no grupo (quando não havia ocorrências suficientes de certos sentidos) foram analisadas para identificar uma única tradução para cada sentença e eliminar as duplicatas. Foi escolhida a tradução apontada pela maioria dos tradutores, ou as $n$ traduções igualmente mais usadas, quando não foi possível eleger uma única tradução - nesse caso, a sentença foi repetida $n$ vezes.

3) Finalmente, a relação entre sentidos e traduções foi examinada de modo a categorizar cada sentido de um verbo (em cada um dos grupos de tradutores) em uma das seguintes classes: 
(a) 1 sentido $\rightarrow 1$ tradução: todas as ocorrências do sentido são traduzidas pela mesma palavra do português. Por exemplo, ask no sentido "inquire, enquire" da WordNet foi sempre traduzido como "perguntar".

(b) 1 sentido $\rightarrow \boldsymbol{n}$ traduções: diferentes ocorrências do sentido são traduzidas por palavras do português diferentes, não sinônimas. Por exemplo, look, no sentido "perceive with attention; direct one's gaze towards" foi traduzido como "olhar", "assistir" e "voltar-se".

(c) $n$ sentidos $\rightarrow 1$ tradução: o sentido possui a mesma tradução que outros sentidos do verbo de acordo com a WordNet, ou seja, diferentes sentidos são traduzidos pela mesma palavra do português, por exemplo, ambos os sentidos "draw advantages from" e "make excessive use of" de "take advantage" foram traduzidos como "aproveitar-se".

(d) $\boldsymbol{n}$ sentidos $\boldsymbol{\rightarrow} \boldsymbol{n}$ traduções: o sentido possui tradução diversa da de outros sentidos da WordNet, ou seja, diferentes sentidos do verbo foram traduzidos por diferentes palavras do português. Por exemplo, os sentidos "move fast" e "carry out a process or program" do verbo run foram traduzidos como "correr" e "executar", respectivamente.

Os itens (a) e (d) representam casos em que a ambigüidade multilíngue apenas reflete a monolíngue, ou seja, a todas as ocorrências de cada sentido de um verbo no inglês corresponde uma tradução específica no português. Por outro lado, os itens (b) e (c) fornecem evidência de que a ambigüidade multilíngue é diferente da monolíngue. $\mathrm{O}$ item (b) indica que critérios distintos são necessários para a desambiguação na tradução para o português, já que a ambigüidade se manifesta apenas durante a tradução. O item (c) indica que a desambiguação não é necessária, seja porque a tradução no português mantém a ambigüidade da palavra fonte, expressando os mesmos sentidos dessa palavra, ou seja porque a língua portuguesa utiliza distinções de sentido menos refinadas.

\subsubsection{Resultados e discussão}

Na Tabela 2.11 são ilustrados o número de sentenças analisadas para cada um dos verbos (após agrupar e eliminar sentenças repetidas) e o número de sentidos do inglês e traduções não sinônimas do português no córpus analisado. Além disso, são apresentadas as porcentagens de ocorrências de cada uma das categorias descritas na seção anterior (a - d) com relação ao número de sentidos (\# sentidos) para aquele verbo. Para os itens (b) e (c), que são os casos de maior interesse neste estudo, também são apresentadas a média de traduções para cada sentido do inglês (média (b)) e a média de sentidos do inglês para cada tradução no português (média (c)). Esses resultados se referem ao primeiro grupo de cinco tradutores. Os 
resultados obtidos para o segundo grupo são bastante similares, conforme mostra a análise da concordância entre os grupos, descrita na próxima seção.

Tabela 2.11: Resultados da análise das traduções do primeiro grupo

\begin{tabular}{|c|c|c|c|c|c|c|c|c|c|}
\hline Verbo & \# sentenças & \# sentidos & \# traduções & $\begin{array}{l}\% \\
\text { (a) }\end{array}$ & $\begin{array}{l}\% \\
\text { (b) }\end{array}$ & $\begin{array}{c}\text { Média } \\
\text { (b) }\end{array}$ & $\begin{array}{l}\% \\
\text { (c) }\end{array}$ & $\begin{array}{c}\text { Média } \\
\text { (c) }\end{array}$ & $\begin{array}{l}\% \\
\text { (d) }\end{array}$ \\
\hline ask & 83 & 8 & 3 & 100 & 0 & 0 & 87.5 & 3.5 & 12.5 \\
\hline come & 202 & 68 & 42 & 62 & 38 & 3.1 & 73.2 & 6.3 & 26.8 \\
\hline get & 226 & 90 & 61 & 70 & 30 & 2.6 & 61.1 & 3.4 & 38.9 \\
\hline give & 241 & 57 & 12 & 48.7 & 51.3 & 3.3 & 84.2 & 6.3 & 15.8 \\
\hline go & 231 & 84 & 54 & 61 & 39 & 2.9 & 76.2 & 4.4 & 23.8 \\
\hline live & 55 & 10 & 7 & 83.3 & 16.7 & 3.0 & 70 & 2.7 & 30 \\
\hline look & 82 & 26 & 18 & 63.2 & 36.8 & 2.4 & 84.6 & 2.7 & 15.4 \\
\hline make & 225 & 53 & 42 & 51.4 & 48.6 & 2.9 & 77.4 & 4.1 & 22.6 \\
\hline tell & 73 & 10 & 10 & 37.5 & 62.5 & 2.8 & 60 & 4.0 & 40 \\
\hline
\end{tabular}

A discussão dos resultados apresentados na Tabela 2.11 é dividida em duas partes: a primeira cobre os itens (c) e (d), enquanto a segunda cobre os itens (a) e (b).

\section{(1) Itens (c) e (d): $n$ sentidos $\rightarrow$ ? traduções}

Em geral, o número de sentidos no córpus é maior que o número de traduções, o que mostra que de fato o nível de refinamento das distinções de sentido na WordNet é muito alto para a tradução inglês-português. Na média para todos os verbos no córpus, o nível de ambigüidade diminuiu de 45.1 (possíveis sentidos) para 27.7 (possíveis traduções). Em particular, diminuiu de 63 para 38 para os seis verbos mais ambíguos, e de 9.3 para 6.7 para os outros três verbos. Vale enfatizar que esses números referem-se aos sentidos / traduções encontrados no córpus, enquanto que os apresentados na Tabela 2.10 diziam respeito aos sentidos / traduções possíveis de acordo com a WordNet e dicionários bilíngües, respectivamente.

A coluna \% (c) mostra a porcentagem de sentidos, com respeito ao total de sentidos no córpus, que compartilham traduções com outros sentidos. Uma tradução compartilhada pelos verbos analisados significa que pelo menos parte dos sentidos do verbo tem a mesma tradução. A coluna média (c) indica a média de sentidos do inglês para cada tradução em português, para aqueles casos em que traduções são compartilhadas. Para todos os verbos, em média, cada tradução cobre mais de dois sentidos. A variação no número de traduções compartilhadas por um sentido é, no entanto, bastante alta. Por exemplo, para o verbo give, varia de dois (tradução = "organizar") a 27 (tradução = "dar”). Pode-se observar que o percentual de sentidos que compartilham traduções, em \% (c), é muito maior que o percentual de sentidos que não compartilham traduções, em \% (d). De fato, a grande maioria dos sentidos possui um número menor de traduções correspondentes, o que mostra que a 
desambiguação na língua fonte entre tais sentidos não se faz necessária em muitos casos. Vale notar, ainda, que tal desambiguação pode resultar em erros, caso o sentido inadequado na língua fonte seja escolhido.

\section{(2) Itens (a) e (b): 1 sentido $\rightarrow$ ? traduções}

Como discutido anteriormente, as diferenças entre os repositórios de sentidos do inglês e do português não se devem, somente, ao fato das distinções da WordNet serem muito refinadas para a tradução. Isso indicaria apenas que usar repositórios monolíngues para propósitos multilíngues implica em esforços desnecessários. No entanto, como ilustrado no item (b) da Tabela 2.11, o problema mais grave diz respeito à necessidade de palavras diferentes para traduzir ocorrências de um único sentido na língua fonte. Para todos os verbos exceto o ask (o menos ambíguo), foram encontrados casos em que diferentes ocorrências do mesmo sentido foram traduzidas por palavras diferentes, não-sinônimas. O percentual de sentidos com mais de uma tradução (\% (b)) é expressivo, embora menor que o percentual de sentidos com uma única tradução (\% (a)). A falta de desambiguação de palavras durante a tradução com base no fato de que tais palavras não são consideradas ambíguas na língua fonte pode resultar em sérios erros quando repositórios monolíngues são utilizados para a DLS multilíngue.

\subsubsection{Concordância entre tradutores}

Na tentativa de quantificar o nível de concordância entre os dois grupos de tradutores e, com isso, investigar a confiabilidade do experimento, calculou-se o coeficiente Kappa, conforme definido em (Carletta, 1996) para tarefas de anotação. O cálculo foi feito separadamente para os itens (1) e (2), discutidos acima, cada um com as seguintes categorias de possíveis julgamentos:

\section{Item (1) $n$ sentido $\rightarrow$ ? traduções}

Categoria 1: uma tradução refere-se a somente um sentido.

Categoria 2: uma tradução é compartilhada por mais de um sentido.

\section{Item (2) 1 sentido $\rightarrow$ ? traduções}

Categoria 1: um sentido tem apenas uma tradução.

Categoria 2: um sentido tem mais de uma tradução.

Para calcular o Kappa para o item (1), considerou-se que os dois grupos concordavam sobre um sentido do verbo caso ambos julgassem que a tradução de tal sentido era ou não 
compartilhada com outros sentidos. Por exemplo, ambos os grupos concordaram que a palavra "fazer" deveria ser usada para traduzir ocorrências de muitos dos sentidos do verbo make, incluindo os sentidos "engage in", "give certain properties to something" e "make or cause to be or to become". Por outro lado, os grupos não concordaram sobre o sentido "go off or discharge" da expressão verbal "go off": o primeiro julgou que a tradução de tal sentido, “disparar", não se aplicava a nenhum outro sentido, enquanto que o segundo grupo usou tal tradução também para o sentido "be discharged or activated" da mesma expressão verbal.

No cálculo do Kappa para o item (2), considerou-se que os grupos concordavam sobre um sentido se ambos julgassem que o sentido tinha ou não mais de uma tradução. Por exemplo, ambos os grupos concordaram que o sentido "reach a state, relation, or condition" do verbo come deveria ser traduzido por mais de uma palavra do português, incluindo “terminar", "vir" e "chegar". Os grupos também concordaram que o sentido "move toward, travel toward something or somebody or approach something or somebody" do mesmo verbo deveria ter uma única tradução, "vir".

A média do coeficiente Kappa obtida para todos os verbos foi de 0.66 para o item (1) e 0.65 para o item (2). Embora não exista um valor de referência para esse tipo de tarefa de anotação (isto é, anotação de tradução), pode-se dizer que os níveis de concordância apontados pelo índice Kappa aqui foram satisfatórios, se comparados com o índice sugerido em (Carletta, 1996) como indicativo de um bom índice de concordância para a tarefa de anotação discursiva (0.67), o qual é comumente adotado como padrão para várias tarefas em PLN.

A conclusão desse experimento é que a desambiguação multilíngue difere da monolíngue em muitos aspectos, particularmente no que se refere ao repositório de sentidos. Os resultados obtidos, contrastando-se repositórios do inglês e repositórios para a tradução inglês-português, corroboram trabalhos anteriores ao mostrar que não há correspondência direta, um-para-um, entre os sentidos do inglês e as suas traduções para outra língua, neste caso, o português. No estudo realizado, na maioria dos casos, muitos sentidos diferentes do inglês foram traduzidos pela mesma palavra do português. Em muitos outros casos, palavras diferentes, não sinônimas, do português foram necessárias para traduzir ocorrências de um único sentido do inglês, mostrando que as diferenças entre DLS monolíngue e multilíngue não são consequiência apenas do alto nível de refinamento da distinção de sentidos na WordNet. Esses resultados reforçam o argumento levantado nesta tese de que a utilização de abordagens monolíngues para a desambiguação multilíngue pode implicar em trabalho desnecessário ou 
resultar em erros de desambiguação e que, portanto, uma abordagem específica para a tradução se faz necessária.

\subsection{CONSIDERAÇÕES FINAIS}

Desde os primeiros trabalhos em TA, a ambigüidade lexical de sentido é reconhecida como um dos principais problemas dessa área. A partir de então, a área de DLS vem sendo constantemente explorada. Contudo, ao tornar-se uma área independente, o foco das abordagens tem se voltado para aplicações monolíngues, em especial, da língua inglesa. Como conseqüência, conforme foi discutido neste capítulo, o problema da ambigüidade lexical de sentido ainda não é endereçado apropriadamente pelos sistemas de TA disponíveis atualmente. A maioria dos sistemas comerciais de TA não possui módulos específicos de DLS, em geral, empregam conhecimento superficial, como a frequiência de cada tradução em determinadas colocações. Alguns sistemas acadêmicos procuram empregar conhecimento profundo para resolver o problema da ambigüidade lexical de sentido, mas são restritos a domínios e gêneros bastante específicos e não são facilmente generalizáveis. Por fim, nos sistemas estatísticos, ainda acadêmicos, a DLS é realizada implicitamente, e só muito recentemente têm-se investigado possíveis formas de integração de módulos dedicados para a DLS em tais sistemas. Em se tratando da TA envolvendo o par de línguas inglês-português, foco deste trabalho, foi evidenciado que o desempenho dos principais sistemas de TA é consideravelmente afetado por tal problema, já que esses sistemas não empregam mecanismos efetivos de DLS.

Neste capítulo foi evidenciado, também, que o uso de abordagens tradicionais de DLS, monolíngues, não é adequado para a DLS na TA, dadas as divergências entre aplicações monolíngues e multilíngues, principalmente no que diz respeito ao repositório de sentidos. No próximo capítulo serão descritos alguns dos principais trabalhos de DLS desenvolvidos nas últimas décadas, tanto monolíngues quanto multilíngues, e que serviram de base para o desenvolvimento da abordagem proposta nesta tese. 


\section{ABORDAGENS PARA A DESAMBIGUAÇÃO LEXICAL DE SENTIDO}

Desde a década de 1960, várias abordagens de DLS vêm sendo propostas. Em sua maioria, as abordagens são monolíngues e foram desenvolvidas para língua inglesa, sem focalizar uma aplicação específica. Neste capítulo, são descritas diversas dessas abordagens, agrupadas cronologicamente de acordo com o seu método de desenvolvimento.

Segundo a classificação de Ide \& Véronis (1998), as abordagens de DLS podem seguir os seguintes métodos de PLN: (a) método baseado em conhecimento lingüístico e/ou extralingüístico, manualmente especificado ou extraído de ferramentas ou recursos lingüísticos, no qual os modelos de desambiguação (regras, por exemplo) são manualmente definidos (Seção 3.2); (b) método empírico, baseado em córpus de exemplos, no qual os modelos de desambiguação são automaticamente adquiridos a partir de conhecimento superficial sobre tais exemplos, disponível em tal córpus, e de técnicas estatísticas ou de aprendizado de máquina (Seção 3.3). Neste trabalho, seguindo-se a classificação de Stevenson (2003), considera-se também um terceiro método, o método híbrido, que combina características dos dois outros métodos: utiliza-se técnicas estatísticas ou de aprendizado de máquina para inferir modelos de desambiguação a partir de córpus de exemplos e de conhecimento lingüístico e/ou extralingüístico manualmente especificado ou extraído de ferramentas ou recursos lingüísticos (Seção 3.3).

Apesar da proposta deste trabalho referir-se a uma abordagem multilíngue, a descrição apresentada nas Seções 3.2 e 3.3 não é limitada apenas aos trabalhos dessa natureza, já que, de modo geral, os principais conceitos e procedimentos de DLS aplicam-se tanto a aplicações monolíngues quanto multilíngues. Vale notar que abordagens de DLS embutidas em sistemas de TA já foram descritas no Capítulo 2. Uma descrição mais detalhada de muitas das abordagens citadas aqui é apresentada em Specia \& Nunes (2004b). A descrição das abordagens publicadas até 1998 pode ser também ser encontrada em (Ide \& Véronis, 1998). Uma revisão das abordagens mais recentes pode ser consultada em (Agirre \& Edmonds, 2006).

Antes da descrição das abordagens de DLS, são discutidas, na Seção 3.1, questões relativas à avaliação de tais abordagens, já que esse é um aspecto relevante e que precisa ser considerado para que seja possível uma análise comparativa dessas abordagens. As medidas discutidas nessa seção serão utilizadas para a descrição de grande parte das abordagens de DLS nas Seções 3.2 e 3.3, bem como para a comparação dos sistemas competidores no exercício de avaliação conjunta da área, a ser apresentada na Seção 3.4. 


\subsection{A AVALIAÇÃO DAS ABORDAGENS DE DLS}

Como a DLS é uma tarefa intermediária, que pode ser utilizada em outras aplicações, há duas possibilidades de avaliação dos sistemas nessa área (Sparck-Jones \& Galliers, 1996): (a) a avaliação intrínseca, na qual os sistemas são testados considerando-se o objetivo específico para o qual foram desenvolvidos, neste caso, para a desambiguação lexical, independentemente da tarefa em que serão aplicados; e (b) a avaliação extrínseca (ou validação), na qual os resultados dos sistemas são avaliados em termos da sua contribuição para o desempenho global de determinada aplicação, como a TA. Nas avaliações extrínsecas do módulo de DLS, apenas o resultado final da tarefa maior é considerado, sujeito aos critérios de avaliação apropriados para essa tarefa.

A avaliação intrínseca normalmente consiste em comparar a saída do sistema para determinadas entradas com os resultados esperados (corretos), obtidos por meio da atribuição manual de sentidos a um córpus de referência. Os resultados dessas comparações são reportados de acordo com diferentes medidas calculadas para cada palavra ambígua ou para o conjunto de todas as palavras ambíguas.

Algumas abordagens reportam resultados em termos de precision e recall (e, ainda, a medida combinada $f$-measure), duas maneiras de expressar a acurácia do sistema. Precision (precisão) indica o percentual de palavras ambíguas corretamente classificadas pelo sistema com relação a todas as palavras ambíguas do conjunto de teste para as quais alguma etiqueta é atribuída por esse sistema. Já recall (cobertura) indica o percentual de palavras ambíguas corretamente classificadas pelo sistema com relação a todas as palavras ambíguas do conjunto de teste.

Precisão e cobertura, de acordo com essa definição, são as medidas usadas no exercício de avaliação conjunta Senseval ${ }^{13}$, descrito logo seguir. Senseval também reporta a medida coverage (abrangência), que identifica o percentual de palavras ambíguas etiquetadas, com relação ao total de palavras ambíguas do conjunto de teste, independentemente da corretude da etiquetação.

Em geral, os sistemas de DLS procuram classificar todos os exemplos de teste, muitas vezes utilizando-se uma regra default que classifica exemplos de acordo com o sentido majoritário quando o sistema não é capaz de identificar seus sentidos. Assim, a medida utilizada para reportar o desempenho dos sistemas é a accuracy (acurácia), definida como o

\footnotetext{
${ }^{13}$ http://www.senseval.org/
} 
percentual de palavras ambíguas corretamente etiquetadas com relação ao total de palavras ambíguas do conjunto de teste, o que corresponde a ambas as medidas de precisão e cobertura descritas acima.

Muito embora as medidas sejam padronizadas, comparações entre abordagens com base apenas nos resultados de tais avaliações nem sempre é possível, dadas as suas variações em termos dos conjuntos de exemplos, níveis de refinamento dos sentidos, metodologias empregadas, etc. A seguir, são apresentados alguns critérios adotados para avaliações individuais e esforços voltados para a realização de avaliações conjuntas, incluindo-se o Senseval.

\subsubsection{Avaliações intrínsecas individuais}

Os resultados de avaliações de abordagens individuais são normalmente comparados aos resultados de algum limite inferior (baseline) pré-definido. A baseline pode ter significados distintos, mas em geral indica o mínimo que se espera que seja superado por um sistema de DLS. Um critério básico, proposto por Gale et al. (1992a) e normalmente utilizado nas avaliações individuais, é o que identifica o sentido mais freqüente, independentemente do contexto, como baseline. De acordo com esse critério, atribui-se o sentido mais freqüente a todas as ocorrências da palavra ambígua nas sentenças de teste e verifica-se qual a acurácia da classificação.

A noção do sentido mais freqüente pode variar. Nas abordagens baseadas em conhecimento, geralmente o primeiro sentido dado por dicionários ou WordNet é assumido como o mais freqüente para uma dada palavra. Em abordagens baseadas em córpus supervisionadas, o sentido mais freqüente de uma palavra é estimado a partir dos exemplos de treinamento, pela contagem do número de vezes que cada sentido é utilizado para anotar ocorrências de tal palavra naqueles exemplos. nas abordagens baseadas em córpus nãosupervisionadas, em que não se dispõe de um córpus anotado com sentidos para extrair o sentido mais freqüente, a baseline pode consistir da escolha aleatória por um sentido. Alternativamente, para esses casos, Gale et al. sugerem um mecanismo para estimar o sentido mais freqüente por meio do sentido mais provável, baseando-se nas distribuições de frequiências em um córpus. McCarthy et al. (2004a) também propõem um método para extrair os sentidos predominantes, mais freqüentes, a partir de um córpus não anotado e de informações de um thesaurus (Seção 3.2.2). 
Pode-se também considerar como baseline os resultados de experimentos prévios com o mesmo conjunto de dados, seja com abordagens totalmente distintas, ou com a mesma abordagem, porém, em diferentes estágios de desenvolvimento, por exemplo, antes e depois da adição de determinadas fontes de conhecimento, estratégias, etc.

Além de baselines, Gale et al. (1992a) sugerem um limite superior para a comparação de sistemas de DLS, considerado o "ideal”. Esse valor ideal corresponde ao desempenho atingido por humanos na tarefa de DLS ou à estimativa desse desempenho. Assim, o limite superior depende do nível de concordância entre os humanos na atribuição de sentidos. Em experimentos de desambiguação com humanos, os autores reportam uma precisão entre $97 \%$ e 99\%. Entretanto, foi considerada somente a desambiguação entre sentidos muito distantes. Mais importante, os experimentos não analisaram a tarefa de desambiguação, propriamente dita, mas a capacidade dos juízes identificarem se duas ocorrências da mesma palavra em uma sentença eram ou não exemplos do mesmo sentido. De fato, os autores visavam testar a sua hipótese de que apenas um sentido é utilizado para cada palavra em um dado discurso (Gale et al., 1992b) (Seção 3.3.2). Considerando sentidos mais refinados e a tarefa de desambiguação, Véronis (1998) reportou uma grande discordância entre os juízes: para as 60 palavras ambíguas analisadas, com cerca de 60 exemplos cada uma, o índice de concordância Kappa (Carletta, 1996) foi, em média, menor que 50\%. Isso mostra que a utilização desse critério como limite superior nas comparações não é direta. Além disso, esse critério requer juízes humanos, o que é inviável para grandes conjuntos de teste.

De fato, no caso de distinções de sentido muito refinadas, a comparação direta com a etiquetação humana torna-se bastante problemática, pois o sentido escolhido pelo sistema pode ser distinto, mas muito próximo do escolhido pelo juiz humano. Resnik \& Yarowsky (1997b) sugerem medidas menos restritivas de avaliação para o cálculo da precisão e cobertura. Uma das medidas propostas atribui pesos diferentes para cada "erro" do sistema de acordo com a distância entre o sentido indicado e o sentido considerado correto: erros em um nível de distinção de sentidos altamente refinado são menos punidos que erros em níveis menos refinados de distinção. Essa medida é parcialmente implementada no sistema de avaliação do Senseval, conforme será apresentado na próxima seção.

Nos últimos 10 anos, com o uso de técnicas estatísticas e de aprendizado de máquina para a DLS, vários trabalhos vêm realizando experimentos comparativos com variações em suas abordagem, fixando-se um determinado conjunto de exemplos para o treinamento e teste, por exemplo, (Mooney, 1996), (Paliouras, 2000), (Escudero et al., 2000a), (Escudero et al., 2000c), (Pedersen, 2002a), (Lee \& Ng, 2002). Exemplos de comparações serão apresentados 
na Seção 3.3.2. Tais experimentos, contudo, são geralmente limitados em termos das variações testadas: em geral, apenas um aspecto é alterado de cada vez (por exemplo, fontes de conhecimento, algoritmos de aprendizado, número de exemplos de treinamento, etc.).

\subsubsection{Avaliações intrínsecas conjuntas}

Conforme ressaltado por Ide \& Véronis (1998), comparar os resultados de avaliações individuais de sistemas de DLS é uma tarefa complexa, em função das diferenças substanciais nas abordagens e nas configurações dos testes realizados, as quais vão desde o conjunto de palavras ambíguas, o domínio e tamanho do conjunto de exemplos, o nível de refinamento dos sentidos, método de aprendizado (supervisionado ou não-supervisionado), etc. Segundo $\mathrm{Ng} \&$ Zelle (1997), por exemplo, verbos são mais difíceis de desambiguar do que substantivos e quanto mais abrangente com relação a gênero e domínio forem as palavras ambíguas e o córpus, maior a complexidade da tarefa.

O primeiro passo na direção de avaliações conjuntas consiste da criação de córpus de exemplos representativos, que possam ser usados pelos diversos sistemas. Para a DLS monolíngue e algumas poucas tarefas multilíngues, córpus vêm sendo manualmente ou semiautomaticamente criados e disponibilizados para teste, os quais serão descritos nas Seções 4.1 e 4.2. Com o objetivo prover padrões para a avaliação e comparação de trabalhos de DLS, acomodando abordagens totalmente distintas, a partir de discussões do grupo SIGLEX ( $A C L$ Special Interest Group on the Lexicon) e das sugestões apresentadas por Resnik \& Yarowsky (1997a), foi criado o Projeto Senseval ${ }^{14}$.

O Projeto Senseval vem promovendo exercícios de avaliação conjunta, para os quais são definidos e disponibilizados córpus de treinamento e teste anotados de acordo com um determinado repositório de sentidos, para diversas tarefas de avaliação. As principais tarefas inicialmente propostas no exercício são: (a) a desambiguação (ou etiquetação) de todas as palavras de conteúdo em um córpus (All Words Task); e (b) a desambiguação de todas as ocorrências de determinadas palavras em um córpus (Lexical Sample Task).

Até o momento, foram realizadas quatro edições do exercício de avaliação, Senseval1, em 1998, e Senseval-2, em 2001, Senseval-3, em 2004, e Senseval-4 (agora chamado SemEval), em 2007. Além das tarefas de avaliação, propriamente ditas, o Projeto promove eventos específicos para apresentação e divulgação dos resultados e para a discussão de perspectivas para a área. Na primeira edição do evento (Kilgarriff \& Rosenzweig, 2000;

\footnotetext{
${ }^{14}$ http://www.senseval.org/
} 
Kilgarriff \& Palmer, 2000), foram realizadas avaliações monolíngues apenas, considerando-se a língua inglesa.

Paralelamente à primeira edição do evento, como uma das suas ramificações, foi realizado um evento voltado especificamente para a desambiguação de outras línguas (francês e italiano), denominado ROMANSEVAL ${ }^{15}$. Os resultados foram apresentados em conjunto com o evento referente ao Senseval-1. Edições posteriores desse evento foram integradas ao Senseval.

Na segunda edição do Senseval (Edmonds \& Cotton, 2001) foram incluídas várias outras línguas (por exemplo, basco, coreano, italiano e espanhol) no procedimento de avaliação, com córpus específicos para cada língua, além de uma tarefa de desambiguação na tradução para o japonês. Os synsets da WordNet foram adotados como repositório de sentidos para a DLS monolíngue.

Para a terceira edição (Mihalcea \& Edmonds, 2004), além das tarefas já existentes, foi incluída uma tarefa de desambiguação multilíngue de 41 palavras (Lexical Sample) do inglês para o híndi. Foram realizadas também outras tarefas monolíngues, como a etiquetação de papéis semânticos e a desambiguação das definições da WordNet.

Na sua última edição (Agirre et al., 2007), o evento foi renomeado para SemEval (SemEval-1), uma denominação mais abrangente para acomodar várias outras tarefas de avaliação semântica. Além das tarefas comuns para o inglês, de variações dessas tarefas para outras línguas (Lexical Sample do turco) e de uma tarefa de DLS multilíngue do chinês para o inglês, tal edição incluiu diversas outras tarefas, tais como a avaliação de DLS para recuperação de informações multilíngues, DLS de preposições, resolução de metonímias, anotação de papéis semânticos, entre muitas outras.

Nas diversas edições do Senseval, os sistemas competidores são avaliados com base em um software chamado scorer, que computa a acurácia média de todas as palavras e exemplos, de acordo com três diferentes níveis de refinamento: fine-grained, coarse-grained e mixed-grained. No modo de avaliação padrão, fine-grained, o sistema compara as anotações de sentido resultantes em cada sistema às anotações de referência. Mais de uma anotação pode ser fornecida como referência e, neste caso, o resultado do sistema é considerado correto se pelo menos uma de tais referências é encontrada. Os sistemas competidores também podem fornecer mais de um sentido como saída para um determinado exemplo de teste, associado ou não a probabilidades (uma distribuição uniforme é assumida caso não sejam fornecidas

\footnotetext{
${ }^{15}$ http://aune.lpl.univ-aix.fr:16080/projects/romanseval/
} 
probabilidades). Além dessa flexibilização do critério de avaliação, a idéia de uma avaliação menos restrita proposta por (Resnik \& Yarowsky, 1997b) é parcialmente implementa no scorer. Os critérios de avaliação alternativa resultantes, coarse-grained e mixed-grained, requerem uma hierarquia de sentidos para que o sistema possa comparar se os sentidos anotados pelos sistemas são "próximos" ao(s) sentido(s) esperado(s). Na avaliação coarsegrained, sentidos mais genéricos ou mais específicos que o(s) sentido(s) esperado(s), ou ainda sentidos com ancestrais imediatos comuns ao sentido esperado recebem o mesmo escore que o sentido esperado, ou seja, são considerados corretos. Na avaliação mixed-grained, por outro lado, apenas sentidos mais específicos que o sentido esperado são considerados corretos. Sentidos mais genéricos que os sentidos esperados recebem um escore parcial de acordo com o número de outros sentidos mais específicos existentes para o mesmo sentido genérico na hierarquia de sentidos. A Tabela 3.1 mostra alguns exemplos de escores (“.” indica um subnível na hierarquia, enquanto “,” indica sentidos alternativos), considerando-se que a hierarquia de sentidos fornecida possui dois sub-sentidos para o sentido 3 (3.1 e 3.2).

Tabela 3.1: Exemplo de escores atribuídos por diferentes critérios de avaliação no sistema scorer

\begin{tabular}{|c|c|c|c|c|}
\hline Sentido esperado & $\begin{array}{c}\text { Sentido anotado } \\
\text { (sistema) }\end{array}$ & $\begin{array}{c}\text { Escore coarse- } \\
\text { grained }\end{array}$ & $\begin{array}{c}\text { Escore mixed- } \\
\text { grained }\end{array}$ & $\begin{array}{c}\text { Escore fine- } \\
\text { grained }\end{array}$ \\
\hline 3 & 3.1 & 1 & 1 & 0 \\
\hline 3.1 & 3 & 1 & 0.5 & 0 \\
\hline 3.1 & 3.2 & 1 & 0 & 0 \\
\hline 1,3 & 1 & 1 & 1 & 1 \\
\hline 1,3 & 2 & 0 & 0 & 0 \\
\hline 3 & $3(0.6), 2(0.4)$ & 0.6 & 0.6 & 0.6 \\
\hline 3 & $3.1(0.6), 2(0.4)$ & 0.6 & 0.3 & 0 \\
\hline
\end{tabular}

Como a maioria dos trabalhos de DLS não é voltada para aplicações específicas, em geral, só são relatadas as avaliações intrínsecas dessas abordagens. Somente na última edição do evento foi incluída uma tarefa para a avaliação extrínseca da DLS, para a recuperação de informações multilíngues, conforme pode ser consultado em Agirre et al. (2007).

A grande maioria das abordagens avaliadas nas diversas edições do exercício Senseval utiliza técnicas estatísticas ou de aprendizado de máquina para a indução de modelos de DLS a partir de exemplos de desambiguação. Isso se deve, em parte, ao tempo bastante limitado que os participantes dispõem para submeter seus resultados a partir do momento em que recebem os dados. Adicionalmente, isso reflete a tendência atual do uso do método baseado em córpus para a DLS. Abordagens seguindo essa metodologia representam também o foco deste trabalho. Entretanto, a seguir, são primeiramente descritas abordagens baseadas em 
conhecimento, as quais serviram de base para muitas das propostas baseadas em córpus e híbridas atuais.

\subsection{MÉTODO BASEADO EM CONHECIMENTO}

Nas abordagens baseadas em conhecimento, a desambiguação é realizada com o uso de regras ou heurísticas explicitamente especificadas e, alternativamente, de conhecimento lingüístico manualmente codificado ou extraído a partir de recursos lexicais. Essa classificação inclui as abordagens mais antigas de DLS, em que o sistema de DLS é completamente codificado manualmente (Seção 3.2.1), abordagens que seguem métodos simbólicos e conexionistas da Inteligência Artificial para a representação de conhecimento (denominadas AI-based approaches por Ide \& Veronis, 1998) (Seção 3.2.1), bem como abordagens relativamente mais recentes, que utilizam recursos lingüísticos juntamente com heurísticas para realizar a desambiguação, tais como as preferências de seleção (Seção 3.2.2).

\subsubsection{Conhecimento manualmente codificado}

A área de DLS surgiu primeiramente no contexto da tradução automática, no fim da década de 1940. O problema foi introduzido por Weaver (1949), que enfatizou a necessidade da análise do contexto de ocorrência de uma palavra para a sua interpretação (e tradução) correta. Muitas das abordagens baseadas em conhecimento para DLS utilizavam técnicas da Inteligência Artificial para representar o conhecimento. Essas abordagens começaram a ser propostas na década de 1960, normalmente para resolver o problema da compreensão da língua natural e, como parte desse problema, a DLS. A maioria delas é baseada em alguma teoria de compreensão da língua natural, envolvendo o uso de conhecimento detalhado sobre sua sintaxe e semântica. Esses trabalhos podem ser divididos em duas categorias, que variam quanto ao tipo de técnica empregada para a representação do conhecimento: simbólica e conexionista.

\subsubsection{Abordagens simbólicas}

As técnicas simbólicas de representação e manipulação do conhecimento que vêm sendo utilizadas para a DLS incluem as redes semânticas (Masterman, 1961; Quillian, 1961) e os frames (Hayes, 1976; Hirst, 1987). Em (Masterman, 1961), uma rede semântica voltada para a TA é usada para derivar representações das sentenças em uma interlíngua. São codificados 15.000 conceitos em um dicionário, classificados de acordo com 100 tipos de conceitos 
primitivos (thing, do, etc.). Esses tipos são organizados em um reticulado por meio do mecanismo de herança de conceitos mais genéricos para os mais específicos. As distinções de sentido são realizadas implicitamente pela seleção das representações que refletem grupos de nós fortemente relacionados na rede.

Quillian (1961) utiliza uma rede semântica que inclui relacionamentos entre palavras e conceitos, as quais são rotuladas com nomes de relações semânticas ou indicam associações entre as palavras. A rede é criada manualmente a partir de definições de um dicionário e é então estendida com outras fontes de conhecimentos, também manualmente codificadas. Para cada duas palavras representadas na rede, a ativação gradual dos nós de conceitos ao longo do caminho dos relacionamentos originados a partir de cada palavra de entrada é simulada por meio da passagem de marcadores. A desambiguação se dá por meio da seleção do nó do conceito que está no caminho mais direto encontrado entre as duas palavras de entrada.

O sistema de Hayes (1976) explora o uso de frames e de uma rede semântica para uma representação mista do conhecimento envolvendo várias fontes distintas. Os sentidos de substantivos são representados como nós na rede, enquanto que os verbos são representados como frames. Essa representação, que pode ser vista como uma rede semântica na qual cada frame é uma parte da rede, facilita a busca por associações semânticas entre as palavras. Outras associações são identificadas para nós e frames antecedentes ou descendentes, de acordo com as relações hierárquicas padrão de hiponímia e meronímia das redes semânticas, levando a uma cadeia de conexões na base de conhecimento. O sistema usa também estruturas de caso e restrições de seleção. Na desambiguação (de substantivos apenas), que ocorre a partir da estrutura sintática produzida para a sentença, os métodos mais restritivos são testados primeiro, na seguinte ordem: estruturas de casos, associações e restrições de seleção. Todos os substantivos ambíguos são considerados simultaneamente para que o sistema possa convergir para uma solução. Segundo Hayes, as associações semânticas são úteis principalmente para tratar casos de homonímia, mas não são muito indicadas para o tratamento de polissemia, já que, neste caso, normalmente encontra-se uma associação para mais de um sentido, os quais são semanticamente relacionados.

Várias características dessas abordagens, como o uso de tipos primitivos e estratégias como a de passagem de marcadores, são reproduzidas em muitos trabalhos subseqüentes, como será descrito posteriormente. Outro aspecto utilizado inicialmente nas abordagens 
simbólicas e que passou a ser empregado em vários trabalhos é a noção de semântica de preferência, definida por Wilks (1975). Inspiradas no mecanismo de traços semânticos (ou primitivas semânticas) de Katz \& Fodor (1963), abordagens de DLS baseadas em semântica de preferência, como a de Wilks, especificam restrições de seleção semânticas para a combinação dos itens lexicais da sentença que podem ser "amenizadas" quando as palavras no contexto da palavra ambígua não satisfazem tais restrições. A partir de uma hierarquia de 100 traços semânticos como "humano", "animado" e "abstrato", manualmente, fórmulas lógicas de itens lexicais de substantivos são criadas e marcadas com tais traços semânticos. As fórmulas para verbos são marcadas com restrições de seleção, especificadas em termos dos traços semânticos exigidos por seus argumentos. Itens lexicais de adjetivos e preposições são também marcados com restrições de seleção, especificadas em termos dos traços semânticos exigidos pelo substantivo ou frase nominal seguinte ao item ou que ele modifica.

Para cada sentido de uma dada palavra, um novo item lexical é criado e descrito por diferentes restrições ou traços semânticos. Em um processo de unificação de templates, a desambiguação entre os vários sentidos de uma palavra ocorre a partir da seleção do sentido que menos infringe as restrições de seleção. Se o sistema chegar a duas ou mais possíveis interpretações da construção, a interpretação que satisfaz as restrições é "preferida". Por outro lado, se todas as possíveis interpretações infringirem as restrições, é escolhida aquela que menos compromete tais restrições. Dessa maneira, o sistema pode manipular alguns usos metafóricos, como o da sentença "My car drinks gasoline”. As desvantagens desse sistema são a necessidade de anotação manual dos traços semânticos, bem como o uso das restrições de seleção como o único mecanismo para a DLS. Essa fonte se mostrou relativamente suficiente na abordagem de Wilks porque o foco era nas distinções de sentidos no nível de homonímia.

Boguraev (1979) procura eliminar os problemas do formalismo de Wilks para representação semântica em seu sistema de geração de paráfrases. O autor utiliza não apenas as preferências semânticas, mas também informações sintáticas. O sistema consiste de um parser, utilizando redes de transição aumentadas, ao qual são adicionados procedimentos semânticos responsáveis pela desambiguação e construção da representação semântica mais adequada para a sentença.

No sistema de Boguraev, a desambiguação de sentido só ocorre depois da análise sintática, da mesma forma que na maioria dos outros sistemas que utilizam restrições de 
seleção. O trabalho de Small (1980), por outro lado, baseia-se na teoria de que o conhecimento humano sobre a língua é primariamente organizado na forma de conhecimento sobre as palavras, e não na forma de regras. No seu sistema de interpretação da língua natural, cada palavra é representada no léxico por um word expert, um repositório que contém todas as informações e procedimentos para a discriminação dos seus sentidos. Assim, as informações de controle sobre a desambiguação são armazenadas juntamente com o conhecimento declarativo sobre a palavra. Diversos desses mecanismos especialistas (um para cada palavra) operam em conjunto, diretamente sobre a sentença de entrada, coordenando a escolha do sentido adequado e, ao mesmo tempo, realizando a análise sintática e semântica, produzindo como resultado a representação semântica da sentença.

Small ressalta que cada word expert requer um processo elaborado para a sua criação. Por exemplo, a descrição do expert para o verbo throw possui seis páginas e, segundo o autor, poderia ser ainda mais detalhadamente especificada, com um tamanho dez vezes maior. A falta de mecanismos de generalização, em função do princípio de definição individualizada e refinada de cada expert, limita severamente a abrangência do sistema.

Hirst (1987) propõe um sistema de interpretação da língua natural que incorpora um módulo específico de desambiguação estrutural e lexical. O maior diferencial desse sistema é a possibilidade de utilizar várias fontes de conhecimento para a seleção lexical, todas representadas uniformemente por meio de um formalismo baseado em frames.

Contemplando um subconjunto de palavras da língua inglesa de um domínio específico, o sistema utiliza a técnica de semantic priming para modelar computacionalmente o processo de desambiguação lexical realizado por seres humanos. De acordo com essa técnica, o processamento mental de alguns conceitos influencia e facilita o processamento de conceitos semanticamente relacionados, introduzidos subseqüentemente. Assim, a representação de uma palavra reduz o tempo de resposta para o reconhecimento de outra palavra semanticamente relacionada.

No modelo construído, a representação mental de conceitos é uma rede semântica, na qual conceitos semanticamente relacionados estão próximos uns dos outros. O uso de um conceito faz com que ele seja ativado, e tal ativação propaga-se a partir da origem para os nós vizinhos, fazendo com que eles também sejam ativados. A ativação torna-se mais fraca à medida que os conceitos se distanciam da origem, de modo que o grau de ativação de um conceito é dado em função da sua proximidade semântica com a origem. A ativação dos conceitos diminui com o tempo, até que eles voltem ao estado normal. 
Hirst implementa esse modelo por meio da estratégia de passagem de marcadores definida por Quillian (1961). Essa estratégia consiste de um modelo discreto de ativação propagada, que passa marcadores pela base de conhecimento para estabelecer quais sentidos de quais palavras são mais fortemente associados a quais sentidos de quais outras palavras na entrada. O objetivo é encontrar o caminho mais curto de associação entre frames de sentido das palavras em um contexto para então escolher o sentido mais apropriado. O trabalho de Hirst é de grande importância para a DLS, pois mostra que é possível integrar técnicas e informações de diferentes áreas da representação do conhecimento em Inteligência Artificial e PLN.

Seguindo a proposta de Hirst, McRoy (1992) propõe um sistema de interpretação da língua natural no qual a DLS é realizada a partir de informações de várias fontes. Além das informações sugeridas por Hirst, McRoy acrescenta traços morfológicos, categorias gramaticais, colocações e relações sintáticas associadas a restrições de seleção. Para tanto, recursos lexicais são manualmente criados.

Uma característica marcante do sistema de McRoy é a sua abrangência. Enquanto a maioria dos sistemas baseados em conhecimento manualmente codificado se limita a poucas dezenas de palavras, esse sistema possui um léxico com 8.775 entradas. Esse léxico, denominado "central", é independente de gênero e domínio. Nele, são armazenadas apenas as distinções de sentido principais (mais genéricas), válidas em todas as situações, além de informações sintáticas e associações a uma hierarquia conceitual. Distinções de sentidos mais refinadas são armazenadas em outro léxico, denominado léxico "dinâmico". O léxico dinâmico contém sentidos válidos apenas em contextos particulares, indicados por colocações que são automaticamente extraídas a partir de um córpus. A partir de uma biblioteca de 1.400 padrões de colocações, se duas ou mais palavras de uma colocação ocorrem em um texto de entrada, assume-se que elas têm o mesmo sentido que a colocação.

McRoy cria também uma hierarquia conceitual, com 1.000 conceitos, em que cada sentido é relacionado a um conceito do léxico. Esse recurso permite simular o processo de passagem de marcadores de Hirst: para testar se dois conceitos são semanticamente relacionados, o sistema busca o ponto mais baixo na taxonomia em que ainda é possível identificar um antecedente comum para ambos; quanto mais baixo na taxonomia estiver esse antecedente, maior a relação semântica entre os conceitos. O uso da hierarquia conceitual permite, ainda, que as restrições ou preferências de seleção, bem como outras informações em 
comum para determinados grupos de palavras, sejam estabelecias apenas para os itens lexicais mais altos na hierarquia.

No processo de desambiguação, os sentidos candidatos de todas as palavras em uma sentença são fornecidos ao analisador sintático-semântico. Esse processo calcula o escore de cada sentido, com base em diferentes pesos atribuídos às características consideradas. $\mathrm{O}$ sentido com o escore mais alto é eleito como o mais adequado, e a representação semântica considerando tal sentido é gerada pelo sistema.

O desempenho do módulo de desambiguação não foi quantitativamente avaliado. Segundo Kilgarriff (1992), o maior problema desse trabalho é que não há uma justificativa clara para a suposição de que distinções mais refinadas entre sentidos sejam sempre dependentes de domínio. Essa característica limita o processo de desambiguação em determinados domínios. Por exemplo, a palavra engage só pode ser interpretada com o sentido de "atacar" no domínio militar. Adicionalmente, os sentidos do léxico central são considerados os mais freqüentes e, por isso, preferidos no processo de DLS. Assim, os sentidos dos léxicos dinâmicos de cada domínio somente são escolhidos quando a escolha falha para todos os sentidos do léxico central. Com isso, a escolha pode tornar-se altamente tendenciosa a sentidos mais genéricos. Em particular, acredita-se que a construção manual de léxicos não se justifica, quando já havia, na época, dicionários como o Longman Dictionary of Contemporary English (Procter, 1978) e Oxford English Dictionary (Burchfield, 1971). Contudo, esse trabalho é relevante por integrar uma grande variedade de fontes de conhecimento, bem como ressaltar a utilidade de colocações para a DLS.

Focalizando na TA, Pedersen (1997) utiliza a teoria da semântica lexical Frame Semantics (Atkins \& Fillmore, 1994) para a DLS. O objetivo é a desambiguação de um subconjunto de verbos de movimento polissêmicos na tradução do dinamarquês para o inglês. A hipótese é que se pode identificar padrões para o tratamento de polissemia sistemática, ou seja, padrões que possam ser aplicados a diversos verbos de movimento com significado relacionado, formalizar e implementar esses padrões como regras lexicais.

A partir da análise das ocorrências de 100 verbos de movimento em diferentes córpus do dinamarquês, essas ocorrências foram manualmente categorizadas de acordo com suas propriedades sintáticas e semânticas, dando origem a grupos de ocorrências com propriedades similares, por exemplo, verbos com uma direção específica, cujo agente é animado, e que implicam o movimento de partes do corpo ou de uma máquina. 
Os verbos foram também classificados em uma taxonomia de acordo com as regularidades nos desvios do significado básico para os demais sentidos. Para a sua representação, foi definido um modelo baseado na teoria Frame Semantics e na Estrutura de Eventos do léxico gerativo de Pustejovsky (1995). Também foram definidas uma hierarquia conceitual parcial e restrições de seleção para os substantivos distribuídos nessa hierarquia.

Os esquemas resultantes foram implementados na forma de regras lexicais e incorporados a um sistema de interpretação do dinamarquês. A autora reporta que em experimentos com 42 sentenças contendo os verbos ambíguos, 39 foram corretamente desambiguados.

Apesar de ser voltada para a TA, o foco dessa abordagem é na especificação das regras lexicais com informações para permitir capturar os padrões sistemáticos entre os diferentes sentidos de um verbo, de modo a evitar descrições ambíguas.

Utilizando-se também de uma teoria da semântica lexical, Dorr \& Katsova (1998) propõem um mecanismo de seleção lexical de verbos e substantivos deverbais voltado para a TA do inglês para o espanhol. O mecanismo se baseia na estrutura argumental desses elementos, representada por meio de estruturas conceituais lexicais (Lexical Conceptual Structures - LCS) (Jackendoff, 1990), e nos sentidos da WordNet. A hipótese é de que a tradução de um elemento da língua-fonte pode ser desambiguada se forem escolhidos, na língua-alvo, elementos que tenham a mesma LCS e que pertençam ao mesmo synset da WordNet, ou seja, que sejam sinônimos do elemento na língua-fonte.

Para testar essa hipótese, o algoritmo de seleção lexical é incorporado a um sistema que converte sentenças em suas representações LCSs. Esse sistema possui um léxico do inglês e outro do espanhol, cujas entradas estão codificadas como LCSs, com um código correspondente ao synset da WordNet ao qual pertencem (anotado manualmente).

Com base na estrutura gerada pelo sistema para uma sentença, o algoritmo extrai a estrutura LCS genérica do verbo a ser desambiguado e recupera do léxico do espanhol todas as entradas correspondentes a verbos que têm a LCS com as mesmas propriedades estruturais. Desse conjunto de verbos, seleciona apenas aqueles que apresentam o mesmo código do synset que o verbo sendo desambiguado. Caso não seja encontrado nenhum verbo com a LCS equivalente no mesmo synset, o algoritmo estende a busca aos synsets hiperônimos em um nível de todos os synsets aos quais o verbo pertence. $\mathrm{O}(\mathrm{s})$ verbo(s) encontrado(s) é(são) então escolhido(s) como a tradução mais adequada para o verbo do inglês.

Experimentos com poucos verbos mostraram que é possível, em alguns casos, 
recuperar apenas um verbo. Contudo, uma avaliação quantitativa não foi realizada. O sistema é limitado às LCSs que já estão codificadas no léxico, às quais já foram atribuídos códigos de synsets. Além disso, o sistema não elimina todas as ambigüidades, já que múltiplas traduções poderem ser retornadas.

Bräscher (2002), no que se considera o único trabalho significativo envolvendo a língua portuguesa para tratamento explícito da ambigüidade lexical, propõe o uso de um sistema de PLN para a resolução de vários tipos de ambigüidades, incluindo as lexicais, em um contexto monolíngue, voltado para a Recuperação de Informações. Esse sistema se baseia em informações relativas à valência sintático-semântica das unidades lexicais que compõem um enunciado, de acordo com a Teoria de Valências de Borba (1996), representadas por Gráficos Conceituais (Sowa, 1984) ${ }^{16}$. Essas informações correspondem à estrutura de argumentos, traços semânticos e restrições de seleção.

São realizados experimentos procurando ilustrar casos em que as informações da valência sintático-semântica das unidades lexicais provêem a resolução de ambigüidades nos diversos níveis, bem como casos em que somente essas informações não são suficientes. No que se refere às ambigüidades lexicais, especificamente, são discutidos diversos casos, tanto de polissemia quanto de homonímia, que não podem ser resolvidos apenas com essas informações. Não são citados detalhes sobre a utilização desse módulo em um sistema de Recuperação de Informações.

\subsubsection{Abordagens conexionistas}

Diversas abordagens das décadas de 1960 e 1970, fundamentados da Ciência Cognitiva, procuravam modelar a técnica de semantic priming, citada anteriormente, por meio de redes neurais artificiais. A motivação é que as redes neurais provêem um ambiente adequado para a tarefa de DLS: muitos processos exigindo que várias restrições sejam simultaneamente satisfeitas. O trabalho de Quillian (1961) é considerado precursor simbólico dos modelos de ativação propagada para a DLS.

Como exemplo de abordagem desenvolvida com base em modelos de ativação propagada, pode-se citar Cottrell \& Small (1983). Nessa rede, assim como nas abordagens simbólicas, cada nó representa uma palavra ou um conceito em uma rede semântica. Os

\footnotetext{
${ }^{16}$ Sowa, J.F. (1984). Conceptual Structures: Information Processing in Mind and Machine. Addison-Wsley, Massachusetts. Apud Bräscher (2002).
} 
conceitos são ativados durante o uso e a ativação se espalha para os nós conectados. Os nós que recebem ativações de diversos outros nós são progressivamente reforçados e têm, portanto, mais chance de serem escolhidos como o sentido mais adequado.

Waltz \& Pollack (1985) propõem um modelo similar para a DLS, mas acrescentam (manualmente) um conjunto de micro-traços semânticos aos nós que representam os conceitos. A motivação é que as palavras codificadas nas redes podem não estar presentes no contexto da palavra a ser desambiguada. Assim, as características podem ser usadas para permitir a correspondência com palavras semelhantes. Os micro-traços correspondem a distinções semânticas básicas (animado/inanimado, etc.), características de duração de eventos (segundo, minuto, etc.), localizações (cidade, país, etc.), entre outras.

Com base no mecanismo de ativação propagada, cada nó da rede é ligado, por meio de relações de inibição ou de ativação bidirecionais, a apenas um subconjunto de micro-traços. Uma palavra pode compartilhar micro-traços com outras palavras, com as quais está semanticamente relacionada. Tal palavra irá, portanto, ativar os nós correspondentes a essas palavras relacionadas quando ela for ativada. Os conjuntos de micro-traços são manualmente inicializados para ativar um contexto para desambiguar uma palavra de entrada subseqüente.

Segundo Véronis \& Ide (1990), os micro-traços correspondem, em essência, às primitivas semânticas de outros trabalhos de PLN. O uso dessas informações é problemático devido à dificuldade em se definir um conjunto apropriado de traços. Além disso, vale notar que tanto os traços quanto a rede neural foram manualmente construídos.

Cottrell (1989) utiliza a DLS para testar a aplicação da técnica de semantic priming. Um módulo lexical é manualmente criado e incorporado a um sistema de compreensão da língua natural. Esse módulo é o mecanismo de entrada para a rede neural. À medida que cada palavra da sentença é lida, sua representação é disparada: as palavras ativam seus sentidos, e estes ativam os papéis sintáticos e os casos que eles esperam preencher ou ter preenchidos, bem como todos os conceitos relacionados, como na passagem de marcadores. Uma interpretação para a sentença é encontrada quando, para cada palavra, somente uma unidade de sentido, uma unidade de caso e uma unidade de papel sintático é disparada.

No modelo de Cottrell é aplicada a mesma representação e processamento para informações sintáticas, semânticas, lexicais, restrições de seleção e associações entre as palavras. Assim, não é possível analisar isoladamente a parte do processamento responsável 
pela desambiguação lexical e, com isso, compreender como a desambiguação é realizada, avaliar esse processo ou, ainda, aprimorá-lo.

Os trabalhos baseados em conhecimento manualmente codificado descritos nesta seção são listados em ordem cronológica na Tabela 3.2, de acordo com a abordagem de IA empregada, a aplicação a que são voltados e a língua endereçada.

Tabela 3.2: Lista dos trabalhos de DLS baseadas em conhecimento manualmente codificado

\begin{tabular}{|l|l|l|l|}
\hline \multicolumn{1}{|c|}{ Trabalho } & \multicolumn{1}{c|}{ Abordagem } & \multicolumn{1}{c|}{ Aplicação } & \multicolumn{1}{c|}{ Língua } \\
\hline (Masterman, 1961) & simbólica & Tradução Automática & inglês - latim \\
\hline (Quillian, 1961) & simbólica & independente (monolíngue) & inglês \\
\hline (Hayes, 1976) & simbólica & independente (monolíngue) & inglês \\
\hline (Wilks, 1975) & simbólica & Compreensão da Língua Natural & inglês \\
\hline (Boguraev, 1979) & simbólica & Geração de paráfrases & inglês \\
\hline (Small, 1980) & simbólica & Compreensão da Língua Natural & inglês \\
\hline (Hirst, 1987) & simbólica & Compreensão da Língua Natural & inglês \\
\hline (McRoy, 1992) & simbólica & Compreensão da Língua Natural & inglês \\
\hline (Pedersen, 1997) & simbólica & Tradução Automática & dinamarquês - inglês \\
\hline (Dorr \& Katsova, 1998) & simbólica & Tradução Automática & inglês - espanhol \\
\hline (Bräscher, 2002) & simbólica & Recuperação de Informações & português \\
\hline (Cottrell \& Small, 1983) & conexionista & independente (monolíngue) & inglês \\
\hline (Waltz \& Pollack, 1985) & conexionista & independente (monolíngue) & inglês \\
\hline (Cottrell, 1989) & conexionista & Compreensão da Língua Natural & inglês \\
\hline
\end{tabular}

\section{Considerações sobre o método baseado em conhecimento manualmente codificado}

A vantagem das abordagens baseadas em conhecimento manualmente codificado é que o seu nível de especialização pode levar a resultados bastante precisos, principalmente na desambiguação de palavras com um grande número de sentidos, com distinções refinadas. Em contrapartida, o problema desses trabalhos é que a tarefa de codificação manual é lenta e custosa, como enfatizado por Small (1980), que exemplifica o nível de detalhes necessário para a especificação de um modelo para uma única palavra dizendo que foram necessárias seis páginas para tal especificação.

De modo geral, as dificuldades para codificar manualmente as fontes de conhecimento, adicionalmente aos modelos de desambiguação, acabam restringindo a implementação dos sistemas de DLS a protótipos bastante limitados, restritos a pequenos subconjuntos da língua natural, ou a domínios e gêneros bem delimitados. Esses sistemas não são facilmente generalizáveis e, portanto, dificilmente poderiam ser utilizados em aplicações reais, em larga escala.

Outro problema é que grande parte dos trabalhos focaliza na desambiguação de sentenças artificialmente construídas, que apresentam casos de ambigüidades bastante 
complexos, os quais exigem distinções extremamente refinadas entre os sentidos. Segundo Ide \& Véronis (1998), a maioria das sentenças analisadas raramente são utilizadas.

Por fim, de acordo com Kilgarriff (1992), geralmente não há justificativa sobre os critérios que levaram à escolha do subconjunto de palavras ambíguas endereçado. Adicionalmente, em muitos casos, os possíveis sentidos das palavras ambíguas são definidos como um recorte dos sentidos encontrados em dicionários, mas os critérios para tal escolha não são claros.

\subsubsection{Conhecimento pré-codificado}

A partir da década de 1980, quando se tornaram disponíveis recursos lexicais eletrônicos em larga escala, começaram a surgir trabalhos em DLS baseados em conhecimento précodificado, isto é, extraído desses recursos. Esse conhecimento inclui os possíveis sentidos de cada palavra, informações associadas a esses sentidos, como a sua categoria gramatical, marcadores de tópico e área, restrições de seleção, definições textuais, etc., bem como relações entre os sentidos ou entre grupos de sentido, como a sinonímia e a antonímia.

Os recursos lexicais utilizados incluem léxicos computacionais, dicionários eletrônicos e thesauri, os quais são distinguíveis, de acordo com a classificação de Ide \& Véronis (1998), com base no método de organização dos dados: em um dicionário, a entrada principal é no nível da palavra, sendo que cada entrada representa os vários sentidos dessa palavra. Em um thesaurus, a entrada principal é um grupo de palavras relacionadas. Em um léxico, a entrada principal é o sentido, que pode corresponder a várias palavras.

Alguns dos trabalhos que utilizam conhecimento pré-codificado dessas diferentes fontes empregam alguma técnica estatística da lingüística de córpus para a extração desse conhecimento, que pode variar desde uma freqüência relativa a cálculos mais complexos, como é o caso, por exemplo, de McRoy (1992) (Seção 3.2.1). Por essa razão, alguns autores (Manning \& Schütze, 2001, por exemplo) classificam essas abordagens como "estatísticas". Contudo, vale notar que os modelos de desambiguação ainda são manualmente codificados. Neste trabalho, são consideradas abordagens estatísticas baseadas em córpus apenas aquelas cujos modelos de desambiguação são automaticamente "aprendidos" a partir de exemplos em um córpus, por meio de técnicas de estatísticas ou de aprendizado de máquina (Seção 3.3).

Galley \& McKeown (2003) utilizam a teoria das cadeias lexicais para a DLS, ou seja, seqüências de palavras relacionadas que ultrapassam o limite do texto. Abordagens para a 
geração de cadeias lexicais, geralmente aplicadas para a verificação de coesão lexical, realizam a DLS implicitamente, antes de inferir quais palavras são semanticamente relacionadas. A idéia é melhorar o processo de DLS atual e, com isso, melhorar a identificação das cadeias lexicais. Primeiramente um grafo é construído para representar todas as possíveis interpretações da palavra ambígua. Para tanto, o texto de entrada é processado seqüencialmente, comparando-se cada palavra a todas as palavras já processadas. Se uma relação existe entre os possíveis sentidos da palavra atual e das anteriores, uma conexão é formada. A identificação das relações ocorre com base na WordNet: são considerados conceitos relacionados os hiperônimos ou hipônimos de um conceito, bem como os conceitos hipônimos de um hiperônimo comum. O peso dessa conexão é dado em função do tipo de relacionamento e da distância entre as palavras no texto. As palavras são representadas como nós no grafo, e as conexões, como arcos com pesos.

$\mathrm{Na}$ etapa de desambiguação, todas as ocorrências de uma dada palavra são analisadas em conjunto. Para cada possível sentido dessa palavra, os pesos de todas as conexões no grafo são somados, resultando no escore final para tal sentido. O sentido com o maior escore é então atribuído a todas as ocorrências da palavra. Esse algoritmo é, portanto, baseado na idéia de que apenas um sentido é utilizado para cada palavra em um dado discurso (conforme será discutido na Seção 3.3.2). Por fim, as cadeias lexicais são construídas. Em experimentos de avaliação para a DLS dos substantivos de um subconjunto do SemCor, a abordagem atingiu uma acurácia de $62 \%$.

Numa adaptação recente da abordagem de Lesk (1986), Pedersen et al. (2004) propõe que o cálculo da sobreposição entre glosas de sentidos pode ser usado como uma medida do relacionamento semântico entre as palavras. A DLS consiste, então, da identificação do sentido da palavra ambígua que mais se relaciona semanticamente com os sentidos das palavras no seu contexto. O framework implementado para essa abordagem, um pacote chamado SenseRelate::TargetWord (Patwardhan et al., 2005), pode ser customizado a partir da escolha entre várias medidas de relacionamento, tamanhos de janelas de contexto (bag-ofwords), opções de pré-processamento e algoritmos para o cálculo da sobreposição. A WordNet é utilizada como repositório de sentidos, bem como para fornecer as glosas para o cálculo da sobreposição e as informações sobre as relações entre os sentidos. Dois métodos são disponibilizados para o cálculo da sobreposição das glosas: um método local, que compara os sentidos da palavra ambígua e de suas vizinhas de dois-a-dois, e um método global, que compara exaustivamente todos os sentidos da palavra ambígua com todos os 
sentidos das palavras vizinhas (como na abordagem original de Lesk). Várias medidas de relacionamento são fornecidas no pacote WordNet::Similarity (Pedersen et al., 2004): seis medidas de similaridade (que quantificam o quanto dois conceitos são similares, com base na sua proximidade na hierarquia is-a da WordNet, por exemplo, "automóvel" e "barco") e três medidas de relacionamento (que identificam outros tipos de relacionamento, com base nas demais relações da WordNet, como part-of, por exemplo, "roda" e automóvel"). Em (Patwardhan et al., 2003) são descritos experimentos comparando várias dessas medidas. A avaliação do método de sobreposição local no conjunto de exemplos da tarefa Lexical Sample to Senseval-2, descrita em (Banerjee \& Pedersen, 2002), resultou em 31.7\% de acurácia média, contra $40 \%$ do melhor sistema não-supervisionado.

McCarthy et al. (2004a) propõem um método para identificar o sentido predominante (mais freqüente) de uma determinada palavra em um texto. A motivação para o uso de tal estratégia é que o desempenho de muitas das abordagens de DLS atuais é similar ou inferior ao da baseline do sentido mais freqüente. O objetivo é atribuir escores para os sentidos de palavras ambíguas em textos não anotados com base na teoria da similaridade distribucional, que mede o nível com que duas palavras vizinhas ocorrem em contextos similares. A idéia é que o sentido de uma dada palavra pode ser encontrado a partir da quantificação do grau de similaridade entre as suas descrições de sentido e a de seus vizinhos similares. Dado um conjunto de palavras vizinhas ordenadas de acordo com sua similaridade distribucional com relação à palavra ambígua (obtidos a partir de córpus analisados sintaticamente), para cada sentido dessa palavra ambígua o algoritmo seleciona o sentido de cada palavra vizinha que maximiza a sua relação com aquele sentido, utilizando uma relação de similaridade semântica baseada na WordNet. O escore de cada sentido da palavra ambígua é aumentado em função desse escore de similaridade, bem como da similaridade distribucional entre a palavra ambígua e suas vizinhas. O sentido predominante é aquele com o maior escore, o qual é atribuído a todas as ocorrências da palavra ambígua no córpus, com base na idéia de que apenas um sentido é utilizado para cada palavra em um dado discurso (conforme será discutido na Seção 3.3.2).

Em experimentos com os substantivos do SemCor, a acurácia na determinação do sentido predominante foi de $54 \%$, com ambas a medida de similaridade Information Content de Jiang \& Conrath (1997) e a medida de similaridade Lesk estendida (Banerjee \& Pedersen, 2002). Já a acurácia média para a DLS dos mesmos substantivos foi de $48 \%$ com a medida Information Content e $46 \%$ com a medida Lesk estendida. Num segundo experimento com o 
conjunto de exemplos da tarefa All Words do Senseval-2, a acurácia média obtida foi de 63\%, contra $69 \%$ do sistema primeiro colocado. São também apresentados experimentos preliminares com textos de domínios específicos, mostrando que a predominância do sentido mais freqüente varia em diferentes domínios. Em experimentos posteriores com a tarefa All Words na competição Senseval-3 (McCarthy et al., 2004b), o sistema obteve a acurácia média de $43.6 \%$, contra $65.5 \%$ do primeiro colocado, e $60.9 \%$ da baseline do sentido mais freqüente (o primeiro sentido da WordNet). Apesar de a acurácia média ser relativamente baixa, tal abordagem é considerada de grande impacto para a comunidade de DLS, já que o sentido predominante pode ser utilizado para complementar outras estratégias de desambiguação.

Navigli (2006a) propõe uma abordagem que utiliza a WordNet como fonte de conhecimento para a criação de um sistema de DLS que possa ser disponibilizado para uso em aplicações online. A abordagem básica, chamada Structural Semantic Interconnections (Navigli \& Velardi, 2005), é baseada no reconhecimento de padrões estruturais. A desambiguação de todas as palavras em um dado contexto ocorre por meio da maximização de uma função que calcula o grau de interconexão semântica mútua entre os possíveis sentidos (dados pela WordNet) de todas as palavras no contexto. Essa função utiliza padrões de interconexão semântica em uma versão da WordNet enriquecida com ligações conectando pares de sentidos relacionados. O enriquecimento ocorre com a aquisição de colocações a partir de dicionários de colocações, as quais são semi-automaticamente mapeadas para os sentidos da WordNet, cada colocação formando um arco de relação. Uma seqüência de arcos de relações constitui um padrão de interconexão. Para cada possível sentido de cada palavra ambígua nessa WordNet enriquecida, padrões de interconexão semântica são exaustivamente extraídos de acordo com uma gramática livre de contexto pré-definida com padrões "válidos". Assim, a cada par de sentidos é associado um conjunto de padrões validos, cada padrão com um peso inversamente proporcional ao seu comprimento. Na versão online da abordagem, a função que calcula o grau de interconexão semântica no grafo é implementada a partir de uma versão do algoritmo page ranking.

Além dos sentidos de todas as palavras no contexto, o algoritmo proposto retorna um grafo semântico mostrando as interconexões que levaram à escolha de tais sentidos. Numa avaliação com os exemplos da tarefa All Words no Senseval-3, uma acurácia média de 59.3\% é reportada, contra $60.4 \%$ da versão off-line da abordagem. Essa acurácia é comparável à obtida pelo melhor sistema supervisionado na tarefa $(65.2 \%)$. 
Brody et al. (2006) apresentam experimentos comparando quatro abordagens de desambiguação baseadas em conhecimento pré-codificado e em estatísticas extraídas de córpus, bem como combinando tais abordagens. As abordagens comparadas, descritas anteriormente, são a extensão da proposta de Lesk por Pedersen et al. (2004), a similaridade distribucional de McCarthy et al. (2004a), as cadeias lexicais de Galley \& McKeown (2003) e as interconexões semânticas estruturais de Navigli \& Velardi (2005). Essas quatro abordagens foram avaliadas com os conjuntos de exemplos do SemCor e Senseval-3, ambos anotados com sentidos da WordNet. A abordagem de interconexões semânticas estruturais obteve o melhor desempenho tanto para a identificação do sentido predominante (53.7\%), quando para a DLS (47.9\%), seguida da similaridade distribucional (54.9\% / 46.5\%), Lesk estendida $(49.4 \% / 42.5 \%)$ e, por fim, cadeias lexicais $(48.3 \%$ / 40.7\%), contra $23 \%$ da baseline do sentido mais freqüente no SemCor.

Experimentos para a combinação das quatro abordagens incluem diferentes métodos: (a) combinação baseada no voto majoritário, em que cada abordagem vota por um sentido e o voto majoritário é escolhido; (b) combinação baseada no voto com probabilidade, em que cada abordagem fornece uma distribuição de probabilidades para todos os sentidos e as probabilidades para cada sentido são somadas; (c) combinação baseada em ranking, em que cada abordagem fornece um ranking de sentidos e as colocações de cada sentido são somadas; e (e) combinação baseada em árbitro, em que a abordagem de interconexões semânticas estruturais é utilizada como árbitro para a decisão entre votos conflitantes de diferentes abordagens. Os resultados desses experimentos mostram que qualquer combinação apresenta desempenho superior ao das abordagens individuais, tanto para a identificação do sentido predominante, quanto para a DLS. Os métodos (b) e (c) mostraram desempenho bastante similar ( $58 \%$ para a identificação do sentido predominante, e $\sim 50 \%$ para a DLS), significativamente superior ao dos demais.

Uma categoria de recurso lexical amplamente utilizada para a DLS são os dicionários eletrônicos. Também chamados de dicionários de máquina, ou Dicionários Legíveis por Máquina (MRDs - Machine-Readable Dictionaries), consistem de versões eletrônicas dicionários publicados em papel, criados normalmente para uso por seres humanos.

Um dos primeiros trabalhos a utilizar MRDs é o de Lesk (1986). Lesk associa uma "assinatura" a cada sentido de uma palavra ambígua e a cada sentido das suas palavras vizinhas em uma sentença. Essa assinatura consiste da lista de palavras de conteúdo que aparecem na definição dos sentidos em um dicionário. A desambiguação é realizada pela 
seleção do sentido da palavra ambígua cuja assinatura apresenta o maior número de sobreposições com as assinaturas das palavras vizinhas na sentença.

Lesk realizou experimentos para analisar possíveis variantes no seu trabalho, como o uso de dicionários com definições mais ou menos extensas, o uso das palavras nos exemplos dessas definições, a atribuição de pesos para diferentes tipos de sobreposições e diferentes tamanhos de janelas de contexto. Definições curtas se mostraram suficientes e o uso dos exemplos dos sentidos acrescentou ruídos à assinatura. A atribuição de pesos às sobreposições também não se mostrou viável. Quanto aos tamanhos de janela, o autor reporta pouca diferença nos resultados para janelas de 4, 6, 8 ou 10 palavras. Como padrão, o sistema utiliza 10 palavras.

Lesk não realizou uma avaliação sistemática do seu trabalho, mas em testes com um pequeno número de exemplos, o sistema obteve acurácias entre $50 \%$ e $70 \%$. Esses resultados são significativos, considerando-se que são empregadas distinções de sentido relativamente refinadas (dadas pelo dicionário) e que apenas as informações disponíveis no dicionário são utilizadas. Uma desvantagem da abordagem é que ela é dependente das definições de um dicionário específico: a presença ou ausência de uma palavra na definição daquele dicionário pode mudar completamente os resultados. Além disso, a simples contagem das palavras nas assinaturas pode privilegiar a escolha de sentidos com definições mais extensas. Outro problema é a complexidade computacional da abordagem, em particular, para a desambiguação de múltiplas palavras em uma sentença, já que são muitas as combinações a serem testadas. Tal abordagem serviu de base para vários trabalhos posteriores, os quais acrescentam diferentes campos de informação dos dicionários ou de outras fontes para aprimorar os resultados da DLS. Na primeira edição da competição Senseval, a abordagem de Lesk, bem como diversas variações dessa abordagem propostas por Kilgarriff \& Rosenzweig (2000), foram utilizadas como baseline para comparação com os sistemas participantes. Muitos dos sistemas, incluindo um supervisionado, não foram capazes de superar tal abordagem.

Com base na abordagem de Lesk, Wilks et al. (1990) analisam a sobreposição de definições no dicionário eletrônico LDOCE (Longman Dictionary of Contemporary English). Segundo os autores, a análise das definições diretas no dicionário é problemática quando as definições são muito curtas, muitas vezes insuficientes para que ocorra alguma sobreposição significativa. Para minimizar esse problema, eles consideram um contexto maior, computando 
informações sobre a vizinhança lexical das palavras do dicionário inteiro por meio da freqüência de co-ocorrência dessas palavras.

A partir dessa informação de freqüência, são aplicadas técnicas de clustering para particionar as palavras de acordo com os seus sentidos. Assim, são derivadas métricas sobre o grau de relacionamento entre as palavras, as quais são usadas em um vetor de relacionamentos entre cada palavra e seu contexto. A classificação é iterativa: primeiramente são comparados os vizinhos mais locais, depois, os vizinhos dos vizinhos, e assim sucessivamente.

Em experimentos com a palavra ambígua bank, os autores reportam uma acurácia máxima de 53\% na identificação dos seus 13 possíveis sentidos no LDOCE. Em testes considerando sentidos menos refinados para essa palavra, a acurácia média obtida ficou entre $85 \%$ e $90 \%$. Vale notar que a complexidade computacional dessa abordagem é ainda maior que a da proposta original de Lesk.

Visando minimizar a complexidade da abordagem baseada na sobreposição de definições de Lesk, Kilgarriff \& Rosenzweig (2000) investigam uma versão simplificada dessa abordagem que evita a explosão combinatorial de sentidos. Nela, o sentido de cada palavra é determinado individualmente a partir da identificação da maior sobreposição entre as definições e exemplos dos sentidos de tal palavra e o seu contexto na sentença. A sobreposição é identificada por meio da medida TF-IDF (Term Frequency - Inverse Document Frequency). A cada palavra coincidente no contexto e na definição / exemplos de um dado sentido de uma palavra, a sobreposição do sentido é calculada como a soma de todos os percentuais de sentenças do dicionário que contêm as palavras coincidentes. Em uma avaliação com os exemplos da tarefa All Words do Senseval-2, a acurácia obtida por essa versão simplificada do método, juntamente com a atribuição de um sentido aleatório para os casos que não podiam ser classificados, foi de $47 \%$, contra $35 \%$ da versão original. Uma avaliação com o mesmo conjunto de exemplos com a atribuição do sentido mais freqüente para os casos não classificados resultou em $58 \%$, contra $42 \%$ da versão original.

Segundo Véronis \& Ide (1990), todos os trabalhos baseados na idéia de Lesk desconsideram informações sobre como as palavras nas definições de dicionários se interrelacionam. Como uma abordagem alternativa, os autores utilizam informações do dicionário CED (Collins English Dictionary), mas procuram manter a informação sobre as relações semânticas entre as palavras. Para tanto, eles definem um mecanismo para automaticamente 
converter as definições do dicionário e os relacionamentos entre suas palavras em uma rede neural.

A rede neural possui nós para cada entrada do dicionário e para cada um dos seus possíveis sentidos. Os nós das entradas são ligados aos nós dos seus sentidos por relações de ativação. Estes são ligados às palavras nas suas definições, que também estão ligadas aos seus sentidos, e assim sucessivamente, criando uma rede complexa. O contexto é dado, portanto, pela conectividade na rede.

Durante a desambiguação, os nós correspondendo às palavras a serem desambiguadas são ativados. Cada nó ativa, então, os nós de seus sentidos, os quais ativam os nós das palavras com as quais estão conectados, e assim sucessivamente, por vários ciclos. A cada ciclo, os nós de palavras e sentidos recebem o retorno da ativação dos nós conectados. Os nós que competem entre si enviam inibições uns para os outros. Depois de vários ciclos, a rede estabiliza em um estado no qual um sentido para cada palavra da sentença de entrada está mais ativo que os outros. Esses sentidos são, então, escolhidos para as palavras ambíguas.

Em experimentos com 23 palavras ambíguas, o sistema alcançou 71.7\% de precisão na desambiguação de acordo com os sentidos do CED. Em geral, essa abordagem é mais flexível por permitir o uso de um contexto maior a partir das informações do dicionário, de modo a tornar o sistema menos dependente das palavras da sentença e das suas definições no dicionário, bem como menos sensível a ruídos.

Outros autores procuram refinar o trabalho de Lesk, incorporando campos de informação adicionais fornecidas pelo dicionário eletrônico para os diferentes sentidos, além da definição das palavras. Por exemplo, Banerjee \& Pedersen (2002) entendem o contexto do dicionário a ser analisado ao adicionar as glosas de palavras relacionadas, de acordo com a estrutura da WordNet. Outros trabalhos empregam o dicionário LDOCE, explorando principalmente suas informações de freqüência dos sentidos, os códigos de área (economia, engenharia, etc.), os traços semânticos (abstrato, humano, etc.) de substantivos e as restrições de seleção de verbos.

Guthrie et al. (1991), por exemplo, exploram os códigos de área do LDOCE. Em vez de considerar a sobreposição entre as definições de todos os possíveis sentidos da palavra ambígua e das suas vizinhas, esse trabalho considera apenas a sobreposição das definições em que o código de área também coincide com o código das palavras vizinhas. Com isso, são estabelecidas relações de co-ocorrência dependentes de área. 
A verificação das correspondências de sentido entre os códigos de área é realizada em duas etapas. Na primeira etapa, verifica-se a intersecção das palavras coletadas para cada área da palavra ambígua com as suas palavras vizinhas na sentença. A área que apresenta a maior intersecção (isto é, mais palavras coincidentes) é escolhida como a área da palavra ambígua. $\mathrm{Na}$ segunda etapa, identifica-se o sentido na área selecionada, por meio da verificação da intersecção das definições dos possíveis sentidos da área selecionada com as palavras da sentença. O sentido com a maior intersecção é escolhido como o sentido da palavra ambígua.

$\mathrm{Na}$ primeira etapa, se um determinado limite inferior não for atingido, um processo iterativo é disparado para aumentar a vizinhança a ser analisada, considerando também as definições de sentidos das palavras coletadas para cada área. Esse processo continua até que o número mínimo de palavras coincidentes na definição da área (e das áreas relacionadas) e na sentença seja alcançado.

Os autores não avaliam seu trabalho, mas mencionam que, em função da quantidade limitada de informações disponíveis no LDOCE para cada código de área, seria mais indicado utilizar, em vez das definições do dicionário, córpus de diferentes áreas para a identificação de palavras significativas em cada área.

Uma extensão desse trabalho é apresentada em Cowie et al. (1992). Nela, os autores adicionam a técnica para otimizar as verificações entre as possíveis combinações de definições. Isso é feito por meio da técnica de otimização computacional simulated annealing, que torna possível considerar toda a sentença como contexto e procurar a melhor combinação entre todos os sentidos de todas as palavras, simultaneamente. Com isso, é possível visualizar se (e como) a desambiguação de uma palavra pode influenciar na desambiguação das demais na sentença ou ser influenciada por essa desambiguação.

O sistema foi avaliado para a desambiguação 50 sentenças extraídas do LDOCE, com uma média de 5.5 palavras ambíguas por sentença. Os resultados foram comparados com a etiquetação manual das 50 sentenças. A acurácia obtida foi de $72 \%$ na identificação de homógrafos e $47 \%$ para distinções entre sentidos refinados. Um problema que se mantém nesse trabalho é que definições mais longas no dicionário tendem a ser preferidas a definições curtas, em função do número maior de combinações possíveis nas definições longas.

Utilizando-se do dicionário LDOCE e de uma estratégia de DLS mais simples que a da sobreposição de definições, Wilks \& Stevenson (1996) defendem a utilização da categoria gramatical das palavras ambíguas, disponíveis nesse dicionário, como fonte de conhecimento 
essencial para a desambiguação. Os autores consideram a desambiguação entre palavras de categorias gramaticais distintas como parte do problema de DLS.

Em seus experimentos, as etiquetas gramaticais são automaticamente atribuídas utilizando um etiquetador morfossintático e então manualmente mapeadas para as etiquetas mais genéricas do LDOCE (homógrafos). Para uma dada palavra ambígua, o processo de DLS consiste da seleção do homógrafo no LDOCE com a categoria gramatical da palavra. Nos casos em que mais de um homógrafo com a mesma categoria gramatical é encontrado no LDOCE, o primeiro homógrafo listado é escolhido, com base na suposição de que este é o mais freqüente. Em um teste com 1.700 palavras, utilizando-se somente essa informação sobre a categoria gramatical no LDOCE, a acurácia obtida foi de $87.4 \%$ para a distinção entre homógrafos. Vale notar, contudo, que tal abordagem simplista não se aplicaria a distinções mais refinadas.

Em trabalhos subseqüentes, Wilks \& Stevenson (1997a; 1997b) fazem uso de outras informações do LDOCE. A hipótese é de que a combinação de vários "métodos fracos" (cada um usando uma fonte de conhecimento), que apresentam baixo desempenho isoladamente, pode levar a um "método forte". Em (Wilks \& Stevenson, 1997a), os autores utilizam um etiquetador gramatical como filtro para eliminar os sentidos que pertencem a categorias distintas da indicada para a palavra ambígua, e as definições do LDOCE para verificar as sobreposições entre as definições de cada sentido da palavra ambígua e dos sentidos das palavras vizinhas a ela. $\mathrm{O}$ algoritmo de simulated annealing é empregado para otimizar o processo de escolha entre as muitas combinações possíveis. Em um experimento com 10 sentenças com palavras ambíguas, foram obtidas acurácias de 86\%, no nível de homonímia, e $57 \%$, no nível de polissemia.

Em (Wilks \& Stevenson, 1997b), os autores incluem um identificador de entidades para isolar nomes próprios, que não precisam ser desambiguados, e informações do LDOCE para verificar a sobreposição entre os códigos de área dos sentidos da palavra ambígua das suas palavras vizinhas, como em (Guthrie et al., 1991). Um mecanismo simples é empregado para combinar os resultados dos diversos processos: o sentido indicado pelo maior número dos processos é escolhido. A avaliação em um córpus com 14 palavras ambíguas resultou em 88\% de acurácia no nível de homonímia e 60\% no nível de polissemia. Outros aperfeiçoamentos dessas abordagens utilizam técnicas de aprendizado de máquina e serão descritas na Seção 3.3. 
Brun (2000) utiliza um dicionário eletrônico para a DLS em um ambiente de processamento de textos de maneira diferenciada dos demais trabalhos. Um extrator de regras de DLS utiliza as definições do dicionário para automaticamente extrair regras baseadas nas relações de dependência funcional encontradas nos exemplos do dicionário para cada sentido. Elas indicam um sentido de acordo com o seu uso em uma relação sintática com a(s) palavra(s) em questão.

As regras extraídas são então generalizadas para classes de palavras co-ocorrentes, com base na sua distribuição na hierarquia conceitual da WordNet. A generalização aumenta a abrangência do sistema, que pode cobrir casos de ambigüidade com outras palavras vizinhas, além daquelas apresentadas nos exemplos do dicionário. Nos casos de ambigüidade em que nenhuma regra se aplica, é automaticamente atribuído à palavra ambígua o primeiro sentido do dicionário, considerado o mais freqüente.

O sistema foi avaliado considerando-se duas configurações: (a) as 34 palavras e o córpus do Senseval-1; e (b) todas as palavras de 400 sentenças de um jornal. Em ambos os casos, a precisão média obtida foi de $79 \%$ e a cobertura, de $36 \%$. Isso mostra que a generalização com base na hierarquia da WordNet não é suficiente para garantir regras abrangentes.

Outra categoria de recurso lexical utilizada para a DLS são os léxicos computacionais, ou bases de dados lexicais. Exemplos de léxicos incluem a WordNet (Fellbaum, 1998), para o inglês, o ACQUILEX (Briscoe, 1991), para o inglês, o italiano, o espanhol e o holandês, e a DIADORIM (Greghi et al., 2002), para o português. Esses léxicos são chamados "enumerativos", uma vez que todos os sentidos de uma palavra são explicitamente fornecidos como diferentes entradas. A exploração de léxicos gerativos, nos quais as informações semânticas são subespecificadas e as informações de sentido são derivadas a partir de regras geração, é pouco comum para a DLS, dada a dificuldade para definir adequadamente as estruturas lexicais e a possibilidade de geração de sentidos desnecessários.

Entre os léxicos enumerativos, a WordNet é o recurso mais comumente utilizado para DLS. Adicionalmente às definições e exemplos de uso para os diversos sentidos de cada palavra, esse recurso especifica relações semânticas entre tais palavras e entre grupos de palavras, incluindo a sinonímia, a antonímia, a meronímia e a hiponímia, entre outras. A sinonímia é a principal relação: grupos de palavras sinônimas são organizadas em conjuntos denominados synsets. Cada synset representa um conceito cujo sentido é válido para todas as 
palavras do conjunto. Por exemplo, o synset \{plant, flora, plant life \} representa um conceito que é compartilhado pelas três palavras. Nos trabalhos de DLS, os synsets são usados, em geral, como os sentidos das palavras.

Palavras e synsets são inter-relacionados por meio de ligações lexicais e semânticoconceituais, respectivamente. Por exemplo, a sinonímia e antonímia relacionam palavras, enquanto a hiponímia e a hiperonímia relacionam synsets. Com isso, a WordNet fornece também uma organização conceitual hierárquica, a qual contém cerca de 45 classes semânticas principais.

Muitas das abordagens que exploram a WordNet para a DLS fazem uso também da sua informação hierárquica. Por exemplo, Voorhees (1993) propõe o uso de um nível refinamento de sentidos menos granular que os synsets, porém, não tão genérico quanto as suas classes semânticas, para a DLS na Recuperação de Informações do inglês. Os sentidos resultantes, denominados "toldos", representam categorias de sentidos agrupando vários synsets, com base nas relações de hiponímia entre synsets de substantivos da WordNet. Para desambiguar uma palavra em um texto, conta-se as palavras desse texto que ocorrem em cada um dos diferentes toldos. Isso é feito tanto para a sentença de busca (soma local) quanto para os documentos encontrados (soma global). O sentido correspondente à raiz do toldo para o qual a diferença entre as somas global e local é a menor é escolhido para aquela palavra. Experimentos com essa abordagem em um sistema de Recuperação de Informações indicam que, na maioria das vezes, não há melhoria na qualidade da recuperação, quando comparada aos procedimentos de busca tradicionais.

Recentemente, outros trabalhos têm focalizado na identificação de conjuntos de sentidos menos refinados que os da WordNet. A maioria deles baseia-se no uso de técnicas de clustering para o agrupamento de sentidos da WordNet. Por exemplo, Navigli (2006b) propõe o mapeamento de tais sentidos para os sentidos menos refinados do dicionário Oxford Dictionary of English. Tal mapeamento se dá a partir da unificação de descritores de sentidos em ambos os recursos, criados para cada sentido de cada palavra utilizando-se palavras na glosa de tal sentido, seus hiperônimos e informações de domínio. Critérios de unificação lexical (palavras em comum nas descrições) e semântico (com o uso de um algoritmo de DLS) são investigados. Grupos de sentidos da WordNet mapeados para o mesmo sentido do dicionário são então considerados um cluster. A qualidade de parte dos clusters gerados foi avaliada comparando-os ao mapeamento humano. Uma acurácia de $77.94 \%$ foi atingida. Abordagens relacionadas são propostas em (Dolan, 1994), (Peters et al., 1998) e (Mihalcea \& Moldovan, 2001). A abordagem Snow et al. (2007), bastante recente, em vez de técnicas de 
clustering, considera a combinação de sentidos da WordNet como um problema de classificação supervisionado, explorando grupos de sentidos anotados manualmente como exemplos de treinamento, juntamente com um conjunto de atributos derivados da estrutura da WordNet, de córpus, e de outros recursos lexicais. A medida de similaridade induzida supera métodos anteriores de agrupamento de sentidos baseados em técnicas de clustering, por exemplo, Peters et al. (1998) e Mihalcea \& Moldovan (2001).

Voltado para a DLS na Recuperação de Informações, a abordagem de Sussna (1993) baseia-se na distância entre os sentidos na hierarquia conceitual da WordNet. A hipótese é de que, para um dado conjunto de termos ocorrendo próximos uns dos outros em um texto, cada um com vários sentidos possíveis, o sentido que minimiza a distância entre eles na hierarquia é o mais adequado. Essa distância é denominada "distância semântica".

A distância semântica é calculada entre os substantivos do texto, de acordo com a distribuição, na hierarquia conceitual, dos seus sentidos e dos sentidos das palavras vizinhas na sentença em uma janela de contexto. O grau de relação entre os pares de sentidos das palavras é computado por uma medida que atribui pesos aos diferentes tipos de relações da WordNet e calcula a distância entre dois sentidos na hierarquia com base no número de arcos do mesmo tipo partindo de um nó (um sentido) e na profundidade de uma determinada aresta na hierarquia global. Como resultado, um escore global do grau de relacionamento é computado entre cada possível sentido e os sentidos das palavras do contexto. O sentido com o maior escore, que corresponde ao caminho mais curto na hierarquia, é então escolhido.

Uma avaliação realizada com cinco documentos jornalísticos, considerando variações no tamanho e no tipo da janela de contexto e diferentes esquemas de pesos das relações hierárquicas, mostrou que os resultados do sistema são significativamente melhores que a baseline de escolhas ao acaso (39\%, em média). Nas melhores configurações, o sistema atingiu uma acurácia entre $53 \%$ e $55 \%$ na desambiguação.

Um dos problemas desse trabalho, conforme apontado por Resnik (1995a), é que são testadas todas as combinações possíveis entre todos os sentidos do substantivo ambíguo e de todos os demais substantivos no seu contexto. Assim, o custo computacional dessa abordagem a torna inviável.

Também utilizando a hierarquia conceitual da WordNet, Resnik (1995a) propõe uma abordagem para identificar o sentido de grupos de substantivos com alguma relação implícita. 
Os grupos são previamente gerados por um processo independente do seu sistema, por exemplo, a partir das classes de um thesaurus ou de um algoritmo de clustering.

A atribuição do sentido é realizada por meio de uma medida de similaridade entre os substantivos do grupo, como no trabalho de Sussna. Contudo, Resnik define essa relação em função da informação de conteúdo das palavras. A medida procura identificar qual o conceito (ou seja, o sentido) mais específico na hierarquia, considerando apenas a relação de hiponímia, que subsume todos os conceitos das palavras do grupo (Resnik, 1995b). A hipótese por trás dessa medida é que quanto mais específico é o conceito que subsume duas ou mais palavras, mais semanticamente relacionadas são essas palavras. Esse sentido mais específico é então escolhido como o sentido para o grupo. Com isso, podem ser atribuídos sentidos mais refinados ou mais genéricos, de categorias superiores na hierarquia da WordNet.

A abordagem foi avaliada em 125 grupos de substantivos provenientes de categorias do thesaurus Roget (Chapman, 1977). Os resultados foram comparados com a identificação de sentidos (da WordNet) realizada manualmente, por dois juízes. Dos sentidos desambiguados pelos juízes, o sistema identificou o sentido correto em $58.6 \%$ e $60.5 \%$ das vezes. Um problema dessa abordagem é que ela requer que grupos de substantivos semanticamente relacionados sejam previamente identificados. Além disso, como discutido em Kilgarriff (1997a), não há garantia de que os níveis de distinção adequados para diferentes problemas podem ser obtidos automaticamente a partir da hierarquia da WordNet.

Agirre \& Rigau (1996) também usam as classes semânticas e a hierarquia de classes da WordNet para a DLS, empregando uma medida denominada "densidade conceitual". Essa medida é similar à "distância semântica", de Sussna, e à "similaridade semântica", de Resnik. A distância entre conceitos é computada em termos da hierarquia semântica como o comprimento do menor caminho que conecta dois conceitos nessa hierarquia. Quanto maior o número de palavras em comum entre esses conceitos, maior o relacionamento semântico entre eles e, portanto, maior a medida de densidade conceitual.

Experimentos para a avaliação da DLS de substantivos em quatro textos do SemCor (Seção 4.1) aleatoriamente selecionados levaram a uma precisão média de 43\% para distinção entre sentidos, e de $53.9 \%$ para a distinção entre as classes semânticas da WordNet. 
A medida de densidade conceitual também é utilizada por Mihalcea \& Moldovan (1999a), contudo, antes de aplicar essa medida, os autores utilizam um filtro para selecionar somente os sentidos com maior probabilidade de co-ocorrência na web.

Considerando-se apenas os sentidos mais freqüentes (ordenados) para cada palavra, de acordo com um limite inferior pré-definido, a ordenação de tais sentidos é refinada a partir da medida de densidade conceitual. Nesse caso, a medida considera o número de palavras comuns que estão a uma distância semântica, dada pela hierarquia da WordNet, de duas ou mais palavras. Essa etapa é realizada apenas para os verbos e substantivos, pois adjetivos e advérbios não estão incluídos na hierarquia da WordNet. Para as palavras dessas duas classes gramaticais, somente as informações de freqüência de co-ocorrência são utilizadas.

O sistema retorna os vários possíveis sentidos classificados de acordo com sua densidade conceitual (e frequiência). Em uma avaliação realizada com 384 pares de palavras do SemCor e a escolha do primeiro sentido da classificação produzida, a acurácia média obtida foi de $80 \%$.

Montoyo et al. (2002) apresentam uma interface para a desambiguação de substantivos e verbos voltada para sistemas multilíngues de Recuperação de Informações, considerando-se o espanhol e o inglês como línguas-fonte para a definição das sentenças de busca e a geração de sentenças equivalentes em catalão e basco.

A taxonomia da EuroWordNet (Vossen, 1998), uma versão da WordNet que inclui outras línguas além do inglês, é utilizada para realizar o mapeamento entre as palavras dessas duas línguas para o catalão e o basco. A EuroWordNet possui ligações entre as palavras das diversas línguas, por meio de um índice interlingual. Assim, a identificação do sentido de uma palavra em uma língua provê, automaticamente, o conjunto de sentidos equivalentes em outras línguas.

O módulo de DLS consulta a EuroWordNet para buscar todos os possíveis sentidos da palavra a ser desambiguada, na sentença de busca, e seleciona o método específico para a DLS, dependendo da classe gramatical da palavra. Para a desambiguação de substantivos é empregado um método de marcas de especificação e para a desambiguação de verbos, um método de similaridade semântica.

O método de marcas de especificação se baseia nas relações da EuroWordNet para identificar quantas palavras do contexto da palavra ambígua na sentença estão relacionadas a cada marca de especificação, que corresponde a uma classe semântica da WordNet. O sentido que contiver o maior número de palavras é escolhido. Já o método de similaridade semântica 
se baseia na similaridade entre os sentidos do verbo e do núcleo do seu objeto, dada pela relação verbo-objeto (com o verbo ambíguo) gerada por um parser. A combinação de sentidos mais similar indica o sentido do verbo.

Embora seja voltada para aplicações multilíngues, a desambiguação é realizada na língua-fonte, de maneira monolíngue. Em experimentos considerando a tarefa de desambiguação monolíngue do Senseval-2, os resultados reportados são ditos superiores aos de sistemas similares.

Uma terceira categoria de recurso lexical utilizado para a DLS é a dos thesauri. Assim como os dicionários eletrônicos, os thesauri usados na DLS são, geralmente, versões eletrônicas de algum thesaurus em papel. Eles contêm informações sobre as categorias semânticas das palavras ou conceitos, bem como sobre as relações semânticas entre as palavras, como a sinonímia, a hiponímia, entre outras. O primeiro trabalho relacionado à DLS a utilizar um thesaurus é provavelmente o de Masterman (1957), que emprega o Roget International Thesaurus (Chapman, 1977) para a seleção lexical na tradução do latim para o inglês. Os cabeçalhos das categorias do Roget são utilizados como sentidos das palavras. O cabeçalho escolhido é aquele cujas palavras são mais proeminentes no contexto.

Patrick (1985) utiliza o thesaurus Roget para discriminar entre os sentidos de verbos a partir da análise de agrupamentos semânticos derivados desse thesaurus, em função das relações de sinonímia. As distinções de sentido são bastante refinadas, uma vez que são baseadas apenas nas palavras mais fortemente relacionadas semanticamente no thesaurus.

Vale notar que os trabalhos descritos anteriormente que utilizam a hierarquia conceitual da WordNet poderiam ser também considerados baseados em thesaurus, já que a hierarquia da WordNet inclui também as informações de um thesaurus.

Além dos trabalhos descritos, muitos outros, baseados em córpus, utilizam recursos lexicais para a DLS, juntamente com técnicas estatísticas ou de aprendizado de máquina. Esses trabalhos serão descritos na Seção 3.3. Os trabalhos baseados em conhecimento précodificado descritos nesta seção são resumidamente ilustrados na Tabela 3.3, em ordem cronológica, de acordo com a abordagem empregada, o(s) recurso(s) lingüístico(s) usado(s), a aplicação a que são voltados e a língua endereçada. 
Tabela 3.3: Lista dos trabalhos de DLS baseados em conhecimento pré-codificado

\begin{tabular}{|c|c|c|c|c|}
\hline Trabalho & Abordagem & Recurso(s) & Aplicação & Língua \\
\hline (Masterman, 1957) & simbólica & $\begin{array}{l}\text { thesaurus } \\
\text { Roget e MRD } \\
\text { bilíngue }\end{array}$ & Tradução Automática & $\begin{array}{l}\text { latim }- \\
\text { inglês }\end{array}$ \\
\hline (Patrick, 1985) & simbólica & $\begin{array}{l}\text { thesaurus } \\
\text { Roget }\end{array}$ & independente (monolíngue) & inglês \\
\hline (Lesk, 1986) & simbólica & MRD & Recuperação de Informações & inglês \\
\hline (Wilks et al., 1990) & simbólica & $\begin{array}{l}\text { MRD } \\
\text { LDOCE }\end{array}$ & independente (monolíngue) & inglês \\
\hline (Véronis \& Ide, 1990) & conexionista & MRD CED & independente (monolíngue) & inglês \\
\hline (Guthrie et al., 1991) & simbólica & $\begin{array}{l}\text { MRD } \\
\text { LDOCE }\end{array}$ & Recuperação de Informações & inglês \\
\hline (Cowie et al., 1992) & simbólica & $\begin{array}{l}\text { MRD } \\
\text { LDOCE }\end{array}$ & independente (monolíngue) & inglês \\
\hline (Voorhees, 1993) & simbólica & WordNet & Recuperação de Informações & inglês \\
\hline (Sussna, 1993) & simbólica & WordNet & Recuperação de Informações & inglês \\
\hline (Resnik, 1995a) & simbólica & WordNet & independente (monolíngue) & inglês \\
\hline (Agirre \& Rigau, 1996) & simbólica & WordNet & independente (monolíngue) & inglês \\
\hline $\begin{array}{l}\text { (Wilks \& Stevenson, } \\
1996)\end{array}$ & simbólica & $\begin{array}{l}\text { MRD } \\
\text { LDOCE }\end{array}$ & independente (monolíngue) & inglês \\
\hline $\begin{array}{l}\text { (Wilks \& Stevenson, } \\
\text { 1997a; 1997b) }\end{array}$ & simbólica & $\begin{array}{l}\text { MRD } \\
\text { LDOCE }\end{array}$ & independente (monolíngue) & inglês \\
\hline $\begin{array}{l}\text { (Mihalcea \& Moldovan, } \\
\text { 1999a) }\end{array}$ & simbólica & WordNet & independente (monolíngue) & inglês \\
\hline $\begin{array}{ll}\text { Kilgarriff } & \& \\
\text { Rosenzweig, 2000) } & \\
\end{array}$ & simbólica & WordNet & independente (monolíngue) & inglês \\
\hline $\begin{array}{l}\text { (Banerjee \& Pedersen, } \\
\text { 2002) }\end{array}$ & simbólica & WordNet & independente (monolíngue) & inglês \\
\hline (Brun, 2000) & simbólica & $\begin{array}{ll}\text { MRD } & \text { e } \\
\text { WordNet }\end{array}$ & independente (monolíngue) & inglês \\
\hline (Montoyo et al., 2002) & simbólica & EuroWordNet & $\begin{array}{l}\text { Recuperação de Informações } \\
\text { multilíngue }\end{array}$ & inglês \\
\hline $\begin{array}{l}\text { (Galley \& McKeown, } \\
2003)\end{array}$ & simbólica & WordNet & coesão lexical & inglês \\
\hline (Pedersen et al., 2004) & simbólica & WordNet & independente (monolíngue) & inglês \\
\hline $\begin{array}{l}\text { (McCarthy et al., 2004a; } \\
\text { 2004b) }\end{array}$ & simbólica & WordNet & independente (monolíngue) & inglês \\
\hline (Navigli, 2006a) & simbólica & WordNet & independente (monolíngue) & inglês \\
\hline (Brody et al., 2006) & simbólica & WordNet & independente (monolíngue) & inglês \\
\hline
\end{tabular}

\section{Considerações sobre o método baseado em conhecimento pré-codificado}

A principal vantagem da utilização de bases de conhecimento pré-codificado (léxicos computacionais, dicionários e thesauri) para a DLS é o fato de que não é necessário codificar esse conhecimento lingüístico manualmente. Em contra-partida, um dos problemas dessas abordagens, principalmente no caso de bases extraídas automaticamente a partir de fontes de informação não eletrônica, é que pode haver inconsistências nos dados eletrônicos, uma vez que os recursos são criados para uso por humanos, e não por computadores. Outra limitação da utilização de bases de conhecimento pré-codificado diz respeito às aplicações multilíngues, 
já que não se dispõe de bases multilíngues com informações para a DLS, em especial, contemplando a língua portuguesa.

Adicionalmente, uma vez que os modelos de DLS são manualmente codificados, as vantagens do método discutido na Seção 3.2.1 também se aplicam, em especial, a possibilidade de geração de sistemas bastante precisos. $\mathrm{O}$ uso das bases de conhecimento certamente facilita o desenvolvimento de modelos de desambiguação mais abrangentes. Contudo, um problema, que também se estende aos trabalhos baseados em conhecimento manualmente codificado, diz respeito à consistência de tais modelos. À medida que novas regras ou heurísticas precisam set incluídas para estender o modelo, torna-se mais e mais complexa a verificação da sua consistência.

\subsection{MÉTODOS BASEADO EM CÓRPUS E HÍBRIDO}

Nos últimos anos, com os avanços na área de Aprendizado de Máquina (AM), tem crescido no PLN a utilização de métodos que permitem extrair conhecimento automaticamente a partir de córpus, visando minimizar o problema do gargalo da aquisição de conhecimento. Um córpus provê um conjunto de exemplos que, quando submetidos a algoritmos de aprendizado ou técnicas estatísticas, dão origem a modelos capazes de descrever esses exemplos ou de predizer o comportamento de novos exemplos. Os trabalhos baseados em córpus, também chamados de trabalhos empíricos, realizam a desambiguação, portanto, com o uso de informações obtidas automaticamente a partir de um córpus.

Os exemplos são descritos em função das suas características, denominadas "atributos". Estas podem incluir informações sobre a palavra ambígua, as palavras da sentença que formam o contexto da palavra ambígua, e também diversos níveis de informações sobre essas palavras e sobre as relações entre elas. Em geral, essas características são representadas por meio de vetores de atributos.

Dependendo da natureza das informações utilizadas como atributos, a abordagem baseada em córpus pode ser considerada híbrida. Abordagens híbridas, na classificação adotada neste trabalho, não se restrinjam à representação de informações extraídas do córpus como atributos. Elas fazem uso de fontes de conhecimento lingüístico (ou extralingüístico), manualmente codificadas, extraídas de recursos lexicais ou geradas por ferramentas de processamento de textos. Contudo, na literatura atual, não é clara a distinção entre trabalhos híbridos e puramente baseados em córpus. Por exemplo, alguns autores consideram que o uso de informações fornecidas por ferramentas como um etiquetador gramatical categoriza a 
abordagem como híbrida, enquanto outros consideram híbridas apenas as abordagens que utilizam conhecimento lingüístico explícito em recursos lexicais como dicionários. Portanto, neste trabalho, todas as abordagens que utilizam exemplos de desambiguação são descritas indistintamente.

O córpus de exemplos para o aprendizado do modelo de DLS pode ser anotado (rotulado, etiquetado) ou não-anotado. Em um córpus anotado, os exemplos são descritos, além das características citadas, pelas etiquetas de sentido da(s) palavra(s) ambígua(s) em questão, normalmente atribuídas com base no conjunto de sentidos de algum recurso lexical, por exemplo, a WordNet. Esse córpus é, portanto, desambiguado com relação a determinadas palavras ambíguas. Abordagens baseadas nesse tipo de córpus seguem o modo de aprendizado supervisionado (DLS supervisionada - Seção 3.3.1). Em um córpus não-anotado, os exemplos não possuem anotação de sentido. Abordagens que utilizam córpus dessa natureza seguem, então, o modo de aprendizado não-supervisionado (DLS não-supervisionada Seção 3.3.2).

Conforme observam Manning \& Schütze (2001), a DLS supervisionada, no contexto das possíveis tarefas supervisionadas de AM (Figura 3.1), corresponde à tarefa de classificação, ou seja, de criação de um modelo que possa identificar (prever) a classe (sentido) mais adequada para novos casos de ambigüidade com base em exemplos já classificados. Já no caso da DLS não-supervisionada, a tarefa de DLS pode ser considerada, em geral, uma tarefa de clustering, ou seja, de descrição dos exemplos de acordo com a similaridade (ou dissimilaridade) entre eles. Neste caso, grupos de sentidos similares são criados, sem a preocupação com a identificação do sentido de cada grupo, e a tarefa é geralmente chamada de discriminação de sentidos, em vez de desambiguação de sentidos. Contudo, como ressaltam $\mathrm{Ng} \&$ Zelle (1997), e como será mostrado na descrição dos trabalhos não-supervisionados, tais trabalhos não se restringem à tarefa de clustering.

Além desses dois modos de aprendizado tradicionalmente utilizados para classificar trabalhos baseados em córpus (por exemplo, Agirre \& Edmonds, 2006), neste trabalho considera-se também o modo semi-supervisionado ou fracamente supervisionado (DLS semi-supervisionada - Seção 3.3.3). Nesse modo, o processo de aprendizado é iterativo. Na classificação, parte-se de um córpus com apenas alguns exemplos anotados, os quais são usados para treinar o sistema para etiquetar novos casos. Em alguns trabalhos, o objetivo é etiquetar a maior quantidade possível de exemplos, conforme será discutido na Seção 4.2. Em outros, o mais importante é garantir a confiabilidade na etiquetação dos novos casos. Um exemplo de técnica semi-supervisionada é a de bootstrapping (ou co-training): o objetivo é 
aumentar conjunto de exemplos de treinamento, adicionando os casos etiquetados a esse conjunto, desde que eles satisfaçam um limite mínimo de confiabilidade para a classe atribuída. Esse processo pode ser repetido várias vezes. Na descrição dos trabalhos de DLS nesta seção, são considerados semi-supervisionados diversas variantes desse modo de aprendizado, incluindo o co-treinamento (co-training), o autotreinamento (self-training) e o aprendizado ativo (active learning).

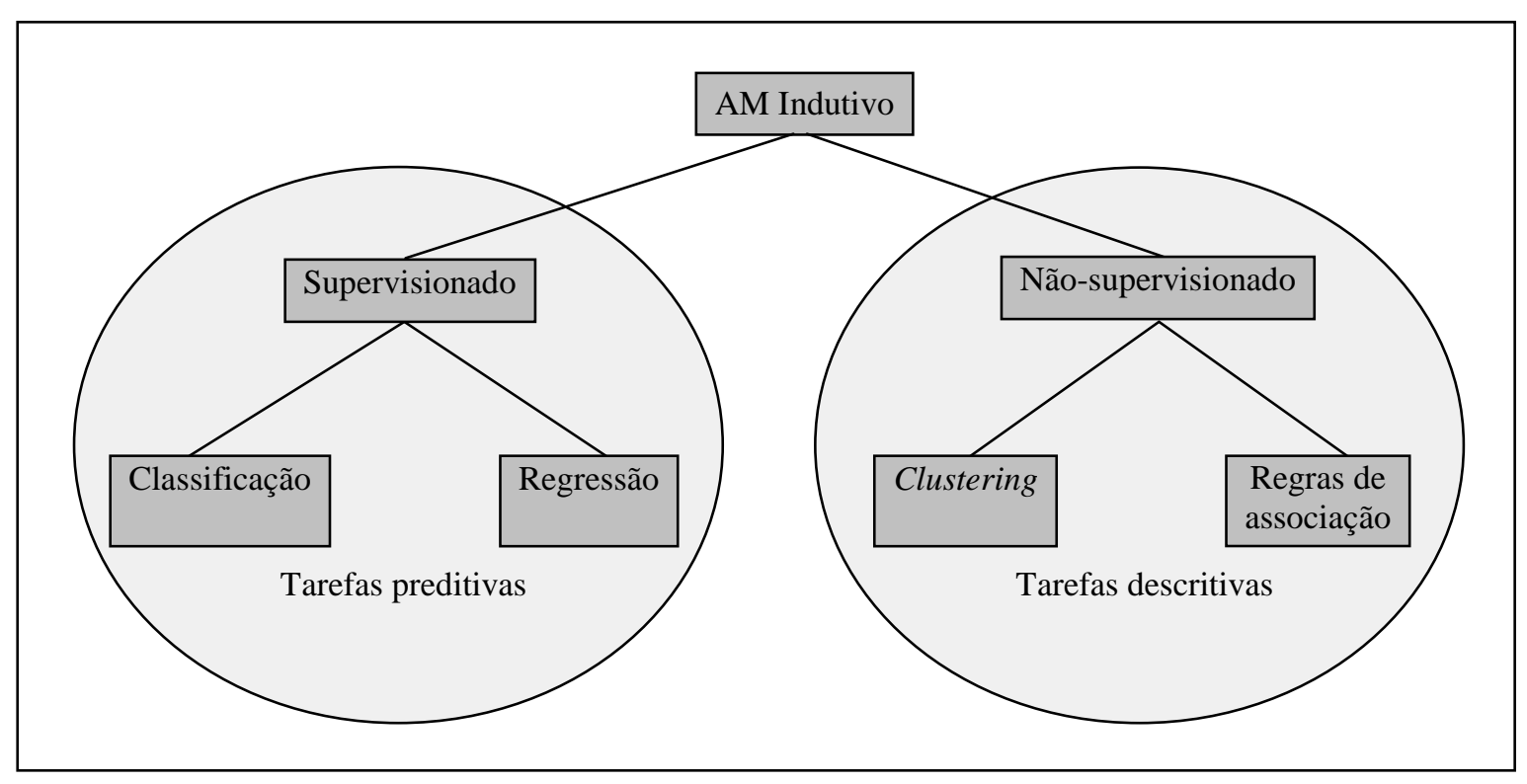

Figura 3.1: Modos e tarefas de aprendizado em AM (Monard \& Baranauskas, 2003, p. 91)

Nos algoritmos de clustering, o aprendizado semi-supervisionado também consiste em partir de um córpus de treinamento pequeno, com os exemplos já agrupados em clusters, para atribuir outros casos, não rotulados, a esses clusters. São usadas medidas de similaridade para identificar a proximidade entre os exemplos já anotados e os casos não anotados. Em geral, novos casos são atribuídos a algum cluster se essa proximidade atinge um limite mínimo préestabelecido de confiabilidade.

Vale notar que as abordagens que utilizam técnicas semi-supervisionadas são consideradas, por alguns autores, como supervisionadas, já que tanto na tarefa de classificação quanto na de clustering, o treinamento ocorre, em geral, a partir de exemplos etiquetados.

Além da distinção com relação ao modo de aprendizado, as abordagens baseadas em córpus variam no que diz respeito ao paradigma de aprendizado. Paradigmas comuns são: simbólico, estatístico, conexionista e baseado em instâncias (instance-based, lazy-learning, case-based, memory-based ou exemplar-based). Entre as implicações da utilização de determinado paradigma está a linguagem de descrição do modelo gerado. Na tarefa de classificação, por exemplo, as abordagens simbólicas dão origem a modelos simbólicos de 
DLS, como árvores de decisão, regras de decisão ou listas de decisão, enquanto abordagens estatísticas dão origem a modelos numéricos.

Algoritmos de AM dos diferentes paradigmas vêm sendo empregados para a DLS, por exemplo, C4.5 (Quinlan, 1988), do paradigma simbólico, variações do k-NN ( $k$-Nearest Neighbor), do paradigma baseado em instâncias, Naive Bayes (Duda \& Hart, 1973), do paradigma estatístico, entre outros.

Na seqüência (Seção 3.3.1 - 3.3.3), serão apresentados várias abordagens de DLS desenvolvidas sob os diferentes modos e paradigmas de aprendizado citados. Focaliza-se nas abordagens supervisionadas e semi-supevisionadas, uma vez que essas vêm constantemente apresentando melhores resultados nas edições do Senseval e são particularmente mais apropriadas para aplicações multilíngues.

\subsubsection{Abordagens supervisionadas}

O primeiro trabalho de DLS baseada em córpus supervisionado de que se tem conhecimento é o de Black (1988), que desenvolveu um modelo utilizando árvores de decisão, criadas manualmente, simulando um processamento automático similar ao do algoritmo C4.5. O trabalho cobre cinco substantivos (interest, point, power, state e terms), cada um descrito por meio de 2.000 sentenças de exemplo manualmente etiquetadas com seus sentidos, divididas em 1.500 exemplos para treinamento e 500 para teste.

O objetivo era testar três configurações de atributos para a desambiguação. Cada configuração consiste de 81 atributos contextuais, determinados de maneira diferente para palavra de teste, e descritos por valores binários de acordo com sua presença ou ausência na sentença.

Na primeira configuração, de domínio geral, os 81 atributos para cada palavra são obtidos a partir das 500 palavras mais freqüentes em todos os exemplos daquela palavra, organizadas de acordo com o seu código de área no LDOCE. As outras duas configurações são de domínio específico. A segunda é baseada nas freqüências dos itens lexicais dos 1.500 exemplos de treinamento de cada palavra. Os atributos são as 41 palavras mais freqüentes em uma janela de duas palavras ao redor do substantivo ambíguo e as 40 palavras mais freqüentes nos exemplos, em qualquer posição. Na terceira configuração, 20 atributos são obtidos com base nas freqüências dos itens lexicais dos exemplos de treinamento, enquanto que os outros 61 são derivados de outras 100 sentenças do córpus que não incluem as cinco palavras de 
teste. O conteúdo dessas sentenças foi manualmente analisado para identificar as possíveis categorias temáticas presentes no córpus (por exemplo,document, energy, powerful_people).

Uma árvore de decisão para cada uma das configurações e cada uma das palavras ambíguas foi criada. Para verificar a acurácia de cada configuração, as três árvores para cada palavra foram testadas nos seus respectivos exemplos de teste. A acurácia média obtida (para todas as palavras) foi de $47 \%$ para primeira configuração, $72 \%$ para a segunda, $75 \%$ para a terceira. Segundo o autor, esses resultados mostram que os atributos contextuais que determinam as principais decisões nas árvores são aqueles relacionados à estrutura e ao conteúdo temático da palavra ambígua.

Num dos primeiros trabalhos que utiliza aprendizado de máquina automatizado, $\mathrm{Ng} \&$ Lee (1996), exploram um algoritmo baseado em instâncias e atributos de diversos tipos: categorias gramaticais das palavras vizinhas, traços morfológicos, co-ocorrência de palavras vizinhas não ordenadas, colocações e relações sintáticas verbo-objeto. O sistema implementado provê a etiquetação de sentidos para todas as palavras de conteúdo de sentenças, com base nos sentidos da WordNet. O algoritmo empregado é do tipo k-NN e permite a atribuição de pesos para os exemplos e atributos. Assim, novos casos são etiquetados de acordo com a sua similaridade com exemplos de treinamento, já anotados.

A abordagem é avaliada no conjunto de teste definido por Bruce \& Wiebe (1994), que contém 2.369 sentenças com ocorrências da palavra interest, etiquetadas com os sentidos do LDOCE. Uma precisão média de $87.4 \%$ foi obtida. Dado o mesmo conjunto de teste, outros experimentos foram realizados para analisar a contribuição de cada tipo de informação empregado. A maior precisão $(80.2 \%)$ de atributos isolados foi obtida com o uso de colocações.

Para uma avaliação mais substancial, $\mathrm{Ng} \&$ Lee construíram, manualmente, o córpus DSO (Ng \& Lee, 1996) (Seção 4.1). Dois testes com subconjuntos desse córpus de tamanhos diferentes foram realizados. O córpus com uma quantidade maior de exemplos apresentou acurácia superior ( $68.6 \%$ contra $54 \%$ ), indicando que o algoritmo baseado em instâncias tende a apresentar um desempenho significativamente maior com o aumento do número de exemplos. Esses resultados superaram a baseline de escolha pelo sentido mais freqüente em ambos os testes $(63 \%$ e $47.1 \%)$.

Com um exemplo de uso do paradigma conexionista, a abordagem de Towell \& Voorhees (1998) utiliza redes neurais para aprender um modelo de classificação. São 
empregadas duas redes que consideram características distintas: o contexto local e o contexto global. Um classificador final combina as saídas das duas redes.

O contexto global é constituído de substantivos que co-ocorrerem com determinados sentidos da palavra ambígua com uma probabilidade acima de um threshold. O contexto local inclui informações sobre a ordem e distâncias das palavras com relação à palavra ambígua e suas relações sintática, considerando-se todas as palavras na sentença.

Diferentemente da rede neural de Véronis \& Ide (Seção 3.2.2), nesse trabalho a rede é alimentada com exemplos anotados. É utilizado, para tanto, um córpus anotado com o mesmo número de exemplos para cada sentido de uma dada palavra ambígua, visando minimizar os efeitos da freqüência de cada sentido.

A abordagem foi testada em três palavras ambíguas de três classes gramaticais distintas (verbo, substantivo e adjetivo) para avaliar o desempenho individual de cada rede, bem como o desempenho da combinação de ambas, com base em diferentes números de exemplos de treinamento. A maior acurácia foi obtida com a combinação das redes, com o maior número de exemplos possível: $87 \%, 90 \%$ e $81 \%$, respectivamente, para as três palavras. Um problema decorrente do uso de redes neurais para o aprendizado é a necessidade de um grande número de exemplos etiquetados para o treinamento do sistema

A abordagem de Wilks \& Stevenson (Wilks \& Stevenson, 1998; Stevenson \& Wilks, 1999; 2000; 2001) procura combinar diversas fontes de conhecimento utilizando algoritmos de aprendizado de máquina para a DLS do inglês. A desambiguação é realizada com base nos sentidos do LDOCE e contempla todas as palavras de conteúdo. Além de uma fase de préprocessamento, as diversas versões da abordagem empregam um filtro que elimina alguns dos possíveis sentidos de cada palavra ambígua, e diversos etiquetadores parciais, que sugerem alguns sentidos para tal palavra. Esses processos são realizados isoladamente, de maneira independente. O resultado de todos os processos é um conjunto reduzido de possíveis sentidos para cada palavra ambígua, incluindo todos os sugeridos pelos etiquetadores parciais, exceto os eliminados pelos filtros, em um determinado contexto. Esse contexto é indicado por 10 palavras na vizinhança da palavra ambígua na sentença, em determinadas posições relativas e com determinadas etiquetas gramaticais, ou seja, 10 colocações. Em seguida, é utilizado um algoritmo de AM para classificar cada sentido desse conjunto como "apropriado" ou "nãoapropriado".

Todas as versões da abordagem empregam praticamente as mesmas fontes de conhecimento, a partir dos mesmos filtros e etiquetadores. As variações dizem respeito 
principalmente ao algoritmo de aprendizado empregado e à configuração dos testes realizados. A descrição a seguir é baseada principalmente em Stevenson \& Wilks (2000).

No pré-processamento dos textos a serem desambiguados, é realizada a etiquetação gramatical das palavras, por meio do etiquetador Brill (Brill, 1992), e a identificação de nomes de entidades, por meio do sistema LaSIE (Gaizauskas et al., 1996). Esse último recurso é empregado para identificar nomes próprios (pessoas, lugares, etc.), que não precisarão, portanto, ser desambiguados. Essa informação será também utilizada em um dos etiquetadores parciais.

O primeiro processo aplicado sobre os dados pré-processados é um filtro baseado na etiqueta gramatical das palavras. As etiquetas identificadas pelo Brill são, primeiramente, manualmente mapeadas em etiquetas do LDOCE, que são mais genéricas (17 etiquetas). Todos os sentidos cuja categoria gramatical não corresponde à categoria retornada para a palavra na sentença são, então, eliminados. Para minimizar a influência de erros de etiquetação gramatical, nos casos mais graves, nos quais nenhum dos possíveis sentidos de uma palavra tem a etiqueta gramatical associada a ela na sentença, todas as etiquetas possíveis são mantidas.

O segundo processo é um etiquetador parcial baseado na identificação de sobreposições nas definições textuais do dicionário LDOCE dos sentidos da palavra a ser desambiguada e dos sentidos das suas palavras vizinhas na sentença, conforme mencionado anteriormente (Wilks \& Stevenson, 1997b). Para minimizar o esforço computacional exigido para testar as várias combinações entre as definições, os autores utilizam o algoritmo de otimização de Cowie et al. (1992), que elimina a necessidade certas combinações de sentidos.

O terceiro processo utiliza códigos de área do LDOCE. Diferentemente de Guthrie et al (1991), Stevenson \& Wilks utilizam ambos os níveis dos códigos de área. O processo consiste da identificação da sobreposição dos códigos de área (nos dois níveis) dos possíveis sentidos da palavra a ser desambiguada com os códigos de área das suas palavras vizinhas. A vizinhança considerada inclui todo o parágrafo, e não apenas a sentença, como na sobreposição de definições. Também é utilizado, aqui, um algoritmo de otimização para minimizar o número de testes de combinações.

O quarto processo utiliza restrições de seleção, com base em informações também contidas no LDOCE. Cada sentido de uma palavra de conteúdo apresenta, nesse dicionário, traços semânticos e/ou restrições de seleção simples, como H (humano), M (humano masculino), P (planta) e S (sólido). Ao todo, são usadas 35 classes semânticas no dicionário. Os sentidos de um substantivo apresentam subconjuntos desses traços. Os sentidos de 
advérbios, adjetivos e verbos, por sua vez, apresentam a lista dos traços que eles exigem nos substantivos que eles modificam ou que os complementam. Para utilizar as restrições é necessário, portanto, identificar relações sintáticas superficiais entre verbos, adjetivos e advérbios e os substantivos que são o núcleo dos seus argumentos. Isso é feito por meio de um analisador sintático.

Além das classes semânticas, o processo de resolução das restrições de seleção faz uso das informações provenientes do identificador de nomes de entidades, obtidas no préprocessamento. Elas podem ajudar a desambiguar as outras palavras na sentença. Por exemplo, se um dos possíveis sentidos de verbo ambíguo exige um objeto com o traço “humano" e o objeto, na sentença, é um nome próprio de pessoa, o sistema seleciona esse sentido como mais apropriado.

O último etiquetador parcial do sistema considera um contexto mais amplo para desambiguar cada palavra. Para tanto, são selecionadas 50 palavras de cada lado da palavra ambígua e é utilizado um modelo estatístico dos códigos de área primários dessas palavras no LDOCE. Esse modelo estatístico é similar ao modelo bayesiano e visa estimar a probabilidade de um determinado código de área predominar, num determinado contexto, dados os códigos de área de todas as palavras nesse contexto (que consiste das 100 palavras vizinhas da palavra ambígua). Definido o código de área predominante para cada palavra ambígua, são selecionados como candidatos todos os sentidos que apresentam, no LDOCE, aquele código.

Como resultado, são obtidos os diferentes conjuntos de sentidos "sugeridos" pelo filtro e pelos etiquetadores parciais para cada palavra, juntamente com exemplos do seu uso em um contexto formado pelas 10 colocações (primeiro substantivo, primeiro verbo e primeira preposição da direita e da esquerda, e primeira e segunda palavras da direita e da esquerda). Os algoritmos de aprendizado empregados nos diferentes trabalhos são todos supervisionados, mas variam no que diz respeito ao paradigma de aprendizado: simbólico (listas de decisão) e baseado em instâncias.

Em Wilks \& Stevenson (1998), os autores empregam listas de decisão. Em testes realizados com o córpus SemCor, é reportada uma acurácia de $83.4 \%$ na identificação dos sentidos para todas as palavras ambíguas. O nível de refinamento dos sentidos é apresentado pelo LDOCE, menos refinado que o nível da WordNet. Os autores apresentam também os resultados da mesma avaliação combinando todos os filtros e etiquetadores parciais por meio de um sistema de votação simples, sem a utilização do algoritmo de aprendizado de máquina. Esse teste resultou em $59 \%$ de acurácia. Com isso, eles concluem que há um benefício 
considerável na utilização do aprendizado de máquina na tentativa de otimizar a combinação entre as diversas evidências de desambiguação.

Em Stevenson \& Wilks (1999; 2000; 2001), os autores empregam um algoritmo baseado em instâncias, denominado TiMBL (Daelemans et al., 1998). Na avaliação descrita em Stevenson \& Wilks (2000), por exemplo, considerando o córpus SemCor e um mapeamento entre os seus sentidos e os do LDOCE, cada processo (filtros e etiquetadores parciais) apresenta, isoladamente, uma acurácia na desambiguação de sentido que varia entre $44 \%$ e $79 \%$. Com a integração dos resultados dos processos, utilizando o algoritmo de AM, essa acurácia chega a $90 \%$ para a desambiguação com um nível refinado de distinção de sentidos e $94 \%$ para a desambiguação no nível de homonímia. Essa abordagem é especialmente importante para esse trabalho, uma vez que visa à combinação de diversas fontes de conhecimento e técnicas de aprendizado de máquina. Conforme será descrito no Capítulo 5, muitas das fontes utilizadas por Stevenson \& Wilks são também implementadas na abordagem de DLS proposta nesta tese.

Paliouras et al. (1999) empregam um algoritmo de aprendizado simbólico de árvores de decisão (C4.5) para a DLS, visando obter modelo capaz de desambiguar todas as palavras de conteúdo de um texto, voltado para a Extração de Informações. Um subconjunto do SemCor, constituído apenas por artigos de notícias financeiras, é utilizado para o treinamento, com suas etiquetas de sentido convertidas em etiquetas do LDOCE, usadas no sistema de Extração de Informações. São utilizados apenas atributos locais, incluindo o lema da palavra ambígua, o escore de freqüência do sentido no LDOCE, a etiqueta gramatical da palavra ambígua e 10 colocações. A palavra ambígua é representada como característica porque os autores pretendem analisar se é possível usar o mesmo modelo para todas as palavras.

O sistema foi avaliado com base em textos do SemCor do mesmo domínio, com os sentidos igualmente mapeados para as etiquetas do LDOCE. Foram considerados apenas verbos e substantivos. Para os verbos, a precisão obtida foi de $71.6 \%$ e a cobertura, de $66.2 \%$. Para os substantivos, a precisão foi de $58.5 \%$ e cobertura, de $39.7 \%$.

Considerando o paradigma simbólico, motivados pelos resultados encorajadores da abordagem baseada em listas de decisão que obteve o primeiro lugar na competição Senseval1, Agirre \& Martínez (2000) empregam essa técnica para a DLS considerando os sentidos refinados da WordNet e o método supervisionado de aprendizado. Atributos locais e globais 
tradicionalmente utilizados são empregados (bigramas, trigramas, etiquetas gramaticais, bagof-words, com diferentes tamanhos de janelas), juntamente com novos atributos como o synset e a categoria semântica das palavras no contexto da palavra ambígua, disponíveis no SemCor.

Para o treinamento e teste do modelo foram utilizados os córpus SemCor e DSO. Em ambos os córpus, os resultados da avaliação indicaram uma precisão de cerca de 70\%. Em um experimento com sentidos menos refinados (as classes semânticas da WordNet), o sistema obteve $83 \%$ de precisão nos dois córpus. A cobertura do modelo, em ambos os casos, foi maior que $90 \%$.

Visando aperfeiçoar a técnica de listas de decisão planas (descrita em Yarowsky, 1995 - Seção 3.3.2), Yarowsky (2000) propõe o uso de listas hierárquicas. A diferença das listas hierárquicas com relação às planas é que elas permitem ramificações condicionais, de modo a dividir o fluxo de controle do processo de decisão em caminhos especializados relativamente independentes para modelar as necessidades de cada parte da divisão. Isso é feito também nas árvores / regras de decisão, contudo, nas árvores / regras de decisão a ramificação ocorre em muitos atributos, o que pode levar, segundo o autor, a uma fragmentação desnecessária nos exemplos. Por essa razão, o seu mecanismo de listas de decisão hierárquicas prevê a especificação dos atributos nos quais deve ocorrer um particionamento dos exemplos, de acordo com os valores para tais atributos.

A proposta foi avaliada nos exemplos da tarefa Lexical Sample do Senseval-2, com base em cinco atributos: a categoria gramatical da palavra ambígua, informações morfológicas da palavra ambígua, expressões idiomáticas, traços sintáticos e, por fim, subsentidos, quando um sentido apresentava uma estrutura de sentidos gerais e mais específicos. Entre todos os candidatos, essa proposta foi a que apresentou a melhor precisão (78.9\%). Sob a mesma configuração de teste, a abordagem de listas de decisão planas obteve resultados $8 \%$ menos precisos.

Escudero et al. (2000b) propõem o uso do algoritmo de boosting AdaBoost (Freund \& Schapire, 1996) para a DLS. Algoritmos de boosting, de modo geral, procuram combinar um número grande de hipóteses simples e com acurácia moderada (geradas por classificadores fracos) em uma única hipótese com uma acurácia alta. Os classificadores fracos são treinados seqüencialmente e, assim, a cada iteração a hipótese fraca aprendida (na forma de regra) tende 
a cobrir exemplos mais difíceis de classificar pelas hipóteses anteriores. As hipóteses fracas aprendidas são combinadas linearmente para formar a hipótese final.

O algoritmo foi avaliado na seguinte configuração: 15 verbos e substantivos, com 373 a 1.500 exemplos por palavra extraídos do córpus DSO, e sete palavras vizinhas como atributos. Além da versão padrão do algoritmo, foi considerada uma variação na qual o critério de parada é otimizado para evitar o superajuste das hipóteses aos exemplos de treinamento (overfitting). Os resultados da avaliação mostraram que as duas variações do algoritmo de boosting apresentam uma acurácia melhor na desambiguação de 14 das 15 palavras, se comparada à de dois trabalhos anteriores dos autores: ambas obtiveram 68\% de acurácia, contra 66\%, em média, dos outros dois trabalhos (Seção 3.3.1.1).

Segundo os autores, o algoritmo AdaBoost é bastante adequado para a tarefa de DLS, contudo, é computacionalmente complexo, em função da alta dimensionalidade do espaço de atributos que é explorado pelos classificadores fracos. Por essa razão, os autores propõem uma adaptação do método, utilizando uma técnica denominada LazyBoosting, que reduz o número de atributos que são examinados em cada iteração do algoritmo. Quando avaliada na configuração descrita acima, a acurácia média obtida por essa variação foi de $69.5 \%$.

Uma nova versão do algoritmo LazyBoosting também foi avaliada na competição Senseval-2 (Escudero et al., 2001). Nessa versão foram incluídos outros atributos locais e um atributo para identificar o domínio. O algoritmo obteve $59.4 \%$ e $67.1 \%$ de acurácia, considerando, respectivamente, sentidos mais refinados e mais genéricos.

Em um contexto multilíngue, o trabalho de Zinovjeva (2000) emprega o método de aprendizado por transformações (TBL - Transformation Based Learning) (Brill, 1995) para aprender automaticamente regras para traduzir palavras ambíguas do inglês para o sueco.

$\mathrm{O}$ córpus de treinamento foi criado a partir da etiquetação manual de determinados verbos e substantivos ambíguos em sentenças do BNC com suas traduções. Foram realizados experimentos considerando-se diferentes tipos de informação como atributos. No primeiro experimento são utilizadas apenas as palavras vizinhas à palavra ambígua na sentença. São gerados modelos para três palavras, dois substantivos e um verbo, a partir de um córpus de 4.800 ocorrências de cada substantivo e 780 ocorrências do verbo. A precisão obtida para cada palavra foi de $92.1 \%, 95.2 \%$ e $73.1 \%$. O segundo experimento considera as categorias gramaticais das palavras no contexto da palavra ambígua. A precisão obtida aumentou para $93.6 \%, 95.4 \%$ e $80.8 \%$. O terceiro experimento considera as relações sintáticas das palavras do contexto da palavra ambígua. Apenas o modelo para o verbo é gerado, a partir de 78 das 
suas ocorrências. A precisão obtida foi de 83.3\%. O quarto experimento considera a combinação das etiquetas gramaticais e relações sintáticas. Novamente, apenas o modelo para o verbo, com 78 das suas ocorrências, é gerado. A precisão obtida foi de $84.6 \%$.

Como as regras geradas são simbólicas, a cada experimento, em uma etapa subsequiente, elas foram ajustadas manualmente e uma nova avaliação com a mesma configuração de teste foi realizada. Em todos os casos, a avaliação considerando os ajustes levou a acurácias superiores.

O trabalho de Zinovjeva é bastante relacionado à abordagem proposta neste trabalho, uma vez que é voltado especificamente para a TA e considera o aprendizado de máquina simbólico para a geração de modelos específicos para cada palavra. Contudo, a desambiguação é realizada com base somente em informações sobre as palavras na línguafonte. Além disso, uma quantidade bastante limitada de informações é utilizada como atributos.

Lee (2002) propõe uma abordagem de DLS voltada para a TA do inglês para o coreano. O sistema de TA segue o método direto de tradução por palavras, empregando técnicas estatísticas para a seleção lexical a partir de córpus paralelos e dicionários bilíngües.

Para a DLS, com base em um conjunto de 689 documentos manualmente traduzidos do inglês para o coreano e manualmente alinhados por palavras, é criado um dicionário de tradução para cada palavra da língua-fonte, que consiste de todas as suas possíveis traduções na língua-alvo, extraídas do córpus. As possíveis traduções são, então, consideradas como sentidos e o algoritmo de aprendizado SNoW (Sparse Network of Winnows) (Carlson et al., 1999) é utilizado para induzir modelos de DLS na forma de redes de funções lineares. São usadas como características colocações correspondendo a todas as combinações de palavras (tomadas de duas a duas) na sentença a ser traduzida.

O sistema foi avaliado em 121 substantivos ambíguos que possuem mais de 50 exemplos no córpus. A precisão média obtida foi de $57.46 \%$, superior à precisão do classificador Naive Bayes (47.49\%) no mesmo conjunto de exemplos. O sistema foi também avaliado nos substantivos coincidentes no conjunto de teste do Senseval-2. Para tanto, os resultados da DLS desses substantivos foram manualmente mapeados para os sentidos monolíngues do Senseval. Os resultados obtidos foram muito próximos aos da baseline do sentido mais freqüente.

Uma observação interessante é que, ao tentar relacionar as possíveis traduções das palavras do seu córpus com os sentidos do Senseval, o autor relata que não há correlação 
direta entre o número de sentidos monolíngues e o número de possíveis traduções para outra língua. Por exemplo, a palavra day possui sete possíveis sentidos no Senseval e 12 possíveis traduções para o coreano.

Também no contexto da TA, Dihn et al. (2003) propõe um sistema híbrido de tradução do inglês para o vietnamita que possui um módulo específico para a DLS. Parte do sistema é constituída de regras manualmente criadas e outra parte, de regras aprendidas a partir de córpus, com base no aprendizado baseado em transformações (Transformation Based Learning) (Brill, 1995). As regras do módulo de DLS são geradas a partir de um córpus de exemplos extraídos de textos paralelos entre as duas línguas por meio do alinhamento automático das palavras, seguido de revisão manual. Os atributos para o aprendizado consistem de n-gramas (de uma a quatro palavras), etiquetas gramaticais e relações sintáticas. Além disso, o algoritmo considera as etiquetas já atribuídas às palavras vizinhas na sentença, ou seja, as palavras já traduzidas. Isso é possível porque todas as palavras estão etiquetadas com a tradução correspondente no córpus de exemplos. Não são reportados resultados da avaliação do módulo de DLS, tampouco sobre a influência desse módulo no desempenho do sistema de TA.

Decadt et al. (2004) utilizam uma abordagem em cascata para a DLS, com classificadores baseados em casos utilizando as classes resultantes de outros classificadores como entrada. Em ambos os casos, o algoritmo TiMBL é utilizado para construir classificadores dedicados para cada palavra. O primeiro classificador é treinado com base em atributos do tipo bag-of-words que ocorrem um número mínimo de vezes e com uma probabilidade mínima para cada sentido. O sentido previsto como saída desse classificador é utilizado, juntamente com atributos locais (colocações, categorias gramaticais e relações sintáticas), como atributo para um segundo classificador. Os parâmetros do primeiro classificador são empiricamente determinados a partir de testes com diversos valores. Os parâmetros do segundo classificador são otimizados utilizando-se um algoritmo genético. Esse algoritmo também realiza a seleção de atributos relevantes.

O sistema obteve o primeiro lugar na tarefa All Words da competição Senseval-3, com $65.2 \%$ de acurácia, contra $60.9 \%$ da baseline do sentido mais freqüente, e $62 \%$ de acurácia do mesmo classificador, TiMBL, sem a otimização de parâmetros pelo algoritmo genético. Já na tarefa Lexical Sample da mesma competição, o sistema obteve o $18^{\circ}$ lugar, com $67.4 \%$ de acurácia, contra $72.9 \%$ do melhor sistema, $55.2 \%$ da baseline do sentido mais freqüente, e 
$60.8 \%$ do algoritmo TiMBL sem otimização de parâmetros. Neste caso, um nível foi adicionado à cascata: o primeiro classificador foi treinado com os atributos bag-of-words em um córpus maior, incluindo o SemCor e edições prévias do Senseval. As predições de tal classificador foram utilizadas como entrada para um classificador intermediário, treinado no mesmo córpus, juntamente com os atributos locais. Por fim, o último classificador foi treinado nos dados da competição, com as predições dos dois primeiros classificadores, bem como os atributos locais. Esse nível adicional da cascata pode ter acrescentado ruídos ao processo.

Cai et al. (2007a) propõem uma abordagem para explorar o contexto global, na forma de atributos de tópico, para a DLS. Os atributos são construídos por meio da técnica Latent Dirichlet Allocation (LDA) (Blei et al., 2003) e incorporados a uma rede bayesiana, juntamente com atributos locais: etiquetas gramaticais, bag-of-words, colocações e padrões sintáticos.

LDA é um modelo probabilístico geralmente utilizado para a classificação de textos. Dado um córpus com vários documentos, a LDA modela cada documento utilizando tópicos, os quais são caracterizados como distribuições de palavras. A idéia de utilizar essa técnica é diminuir a esparsidade dos atributos, em especial, daqueles do tipo bag-of-words, que representam o contexto global. Para tanto, utilizando LDA, um modelo de tópico é treinado em exemplos não etiquetados para a construção dos atributos de tópico, agrupando as palavras que ocorrem naquele córpus de acordo com um determinado número de tópicos. Mais especificamente, o algoritmo LDA é utilizado para obter os parâmetros que representam a probabilidade de uma dada palavra ser igual à outra em um dado tópico. O modelo de tópico resultante é então utilizado para anotar as bag-of-words no córpus de exemplos com suas distribuições de tópico. Os atributos de tópico são então incorporados à rede bayesiana.

Em experimentos com os exemplos da tarefa Lexical Sample do Senseval-3, o sistema obteve $73.6 \%$ de acurácia, contra $69.8 \%$ da mesma abordagem sem o uso dos atributos de tópico, e 72.9\% do melhor sistema na competição. Na tarefa Lexical Sample do Senseval-2, o sistema obteve $68.9 \%$ de acurácia, contra $63.4 \%$ da mesma abordagem sem o uso dos atributos de tópico, e $64.2 \%$ do melhor sistema na competição. Os autores também mostram que um classificador SVM com o atributo de tópico atinge acurácias comparáveis. Na tarefa All Words do Senseval-3, o sistema obteve $66.1 \%$ de acurácia, contra $64.6 \%$ da mesma abordagem sem o uso dos atributos de tópico, e $65.2 \%$ do melhor sistema na competição. $\mathrm{Na}$ tarefa All Words do Senseval-2, o sistema obteve $66.3 \%$ de acurácia, contra $63.7 \%$ da mesma abordagem sem o uso dos atributos de tópico, e $63.6 \%$ do melhor sistema na competição. Por 
fim, os autores participam da competição SemEval (Cai et al., 2007b), obtendo o primeiro lugar na tarefa Lexical Sample (88.7\% de acurácia), o quarto lugar na tarefa fine-grained All Words, com $57.6 \%$, contra $59.1 \%$ do melhor sistema e $51.4 \%$ da baseline do sentido mais freqüente, e o segundo lugar na tarefa coarse-grained All Words, com $81.6 \%$ de acurácia, contra $82.5 \%$ do primeiro colocado e $78.9 \%$ da baseline do sentido mais freqüente. Um modelo de tópico similar para a DLS, também baseado na LDA, é proposto em (Boyd-Graber et al., 2007).

\subsubsection{Comparações entre trabalhos}

Na tentativa de comparar sistematicamente o desempenho de diferentes abordagens, alguns autores repetem experimentos com tais abordagens, analisando-as sob as mesmas condições de treinamento e teste, com variações no que diz respeito a algoritmos de aprendizado, fontes de conhecimento, etc. Mooney (1996), por exemplo, realiza experimentos de avaliação comparativa com sete algoritmos de diferentes paradigmas de aprendizado supervisionado: estatístico (Naive Bayes), conexionista (perceptrons), baseado em instâncias (k-NN) e simbólico (C4.5, listas de decisão, DNF - Disjunctive Normal Form e CNF - Conjuctive Normal Form).

Os algoritmos foram testados para a desambiguação da palavra line e os seus 6 sentidos na WordNet. Para tanto, foram coletados 1.200 exemplos de treinamento e 894 casos de teste. Os atributos empregados são todas as palavras da sentença ambígua e as palavras da sentença anterior no córpus, sem considerar sua ordenação. Os resultados mostraram que o algoritmo Naive Bayes apresenta a melhor acurácia, seguido dos algoritmos de redes neurais, listas de decisão e C4.5.

O bom desempenho do classificador Naive Bayes sob as condições simples de teste é confirmado em trabalhos posteriores, por exemplo, Ng \& Zelle (1997). Contudo, como apontado por $\mathrm{Ng}$ (1997a), a configuração de teste usada por Mooney é limitada: apenas uma palavra ambígua, poucos exemplos e somente bag-of-words ${ }^{17}$ como atributos. Além disso, não foram exploradas configurações mais adequadas nos parâmetros dos algoritmos. Por exemplo, o algoritmo k-NN foi testado para analisar a semelhança com apenas três vizinhos $(k$ = 3). Como mostram Escudero et al. (2000b), valores maiores desse parâmetro tendem a apresentar resultados melhores.

\footnotetext{
${ }^{17}$ Conjunto (de quantidades variadas) de palavras que circundam a palavra a ser desambiguada, sem considerar a sua ordenação.
} 
$\mathrm{Ng}$ (1997a) procura aperfeiçoar um trabalho anterior baseado em instâncias (Ng \& Lee, 1996) para então compará-lo ao classificador Naive Bayes. Um procedimento de validação cruzada sobre os exemplos de treinamento é utilizado para determinar o melhor valor $k$ para os vizinhos mais próximos como parâmetro em um algoritmo do tipo k-NN. Os resultados de diversos testes apontaram para um valor de $k$ maior que 1 , que é o valor freqüentemente usado.

Para a avaliação da abordagem são utilizados dois subconjuntos do córpus DSO e colocações como atributos, já que esses se mostraram os atributos individuais mais importantes na avaliação da abordagem anterior. Os resultados da avaliação mostraram que a determinação automática do parâmetro $k$ melhora a acurácia da desambiguação $(75.2 \%$ e $58.7 \%$ nos dois conjuntos, contra os $68.6 \%$ e $54 \%$ apresentados na proposta anterior). Com essa configuração, o algoritmo k-NN utilizado apresentou uma acurácia similar à do Naive Bayes (74.5\% e $58.2 \%)$.

Escudero et al. (2000a) também comparam o algoritmo Naive Bayes a um algoritmo da família k-NN, considerando diferentes configurações nos parâmetros desse algoritmo, como a atribuição de pesos aos exemplos e/ou aos atributos e diferentes métricas de similaridade.

Os testes foram realizados para 15 verbos e substantivos ambíguos. Para cada palavra foram coletados todos os exemplos do córpus DSO (373 a 1.500 exemplos por palavra). Sete palavras vizinhas à palavra ambígua foram usadas como atributos. Foram criados dois conjuntos com diferentes variações nesses atributos, de modo a avaliar o comportamento dos algoritmos mediante o aumento do número de atributos.

Os resultados mostraram que o algoritmo baseado em instâncias (com a atribuição de pesos) apresenta uma acurácia superior a do Naive Bayes, em ambos os conjuntos de características. Além disso, somente o algoritmo baseado em instâncias obteve uma melhora na sua acurácia com o aumento do conjunto de características.

Escudero et al., (2000c) comparam a acurácia do seu algoritmo LazyBoosting (Escudero et al., 2000b) a outros quatro algoritmos supervisionados: Naive Bayes, k-NN, listas de decisão e SNoW (Sparse Network of Winnows) (Carlson et al., 1999).

Os algoritmos foram testados em um subconjunto de 21 palavras altamente ambíguas do córpus DSO, com 1.000 exemplos para cada palavra. Foram utilizadas 15 atributos locais (palavras de conteúdo vizinhas em determinadas posições e etiquetas gramaticais de algumas 
dessas palavras) e globais (todas as palavras da sentença). Em sete testes com diferentes combinações dos conjuntos de treinamento e teste, os resultados da avaliação mostraram que o algoritmo LazyBoosting supera todos os demais, com uma acurácia média de 62\%, enquanto que o algoritmo Naive Bayes, na última colocação, obteve uma acurácia média de $56.6 \%$.

Pedersen (2002a) compara classificadores estatísticos (Naive Bayes) e simbólicos (árvores de decisão - C4.5), para verificar a utilidade do uso de atributos lexicais simples, extraídos dos exemplos de treinamento, para a desambiguação. São consideradas todas as palavras do contexto (bag-of-words) e todas as possíveis bigramas e co-ocorrências como atributos.

As variações nos experimentos realizados incluem classificadores Naive Bayes individuais, cada um com um dos três tipos de atributos, o bagging de uma árvore de decisão considerando somente bigramas, e uma combinação (ensemble) do bagging de três árvores de decisão, cada uma utilizando um dos três tipos de atributos. A técnica de bagging simula uma combinação de classificadores: o conjunto de exemplos de treinamento é dividido em 10 amostras, sendo que uma árvore de decisão é aprendida para cada uma das amostras e o sentido atribuído é aquele indicado pela maioria das 10 árvores geradas. O uso dessa técnica permite para minimizar a instabilidade e alta variância dos modelos baseados em árvores de decisão

As abordagens foram avaliadas nos dados do Senseval-2 para o inglês e o espanhol. Os melhores resultados foram obtidos pela combinação do bagging de três árvores de decisão: acurácia de $54 \%$ para o espanhol e de $60 \%$ para o inglês. Esses resultados estão entre $7 \%$ e $10 \%$ abaixo dos sistemas que atingiram os melhores escores na competição. Segundo os autores, isso mostra o potencial de atributos lexicais superficiais para a DLS.

Paliouras et al. (2000) confrontam o desempenho da sua abordagem simbólica (Paliouras et al., 1999) com o desempenho de outros algoritmos supervisionados disponíveis no ambiente de aprendizado de máquina $\mathrm{Weka}^{18}$, de três paradigmas de aprendizado: simbólico (C4.5 e C4.5rules), estatístico (Naive Bayes) e baseado em instâncias (k-NN e tabelas de decisões).

A avaliação realizada mostrou que os algoritmos do paradigma simbólico apresentam resultados superiores, seguidos do algoritmo Naive Bayes e, por fim, dos dois algoritmos

\footnotetext{
${ }^{18}$ http://www.cs.waikato.ac.nz/ ml/weka/
} 
baseados em instâncias. Em primeiro lugar ficou o algoritmo C4.5, com 77.4\% de cobertura e $82.6 \%$ de precisão. Em último, o k-NN, com 49\% de cobertura e $66.3 \%$ de precisão. Segundo os autores, os algoritmos simbólicos apresentaram um desempenho melhor que os demais em função da grande quantidade de valores distintos que cada atributo pode ter. Essa característica favorece os algoritmos que são capazes de realizar uma seleção e ordenação de atributos de maneira mais flexível, como é o caso das árvores de decisão.

Lee \& Ng (2002) apresentam uma avaliação comparativa de quatro algoritmos de aprendizado para DLS e quatro fontes de conhecimento. O objetivo é analisar a contribuição de cada fonte nos diferentes algoritmos e a viabilidade do uso de um método de seleção automática de características para o treinamento.

As fontes de conhecimento utilizadas são a categoria gramatical da palavra ambígua e de três palavras vizinhas a ela, todas as palavras vizinhas à palavra ambígua na sentença, colocações e relações sintáticas. Para todos os atributos binários, os algoritmos foram testados com e sem o uso de um método para a seleção de atributos: um parâmetro configurado com o valor "3" que determina a quantidade mínima de vezes que o atributo deve ocorrer nos exemplos de treinamento para que ele seja utilizado. Foram utilizados os algoritmos SVM, AdaBoost, Naive Bayes e C4.5, todos disponíveis no ambiente Weka, com os valores padrão dos seus parâmetros.

Tais algoritmos foram testados com os conjuntos de exemplos do Senseval-1 e Senseval-2. Os algoritmos foram testados utilizando cada uma das fontes de conhecimento individualmente, com e sem o método de seleção de atributos, e com todas as fontes de conhecimento combinadas. Em todos os classificadores, a melhor acurácia foi obtida com a combinação de todas as fontes de conhecimento, com o uso do método de seleção de atributos. Entre os classificadores, o SVM apresentou a maior acurácia (79.2\% e 65.4\%, nos dois exercícios). Essa acurácia é maior que a obtida pelos três melhores colocados nas duas edições do Senseval.

Os autores enfatizam que a contribuição relativa de cada fonte de conhecimento para a acurácia do trabalho depende do algoritmo utilizado. Por exemplo, colocações são os atributos que mais contribuem para o SVM, enquanto que categorias gramaticais são as mais relevantes para o Naive Bayes. 


\subsubsection{Combinações de modelos}

Além dos trabalhos já descritos que envolvem alguma forma de combinação entre hipóteses geradas por um único ou por vários classificadores (Pedersen, 2002a; Escudero et al., 2000b e Towell \& Voorhess, 1998), outras propostas mais específicas de combinações podem ser mencionadas. A idéia de combinar diferentes algoritmos de aprendizado para a DLS é motivada pelo fato de que cada algoritmo varia com relação a dois componentes principais: bias e variância. Por exemplo, algoritmos baseados em árvores de decisão constroem um modelo para representar os exemplos de treinamento e, portanto, possuem um bias baixo, mas uma variância alta (se os exemplos mudarem, uma representação totalmente distinta pode ser construída). Já algoritmos como o Naive Bayes assumem uma forma parametrizada dos exemplos de treinamento, sem construir modelos e, portanto, possuem um bias alto, mas uma variância baixa. A hipótese, portanto, é que a combinação de algoritmos com bias e variância diferentes pode levar a um desempenho superior. Outra forma de combinação diz respeito ao uso do mesmo classificador com diferentes conjuntos de atributos.

Pedersen (2000), por exemplo, propõe a combinação de vários classificadores estatísticos (Naive Bayes) em um conjunto (ensemble) de classificadores, de modo que a escolha do sentido é determinada pelo voto da maioria dos classificadores. A suposição é de que a combinação de vários classificadores estatísticos simples, empregando diferentes conjuntos de atributos, pode melhorar significativamente o desempenho da DLS.

A combinação inclui 81 classificadores simples, que consideram diferentes janelas de contexto como atributos, incluindo variações no tamanho da janela $(0,1,2,3,4,5,10,25$ ou 50 palavras) e nas configurações desse tamanho para contextos dos dois lados da palavra ambígua.

A proposta foi avaliada em dois grupos de palavras ambíguas, line e interest, considerando-se os seis possíveis sentidos distintos da WordNet para cada uma delas. A combinação de classificadores, bem como cada classificador individual, foram testados para cada palavra. Comparado ao desempenho do melhor classificador individual, o desempenho da combinação de classificadores aumentou $4 \%$ para a palavra line (de $84 \%$ para $88 \%$ ) e $3 \%$ para a palavra interest (de $86 \%$ para $89 \%$ ).

Pedersen (2002b) apresenta os resultados da avaliação de combinações (ensembles) de árvores de decisão para a desambiguação. São combinados três classificadores simbólicos simples, baseados em árvore de decisão, utilizando o algoritmo C4.5. Cada classificador 
utiliza apenas um tipo de atributo: bag-of-words, bigramas ou co-ocorrências. O objetivo é verificar se esses três atributos são complementares ou redundantes. Para tanto, foi analisado o desempenho dos três classificadores em conjunto, individualmente e em diversas combinações de dois a dois.

Os testes foram feitos com base nos conjuntos de exemplos do Senseval-1 e Senseval2. As combinações com três classificadores obtiveram resultados inferiores a apenas dois dos sistemas avaliados na competição, apresentando uma acurácia de $71.3 \%$ na primeira edição, $57.3 \%$ na segunda, ambas para a língua inglesa, e $61.2 \%$ na segunda edição para a língua espanhola.

$\mathrm{Na}$ avaliação dos classificadores individuais e das combinações de dois a dois, o autor concluiu que a acurácia do conjunto não é significativamente melhor que a acurácia dos classificadores individuais ou combinados de dois a dois. Isso mostrou que os três classificadores são, na maioria das vezes, redundantes. Nas avaliações individuais, o classificador baseado em co-ocorrências foi o que apresentou a melhor acurácia.

Florian et al. (2002) também investigam várias possibilidades de combinação dos resultados de diferentes classificadores supervisionados em um único modelo de DLS. A hipótese é que classificadores com diferentes bias de aprendizado, diferentes métodos para a seleção de atributos e diferentes tipos de atributos levam a resultados distintos que, quando combinados, podem melhorar o desempenho dos classificadores individuais.

Para verificar essa hipótese, foi primeiramente analisado o desempenho individual de seis algoritmos de classificação: Naive Bayes e Cosine estendidos (com a atribuição de pesos às características), Bayes Ratio (Gale et al., 1992c), MMVC (Mixture Maximum Variance Correction) (Cucerzan \& Yarowsky, 2002), listas de decisão e Transformation Based Learning (Brill, 1995). Os quatro primeiros algoritmos são estatísticos, enquanto os dois últimos são simbólicos.

Os algoritmos foram testados no conjunto de palavras do Senseval-2, para quatro diferentes línguas, e atributos locais e globais variados, incluindo lemas e etiquetas gramaticais de n-gramas (com duas e três palavras), colocações, relações sintáticas e bag-ofwords. Vários métodos de combinação de classificadores foram utilizados, incluindo desde a simples contagem dos votos de cada classificador até a contagem dos votos com pesos para cada classificador de acordo com seu desempenho. Esse último método levou ao melhor desempenho dos classificadores em conjunto e foi então escolhido para a combinação. 
Em todos os casos, a acurácia da combinação de classificadores (71.8\%) superou a acurácia de classificadores individuais (68.9\% para o melhor classificador). Essa acurácia também superou a obtida pelo sistema de melhor desempenho no Senseval-2 (70.3\%). Para analisar a contribuição de cada classificador para a combinação, experimentos repetidos, onde se eliminava cada classificador da combinação por vez, foram realizados. Os classificadores que mais influenciaram positivamente na combinação foram os simbólicos, primeiramente, o TBL e, na seqüência, o baseado em listas de decisão.

\subsubsection{Abordagens semi-supervisionadas}

Um dos primeiros trabalhos de DLS a utilizar algoritmos de AM, a proposta de Hearst (1991), que visa à desambiguação de substantivos, pode ser considerada de aprendizado semisupervisionado. Para aumentar o conjunto inicial de exemplos com sentidos manualmente etiquetados, esse conjunto é usado para o treinamento de um algoritmo de aprendizado supervisionado. $\mathrm{O}$ modelo gerado classifica parte dos exemplos não anotados, adicionando os exemplos "confiáveis" ao conjunto de treinamento. O processo continua até que um determinado número de exemplos seja etiquetado. A partir de então, o modelo gerado com base em todos os exemplos etiquetados é utilizado para desambiguar novos casos.

Como atributos são usadas informações morfológicas, as palavras da sentença, suas categorias gramaticais e relações sintáticas. Um método de seleção de atributos é aplicado para determinar a importância dos atributos para a distinção dos sentidos de cada palavra.

Em experimentos com quatro substantivos e quatro conjuntos de exemplos de treinamento inicialmente etiquetados com 20 a 70 exemplos por sentido de cada palavra, a acurácia média obtida, considerando-se apenas os exemplos etiquetados manualmente, foi de $80 \%$. Segundo a autora, essa acurácia aumenta de acordo com o número de exemplos etiquetados fornecidos. A autora determina que são necessárias pelo menos 10 ocorrências iniciais já desambiguadas. Já a acurácia média obtida após uma iteração do algoritmo, incorporando também os exemplos etiquetados pelo sistema ao conjunto de treinamento, foi de $83 \%$.

Esses resultados mostram, segundo a autora, que a técnica empregada, além de permitir um número pequeno de exemplos manualmente etiquetados, não leva a nenhuma degradação nos resultados. Vale notar que apenas a desambiguação entre dois sentidos homônimos foi contemplada. 
O trabalho semi-supervisionado mais representativo é provavelmente o de Yarowsky (1995). Yarowsky emprega uma proposta definida por ele anteriormente (Yarowsky, 1994), de adaptação da técnica de Listas de Decisão de Rivest (1987) para a resolução da ambigüidade lexical de sentido. A técnica de listas de decisão consiste em inicialmente processar os exemplos de treinamento para extrair os atributos, os quais recebem pesos de acordo com uma medida de verossimilhança. A lista de todos os atributos ordenados (em ordem decrescente) de acordo com seus pesos constitui a lista de decisão. Para desambiguar novos exemplos, a lista de decisão é percorrida em ordem e os atributos com o peso mais alto selecionam o sentido mais apropriado.

A abordagem de Yarowsky é fundamentada em duas teorias bastante relevantes para a área de DLS: one sense per discourse (Gale et al., 1992b) e one sense per collocation (Yarowsky, 1993). A primeira teoria foi levantada durante a realização de experimentos de DLS, quando Gale et al. observaram um forte relacionamento entre o discurso e o significado. Os autores então propuseram a hipótese que define que quando uma palavra ocorre mais de uma vez em um discurso, todas as ocorrências dessa palavra compartilham o mesmo sentido no nível da homonímia. Os autores conduziram um experimento com cinco juízes humanos em que cada juiz recebeu um conjunto de definições para nove palavras ambíguas e 82 pares de sentenças extraídas do mesmo texto com duas ocorrências de cada palavra. Eles deveriam determinar, em cada par de ocorrências, se o sentido da palavra ambígua era o mesmo ou não. Foi reportado um percentual de 0.94 de duas ocorrências da palavra ambígua no mesmo discurso terem o mesmo sentido. Essa hipótese foi avaliada por Krovetz (1998) para sentidos da WordNet nos córpus DSO e SEMCOR, com o discurso consistindo de um documento do córpus. $\mathrm{O}$ autor mostra que essa hipótese não se aplica para distinções de sentidos refinadas. Krovetz reporta $33 \%$ de ocorrências de múltiplos sentidos por discurso para palavras ambíguas, em média, em vez dos $6 \%$ relatados por Gale et al. A segunda teoria, one sense per collocation, restringe a noção de um sentido por discurso para um sentido por colocação: duas palavras dificilmente aparecem em uma mesma colocação com sentidos diferentes em um mesmo córpus. Em experimentos similares com distinções no nível de homonímia, Yarowsky reporta uma precisão de 99\%. Martínez \& Agirre (2000) avaliam o uso dessa hipótese considerando as distinções da WordNet no córpus DSO e reportam uma precisão menor que $80 \%$ em experimentos com o mesmo córpus para treinamento e teste, e menos que $70 \%$ em experimentos considerando diferentes porções do córpus para treinamento e teste.

Com base nessas duas teorias para distinções no nível de homonímia, a abordagem de Yarowsky provê mecanismos para alimentar o sistema com "sementes" (seeds) para o 
processo de desambiguação semi-supervisionada. As sementes correspondem a um pequeno conjunto de colocações, definidas como ocorrências de cada palavra a ser desambiguada juntamente com o seu contexto e a indicação do seu sentido, naquele contexto. Três estratégias para gerar colocações são testadas: (a) são usadas definições de cada sentido das palavras em um dicionário eletrônico; (b) o usuário identifica uma colocação para cada sentido da palavra ambígua; (c) o usuário escolhe o sentido adequado para colocações fornecidas pelo sistema, identificadas a partir de informações sobre a co-ocorrência da palavra ambígua com outras palavras em um córpus.

O sistema determina, portanto, entre quais sentidos a desambiguação deve ocorrer a partir dos sentidos do dicionário eletrônico ou dos sentidos indicados pelo usuário nas sementes. As sementes para cada palavra ambígua são usadas para classificar os casos do córpus que contêm tais sementes. A partir de então, o processo semi-supervisionado é disparado e continua até que a lista de decisão torne-se estável e que todas (ou uma proporção acima de um limite pré-estabelecido) as sentenças do córpus sejam classificadas. A lista ordenada resultante, na forma de um conjunto de regras simbólicas, representa o modelo de DLS.

Yarowsky avaliou seu trabalho em um conjunto de 12 palavras ambíguas, considerando a desambiguação apenas entre dois sentidos homônimos. A acurácia média obtida foi de $96 \%$. McCarthy (1997), ao tentar generalizar a abordagem para outras palavras e sentidos refinados da WordNet, reporta que a acurácia média obtida é consideravelmente menor. Em trabalhos recentes, a noção de um sentido por colocação é geralmente utilizada para complementar outras fontes de conhecimento. Por exemplo, Bordag (2006) explora essa noção para a indução de sentidos, analisando co-ocorrências entre três palavras, em vez de pares de palavras.

Park et al. (2003) propõe uma abordagem para a DLS do coreano baseada em técnicas de amostragem seletiva dos exemplos para aumentar o número de exemplos etiquetados. Os atributos usados incluem a categoria gramatical e a função sintática da palavra ambígua, palavras vizinhas e suas relações sintáticas com a palavra ambígua e a existência ou não de certas relações sintáticas na sentença.

São empregados 15 classificadores para gerar árvores de decisão, sendo que cada classificador utiliza as mesmas características, contudo, com subconjuntos distintos de exemplos de treinamento, gerados por uma técnica de amostragem aleatória com reposição e repetição. O sentido é aprendido e adicionado ao conjunto de treinamento se for indicado por 
pelo menos 10 dos classificadores. Esse processo é repetido até que todos os exemplos sejam etiquetados.

Em experimentos de avaliação com quatro substantivos ambíguos e um número entre 350 e 876 exemplos para cada um deles, a acurácia obtida pelo classificador final, com todos os exemplos rotulados, foi de $87 \%$.

Mihalcea (2004) investiga duas técnicas para o aprendizado semi-supervisionado: cotreinamento (co-training) e autotreinamento (self-training). No co-treinamento, são gerados vários classificadores treinados com base em diferentes "visões" que, neste caso, consistem de diferentes conjuntos de atributos. No autotreinamento, é gerado apenas um classificador, considerando todos os atributos. Em ambos os métodos, a cada iteração, os exemplos que são etiquetados com um alto grau de confiabilidade são adicionados ao conjunto de treinamento.

Para avaliar o co-treinamento, foram usados dois subconjuntos de atributos: atributos locais (as palavras vizinhas na sentença, a categoria gramatical da palavra ambígua das palavras vizinhas, relações sintáticas e quatro colocações) e atributos globais (10 palavras coocorrendo pelo menos três vezes com a palavra ambígua em qualquer posição na sentença). Todos os atributos foram utilizados em conjunto para avaliar o autotreinamento. Os classificadores foram construídos utilizando o algoritmo Naive Bayes.

Variações de ambas as técnicas de aprendizado foram testadas nos substantivos dos conjuntos de exemplos do Senseval-2 e num subconjunto de exemplos não etiquetados extraídos do córpus BNC. Foram definidas duas configurações de teste: a configuração ideal dos diferentes parâmetros do modelo e uma definição empírica dessa configuração. Esses parâmetros consistem do número de repetições do processo de etiquetação iterativa, número de exemplos não rotulados selecionados a cada iteração e quantidade dos exemplos cuja etiquetação com um nível aceitável de confiabilidade para ser inserida no conjunto de exemplos de treinamento. Com os parâmetros ideais, obtidos a partir de medições nos exemplos de teste, ambas as técnicas levaram a uma diminuição de $25.5 \%$ no erro da desambiguação. Já com os parâmetros empiricamente definidos a partir dos exemplos de treinamento, a redução de erro máxima foi de $9.8 \%$, alcançada por meio da combinação dos classificadores gerados pelo co-treinamento. 
Mihalcea \& Ehsanul (2004) propõe um sistema minimamente supervisionado para a DLS de todas as palavras de conteúdo, chamado SenseLearner ${ }^{19}$, de acordo com os sentidos da WordNet. Os exemplos anotados com sentidos do SemCor são utilizados para a geração de modelos para as palavras conhecidas, ou seja, palavras para as quais existe pelo menos um exemplo de treinamento no SemCor. Informações da WordNet são então utilizadas para generalizar tal modelo, de modo que ele possa cobrir palavras desconhecidas (não-anotadas) no SemCor. Portanto, numa primeira etapa, modelos são gerados (separadamente) para os verbos, substantivos e adjetivos do SemCor. Vetores de diferentes atributos são utilizados para cada categoria gramatical, consistindo de diferentes janelas de bag-of-words e colocações, bem como categorias gramaticais nessa janela. O algoritmo baseado em casos TiMBL (Daelemans et al., 1998) é então empregado para anotar todas as palavras conhecidas com base na sua similaridade com os exemplos do SemCor. Numa segunda etapa, um método de generalização semântica, baseado em dependências sintáticas e na rede semântica da WordNet, é aplicado para aquelas palavras que não foram anotadas na primeira etapa. Esse método também utiliza as sentenças do SemCor para treinamento. Primeiramente, tais sentenças são sintaticamente analisadas, gerando estruturas de dependência sintática. A cada verbo e substantivo num par nessas estruturas são anexadas as informações de sentido e categoria gramatical do SemCor, bem como a sua árvore de hiperonímia da WordNet. Para cada par é construído um vetor com as palavras, suas categorias gramaticais, seus sentidos e seus synsets hiperônimos, o qual é utilizado para o treinamento do sistema. $\mathrm{O}$ algoritmo TiMBL é utilizado novamente para atribuir sentidos a novos pares incluindo verbos e substantivos, com base na sua similaridade aos exemplos de treinamento. Na avaliação da tarefa All Words do Senseval-3, o sistema foi o segundo melhor colocado, com $64.6 \%$ de acurácia média, contra $60.9 \%$ da baseline do sentido mais freqüente.

Zhu \& Hovy (2007) utilizam uma técnica de active learning para minimizar a quantidade de exemplos de treinamento necessários para a DLS e, em especial, para contornar o problema dos dados esparsos, ou seja, de exemplos insuficientes para determinados sentidos. A motivação é que, em geral, classificadores gerados a partir de dados não balanceados tendem ser superajustados para as classes majoritárias, ignorando classes com poucos exemplos. $\mathrm{O}$ processo original de active learning seleciona aleatoriamente exemplos a serem incluídos nos exemplos de treinamento, mas os autores investigam diferentes métodos

\footnotetext{
${ }^{19}$ Disponível para donwload em http://lit.csci.unt.edu/ senselearner/
} 
de reamostragem para a seleção de tais exemplos, bem como critérios de parada para o processo de active learning.

Entre os métodos de reamostragem testados, o método under-sampling remove exemplos de treinamento que possuem a classe majoritária, os quais são aleatoriamente selecionados até que uma proporção entre exemplos das classes majoritária e minoritária seja atingida (0.8). O método over-sampling, por outro lado, multiplica exemplos da classe minoritária, selecionados aleatoriamente, até que uma determinada proporção de balanço seja encontrada (0.8). Adicionalmente, o método bootstrapping é utilizado para compensar a falta de balanço entre os exemplos de uma determinada classe, resultante da aplicação de métodos como o oversampling, que leva a muitos exemplos idênticos. Assim, o método de bootstrapping é utilizado durante o over-sampling, de modo a evitar cópias exatas dos exemplos com a classe majoritária: a seleção dos exemplos a serem duplicados deixa de ser aleatória, já que todos os exemplos da classe minoritária passam a ter a mesma chance de serem selecionados.

A idéia do processo de active learning com reamostragem é selecionar exemplos que aumentem a variação no conjunto de treinamento, ou seja, exemplos que o classificador teria menor confiança em classificar. Um algoritmo de entropia máxima é utilizado para medir esse grau de confiança na seleção de exemplos (Berger et al., 1996). Os atributos usados pelo classificador incluem bag-of-words locais e globais, etiquetas gramaticais locais e colocações.

Para estimar o melhor critério de parada no processo de active learning, os autores consideram a sua confiança na classificação dos exemplos não classificados. Se o exemplo pode ser classificado com certa confiança, ele é considerado redundante. Duas condições de parada são consideradas: confiança máxima, que deixa de selecionar exemplos não etiquetados caso sua entropia seja menor que um limite bastante baixo (0.001); e erro mínimo, que considera o classificador atual como um oráculo e deixa de selecionar exemplos não etiquetados quando tal classificador já pode prever a classe dos exemplos com uma acurácia acima de um certo limite.

Experimentos são realizados com 38 substantivos do projeto OntoNotes (Hovy et al., 2006), que possui conjuntos de exemplos com distribuições bastante desbalanceadas. Os três métodos de reamostragem propostos foram avaliados, under-sampling, over-sampling e bootstrapping, adicionalmente a dois métodos tradicionais random sampling e uncertainty sampling. Os experimentos mostraram que, quando o número de exemplos aprendidos para uma palavra é inferior a 120, o método bootstrapping apresenta o melhor desempenho. À medida que esse número aumenta, tal método passa a apresentar a mesma acurácia que oversampling e uncertainty sampling. Under-sampling e random sampling sempre apresentam 
acurácia inferior. Num segundo experimento visando analisar o desempenho da técnica active learning no aprendizado de exemplos com sentidos pouco freqüentes, os autores reportam que o método random sampling obtém o pior desempenho, seguido de under-sampling. Quando o número de exemplos aprendidos para uma palavra é menor que 80, bootstrapping alcança a melhor acurácia. À medida que o número de exemplos aumenta, uncertainty sampling mostra acurácia superior. Utilizando-se dessa técnica para avaliar o desempenho das diferentes condições de parada, os autores reportam uma acurácia superior com a condição erro mínimo.

Vale notar que muitas das abordagens classificadas aqui como semi-supervisionadas são consideradas, por alguns autores, como não-supervisionadas, uma vez que não utilizam recursos externos ao córpus. Na classificação utilizada aqui, no entanto, são abordagens nãosupervisionadas somente aquelas que não córpus não-anotados, conforme será descrito na próxima seção.

\subsubsection{Abordagens não-supervisionadas}

Em uma das primeiras abordagens não-supervisionadas para a DLS, Dagan et al. (1991) e Dagan \& Itai (1994) propõem um mecanismo para a desambiguação de uma língua (L1), baseado em córpus comparáveis entre L1 e outra língua (L2) e nas correspondências lexicais entre essas duas línguas indicadas por um dicionário bilíngüe. A suposição dos autores é de que os diferentes sentidos de uma palavra ambígua em uma língua se manifestam por diferentes itens lexicais em outras línguas. A idéia, portanto, é desambiguar os sentidos das palavras de L1, usando as suas traduções em L2.

Para identificar a tradução correta das palavras de conteúdo de uma sentença em L1 na L2, o mecanismo se divide em duas fases: fase lingüística e fase estatística. Na fase lingüística, é realizada a análise sintática superficial da sentença com a palavra ambígua em L1 e de exemplos de sentenças em L2, coletadas a partir do córpus da L2, que contêm as possíveis traduções da palavra ambígua, dadas por um dicionário bilíngüe L1-L2. Um analisador sintático similar em ambas as línguas é empregado para que as relações entre as duas língua sejam intercambiáveis.

As relações sintáticas são utilizadas como filtro no processo de seleção da palavra-alvo para descartar todos os exemplos coletados de L2 que ocorrem em relações sintáticas diferentes daquela em que a palavra ambígua ocorre na sentença em L1. Como resultado dessa fase, obtém-se um subconjunto de ocorrências das possíveis traduções da palavra ambígua na L2. Se essa palavra só ocorre com uma tradução em L2, nas suas várias relações 
sintáticas da L1, então essa tradução é automaticamente escolhida. Caso contrário, o sistema dispara à fase estatística.

$\mathrm{Na}$ fase estatística, é empregado um modelo probabilístico que se baseia na frequiência de ocorrências de cada uma das possíveis traduções em L2, restritas pelo filtro das relações sintáticas. A seleção de uma palavra-alvo para cada palavra ambígua leva em consideração, também, a ocorrência dessa palavra ambígua em mais de uma relação sintática, pois a escolha da tradução deve ser consistente em todas as relações em que a palavra ocorre. Por fim, a seleção considera as demais palavras na sentença já desambiguadas, como um processo de propagação de restrições.

A avaliação da abordagem consistiu de experimentos com 103 palavras ambíguas do hebreu e 54 palavras ambíguas do alemão como L1 e o inglês como L2. Nessa simulação, em função da inexistência de processos e recursos lingüísticos eletrônicos apropriados, várias etapas do mecanismo de escolha foram realizadas manualmente. Por exemplo, a eliminação das possíveis traduções ocorrendo em relações sintáticas distintas das da língua fonte. Os resultados da abordagem foram comparados às escolhas indicadas por um tradutor humano. Para o hebreu, a abordagem obteve $68 \%$ de cobertura e $91 \%$ de precisão; para o alemão, 50\% de cobertura e $78 \%$ de precisão. Os autores relatam que a cobertura da abordagem é baixa dada a insuficiência de exemplos no córpus monolíngue e que a precisão poderia ser maior caso fossem utilizadas fontes de conhecimento mais profundas.

Alguns dos principais problemas desse trabalho incluem o fato de o filtro das relações sintáticas exigir que as duas línguas sejam sintaticamente similares, de modo que possam ser analisadas pelo mesmo parser ou que um processo de mapeamento de relações entre as duas línguas seja definido. Além disso, pode haver ambigüidade entre as relações: uma relação de uma língua ter mais de uma equivalente em outra língua. Outro problema não analisado nos dois trabalhos diz respeito às ambigüidades lexicais que se mantêm entre as línguas. $\mathrm{O}$ fato de parte do processo ter sido realizada manualmente pode ter tido grande influencia nos resultados.

Apesar de voltada para DLS monolíngue, em L1, somente a parte do processo que corresponde à desambiguação multilíngue, na tradução de L1 para L2, é especificada. Para a desambiguação monolíngue, Dagan et al. indicam que seria necessário um dicionário bilíngüe do tipo L1-L1 $\rightarrow$ L2, ou seja, que fornecesse, para cada entrada da L1, sua definição (sentido) em L1 e sua tradução para L2. Por outro lado, a abordagem proposta tem aplicação direta para a desambiguação na TA. 
Num dos trabalhos mais relevantes para a DLS não-supervisionada, Yarowsky (1992) propõe um mecanismo para a desambiguação monolíngue utilizando um modelo estatístico sobre as categorias mais genéricas do thesaurus Roget. Os sentidos correspondem, portanto, às categorias genéricas do thesaurus. A identificação da categoria na qual uma palavra se enquadra se dá pela análise do contexto da palavra ambígua, seguida da sua comparação com palavras indicativas de cada uma das categorias, identificadas a partir de um método baseado no ganho de informação. Para tanto, modelos estatísticos to tipo Naive Bayes para cada categoria do thesaurus são construídos a partir da extração dos contextos contendo palavras de tal categoria. O contexto considerado aqui é bem maior do que nos trabalhos de DLS anteriores: 50 palavras à direita e esquerda da palavra ambígua. Adicionalmente, o treinamento foi realizado num córpus bastante expressivo, com 10 milhões de palavras. Essa é a única fonte de conhecimento considerada.

Em testes com 12 substantivos ambíguos, o modelo obteve uma acurácia média de 92\%. Vale notar que as categorias genéricas do thesaurus utilizadas correspondem a sentidos muito distintos. Além disso, essa abordagem não se aplica nos casos em que um sentido se distribui por várias categorias, ou seja, quando uma distinção de sentido deve ser realizada independentemente da categoria, como ocorre, por exemplo, com o sentido "vantagem" da palavra interest. Esse sentido pode ocorrer independentemente da área (finanças, música, etc.).

Resnik (1997) propõe um algoritmo não-supervisionado para desambiguar os sentidos de substantivos com base em preferências de seleção e na hierarquia conceitual da WordNet. As preferências de seleção são automaticamente obtidas a partir de um córpus, de medidas estatísticas e de informações da hierarquia conceitual. Um modelo probabilístico (Resnik, 1995a) captura co-ocorrências nas relações sintáticas no córpus e sentidos da WordNet. As probabilidades de co-ocorrência determinam as preferências de seleção.

A abordagem foi avaliada num subconjunto do córpus Brown, com as estruturas sintáticas geradas manualmente. A acurácia média obtida entre todos os tipos de relação sintática foi de $40 \%$. Vale notar que nesses experimentos a desambiguação considera as distinções refinadas da WordNet.

Karov \& Edelman (1998) propõem uma abordagem baseada na similaridade de palavras e contextos (sentenças): duas palavras são similares se aparecem em contextos similares; contextos são similares se possuem palavras similares. Como o trabalho se baseia 
em definições de dicionário eletrônico, isso pode levar a uma medida transitiva de similaridade, na qual dois contextos são considerados similares mesmo que não compartilhem as mesmas palavras, e duas palavras são consideradas similares mesmo que não compartilhem palavras vizinhas similares.

Um algoritmo de aprendizado é aplicado inicialmente sobre um córpus não-anotado. As palavras ambíguas são etiquetadas por meio de um processo iterativo, a partir da análise dos exemplos que contêm palavras relacionadas a elas, extraídas das suas definições no dicionário. O sistema aprende, então, a partir do córpus, um conjunto de usos típicos de cada sentido da palavra ambígua para cada um dos sentidos no dicionário.

O cálculo da similaridade é feito com base nas semelhanças do uso as palavras ambíguas nas sentenças, e não com base no seu significado. São analisados, basicamente, o contexto de ocorrência das palavras e as relações de distância nesse contexto. Assim, palavras como doctor e health podem ser consideradas similares, pois tendem a aparecer nos mesmos contextos. Além de minimizar a necessidade de etiquetação manual prévia dos exemplos de treinamento, o trabalho minimiza o problema de dados esparsos. Isso é feito considerando-se como exemplos para uma palavra, além dos existentes no córpus, aqueles provenientes dos exemplos nas definições para essa palavra no dicionário. A avaliação desse trabalho em 500 exemplos de quatro palavras (drug, sentence, suit e player), utilizando-se uma combinação dos dicionários Webster's e Oxford, bem como da WordNet, resultou em 92\% de precisão.

A abordagem de Schütze (1992; 1998), voltada para a Recuperação de Informações, é o exemplo mais representativo do uso de clustering para a DLS. Schütze propõe um esquema de representação no qual as palavras, os sentidos e os contextos são representados por vetores de alta dimensionalidade, sendo que a similaridade entre os vetores corresponde à proximidade semântica entre as palavras. Essa similaridade é baseada na co-ocorrência de segunda ordem entre as palavras do contexto: duas palavras (dois contextos) na vizinhança da palavra ambígua são atribuídas ao mesmo cluster se elas co-ocorrem com alguma palavra que, por sua vez, co-ocorre com palavras do córpus de treinamento. Segundo o autor, esse tipo de co-ocorrência é mais robusto e menos esparso que a co-ocorrência de primeira ordem. A hipótese do autor é que duas ocorrências de uma palavra ambígua pertencem ao mesmo sentido se suas representações contextuais são similares.

A partir dos vetores de contexto, o sistema procura identificar as suas relações de significado, agrupando-os por um processo de clustering hierárquico. Os vetores são agrupados de modo que ocorrências similares, de acordo com as co-ocorrências, sejam 
atribuídas ao mesmo cluster. $\mathrm{O}$ algoritmo identifica, automaticamente, o número de clusters mais apropriado para dividir o conjunto. Os clusters resultantes representam, implicitamente, os vários sentidos da palavra, ou seja, um "sentido" é um grupo de palavras com contextos similares. Para a desambiguação de uma nova palavra ambígua, é computado o seu vetor de contexto de segunda ordem e em seguida ela é atribuída ao cluster cujo centróide é mais próximo dessa representação.

Em experimentos com 10 palavras ambíguas, uma acurácia média de 92\% foi obtida. Contudo, é importante notar que foi testada apenas a desambiguação entre dois sentidos totalmente distintos, de categorias gramaticais distintas, em alguns casos. Adicionalmente, a abordagem focaliza na etapa de discriminação de sentidos, ou seja, de formação dos clusters, e não a etapa posterior de atribuição de sentidos aos clusters. Para a DLS em grande parte das aplicações, incluindo-se a TA, os clusters precisariam ser manualmente rotulados com tais sentidos. Segundo o autor, essa atribuição manual requer, em cada cluster, a análise de 10 a 20 dos seus membros.

Segundo Ide \& Véronis (1998), um problema dessa abordagem é que não há garantia de que os sentidos derivados dos clusters correspondem a distinções reais de sentido e que, por isso, essas distinções dificilmente poderão ser aplicadas em outras tarefas. Outro problema, segundo Yarowsky (1995), é que os exemplos são tratados como bag-of-words e, por isso, não são analisadas muitas características importantes presentes nesses exemplos e que poderiam ser facilmente extraídas, como colocações e outras relações de distância entre as palavras.

Em (Schütze \& Pedersen, 1995), os autores comparam sua proposta baseada em vetores de contextos para a Recuperação de Informações com as propostas tradicionais, baseadas em vetores de palavras. Foi obtido um aumento de $7.4 \%$ na precisão do sistema de Recuperação de Informações com o uso da abordagem e um aumento de $14.4 \%$ considerando a combinação dos dois tipos de vetores. Esse foi o primeiro trabalho a reportar melhorias em um sistema de Recuperação de Informações a partir do uso de DLS. Mais recentemente, Stokoe et al. (2003), com um trabalho baseado em córpus supervisionado usando estatísticas de co-ocorrência e colocações do córpus SemCor e as freqüências dos sentidos na WordNet, também relataram impacto positivo resultante da aplicação do mecanismo de DLS na Recuperação de Informações, com uma precisão de $62.1 \%$, contra $45.9 \%$ de precisão usando a medida tradicional TF-IDF (Term Frequency - Inverse Document Frequency). 
Outras abordagens envolvendo clustering incluem as de Pedersen \& Bruce (1997; 1998), Dini et al. (1998), Pantel \& Lin (2002) e Rapp (2004). Pedersen \& Bruce utilizam o algoritmo Expectation Maximization (Dempster et al., 1977), juntamente com um método de análise de similaridade e outro de análise de variância. Considerando informações morfológicas, categorias gramaticais e diversos tipos de colocações como atributos, foi obtida uma acurácia média de $68.5 \%$ na desambiguação de 13 palavras. Já Dini et al. consideram outras características no processo de clustering, como relações sintáticas e restrições de seleção para a discriminação entre as etiquetas das classes semânticas da WordNet para a Recuperação de Informações. Também para a DLS na Recuperação de Informações, Pantel \& Lin utilizam um algoritmo de clustering distribucional, considerando como atributos apenas as palavras da sentença e os sentidos da WordNet. Em uma avaliação com cerca de 13.000 palavras de textos jornalísticos, a precisão média obtida foi de $60.8 \%$ e a cobertura, de $50.8 \%$. Por fim, Rapp emprega o método Singular Value Decomposition (SVD) para a representação dos exemplos em vetores de dimensionalidade reduzida. O clustering é realizado implicitamente pelo método SVD aplicado sobre matrizes de co-ocorrência entre palavras e contextos. Contudo, a interpretação da semântica dos grupos gerados não foi investigada.

Também utilizando um algoritmo de clustering, Pedersen \& Kulkarni (2006) propõem uma abordagem para a discriminação de sentidos a partir de córpus não anotados em que o número $k$ de clusters para uma dada palavra ambígua é automaticamente induzido. A técnica de clustering particional $k$-means é aplicada sucessivamente com diferentes valores de $k$ e os resultados são avaliados com base na função de critério $H 2$, que calcula a proporção da similaridade em cada cluster e entre clusters. O valor de $k$ anterior ao ponto em que a qualidade do agrupamento não melhora significativamente é escolhido como limite superior. Quatro métodos que assumem os valores gerados por $H 2$ entre 1 e esse limite superior como entrada são implementados para determinar o valor ideal de $k$ para cada palavra.

Foram realizados experimentos com três palavras (hard, serve e line) manualmente etiquetadas com 3, 4 e 6 sentidos cada. Além disso, foram considerados 19 nomes de entidades (pessoas, lugares e organizações), onde conjuntos de 2, 3, 4 e 6 nomes foram substituídos por um único identificador (método pseudo-words). Das 22 palavras testadas, o segundo método resultou no número de sentidos identificado manualmente em todos os 22 casos. Esse método considera a proporção da função $H 2$ em $k$ e $k$ - 1 para computar a melhoria relativa a cada aumento em $k$. 
De maneira sintetizada, os trabalhos baseados em córpus descritos nessa seção são listados na Tabela 3.4, em ordem cronológica, de acordo com o modo e o paradigma de aprendizado, a aplicação a que são voltados e a língua endereçada.

Tabela 3.4: Lista dos trabalhos de DLS baseados em córpus

\begin{tabular}{|c|c|c|c|c|}
\hline Trabalho & Modo & Paradigma & Aplicação & Língua \\
\hline (Black, 1988) & supervisionado & simbólico & $\begin{array}{l}\text { independente } \\
\text { (monolíngue) }\end{array}$ & inglês \\
\hline (Hearst, 1991) & $\begin{array}{l}\text { semi- } \\
\text { supervisionado }\end{array}$ & simbólico & $\begin{array}{l}\text { Compreensão da } \\
\text { Língua Natural }\end{array}$ & inglês \\
\hline $\begin{array}{l}\text { (Dagan et al., 1991) e } \\
\text { (Dagan \& Itai, 1994) }\end{array}$ & $\begin{array}{l}\text { não-supervisio- } \\
\text { nado }\end{array}$ & - & Tradução Automática & $\begin{array}{l}\text { inglês - } \\
\text { hebreu e } \\
\text { alemão }\end{array}$ \\
\hline (Yarowsky, 1992) & $\begin{array}{l}\text { não-supervisio- } \\
\text { nado }\end{array}$ & - & $\begin{array}{l}\text { independente } \\
\text { (monolíngue) }\end{array}$ & inglês \\
\hline $\begin{array}{l}\text { (Schütze, 1992; } \\
\text { 1998) }\end{array}$ & $\begin{array}{l}\text { não- } \\
\text { supervisionado }\end{array}$ & - & $\begin{array}{l}\text { Recuperação de } \\
\text { Informações }\end{array}$ & inglês \\
\hline $\begin{array}{l}\text { (Schütze \& Pedersen, } \\
\text { 1995) }\end{array}$ & $\begin{array}{l}\text { não- } \\
\text { supervisionado }\end{array}$ & - & $\begin{array}{l}\text { Recuperação de } \\
\text { Informações }\end{array}$ & inglês \\
\hline (Yarowsky, 1995) & $\begin{array}{l}\text { semi- } \\
\text { supervisionado }\end{array}$ & simbólico & $\begin{array}{l}\text { independente } \\
\text { (monolíngue) }\end{array}$ & inglês \\
\hline (Mooney, 1996) & supervisionado & $\begin{array}{l}\text { comparação entre } \\
\text { simbólico, estatístico, } \\
\text { conexionista e } \\
\text { baseado em instâncias }\end{array}$ & $\begin{array}{l}\text { independente } \\
\text { (monolíngue) }\end{array}$ & inglês \\
\hline (Ng \& Lee, 1996) & supervisionado & baseado em instâncias & $\begin{array}{l}\text { independente } \\
\text { (monolíngue) }\end{array}$ & inglês \\
\hline$(\mathrm{Ng}, 1997 \mathrm{a})$ & supervisionado & baseado em instâncias & $\begin{array}{l}\text { independente } \\
\text { (monolíngue) }\end{array}$ & inglês \\
\hline Resnik (1997) & $\begin{array}{l}\text { não-supervisio- } \\
\text { nado }\end{array}$ & - & $\begin{array}{l}\text { independente } \\
\text { (monolíngue) }\end{array}$ & inglês \\
\hline $\begin{array}{l}\text { (Pedersen \& Bruce, } \\
1997 ; 1998)\end{array}$ & $\begin{array}{l}\text { não- } \\
\text { supervisionado }\end{array}$ & - & $\begin{array}{l}\text { independente } \\
\text { (monolíngue) }\end{array}$ & inglês \\
\hline (Dini et al., 1998) & $\begin{array}{l}\text { não- } \\
\text { supervisionado }\end{array}$ & - & $\begin{array}{l}\text { Recuperação de } \\
\text { Informações }\end{array}$ & inglês \\
\hline $\begin{array}{l}\text { (Karov \& Edelman, } \\
\text { 1998) }\end{array}$ & $\begin{array}{l}\text { não- } \\
\text { supervisionado }\end{array}$ & - & $\begin{array}{l}\text { independente } \\
\text { (monolíngue) }\end{array}$ & inglês \\
\hline $\begin{array}{l}\text { (Wilks \& Stevenson, } \\
\text { 1998) e (Stevenson \& } \\
\text { Wilks, 1999; 2000; } \\
\text { 2001) }\end{array}$ & supervisionado & $\begin{array}{l}\text { simbólico e baseado } \\
\text { em instâncias }\end{array}$ & $\begin{array}{l}\text { independente } \\
\text { (monolíngue) }\end{array}$ & inglês \\
\hline $\begin{array}{l}\text { (Towell \& Voorhess, } \\
1998)\end{array}$ & supervisionado & conexionista & $\begin{array}{l}\text { Recuperação de } \\
\text { Informações }\end{array}$ & inglês \\
\hline $\begin{array}{l}\text { (Paliouras et al., } \\
\text { 1999) }\end{array}$ & supervisionado & simbólico & $\begin{array}{l}\text { Extração de } \\
\text { Informações }\end{array}$ & inglês \\
\hline $\begin{array}{l}\text { (Paliouras et al., } \\
2000)\end{array}$ & supervisionado & $\begin{array}{l}\text { comparação entre } \\
\text { simbólico, estatístico } \\
\text { e baseado em } \\
\text { instâncias }\end{array}$ & $\begin{array}{l}\text { Extração de } \\
\text { Informações }\end{array}$ & inglês \\
\hline (Yarowsky, 2000) & supervisionado & simbólico & $\begin{array}{l}\text { independente } \\
\text { (monolíngue) }\end{array}$ & inglês \\
\hline (Pedersen, 2000) & supervisionado & estatístico & $\begin{array}{l}\text { independente } \\
\text { (monolíngue) }\end{array}$ & inglês \\
\hline (Zinovjeva, 2000) & supervisionado & simbólico & Tradução Automática & $\begin{array}{l}\text { inglês - } \\
\text { sueco }\end{array}$ \\
\hline
\end{tabular}




\begin{tabular}{|c|c|c|c|c|}
\hline $\begin{array}{l}\text { (Agirre \& Martinez, } \\
2000)\end{array}$ & supervisionado & simbólico & $\begin{array}{l}\text { independente } \\
\text { (monolíngue) }\end{array}$ & inglês \\
\hline $\begin{array}{l}\text { (Escudero et al., } \\
\text { 2000a) }\end{array}$ & supervisionado & $\begin{array}{l}\text { estatístico e baseado } \\
\text { em instâncias }\end{array}$ & $\begin{array}{l}\text { independente } \\
\text { (monolíngue) }\end{array}$ & inglês \\
\hline $\begin{array}{l}\text { (Escudero et al., } \\
2000 b ; 2001)\end{array}$ & supervisionado & simbólico & $\begin{array}{l}\text { independente } \\
\text { (monolíngue) }\end{array}$ & inglês \\
\hline $\begin{array}{l}\text { (Escudero et al., } \\
2000 \mathrm{c})\end{array}$ & supervisionado & $\begin{array}{l}\text { comparação entre } \\
\text { simbólicos, } \\
\text { estatísticos, baseados } \\
\text { em instâncias, etc. }\end{array}$ & $\begin{array}{l}\text { independente } \\
\text { (monolíngue) }\end{array}$ & inglês \\
\hline (Lee, 2002) & supervisionado & funções lineares & Tradução Automática & $\begin{array}{l}\text { inglês - } \\
\text { coreano }\end{array}$ \\
\hline (Pedersen, 2002a) & supervisionado & estatístico e simbólico & $\begin{array}{l}\text { independente } \\
\text { (monolíngue) }\end{array}$ & $\begin{array}{l}\text { inglês e } \\
\text { espanhol }\end{array}$ \\
\hline (Pedersen, 2002b) & supervisionado & simbólico & $\begin{array}{l}\text { independente } \\
\text { (monolíngue) }\end{array}$ & $\begin{array}{l}\text { inglês e } \\
\text { espanhol }\end{array}$ \\
\hline (Lee \& Ng, 2002) & supervisionado & $\begin{array}{l}\text { comparação entre } \\
\text { estatístico, simbólico, } \\
\text { etc. }\end{array}$ & $\begin{array}{l}\text { independente } \\
\text { (monolíngue) }\end{array}$ & inglês \\
\hline (Florian et al., 2002) & supervisionado & $\begin{array}{l}\text { combinação de } \\
\text { estatísticos, } \\
\text { simbólicos, etc. }\end{array}$ & $\begin{array}{l}\text { independente } \\
\text { (monolíngue) }\end{array}$ & inglês \\
\hline (Pantel \& Lin, 2002) & $\begin{array}{l}\text { não- } \\
\text { supervisionado }\end{array}$ & - & $\begin{array}{l}\text { Recuperação de } \\
\text { Informações }\end{array}$ & inglês \\
\hline (Dihn et al., 2003) & supervisionado & simbólico & Tradução Automática & $\begin{array}{l}\text { inglês - } \\
\text { vietnami } \\
\text { ta }\end{array}$ \\
\hline (Stokoe et al., 2003) & $\begin{array}{l}\text { não- } \\
\text { supervisionado }\end{array}$ & - & $\begin{array}{l}\text { Recuperação de } \\
\text { Informações }\end{array}$ & inglês \\
\hline (Park et al., 2003) & $\begin{array}{l}\text { semi- } \\
\text { supervisionado }\end{array}$ & simbólico & $\begin{array}{l}\text { independente } \\
\text { (monolíngue) }\end{array}$ & coreano \\
\hline (Mihalcea, 2004) & $\begin{array}{l}\text { semi- } \\
\text { supervisionado }\end{array}$ & estatístico & $\begin{array}{l}\text { independente } \\
\text { (monolíngue) }\end{array}$ & inglês \\
\hline (Rapp, 2004) & $\begin{array}{l}\text { não- } \\
\text { supervisionado }\end{array}$ & - & $\begin{array}{l}\text { independente } \\
\text { (monolíngue) }\end{array}$ & inglês \\
\hline $\begin{array}{l}\text { (Mihalcea \& Ehsanul, } \\
\text { 2004) }\end{array}$ & $\begin{array}{l}\text { semi- } \\
\text { supervisionado }\end{array}$ & baseado em casos & $\begin{array}{l}\text { independente } \\
\text { (monolíngue) }\end{array}$ & inglês \\
\hline (Decadt et al., 2004) & supervisionado & baseado em casos & $\begin{array}{l}\text { independente } \\
\text { (monolíngue) }\end{array}$ & inglês \\
\hline $\begin{array}{l}\text { (Pedersen \& } \\
\text { Kulkarni, 2006) } \\
\end{array}$ & $\begin{array}{l}\text { não- } \\
\text { supervisionado }\end{array}$ & - & $\begin{array}{l}\text { independente } \\
\text { (monolíngue) }\end{array}$ & inglês \\
\hline $\begin{array}{l}\text { (Cai et al., 2007a; } \\
\text { 2007b) }\end{array}$ & supervisionado & estatístico & $\begin{array}{l}\text { independente } \\
\text { (monolíngue) }\end{array}$ & inglês \\
\hline (Zhu \& Hovy, 2007) & $\begin{array}{l}\text { semi- } \\
\text { supervisionado }\end{array}$ & estatístico & $\begin{array}{l}\text { independente } \\
\text { (monolíngue) }\end{array}$ & inglês \\
\hline
\end{tabular}

\section{Considerações sobre as abordagens baseadas em córpus e híbridas}

De modo geral, as principais vantagens das abordagens baseadas em córpus são: (1) não é necessário codificar todo o conhecimento manualmente; (2) podem ser utilizados algoritmos tradicionais de AM já implementados e disponíveis para a aquisição automática ou semiautomática de conhecimento; (3) os modelos criados podem ser mais facilmente generalizáveis para grandes quantidades de palavras, novos gêneros e/ou domínios de textos 
e, com isso, são aplicáveis em larga escala; e (4) os modelos gerados podem expressar conhecimento novo sobre o uso da palavra ambígua ou sobre as informações utilizadas para a distinção entre os seus sentidos.

Uma desvantagem do método baseado em córpus, em geral, é que não há garantia de que os modelos gerados produzam resultados adequados, em função de várias características do processo automático de aprendizado, como a possibilidade de inconsistências nos exemplos (ruídos) e a dificuldade de avaliação dos modelos.

Outro problema dessas abordagens refere-se aos córpus de exemplos necessários para a criação do modelo. Esses córpus precisam ser representativos da língua natural para o gênero e/ou domínio em questão. Apesar da atual disponibilidade de córpus de tamanho considerável, poucos possuem as informações necessárias. Outro problema é a esparsidade dos dados, que ocorre quando há uma quantidade muito pequena de exemplos para alguns sentidos no córpus (ou quando não há exemplos para tais sentidos), que acabam se tornando estatisticamente insignificantes. Isso indica que, em um grande espaço de interpretações alternativas produzidas por palavras ambíguas, somente uma parte é utilizada. Muito embora diferentes técnicas venham sendo aplicadas para tal problema (por exemplo, técnicas de suavização (Gale \& Church, 1991), modelos baseados em classe (Pereira et al., 1993); e métodos baseados em similaridade (Dagan et al., 1993)), a esparsidade dos dados ainda representa um grande problema. Além disso, as fontes de conhecimento que a maioria das abordagens utilizam, como co-ocorrências da palavra ambígua com outras palavras, são naturalmente esparsas, já que muitas das possíveis co-ocorrências são improváveis ou pouco freqüentes. Assim, muitos dos atributos não possuem valores para determinados exemplos. Esse problema torna-se mais crítico no caso de abordagens híbridas: quanto mais conhecimento é representado como atributos dos exemplos, maiores são as chances de vários atributos possuírem valores nulos para determinados exemplos, que são muitas vezes interpretados como ruídos, prejudicando o processo de aprendizado.

Especificamente para a DLS supervisionada, o maior problema é a necessidade de etiquetação de um córpus de treinamento, normalmente feita ou revisada manualmente. Conforme será discutido no Capítulo 4, para a desambiguação monolíngue do inglês, alguns córpus já foram desenvolvidos para a tarefa de DLS. Já para a desambiguação em outras línguas e, principalmente, para a desambiguação multilíngue, os córpus são ainda muito escassos. Os córpus criados para uma aplicação muito dificilmente são adequados para outras aplicações, uma vez que o nível de refinamento da etiquetação, bem como as etiquetas de sentido, propriamente ditas, dependem da aplicação. Em particular, córpus para aplicações 
monolíngues não são indicados para aplicações multilíngues, uma vez que seria necessário mapear os sentidos em uma língua para as traduções na outra, o que, por si só, é um problema complexo. De fato, um dos maiores problemas da DLS para aplicações multilíngues diz respeito à inexistência de córpus adequados, suficientemente abrangentes e com as informações necessárias, especialmente para a DLS supervisionada. Para aplicações envolvendo o inglês e o português, não se tem conhecimento de córpus com etiquetas de sentidos disponíveis, além dos criados neste trabalho.

Por outro lado, a DLS supervisionada (em oposição à não-supervisionada) apresenta a vantagem de os sentidos serem especificados previamente, o que permite a etiquetação adequada para tarefas específicas, como a TA. De fato, todas as edições do exercício de avaliação Senseval comprovam que os trabalhos supervisionados apresentam acurácia consideravelmente superior tanto na tarefa de desambiguação de um pequeno grupo de palavras (Lexical Sample), quanto na tarefa de desambiguação de todas as palavras da sentença (All Words).

A grande vantagem das abordagens não-supervisionadas, por sua vez, é justamente o fato de que não há necessidade de etiquetação dos sentidos no córpus de exemplos. Por outro lado, os resultados obtidos por abordagens dessa natureza são em geral bastante inferiores aos das abordagens supervisionadas. Os resultados gerados por grande parte das abordagens nãosupervisionadas são agrupamentos de palavras que, idealmente, compartilham o mesmo sentido. Uma vez que a desambiguação não é realizada com respeito a um conjunto prédefinido de sentidos, essa abordagem não é apropriada para uma série de aplicações que necessitam de uma explicitação dos sentidos, como é o caso da TA. Os grupos obtidos sem sempre correspondem a sentidos de uma classificação padrão muitas vezes não são bem definidos.

Manning \& Schütze (2001) enfatizam o problema de que não há garantia de que os sentidos identificados distinguem adequadamente as ocorrências das palavras ambíguas, uma vez que eles podem ser muito genéricos ou muito refinados, ou, ainda, não corresponder às distinções padrão. Segundo Wilks (1997), nessas abordagens sempre haverá a atribuição das palavras ambíguas a algum grupo, de modo que a DLS sempre ocorre. O problema é como interpretar os resultados.

Em se tratando de algoritmos e paradigmas de aprendizado, as diversas comparações na literatura mostram que diferentes algoritmos podem ser mais apropriados para desambiguar determinadas palavras, em conjuntos de teste específicos, de acordo também com as fontes de conhecimento utilizadas. A combinação de diversas fontes de conhecimento leva, em geral, a 
resultados superiores. O mesmo vale para combinações de diversos algoritmos, ou do mesmo algoritmo com diferentes subconjuntos de exemplos ou fontes de conhecimento. Uma vantagem das abordagens simbólicas com relação às desenvolvidas sob os demais paradigmas é que o conhecimento adquirido automaticamente é facilmente compreensível por seres humanos, mesmo que estes não sejam especialistas no domínio. Assim, conhecimento útil, potencialmente novo, pode ser adquirido a partir da análise dos modelos. Além disso, tais modelos podem ser ajustados com o uso de conhecimento especificado por humanos, ou de mais exemplos de determinados fenômenos que não são apropriadamente cobertos pelo modelo.

As vantagens dos trabalhos que seguem o método híbrido, em teoria, correspondem à união das principais vantagens dos métodos baseados em conhecimento e em córpus: a precisão do método baseado em conhecimento e a abrangência do método baseado em córpus. Contudo, conforme será discutido no Capítulo 5, os trabalhos atuais são híbridos de maneira limitada, por conta das limitações no formalismo de representação utilizado, baseado em vetores de atributos. A proposta deste trabalho é justamente superar tal limitação, por meio do uso de um formalismo de representação mais elaborado e de uma vasta gama de fontes de conhecimento. No próximo capítulo será apresentada a estratégia proposta para a criação automática de córpus de exemplos etiquetados com sentidos multilíngues, juntamente com outras informações úteis para a DLS.

\subsection{O ESTADO DA ARTE EM ABORDAGENS DE DLS}

Conforme foi mencionado anteriormente, muito embora muitas das abordagens descritas nas Seções 3.2 e 3.3 reportem resultados com respeito à medida de acurácia, a comparação direta entre tais resultados não é possível, uma vez que diferentes bases de exemplos são utilizadas para a avaliação dos sistemas. Portanto, tem-se considerando os resultados das várias edições da competição Senseval como o estado da arte em DLS. Nessa seção são sumarizados os principais resultados das edições, focalizando-se na desambiguação fine-grained das tarefas Lexical Sample para o inglês e outras línguas, bem como nas tarefas de DLS multilíngue. Vale notar que tais resultados referem-se à desambiguação no nível de polissemia. A desambiguação no nível de homonímia é considerada um problema resolvido: Stevenson \& Wilks (2001), por exemplo, alcançam 94.7\% de precisão com uma abordagem supervisionada para a desambiguação de todas as palavras de conteúdo, enquanto Yarowsky (1995) alcança 96.5\% com uma abordagem semi-supervisionada, para um subconjunto de palavras. 
A desambiguação no nível de polissemia, por outro lado, ainda é um problema complexo, muito embora o desempenho das abordagens venha melhorando com o tempo. $\mathrm{Na}$ primeira edição da competição, debatia-se ainda sobre a potencial superioridade das abordagens baseadas em conhecimento. A partir da segunda edição, tornou-se claro que abordagens baseadas em córpus (e híbridas), desde que supervisionadas, apresentam o melhor desempenho, dadas as restrições de tempo para a construção ou treinamento dos sistemas. De fato, apenas abordagens baseadas em córpus ou híbridas vêm sendo submetidas na últimas edições do Senseval, e aquelas supervisionadas mostram desempenho consideravelmente superior ao das não supervisionadas.

Na tarefa Lexical Sample do inglês, o sistema primeiro colocado no Senseval-1 emprega uma abordagem supervisionada simbólica baseada em listas de decisão (Hawkins, 1999). Tal sistema alcançou a acurácia de $77 \%$, contra $56.6 \%$ da baseline do sentido mais freqüente. A concordância entre juízes humanos para tal tarefa, que pode ser considerada um limite superior para a avaliação, foi de $80 \%$. O repositório de sentidos e córpus utilizados haviam sido desenvolvidos no Projeto Hector (Atkins, 1992).

A segunda edição da avaliação foi considerada mais difícil, já que os sentidos mais refinados da WordNet foram utilizados. Um sistema combinando seis algoritmos de aprendizado (listas de decisão, Naive Bayes, etc.) foi o primeiro colocado (Yarowsky et al., 2002), com acurácia de $64 \%$, contra $40 \%$ do melhor sistema não-supervisionado (FernándezAmorós et al., 2001) e a baseline do sentido mais freqüente de $48 \%$. A concordância entre os juízes humanos para tal tarefa foi de $86 \%$. Os resultados dos sistemas mais bem colocados para as diferentes versões da tarefa Lexical Sample (para diferentes línguas) são ilustrados na Tabela 3.5. Vale notar que tarefas para diferentes línguas são independentes umas das outras. Assim, diferentes conjuntos de exemplos são utilizados para cada língua, com níveis de refinamento e distribuições de sentido distintas e, portanto, níveis de dificuldade distintos.

Tabela 3.5: Acurácias dos melhores sistemas na tarefa Lexical Sample do Senseval-2

\begin{tabular}{|l|r|r|r|}
\hline \multicolumn{1}{|c|}{ Língua } & \multicolumn{1}{c|}{$\begin{array}{c}\text { Concordância } \\
\text { entre juízes }\end{array}$} & \multicolumn{1}{c|}{ Baseline } & \multicolumn{2}{c|}{$\begin{array}{c}\text { Sistema melhor } \\
\text { colocado }\end{array}$} \\
\hline Inglês (supervisionado) & 0.86 & 0.48 & 0.64 \\
\hline Inglês (não-supervisionado) & 0.86 & 0.48 & 0.40 \\
\hline Basco & 0.75 & 0.65 & 0.76 \\
\hline Italiano & 0.21 & - & 0.39 \\
\hline Japonês & 0.86 & 0.72 & 0.78 \\
\hline Coreano & - & 0.71 & 0.74 \\
\hline Espanhol & 0.64 & 0.48 & 0.65 \\
\hline Sueco & 0.95 & - & 0.70 \\
\hline Inglês $\rightarrow$ Japonês & 0.81 & 0.37 & 0.79 \\
\hline
\end{tabular}


Na terceira edição do evento, que utiliza sentidos da WordNet para substantivos e sentidos do WordSmith para verbos, um sistema utilizando Naive Bayes com a correção das probabilidades a priori de acordo com a frequiência dos sentidos obteve o primeiro lugar com um escore de $73 \%$ (Grozea, 2004), contra 66\% do melhor sistema não-supervisionado (Ramakrishnan et al., 2004) e 55\% da baseline do sentido mais freqüente. Outros candidatos obtiveram resultados similares com o algoritmo SVMs. Os dez melhores sistemas nessa tarefa obtiveram acurácias entre 71.8 e $72.9 \%$, superando o escore de concordância entre juízes humanos para tal tarefa: 67\%. Vale notar que, pela primeira vez, um sistema nãosupervisionado obteve acurácia significativamente superior à da baseline do sentido mais freqüente, e muito próxima à da concordância entre juízes humanos.

Na tarefa multilíngue realizada nessa mesma edição do Senseval, do inglês para o híndi, a baseline foi de 51.9\%. Um sistema utilizando SVMs foi o primeiro colocado, com 63.4\% de acurácia (Lee et al., 2004). O segundo colocado foi um sistema utilizando a combinação de três algoritmos de aprendizado (maximum entropy, principal component analysis, boosting model), com acurácia de 62\% (Carpuat et al., 2004). O terceiro colocado, que também utiliza SVMs, obteve acurácia de 61.4\% (Montcheuil et al., 2004). Nenhum dos sistemas participantes utilizou o método de aprendizado não-supervisionado. Os escores dos sistemas mais bem colocados para as diferentes versões da tarefa Lexical Sample são ilustrados na Tabela 3.6.

Tabela 3.6: Acurácias dos melhores sistemas na tarefa Lexical Sample do Senseval-3

\begin{tabular}{|l|r|r|r|}
\hline \multicolumn{1}{|c|}{ Língua } & \multicolumn{1}{|c|}{$\begin{array}{c}\text { Concordância } \\
\text { entre juízes }\end{array}$} & \multicolumn{1}{c|}{ Baseline } & \multicolumn{1}{c|}{$\begin{array}{c}\text { Sistema melhor } \\
\text { colocado }\end{array}$} \\
\hline Inglês (supervisionado) & 0.67 & 0.55 & 0.73 \\
\hline Inglês (não-supervisionado) & 0.67 & 0.55 & 0.66 \\
\hline Basco & 0.78 & 0.59 & 0.70 \\
\hline Catalão & 0.93 & 0.66 & 0.85 \\
\hline Italiano & 0.89 & 0.18 & 0.53 \\
\hline Romeno & - & 0.58 & 0.73 \\
\hline Espanhol & $0.83-0.90$ & 0.67 & 0.84 \\
\hline Inglês $\rightarrow$ Híndi & - & 0.51 & 0.63 \\
\hline
\end{tabular}

Por fim, na última edição do evento, a baseline do sentido mais freqüente foi de $51.4 \%$. O sistema supervisionado na primeira posição obteve $88.7 \%$ de acurácia (Cai et al., 2007), utilizando uma versão modificada do algoritmo Naive Bayes e um atributo especial para capturar a informação de tópico da sentença, extraída a partir de um modelo probabilístico, além de atributos tradicionalmente utilizados, como colocações, bag-of-words, etiquetas gramaticais e relações sintáticas. O sistema que obteve segundo lugar com 86.9\% de acurácia utiliza uma combinação de vários k-NNs, cada classificador com um conjunto diferente de 
atributos: atributos locais (estrutura sintática, colocações), globais (bag-of-words, informação de domínio) e latentes (extraídos a partir da técnica Singular Value Decomposition) (Agirre \& Lacalle, 2007). O terceiro colocado, com acurácia de 86.4\%, utiliza um algoritmo do tipo label propagation que propaga as etiquetas de um vértice em um grafo para vértices próximos a ele a partir da informação de pesos dos arcos, de modo que os exemplos de treinamento são utilizados para etiquetar novos casos de acordo com a proximidade entre eles (Niu et al., 2007). O melhor candidato não-supervisionado obteve 53.8\% de acurácia (Patwardhan et al., 2007). As abordagens propostas neste trabalho ocupam a quarta e quinta posição, conforme será discutido no Capítulo 6. Vale notar que, na última edição do Senseval, a granularidade dos sentidos, anotados com etiquetas OntoNotes (Hovy et al., 2006), é menos refinada que na WordNet.

Na tarefa de DLS multilíngue entre o inglês e o chinês, o sistema melhor colocado utiliza um algoritmo do tipo maximum-entropy e obteve $74.9 \%$ de acurácia, contra $46 \%$ da baseline do sentido mais freqüente e $43 \%$ do melhor sistema não-supervisionado. O segundo colocado utiliza um algoritmo semi-supervisionado do tipo label propagation, enquanto o terceiro colocado utiliza um classificador Naive Bayes. Os resultados dos sistemas mais bem colocados para as diferentes versões da tarefa Lexical Sample (diferentes línguas) são ilustrados na Tabela 3.7 .

Tabela 3.7: Acurácias dos melhores sistemas na tarefa Lexical Sample do Senseval-4

\begin{tabular}{|l|r|r|r|}
\hline \multicolumn{1}{|c|}{ Língua } & \multicolumn{1}{c|}{$\begin{array}{c}\text { Concordância } \\
\text { entre juízes }\end{array}$} & \multicolumn{1}{c|}{ Baseline } & \multicolumn{1}{c|}{$\begin{array}{c}\text { Sistema melhor } \\
\text { colocado }\end{array}$} \\
\hline Inglês (supervisionado) & 0.90 & 0.51 & 0.88 \\
\hline Inglês (não-supervisionado) & 0.90 & 0.51 & 0.53 \\
\hline Inglês com corpus paralelo inglês-chinês & - & 0.68 & 0.81 \\
\hline Turco & 0.90 & - & 0.13 \\
\hline Inglês $\rightarrow$ Chinês & 0.84 & 0.46 & 0.74 \\
\hline
\end{tabular}

Como se pode observar, tomando-se a tarefa Lexical Sample para distinções fine-grained do inglês, que vem sendo avaliada desde a primeira edição do Senseval, a acurácia média dos sistemas supervisionados vem melhorando consideravelmente com relação à baseline do sentido mais freqüente (a diferença aumentou de 21 pontos percentuais, na primeira edição, para 37 pontos, na última). Adicionalmente, tal acurácia vem se tornando mais próxima ou mesmo superior à concordância entre juízes humanos (a diferença, na última edição, foi de dois pontos percentuais, enquanto que na terceira edição o melhor sistema superou a concordância entre humanos). Muito embora tais resultados pareçam bastante positivos, vale 
lembrar que as avaliações descritas não contemplam o uso da DLS em aplicações práticas, o que seria necessário para demonstrar o real valor dessa tarefa.

\subsection{CONSIDERAÇÕES FINAIS}

Conforme apresentado neste capítulo, os trabalhos que vêm sendo desenvolvidos para a DLS possuem variações em muitos aspectos, como o método de PLN, o paradigma de aprendizado, os tipos de conhecimento, etc. Além dos trabalhos citados, vários outros podem ser encontrados nos anais das quatro edições do Senseval. Contudo, em geral, os sistemas participantes em tal competição são implementações de abordagens já existentes, as quais são apenas testadas em conjuntos de exemplos distintos. De fato, a maioria das abordagens emprega alguma técnica de aprendizado de máquina para a indução supervisionada de modelos a partir de atributos superficiais representados por vetores do tipo atributo-valor. Por essa razão, muitos desses sistemas não foram descritos neste capítulo. Vale notar também que, além dos trabalhos voltados para aplicações multilíngues como a TA que foram apresentados neste capítulo, existem os sistemas completos de TA seguindo métodos estatísticos, nos quais DLS é realizada implicitamente. Alguns desses sistemas foram brevemente discutidos no Capítulo 2. Nesses sistemas, contudo, a DLS se baseia em informações simples, como a freqüência das ocorrências de cada tradução em um contexto bastante limitado.

Em se tratando de abordagens envolvendo o português, os únicos trabalhos de que se tem conhecimento são os de Leffa (1998) e Bräscher (2002). O trabalho de Bräscher, descrito na Seção 3.2.1, não é voltado especificamente para a DLS e apenas mostra a importância de informações da valência sintático-semântica para a resolução de ambigüidades nos diversos níveis. Já Leffa realiza experimentos manualmente para mostrar a importância do uso do contexto local da palavra ambígua, na forma de colocações, para a escolha lexical na tradução inglês-português, bem como o uso de córpus para a definição do repositório de sentidos. Contudo, um sistema de DLS não foi implementado.

De modo geral, entre os trabalhos recentes, os trabalhos híbridos desenvolvidos utilizando o método de aprendizado supervisionado apresentam os melhores resultados. Diversos trabalhos mostram que quanto maior a quantidade e variedade de conhecimentos empregados, maior a acurácia na desambiguação. Contudo, esses trabalhos apresentam limitações no que diz respeito ao modo como as várias fontes de conhecimento são representadas, bem como sobre a utilização desse conhecimento de maneira efetiva. Essas limitações se devem ao formalismo de representação utilizado para codificar o conhecimento 
relativo aos exemplos: vetores de atributos. Tal representação tem o mesmo poder de expressividade que a Lógica Proposicional, ou seja, permite apenas proposições atômicas e é por isso reconhecidamente limitada para aplicações de PLN, já que grande parte do conhecimento lingüístico necessário para essas aplicações é de natureza relacional, por exemplo, as relações sintáticas e semânticas entre os elementos de uma sentença.

A representação de fontes de conhecimento relacional por meio de vetores de atributos, quando possível, requer a simplificação dessas fontes e / ou implica em uma grande esparsidade nos vetores, que tende a piorar à medida que mais fontes de conhecimento são utilizadas. As representações resultantes, com dados faltantes, podem acarretar grandes problemas para o processo de aprendizado. Por essa razão, trabalhos que empregam fontes de conhecimento substanciais para a DLS normalmente o fazem em etapas anteriores ao processo de aprendizado de máquina. Esse é o caso, por exemplo, dos trabalhos de Stevenson \& Wilks.

Assim, pode-se considerar que as abordagens atuais são híbridas em um sentido bastante restrito, já que não utilizam conhecimento substancial de maneira realmente integrada ao aprendizado de máquina. Conforme será descrito no Capítulo 5, a proposta deste trabalho visa superar tal limitação a partir da utilização de um formalismo relacional, mais expressivo, para a representação de conhecimento. No próximo capítulo será apresentada a abordagem desenvolvida para a criação automática de córpus de exemplos de desambiguação para tal proposta. 


\section{A CRIAÇÃO DE CÓRPUS DE EXEMPLOS DE DLS}

Conforme foi apresentado no Capítulo 3, abordagens recentes de DLS têm focalizado no uso de córpus, recursos eletrônicos e técnicas de aprendizado de máquina visando evitar a necessidade de codificação manual de conhecimento lingüístico. Entre tais abordagens, aquelas desenvolvidas utilizando-se aprendizado de máquina supervisionado têm apresentado os melhores resultados (Edmonds \& Cotton, 2001; Mihalcea \& Edmonds, 2004; Agirre et al., 2007). Tais abordagens requerem córpus de treinamento anotados com os sentidos das palavras ambíguas a serem manipuladas. A criação manual de tais córpus, além de exigir considerável esforço e tempo, apresenta vários problemas, tais como a escolha do nível apropriado de refinamento dos sentidos e outros aspectos que podem variar consideravelmente entre diferentes anotadores humanos. Neste capítulo são primeiramente apresentados alguns dos córpus manualmente etiquetados com sentidos que vêm sendo tradicionalmente utilizados para treinamento e / ou avaliação de sistemas de DLS (Seção 4.1). Em seguida, são discutidas abordagens recentes para a criação automática de córpus de exemplos de desambiguação (Seção 4.2). Finalmente, é apresentado o método desenvolvido neste trabalho para a etiquetação do córpus multilíngue a ser utilizado para o treinamento da abordagem de DLS proposta (Seção 4.3). Vale notar que todas as abordagens descritas nesse capítulo referem-se a córpus de exemplos para a desambiguação de uma determinada palavra em um contexto (sentença, parágrafo, etc.), e não para a desambiguação de todas as palavras em tal contexto. Essas tarefas constituem problemas distintos, que são geralmente denominadas Lexical Sample Task e All Words Task, respectivamente.

\subsection{CÓRPUS ETIQUETADOS MANUALMENTE}

Os principais córpus disponíveis atualmente foram desenvolvidos para a desambiguação monolíngue do inglês e anotados de acordo com diferentes repositórios de sentidos e diversos níveis de granularidade de tais sentidos. Dois dos córpus mais comumente utilizados para o treinamento e avaliação de trabalhos de DLS são o DSO (Ng \& Lee, 1996) e o SemCor (Miller et al., 1994), ambos anotados com os sentidos da WordNet 1.5.

O córpus DSO (Defence Science Organisation) consiste de ocorrências anotadas para 121 substantivos e 70 verbos mais frequientes da língua inglesa, distribuídas em 192.800 sentenças de exemplo extraídas do córpus Brown (Francis \& Kucera, 1979) e de artigos do Wall Street Journal. Em média, cada verbo considerado possui 12 sentidos, enquanto cada 
substantivo possui 7.8 sentidos. Para cada palavra, foram extraídos até 1.500 exemplos. A etiquetação manual do córpus estendeu-se por um ano. O SemCor também consiste de um subconjunto do córpus Brown, neste caso, com cerca de 200.000 palavras. Contudo, todas as palavras de conteúdo são etiquetadas com os sentidos da WordNet 1.6. Por ser disponível para uso gratuito (em http://www.cs.unt.edu/ rada/downloads.html\#semcor), o SemCor vem sendo utilizado para o treinamento e avaliação de várias abordagens DLS.

Córpus menores criados em determinados trabalhos de DLS também foram disponibilizados para uso em outros trabalhos. Por exemplo, os córpus criados por Leacock et al. (1993) e Bruce \& Wiebe (1994), cada um com pouco mais de 2.000 sentenças de exemplos com seis diferentes sentidos da palavra line e interest, respectivamente.

Outros exemplos de córpus comumente utilizados para a avaliação de sistemas de DLS são os córpus criados para as quatro edições do exercício de avaliação Senseval (http://www.senseval.org/). Desde a sua primeira edição, em 1998, córpus vêm sendo criados para diferentes tarefas, as quais incluem a desambiguação monolíngue do inglês e de várias outras línguas e, a partir da segunda edição, a desambiguação multilíngue, por exemplo, inglês-híndi, na terceira edição (córpus anotado com as traduções das ocorrências de 15 substantivos, 10 verbos e 6 adjetivos, totalizando 10.281 sentenças). Nenhuma tarefa proposta inclui o português. Os sentidos utilizados para a anotação variam de edição para edição. Por exemplo, os sentidos da WordNet foram utilizados na segunda edição, e também para a anotação dos substantivos e adjetivos na terceira edição, enquanto os verbos foram anotados com os sentidos do WordSmith (http://www.wordsmyth.net). O tamanho dos córpus também varia de acordo com a edição e tarefa. Por exemplo, o córpus para a tarefa lexical sample na quarta e última edição contém 65 verbos e 35 substantivos, num total de 27.132 exemplos, entre treinamento e teste, anotados com sentidos da OntoNotes (Hovy et al., 2006), que são agrupamentos de sentidos de WordNet.

Para aplicações multilíngues, com exceção dos córpus utilizados no Senseval, não há córpus de exemplos significativos. Em particular, não se tem conhecimento de um córpus envolvendo para o par de línguas inglês-português. Além disso, como afirma Ng (1997b), mesmo os córpus monolíngues são ainda muito pequenos para serem utilizados para a criação de abordagens irrestritas de DLS. Com base no DSO, o autor examina o efeito do tamanho do córpus de treinamento, em termos do número de exemplos para a DLS. Para tanto, ele define uma abordagem baseada em exemplos e realiza testes com vários subconjuntos do córpus, de modo a obter as curvas de aprendizado nesse córpus. Os resultados do experimento mostram 
que a precisão aumenta à medida que o número de exemplos do córpus cresce e que todos os exemplos do córpus são efetivamente utilizados pelo algoritmo empregado.

Como conclusão desses experimentos, o autor estima que um córpus de 3.200 palavras diferentes etiquetadas com seus sentidos é suficiente para construir um sistema de DLS de ampla cobertura e alta precisão, considerando-se qualquer palavra de conteúdo, em textos irrestritos da língua inglesa. Assumindo uma média de 1.000 ocorrências etiquetadas por sentido por palavra, isso significa um córpus de 3.2 milhões de palavras etiquetadas. Com base na sua experiência com a criação do DSO, segundo o autor, a produção manual desse córpus demandaria um tempo de 16 anos, considerando-se o esforço de um etiquetador humano.

Uma alternativa para o problema da etiquetação manual que tem sido investigada ultimamente é a etiquetação automática dos sentidos dos exemplos.

\subsection{CÓRPUS ETIQUETADOS AUTOMATICAMENTE}

Segundo Agirre \& Martínez (2004), a criação automática de córpus é uma das estratégias mais indicadas para minimizar o problema do gargalo da aquisição do conhecimento, contudo, é ainda muito pouco explorada. Para Dagan \& Itai (1994), além de permitir a aquisição de córpus mais representativos, a etiquetação automática permite capturar distinções diferentes das que seriam atribuídas por um anotador humano, por exemplo, distinções específicas de algum domínio ou pouco comuns.

Uma possibilidade para a criação automática de córpus é a exploração de textos paralelos, que facilita principalmente a criação de córpus multilíngues, mas vem sendo também empregada para a desambiguação monolíngue. Alguns exemplos do uso de córpus paralelos para a criação de córpus para a DLS monolíngue são os trabalhos de Ide et al. (2002) e Diab \& Resnik (2002).

Ide et al. (2002) utilizam textos paralelos em sete línguas para verificar em que nível as traduções para os diferentes significados de um item polissêmico do inglês são lexicalizadas por itens diferentes nessas línguas. Um algoritmo de clustering é utilizado para criar grupos de sentidos de acordo com as diferentes traduções de cada palavra do inglês, nas diferentes línguas. As distinções de sentido são, então, adquiridas a partir do córpus.

Diab \& Resnik (2002), por sua vez, propõem uma abordagem para a criação de um córpus etiquetado com sentidos a partir de córpus paralelos bilíngües, produzidos por um sistema de TA, e de um inventário de sentidos pré-definido da língua para a qual se pretende 
criar o córpus etiquetado (língua alvo). Os textos paralelos são automaticamente alinhados por sentenças e por palavras. Esse alinhamento permite identificar, nos textos da língua alvo, quais as traduções correspondentes a palavras da língua fonte. As palavras que são traduções de uma mesma forma na língua fonte são, então, agrupadas. Para cada um dos grupos gerados, são considerados todos os possíveis sentidos para cada palavra. A etiqueta de sentido adequada para cada palavra é atribuída de acordo com a sua similaridade semântica com as outras palavras no grupo. Apesar da possibilidade de geração do córpus paralelo alinhado automaticamente, é importante ressaltar que esse córpus pode apresentar diversos erros decorrentes de traduções ou alinhamentos automáticos inadequados, os quais podem propagar-se no processo de criação do córpus.

Seguindo uma metodologia diferenciada, sem a utilização de córpus paralelos, Agirre \& Martínez (2004) descrevem um processo de criação automática de córpus de exemplos etiquetados com sentidos monolíngues. O método empregado é o proposto por Leacock et al. (1998), que se baseia nos "parentes" não-polissêmicos dos itens ambíguos para obter exemplos etiquetados com sentidos para esses itens. Os parentes, nesse caso, são os sinônimos dos itens ambíguos de acordo com a WordNet. Para cada item polissêmico, são realizadas buscas na web, considerando sentenças de busca com os sinônimos não-polissêmicos para recuperar exemplos contendo esses sinônimos. A suposição do método é que, para um determinado sentido da palavra ambígua, se for possível encontrar um sinônimo não-ambíguo desse sentido, então os exemplos que contêm esse sinônimo devem ser muito similares ao sentido da palavra ambígua e podem, portanto, ser usados para gerar um modelo supervisionado para tal sentido da palavra. Para avaliar o método, o sistema treinado utilizando o SemCor juntamente com córpus construído é comparado a um sistema treinado somente com o SemCor, sendo ambos testados no conjunto de teste da tarefa lexical sample do Senseval-2. Os resultados mostram que o sistema combinando os dois córpus alcança desempenho consideravelmente superior, principalmente para palavras com poucos exemplos no SemCor.

Em uma abordagem similar, Mihalcea \& Moldovan (1999b) utilizam os sinônimos não-polissêmicos das palavras ambíguas dados pela WordNet para construir queries, que são então submetidas a um sistema de buscas na web (Altavista). Em uma avaliação manual dos exemplos coletados, é reportado que $91 \%$ desses exemplos foram corretamente recuperados, dado um conjunto de 1.080 exemplos contendo 120 sentidos. Não houve preocupação com a correlação entre o número de exemplos recuperados e a frequiência dos diversos sentidos e o córpus resultante não foi utilizado para treinar sistemas de DLS. Num trabalho posterior, 
Mihalcea (2002) produz um córpus etiquetado com sentidos (GenCor) utilizando um conjunto de sementes consistindo de exemplos etiquetados com sentidos de quatro fontes distintas: SemCor, WordNet, exemplos criados usando o método descrito e exemplos manualmente etiquetados de outras fontes, incluindo o córpus do Senseval-2. Por meio de um processo iterativo, o sistema obtém novas sementes a partir dos exemplos recuperados. No total, um córpus de 160.000 exemplos foi criado. A avaliação num subconjunto de 5 palavras dos dados da tarefa lexical sample do Senseval-2 mostrou que o método é útil para tal subconjunto, melhorando a sua precisão.

Assim como Agirre \& Martínez, Fernández et al. (2004) apresentam uma estratégia para a criação automática de córpus baseada na formação de sentenças de busca a partir das definições e relações da WordNet e na busca de exemplos com essas sentenças em córpus ou na web. Cada synset a que pertence uma palavra na WordNet é caracterizado, por meio de suas relações com outros synsets ou palavras, como uma potencial sentença de busca. Contudo, os critérios para a construção das sentenças de busca são mais elaborados e flexíveis.

Na abordagem de Agirre \& Martínez, a estrutura das sentenças de busca é fixa, definida previamente, constituída sempre de um contexto curto da palavra alvo e de mais um sinônimo não ambíguo dessa palavra. Fernández et al., por outro lado, definem uma linguagem para especificação de padrões de sentenças de busca, de modo que várias estratégias de busca possam ser previamente definidas para formar diferentes sentenças para a busca nos córpus. Com isso, a abordagem se torna mais flexível e as buscas podem retornar um número muito maior de exemplos.

Em um experimento com o córpus do SemCor, foram criadas seis estratégias de busca e essas estratégias foram aplicadas às 73 palavras ambíguas usadas no Senseval-2. As sentenças de busca geradas foram então utilizadas para recuperar exemplos similares aos do SemCor. Como cada estratégia envolve um possível sentido da palavra ambígua e as sentenças de busca mantêm esse sentido, os exemplos recuperados já possuem, automaticamente, uma etiqueta de sentido. Para todas as palavras, as sentenças de busca de todas as estratégias recuperaram, em conjunto, 48.980 exemplos (não necessariamente todos corretos de acordo com sentido buscado).

Uma abordagem para a construção semi-automática de córpus de exemplos para um conjunto de verbos é proposta por Fujii et al. (1998). Um algoritmo baseado em casos é utilizado para a amostragem seletiva de exemplos de acordo com sua utilidade para o 
treinamento de um sistema de DLS, dados um número inicial mínimo de exemplos manualmente desambiguados e um conjunto de exemplos não desambiguados de qualquer tamanho. Cada novo exemplo é submetido ao sistema baseado em casos, que atribui ao verbo ambíguo uma etiqueta de sentido. Esse exemplo é então analisado pelo método de amostragem seletiva para determinar a sua utilidade para a classificação de novos exemplos, com base (a) na quantidade de exemplos não desambiguados que se assemelham a tal exemplo, de modo a incluir exemplos que cobrem um grande número de novos casos; e (b) na diferença desse exemplo com relação aos exemplos já desambiguados, já pertencentes ao conjunto de treinamento do sistema, de modo a evitar exemplos redundantes. A etiquetação de sentido realizada pelo sistema para os exemplos selecionados é submetida à revisão humana. Em seguida, tais exemplos são acrescentados à base de exemplos de treinamento. Os exemplos não selecionados retornam para a base de exemplos não desambiguados.

Vale notar que algumas abordagens de DLS também podem ser vistas como auxiliares para a criação de córpus de exemplos: abordagens que utilizam técnicas de bootstrapping (cotraining, etc.) ou active learning, ambas comumente referenciadas como abordagens semisupervisionadas. A técnica de bootstrapping permite o aprendizado a partir de uma combinação de exemplos etiquetados e não etiquetados. A técnica active learning é usada para a escolha, a partir de dados não anotados, de exemplos relevantes, que devem ser então manualmente anotados, reduzindo assim o custo da anotação. Exemplos de tais trabalhos foram apresentados no Capítulo 3. A seguir, é apresentada a abordagem proposta neste trabalho especificamente para a criação de córpus anotados com sentidos multilíngues, ou seja, com as traduções das palavras ambíguas.

\subsection{A ABORDAGEM PROPOSTA PARA A CONSTRUÇÃO AUTOMÁTICA DE CÓRPUS ETIQUETADOS COM SENTIDOS MULTILÍNGUES}

Para a criação de córpus anotados com sentidos multilíngues, ou seja, com traduções, o uso de córpus paralelos e métodos estatísticos de alinhamento por palavras para identificar as correspondências entre as palavras nas duas ou mais línguas é uma solução bastante direta e prática, principalmente para a anotação de todas as palavras em um dado contexto. Por exemplo, Dinh (2002) utiliza córpus paralelos bilíngües e um método estatístico de alinhamento de palavras para criar um córpus do inglês etiquetado com as traduções das palavras em vietnamita. No entanto, a qualidade dos métodos de alinhamento não é 
suficientemente satisfatória na grande maioria dos casos, principalmente para traduções livres, de textos domínios e gêneros diversos. Por exemplo, Caseli et al. (2004) reportam o máximo de $57 \%$ de precisão e $61 \%$ de recall em testes com diversos métodos de alinhamento estatístico para o par inglês-português. Além disso, grandes quantidades de texto paralelo são necessárias para treinar tais métodos. Neste trabalho, um método bastante simples é proposto para a anotação da tradução de um conjunto pré-definido de palavras ambíguas, com base em córpus paralelos, informações estatísticas e lingüísticas, juntamente com um pequeno conjunto de heurísticas.

\subsubsection{Escopo}

Os experimentos para a criação do córpus foram realizados considerando-se o mesmo escopo inicial da abordagem de DLS proposta nesta tese: os sete verbos escolhidos de acordo com o estudo apresentado na Seção 2.4, juntamente com os três verbos menos ambíguos (cf. Seção 2.5). A lista dos verbos e suas possíveis traduções é exibida na Tabela 4.1. Novamente, o número de traduções foi extraído de dicionários bilíngües inglês-português, em particular, DIC Prático Michaelis®, versão 5.1, Houaiss ${ }^{\circledR}$ e Collins Gem® edição 4. São consideradas possíveis traduções palavras individuais, incluindo traduções sinônimas, e usos dos verbos em expressões verbais (phrasal verbs). Traduções do verbo em expressões verbais são consideradas porque a ocorrência do verbo seguida de uma preposição / partícula não necessariamente indica a ocorrência de uma expressão verbal. Por exemplo, na construção "she came in red", "come in" não é utilizado como uma expressão verbal, em oposição a "she came in and took off her shoes". Construções multi-palavras não são consideradas possíveis traduções por razões práticas. De fato, esses são os critérios considerados em geral em trabalhos de desambiguação multilíngue. O número médio de traduções para os sete verbos mais ambíguos (come, get, give, go look, make e take) é 203, enquanto o número médio para os demais verbos (ask, live e tell) é 19.

Tabela 4.1: Verbos e suas possíveis traduções, de acordo com dicionários bilíngües

\begin{tabular}{|l|r|r|r|r|r|r|r|r|r|r|}
\cline { 2 - 11 } \multicolumn{1}{c|}{} & ask & come & \multicolumn{1}{c|}{ get } & give & \multicolumn{1}{c|}{ go } & live & look & make & take & tell \\
\hline \# traduções & 16 & 226 & 242 & 128 & 197 & 15 & 63 & 239 & 331 & 28 \\
\hline
\end{tabular}

\subsubsection{Córpus paralelos}

O córpus paralelo utilizado para os experimentos consiste de sentenças do inglês contendo os 10 verbos, juntamente com suas correspondentes traduções (realizadas por humanos) para o 
português. Tais sentenças foram coletadas de nove fontes, de variados gêneros e domínios, conforme ilustrado na Tabela 4.2:

- Europarl (Koehn, 2002) contém as versões bilíngües dos documentos do Parlamento Europeu, portanto, do português europeu.

- Compara (Frankenberg-Garcia \& Santos, 2003) contém traduções de livros de ficção em ambas as direções, ou seja, português-inglês e inglês-português, incluindo tanto o português europeu quanto o brasileiro.

- Messages (www.gnome.org) contém mensagens de entrada e saída utilizadas pelo sistema operacional Linux.

- Bible contém versões bilíngües da bíblia cristã.

- Miscellaneous contém uma variedade de pequenos córpus paralelos, com menos de 1.000 sentenças cada, incluindo o romance The Red Badge of Courage (Stephen Crane), o manual do usuário da linguagem de programação PHP (www.php.net/download-docs.php), documentos da ALCA (Área de Livre Comércio das Américas - www.ftaa-alca.org/alca_p.as), artigos da edição on-line do jornal New York Times (www.nytimes.com) e resumos de teses e dissertações em Ciência da Computação do ICMC - Universidade de São Paulo.

Tabela 4.2: Número de unidades e palavras nos córpus paralelos

\begin{tabular}{|l|r|r|r|}
\hline \multicolumn{1}{|c|}{ Córpus } & \# unidades & \# palavras inglês & \# palavras português \\
\hline Europarl & 167.339 & 6.193 .904 & 6.299 .686 \\
\hline Compara & 19.706 & 518.710 & 475.679 \\
\hline Messages & 16.844 & 385.539 & 394.095 \\
\hline Bible & 15.189 & 474.459 & 443.349 \\
\hline Miscellaneous & 1.328 & 33.538 & 29.239 \\
\hline Total & $\mathbf{2 2 0 . 4 0 6}$ & $\mathbf{7 . 6 0 6 . 1 5 0}$ & $\mathbf{7 . 6 4 2 . 0 4 8}$ \\
\hline
\end{tabular}

Tais córpus foram escolhidos devido a sua disponibilidade e também ao fato de serem alinhados no nível de sentenças. O córpus Compara fornece uma ferramenta para extração de sentenças paralelas contendo determinada(s) palavra(s). No caso dos demais córpus, concordanciadores foram desenvolvidos para extrair sentenças contendo as diversas formas (pessoa e tempo) dos 10 verbos. Nos números ilustrados na Tabela 4.2, as múltiplas sentenças encontradas em alinhamentos do tipo muitos-para-um ou um-para-muitos foram agrupadas formando uma "unidade", o que resultou no mesmo número de unidades em ambas as línguas. Além do número de unidades selecionadas em cada córpus, a tabela mostra os números de palavras do inglês e do português em tais unidades. A proporção de unidades para cada verbo varia de córpus para córpus e não é relevante, no momento, uma vez que apenas uma porção 
do córpus contendo o mesmo número de sentenças para cada verbo será utilizada, como será discutido no decorrer desta tese.

\subsubsection{Pré-processamento do córpus}

Para transformar o córpus no formato apropriado para a anotação e remover pares de sentenças inadequados, os seguintes passos de pré-processamento foram realizados:

1. Unidades do inglês foram lematizadas utilizando-se o parser Minipar (Lin, 1993), de modo a obter uma representação única das formas variantes de cada palavra para o processamento estatístico.

2. Pares de unidades contendo expressões idiomáticas do inglês envolvendo um dos 10 verbos foram eliminadas. A identificação automática das traduções nesses casos seria demasiado complexa, já que tais traduções muitas vezes envolvem múltiplas palavras e muito raramente são literais. Para esse filtro, uma lista de expressões idiomáticas contendo os verbos foi criada a partir da versão eletrônica do Cambridge Dictionary of Idioms ${ }^{20}$.

3. Unidades em ambas as línguas foram anotadas com suas etiquetas gramaticais utilizando o etiquetador gramatical Mxpost (Ratnaparkhi, 1996), em versões previamente treinadas para o inglês e para o português.

4. Os verbos e expressões verbais do português foram lematizados utilizando-se heurísticas para a escolha do lema adequado a partir das opções disponíveis no léxico do português (Nunes et al., 1996). A lematização do verbo foi necessária para a generalização das regras de anotação de sentido. As demais palavras não foram lematizadas, uma vez que não se dispunha de um lematizador do português para outras categorias gramaticais.

5. Pares de unidades nos quais o verbo do inglês foi anotado com uma categoria gramatical diferente de verbo pelo Mxpost foram eliminados, uma vez que não havia sido feita distinção, nos concordanciadores, de categoria gramatical e, portanto, usos de verbos como live e look como substantivos também haviam sido selecionados.

Dessas etapas de pré-processamento resultaram 206.913 pares de unidades (em todos os córpus), sendo todas as suas palavras etiquetadas com categorias gramaticais e as palavras do

\footnotetext{
${ }^{20}$ http://dictionary.cambridge.org/default.asp?dict=I
} 
inglês e os verbos do português lematizados.

\subsubsection{Identificação da tradução dos verbos}

As seguintes suposições foram feitas para a identificação da tradução de cada ocorrência do verbo nas sentenças em inglês, dadas as suas sentenças correspondentes em português no corpus paralelo:

- Dado um córpus paralelo alinhado por sentenças, uma tradução para o verbo na unidade em inglês pode ser encontrada na unidade correspondente em português.

- Cada verbo do inglês possui um conjunto pré-definido de possíveis traduções, que inclui traduções referentes a expressões verbais, e esse conjunto pode ser extraído de dicionários bilíngües e por meio da análise estatística de córpus paralelos.

- Expressões verbais têm traduções específicas, portanto, quando da ocorrência do verbo juntamente com preposições / partículas que podem caracterizar uma expressão verbal, as possíveis traduções do verbo para tal expressão têm preferência com relação às traduções do verbo individualmente.

- Traduções têm diferentes probabilidades de serem utilizadas em um dado córpus e tais probabilidades podem ser identificadas por meio da análise estatística de coocorrências no córpus paralelo.

- Se existirem duas ou mais possíveis traduções para uma ocorrência do verbo do inglês na sentença em português, quanto mais próxima a posição da tradução candidata na sentença em português com relação ao verbo na sentença em inglês, maior é a chance de tal candidata ser a tradução correta.

As possíveis traduções de cada verbo foram extraídas dos dicionários bilíngües DIC Prático Michaelis ${ }^{\circledR}$, versão 5.1, Houaiss ${ }^{\circledR}$ e Collins Gem ${ }^{\circledR}$ edição 4. Os mesmos dicionários foram utilizados para criar listas de expressões verbais para cada verbo, juntamente com suas traduções. Para guiar a busca de possíveis expressões verbais nas sentenças do inglês, a versão eletrônica do Cambridge Dictionary of Phrasal Verbs ${ }^{21}$ foi utilizada para dividir tais expressões em separáveis e inseparáveis, ou seja, expressões verbais que aceitam (ou não) outras palavras entre o verbo e a partícula. Adicionalmente, ocorrências de todas as expressões no British National Corpus foram manualmente analisadas para anotar as construções que podem caracterizar tanto expressões verbais quanto usos do verbo

\footnotetext{
${ }^{21}$ http://dictionary.cambridge.org/default.asp?dict=P
} 
individualmente seguido de preposição (por exemplo, come in).

O pacote de ferramentas NATools para o alinhamento de palavras (Simões \& Almeida, 2003) foi utilizado para produzir uma lista de possíveis traduções para cada verbo em cada um dos córpus da Tabela 4.2, a ser utilizada como recurso auxiliar para o caso de unidades do português contendo múltiplas possíveis traduções do verbo em questão. A ferramenta utilizada do NATools explora técnicas estatísticas para criar dicionários bilíngües a partir de córpus paralelos alinhados por sentenças. Na versão utilizada, são produzidas listas bidirecionais de no máximo 20 possíveis traduções mais prováveis para cada palavra no córpus paralelo, juntamente com as suas probabilidades naquele córpus. Muito embora a ferramenta não requeira processamento lingüístico, após experimentos com e sem o uso de ferramentas de processamento lingüística superficial, optou-se por pré-processar cada córpus paralelo da Tabela 4.2 para melhorar os dicionários produzidos, por meio dos seguintes passos:

1. Os verbos nas unidades de ambas as línguas foram identificados utilizando-se o Mxpost.

2. Os verbos nas unidades de ambas as línguas foram lematizados, utilizando-se para tanto o parser Minipar e as heurísticas baseadas no léxico do português, respectivamente.

3. Os pares de unidades contendo expressões idiomáticas envolvendo os verbos em questão na unidade do inglês foram eliminados, utilizando-se a lista de expressões idiomáticas previamente mencionada.

4. Stop words, sinais de pontuação e outros símbolos foram removidos das unidades em ambas as línguas, utilizando-se uma pequena lista de stop words relativamente simétrica para ambas as línguas, composta essencialmente de artigos, conjunções, pronomes relativos e demonstrativos, entre outras palavras freqüentes.

Como exemplo dos resultados do NATools, considere a lista de probabilidades de traduções produzidas para o verbo give, no córpus Compara, ilustrada na Tabela 4.3. Vale notar que a lista de 20 traduções encontradas para os verbos em questão tende a refletir apenas alinhamentos um-para-um, com raras exceções. 
Tabela 4.3: Probabilidades de traduções para give no córpus Compara

\begin{tabular}{|l|r|}
\hline \multicolumn{1}{|c|}{ Tradução } & Probabilidade \\
\hline dar_v & 0.5783 \\
\hline$\backslash$ (null\) & 0.1520 \\
\hline fazer_v & 0.0309 \\
\hline entregar_v & 0.0252 \\
\hline ser_v & 0.0230 \\
\hline desistir_v & 0.0225 \\
\hline lançar_v & 0.0131 \\
\hline ceder_v & 0.0117 \\
\hline receber_v & 0.0079 \\
\hline provocar_v & 0.0077 \\
\hline deixar_v & 0.0065 \\
\hline pergunta & 0.0063 \\
\hline soltar_v & 0.0060 \\
\hline renunciar_v & 0.0055 \\
\hline devolver_v & 0.0053 \\
\hline
\end{tabular}

Para cada verbo do inglês, a lista produzida contém, na sua maioria, verbos do português que são considerados possíveis traduções de tal verbo (verbos em negrito no exemplo da Tabela 4.3), mas também outros verbos que não são considerados possíveis traduções de acordo com os dicionários bilíngües utilizados (outras palavras com_v na Tabela 4.3), palavras de outras categorias gramaticais e a tradução vazia, que indica que o verbo não é traduzido. A probabilidade de tradução vazia é bastante alta para certos verbos, como é o caso do verbo give no exemplo da Tabela 4.3, na qual essa probabilidade aparece em segundo lugar. Isso pode ser decorrente de alinhamentos nulos ou causados pela insuficiência de exemplos para o processamento estatístico de certas traduções. Uma vez que se assume que pelo menos uma possível tradução do verbo existe na unidade do português, e que essa tradução é também um verbo, as listas foram normalizadas, eliminando-se a probabilidade de tradução nula e as palavras de outras categorias gramaticais.

Como se espera que as probabilidades de tradução variem de córpus para córpus, de acordo com o domínio e gênero de tal córpus, dicionários foram gerados para cada córpus individualmente. Tais dicionários incluem, como mencionado, no máximo 20 traduções para cada verbo, e não todas as possíveis traduções do verbo de acordo com os dicionários bilíngües (Tabela 4.1), uma vez que muitas delas não são utilizadas no córpus, ou são utilizadas com freqüência muito baixa. Para tais traduções foi atribuída probabilidade zero.

Dado o córpus paralelo pré-processado conforme foi descrito na Seção 4.3.2, as suposições mencionadas no início desta seção e os recursos acima descritos, para cada unidade paralela de cada um dos verbos, o seguinte procedimento foi definido para encontrar, na unidade em português (UP), a tradução mais adequada para cada ocorrência do verbo numa 
unidade do inglês (UE) (conforme ilustrado na Figura 4.1):

1. Identificar expressões verbais inseparáveis na UE, anotando a unidade como do tipo “expressão inseparável”, quando ela contém tais expressões. Cada ocorrência do verbo em questão na UE, juntamente com um contexto de até cinco palavras seguintes, é comparada às expressões na lista de expressões verbais inseparáveis do verbo em questão.

2. Identificar, nas UEs restantes, expressões verbais separáveis, anotando a unidade como do tipo "expressão separável", quando ela contém tais expressões. Cada ocorrência do verbo em questão, juntamente com um contexto de até oito palavras seguintes, é comparada às expressões na lista de expressões verbais separáveis do verbo em questão, permitindo até três palavras entre o verbo e a partícula. As demais unidades são anotadas como do tipo "sem expressão".

3. Identificar a posição absoluta do verbo (anotado como expressão verbal ou não) na UE, ignorando sinais de pontuação e outros símbolos.

4. Procurar, nas palavras etiquetadas como verbos na UP, por todas as possíveis traduções do verbo, utilizando-se a lista de expressões verbais inseparáveis, a lista de expressões verbais separáveis, e a lista de traduções do verbo individualmente, de acordo com a anotação do tipo de unidade. Como resultado, três possíveis situações podem surgir:

i. Nenhuma possível tradução é encontrada - avançar para o passo 5.

ii. Uma única tradução é encontrada - selecionar tal tradução para anotar a UE e finalizar o processo para tal ocorrência.

iii. Duas ou mais traduções são encontradas - avançar para o passo 6.

5. Se a unidade for do tipo "sem expressão", finalizar o processo para a ocorrência em questão, considerando que nenhuma tradução foi encontrada. Caso contrário, ou seja, se a ocorrência tiver sido anotada como "expressão inseparável" ou “expressão separável”, primeiramente verificar se a construção contendo o verbo + partícula / preposição pode também caracterizar o uso do verbo individualmente. Em caso negativo, finalizar o processo para a ocorrência em questão, considerando que nenhuma tradução foi encontrada. Em caso positivo, voltar ao passo 4, procurando agora pelas possíveis traduções do verbo na lista de usos do verbo individualmente.

6. Identificar a posição absoluta de cada uma das possíveis traduções na UP e atribuir um peso de acordo com a posição $(\operatorname{Pos} W)$ de tal tradução, penalizando traduções 
em posições distantes à posição do verbo na UE, de acordo com a seguinte fórmula:

$$
\text { Pos } W=1-\left(\frac{\mid \text { UEposition }- \text { UPposition } \mid}{10}\right)
$$

7. Calcular o peso final de cada tradução (TraW) adicionando a probabilidade da tradução candidata, de acordo com o dicionário de probabilidades fornecido pela ferramenta NATools:

$$
\text { TraW }=\text { Pos W }+ \text { probabilidade da tradução }
$$

8. Selecionar a tradução com o maior peso $(\operatorname{Tr} a W)$ para anotar a UE e finalizar o processo para tal ocorrência.

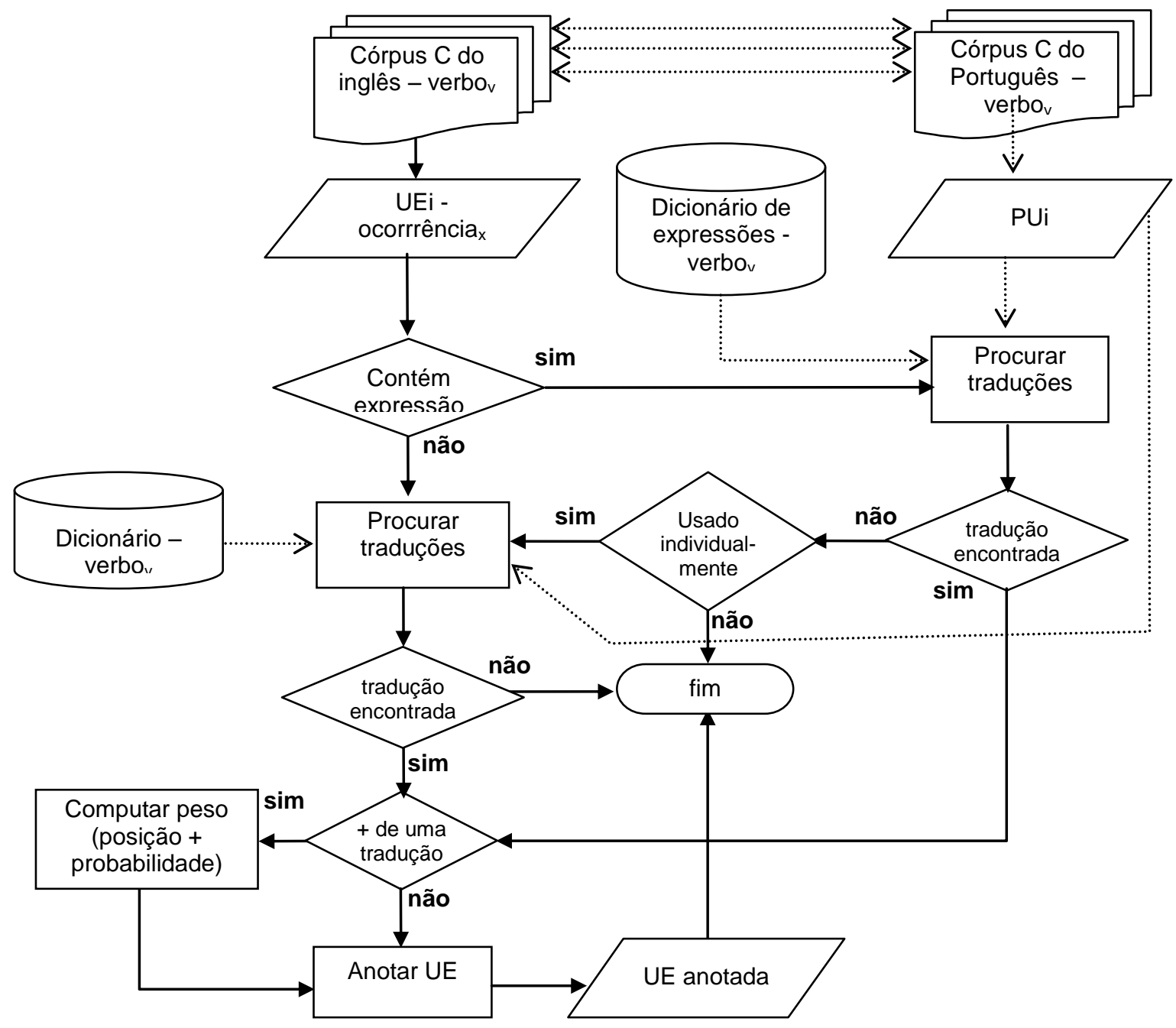

Figura 4.1: Processo de identificação e anotação da tradução de cada ocorrência (ocorrência ${ }_{x}$ ) do verbo (verbo ${ }_{v}$ ) em uma unidade paralela (EUi e PUi) de um dado córpus C 
O esquema de pesos adotado nos casos em que mais de uma tradução candidata é encontrada na unidade do português, que contempla a posição dos verbos nas unidades do inglês e português e a probabilidade de cada tradução no córpus, foi empiricamente definido após experimentos com diferentes esquemas e valores de pesos. A heurística da posição, em particular, é baseada na idéia de que o alinhamento de palavras entre duas línguas relativamente próximas como português e inglês tende a ser monotônico, isto é, palavras correspondentes nas duas línguas tendem a ser distribuídas em posições próximas nas sentenças (Gale and Church, 1993). Como um exemplo do uso desse esquema, considere o par de sentenças na Figura 4.2 para o verbo come (posição da UE =7). As traduções candidatas na unidade do português são ilustradas na Figura 4.3.

"I'd rather leave without whatever I came for."

"Prefiro sair sem o que for que tenha vindo buscar."

Figura 4.2: Exemplo de unidade paralela

\begin{tabular}{|l|}
\hline vir $($ lema de vindo) - posição na UP $=9$, PosW $=0.8$, probabilidade $=0.432$, TraW $=1.232$ \\
\hline sair - posição na UP $=2$, PosW $=0.5$, probabilidade $=0.053$, TraW $=0.553$ \\
\hline ir (lema de for) (posição na UP $=6$, PosW $=0.9$, probabilidade $=0.04$, TraW $=0.94$ \\
\hline
\end{tabular}

Figura 4.3: Traduções candidatas para a unidade paralela na Figura 4.2

O sistema corretamente identifica que a tradução é vir, lema de vindo, já que as duas outras traduções candidatas na unidade do português possuem um escore inferior. Vale notar que, neste exemplo, tanto a heurística da proximidade da posição do verbo nas unidades em ambas as línguas quanto a probabilidade de tradução têm papel importante para a escolha da tradução adequada. Em geral, a probabilidade de tradução é especialmente importante quando várias traduções candidatas localizam-se em posições próximas da posição do verbo na unidade do inglês. Neste exemplo, se apenas as posições dos verbos tivessem sido consideradas, sem o esquema de pesos, o sistema teria indicado como tradução $i r$, que está em posição mais próxima. De fato, uma primeira versão do sistema implementada considerandose apenas a informação sobre as posições (Specia et al., 2005a) mostrou resultados inferiores, como será apresentado na próxima seção.

Vale notar que, no córpus resultante, além da anotação da tradução para o verbo em questão, todas as palavras da sentença em inglês são anotadas com suas categorias gramaticais e lemas. Essas informações, juntamente com as palavras das sentenças do inglês e português, propriamente ditas, podem ser diretamente extraídas e utilizadas como fontes de conhecimento na abordagem de DLS proposta, que será apresentada no Capítulo 4. Exemplos 
de sentenças resultantes são ilustrados na Figura 4.4. A primeira linha indica as informações em cada elemento do córpus.

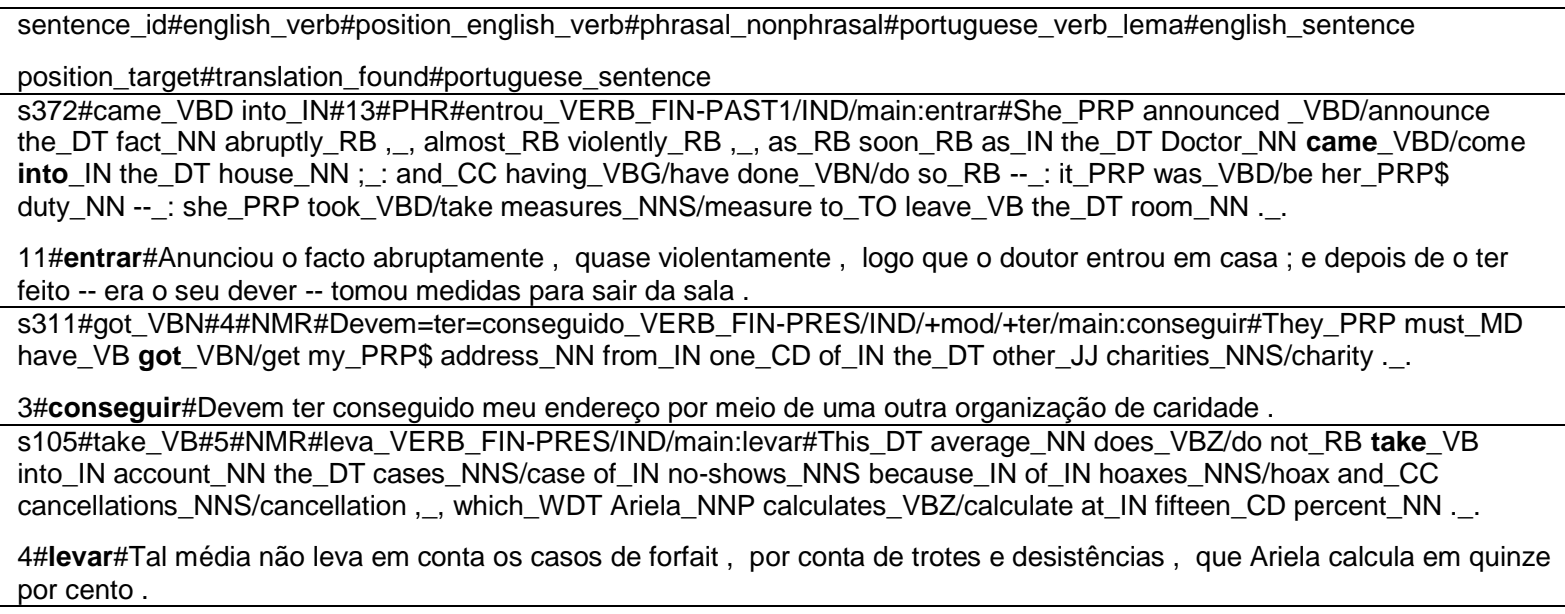

Figura 4.4: Exemplos de anotações produzidas para sentenças dos verbos come, get e take

\subsubsection{Avaliação e discussão}

Quando aplicado a cada um dos córpus da Tabela 4.2 (individualmente), o sistema de anotação de sentido proposto foi capaz de encontrar uma tradução para 55\% de todas as ocorrências dos verbos, ou seja, 113,802 unidades do inglês foram anotadas. Percentuais similares de identificação foram observados entre os diversos verbos e córpus. Essa medida pode ser considerada como a cobertura do sistema. A falta de identificação no restante dos casos se deve a três razões principais:

(a) Não se considera multipalavras como traduções candidatas, e com isso eliminamse certas unidades, principalmente aquelas incluindo usos conotativos do verbo, os quais são geralmente traduzidos por expressões ${ }^{22}$.

(b) As ferramentas utilizadas para o pré-processamento falham em alguns casos e isso tem efeito na anotação das traduções. Em particular, o etiquetador gramatical Mxpost em alguns casos anota incorretamente verbos na unidade do português como substantivos ou adjetivos.

(c) Muitas unidades do português apresentam traduções não-literais da unidade do inglês com modificações consideravelmente grandes, incluindo casos de omissão do verbo em questão ou da sua tradução utilizando-se palavras de outras categorias gramaticais, as quais não são consideradas aqui.

A cobertura relativamente baixa do sistema não representa um problema para este

\footnotetext{
${ }^{22}$ Apesar de a lista de expressões idiomáticas ter sido utilizada para filtrar sentenças, tal lista não cobre muitas expressões e, principalmente, casos de variações mais sutis do uso dos verbos.
} 
trabalho, uma vez que a abordagem proposta visa justamente dar preferência à precisão da etiquetação, em detrimento da sua cobertura. De fato, como a intenção é utilizar o córpus anotado para o treinamento de sistemas de DLS, as traduções devem ser anotadas corretamente.

Para estimar a precisão do sistema na anotação das traduções, 30 unidades de cada verbo, em cada córpus, foram aleatoriamente selecionadas, incluindo-se aquelas com e sem expressões verbais, totalizando 1.500 unidades. A precisão de cada verbo em cada córpus, definida como o percentual de unidades corretamente anotadas, é ilustrada na Tabela 4.4.

Tabela 4.4: Precisão do processo de anotação das traduções (Specia et al., 2005b)

\begin{tabular}{|l|r|r|r|r|r|}
\hline \multirow{2}{*}{ Verbo } & \multicolumn{6}{|c|}{ Precisão por córpus } \\
\cline { 2 - 6 } & Europarl & Compara & Messages & Bible & Miscellaneous \\
\hline come & 80 & 84 & 95 & 90 & 91 \\
\hline get & 93 & 87 & 100 & 95 & 82 \\
\hline give & 97 & 95 & 95 & 97 & 93 \\
\hline go & 90 & 90 & 95 & 85 & 95 \\
\hline look & 100 & 98 & 95 & 90 & 100 \\
\hline make & 87 & 86 & 100 & 93 & 97 \\
\hline take & 80 & 88 & 91 & 90 & 93 \\
\hline ask & 100 & 98 & 100 & 100 & 100 \\
\hline live & 100 & 100 & 100 & 100 & 100 \\
\hline tell & 100 & 94 & 100 & 100 & 96 \\
\hline Média & $\mathbf{9 3}$ & $\mathbf{9 2}$ & $\mathbf{9 7}$ & $\mathbf{9 4}$ & $\mathbf{9 5}$ \\
\hline
\end{tabular}

Em média, o sistema foi capaz de identificar o sentido correto de $94.2 \%$ das unidades analisadas. Uma precisão bastante alta (99.2\%) foi obtida para os três verbos menos ambíguos. Uma precisão mais alta que a média (96\%) foi alcançada para look e give, que têm os menores números de possíveis traduções, entre os sete verbos mais ambíguos. A precisão média para os cinco verbos restantes foi de $90.3 \%$. Portanto, muito embora não exista relação direta entre o número de possíveis traduções e a precisão alcançada, esta é em geral mais baixa para os verbos mais ambíguos.

Os erros de anotação são conseqüência dos problemas mencionados anteriormente, referentes à cobertura do sistema, mas são também decorrentes de limitações das heurísticas propostas. A distribuição das fontes de erros para cada córpus, em percentual, é ilustrada na Tabela 4.5. A maioria dos erros deve-se a modificações consideráveis nas traduções, com relação à unidade no inglês, incluindo omissões do verbo e paráfrases, por exemplo, sentenças na voz ativa sendo traduzidas para sentenças na voz passiva, com o uso de verbos diferentes. De fato, mesmo nos córpus de textos técnicos, como o Messages, as traduções, em geral, não eram literais. Assim, em muitos casos de traduções não literais, incluindo-se os de uso de expressões verbais na unidade do inglês, não consta na unidade do português a tradução do 
verbo, ou esta é expressa por outras palavras que não são consideradas possíveis traduções, de acordo com os dicionários bilíngües. No entanto, as heurísticas permitem que o sistema encontre outras traduções, correspondentes a outros verbos na unidade do inglês, as quais também são consideradas traduções válidas para o verbo em questão, mas não são a tradução correta para a ocorrência em questão, o que leva a anotações inadequadas. Essa é considerada uma deficiência das heurísticas, conforme ilustrado na última coluna da Tabela 4.5. Erros do etiquetador gramatical, conforme mencionado, referem-se geralmente à anotação dos verbos do português com categorias gramaticais incorretas. Em muitos desses casos, o sistema também encontra outra possível tradução, referente a um segundo verbo, na unidade do português. Erros atribuídos às escolhas feitas pelas heurísticas também se relacionam, em muitos casos, às outras fontes de erros. Em particular, o uso da posição das palavras como principal evidência pode ser uma estratégia inapropriada quando a ordem das palavras na tradução é radicalmente modificada.

Tabela 4.5: Fontes de erros de etiquetação

\begin{tabular}{|l|r|r|r|r|}
\hline \multicolumn{1}{|c|}{ Córpus } & \% expressões & \% traduções modificadas & \% pré-processamento & \% erros das heurísticas \\
\hline Europarl & 6 & 66 & 8 & 20 \\
\hline Compara & 8 & 71 & 0 & 21 \\
\hline Messages & 0 & 100 & 0 & 0 \\
\hline Bible & 6 & 74 & 10 & 10 \\
\hline Miscellaneous & 10 & 69 & 16 & 5 \\
\hline
\end{tabular}

É importante notar que a complexidade da tarefa de anotação deve-se não apenas ao nível de ambigüidade dos verbos, mas também a características do córpus. Em particular, certas unidades são bastante longas (por exemplo, 180 palavras), contendo múltiplas ocorrências do verbo em questão ou diversos verbos que compartilham possíveis traduções (por exemplo, get e take compartilham traduções como "pegar”). Com isso, é comum encontrar várias possíveis traduções na unidade do português, o que dificulta a identificação da tradução correta. $\mathrm{O}$ alinhamento de sentenças certamente minimiza o número de traduções possíveis apontadas pelos dicionários bilíngües, contudo, o número de traduções candidatas em cada unidade do português ainda se mostra bastante alto nos experimentos realizados aqui: $1.5 \mathrm{em}$ média, para todos os córpus e verbos. Considerando-se apenas os sete verbos mais ambíguos, esse número cresce para 2.4 (foram encontradas de 1 a 15 possíveis traduções em cada unidade do português).

Apesar de simples, no entanto, as heurísticas considerando posição e probabilidade de tradução no córpus se mostraram efetivas. A contribuição da probabilidade de tradução no córpus, em particular, pode ser confirmada por experimentos anteriormente realizados 
considerando-se apenas as posições das traduções candidatas na unidade do português com relação à posição do verbo na unidade do inglês. Em (Specia et al., 2005a), uma versão preliminar do sistema de etiquetação foi avaliada com um número reduzido de sentenças para os sete verbos mais ambíguos (20 ocorrências de cada verbo), e em apenas dois córpus, Compara e Europarl. Os resultados são ilustrados na Tabela 4.6.

Tabela 4.6: Precisão de uma versão preliminar do processo de etiquetação de traduções, baseada apenas nas posições das palavras (Specia et al., 2005a)

\begin{tabular}{|l|r|r|}
\hline \multirow{2}{*}{ Verbo } & \multicolumn{2}{|c|}{ Precisão por córpus } \\
\cline { 2 - 3 } & Compara & \multicolumn{1}{c|}{ Europarl } \\
\hline come & 75 & 70 \\
\hline get & 70 & 85 \\
\hline give & 90 & 95 \\
\hline go & 80 & 55 \\
\hline look & 95 & 100 \\
\hline make & 90 & 80 \\
\hline take & 80 & 85 \\
\hline Média & 82.86 & 81.43 \\
\hline
\end{tabular}

A comparação direta de tais resultados com os obtidos na versão nova do sistema não se aplica, já que diferentes conjuntos de sentenças foram analisadas nas duas versões. Contudo, pode-se perceber que, nos dois córpus analisados em ambos experimentos (Compara e Europarl), para a grande maioria dos verbos, a segunda versão do sistema, que considera ambas as heurísticas de posição e probabilidades de tradução no córpus, apresenta melhoria significativa na precisão média para os sete verbos mais ambíguos: de $82.86 \%$ (Compara) e $81.43 \%$ (Europarl) para $89.71 \%$ (Compara) e $89.57 \%$ (Europarl).

O sistema de anotação automática também foi utilizado para a etiquetação de uma nova seleção aleatória de sentenças extraídas dos córpus paralelos da Tabela 4.2, com diferentes distribuições, dependendo da disponibilidade de sentenças com os verbos em questão em tais córpus. Tinha-se por objetivo a construção de um córpus maior, com 500 sentenças para cada um dos 10 verbos. As anotações foram manualmente revisadas, mas uma avaliação sistemática da precisão do sistema não foi realizada em função da limitação de tempo. Contudo, confirmou-se que a revisão manual requer esforço consideravelmente menor que o da anotação manual. Neste caso, a revisão foi realizada por duas tradutoras humanas em tempo relativamente curto, já que restava apenas confirmar se a tradução escolhida pelo sistema, já anotada e indexada pela sua posição na sentença do português e pela posição da palavra fonte na sentença do inglês, era a correta e, em caso negativo, corrigir tal anotação.

A distribuição das origens das sentenças nesse novo córpus, ou seja, os córpus paralelos dos quais elas foram extraídas, é ilustrada na Tabela 4.7. A idéia era selecionar os 
exemplos de acordo com a seguinte distribuição, para cada verbo: 200 exemplos do Compara (40\%), 100\% do corpus Bible (20\%), 90 exemplos do Europarl (18\%), 60 exemplos de Miscellaneous (12\%) e 50 exemplos do corpus Messages (10\%). No entanto, como alguns dos corpus não dispunham de exemplos suficientes para determinados verbos, a distribuição foi redefinida, conforme ilustrado na Tabela 4.7. Tal córpus é o mais relevante para esse trabalho, por conter o maior número de sentenças por verbo, e por apresentar maior variabilidade quanto a gênero e domínio. Experimentos com esse córpus, bem como com os córpus anteriormente apresentados, serão descritos no Capítulo 6.

Tabela 4.7: Distribuição da origem das sentenças no novo córpus

\begin{tabular}{|l|r|r|r|r|r|r|r|r|r|r|}
\hline \multirow{2}{*}{ Córpus } & \multicolumn{10}{|c|}{ unidades por verbo } \\
\cline { 2 - 12 } & ask & \multicolumn{1}{c|}{ come } & \multicolumn{1}{c|}{ get } & \multicolumn{1}{c|}{ give } & \multicolumn{1}{c|}{ go } & \multicolumn{1}{c|}{ live } & \multicolumn{1}{c|}{ look } & make & take & tell \\
\hline Europarl & 138 & 123 & 90 & 140 & 140 & 90 & 90 & 140 & 140 & 139 \\
\hline Compara & 200 & 200 & 200 & 200 & 200 & 200 & 200 & 200 & 200 & 200 \\
\hline Messages & 2 & 2 & 50 & 0 & 0 & 2 & 50 & 0 & 0 & 1 \\
\hline Bible & 142 & 115 & 109 & 114 & 100 & 208 & 113 & 100 & 100 & 128 \\
\hline Miscellaneous & 18 & 60 & 51 & 46 & 60 & 0 & 47 & 60 & 60 & 32 \\
\hline Total & 500 & 500 & 500 & 500 & 500 & 500 & 500 & 500 & 500 & 500 \\
\hline
\end{tabular}

\subsubsection{Comparação com abordagem alternativa}

Conforme mencionado, uma abordagem que se mostra, em princípio, bastante apropriada para a anotação de córpus com sentidos multilíngues a partir de córpus paralelos é a utilização de métodos de alinhamento de palavras. Contudo, a qualidade dos sistemas de alinhamento não é suficientemente satisfatória para o alinhamento dos verbos nos córpus em questão. Para investigar tal afirmação, a precisão do sistema proposto foi comparada ao do sistema de alinhamento GIZA++ (Och \& Ney, 2003), considerado o melhor método de alinhamento estatístico. Cada córpus pré-processado foi submetido ao GIZA++ e os alinhamentos produzidos para os verbos em questão, nas mesmas sentenças analisadas na avaliação do sistema proposto, foram manualmente verificados. Considerou-se que um alinhamento era correto caso ele incluísse a tradução do verbo, ainda que juntamente com outras palavras (ou seja, alinhamentos diferentes de um-para-um). A precisão média para cada córpus é ilustrada na Tabela 4.8. Como se pode verificar, tal precisão é consideravelmente mais baixa que a precisão do sistema proposto neste trabalho. A diferença entre as duas abordagens é estatisticamente significativa ( $\mathrm{p}<0.05$, Wilcoxon Signed Ranks Test (Wilcoxon, 1945)). Uma vez que a única fonte de informação utilizada pelo GIZA++ é a estatística, o sistema não foi capaz de identificar alinhamentos com traduções pouco freqüentes. O problema se mostrou ainda crítico no caso de traduções não literais. 
Tabela 4.8: Precisão média do sistema de alinhamento de palavras GIZA++ nos córpus

\begin{tabular}{|l|r|}
\hline \multicolumn{1}{|c|}{ Córpus } & \multicolumn{1}{c|}{ Precisão } \\
\hline Europarl & 51 \\
\hline Compara & 61 \\
\hline Messages & 70 \\
\hline Bible & 42 \\
\hline Miscellaneous & 66 \\
\hline
\end{tabular}

Vale notar que nos resultados ilustrados na Tabela 4.8 foram considerados apenas os casos nos quais o sistema proposto neste trabalho havia identificado uma tradução, ou seja, os casos “mais bem comportados". Para verificar a performance do sistema GIZA++ para os demais casos, ou seja, as unidades não anotadas pelo sistema proposto, 10 unidades foram analisadas para cada um dos 10 verbos em todos os córpus, totalizando 500 unidades. Esperava-se que o GIZA++ resultasse em alinhamentos nulos para grande parte dessas unidades, já que havia muitos casos de modificações consideráveis na tradução, incluindo a omissão do verbo. Contudo, na média (todos os verbos e córpus), somente $1 \%$ das unidades não-anotadas resultaram em alinhamentos nulos do GIZA++. Para 29\% das unidades, GIZA++ produziu um alinhamento correto, enquanto que nas demais unidades (70\%), um alinhamento incorreto foi produzido. Na maioria dessas unidades, GIZA++ indicou um alinhamento mesmo quando a tradução do verbo não estava na unidade do português. Assim, o método de alinhamento resulta num aumento da cobertura da anotação, mas, por outro lado, a precisão é enormemente degradada, devido às limitações da abordagem estatística.

\subsection{CONSIDERAÇÕES FINAIS}

Nesse capítulo foi apresentada uma abordagem para a criação automática de um córpus anotado com as traduções de determinadas palavras ambíguas, voltado para a DLS multilíngue. Os resultados de diferentes experimentos de avaliação realizados mostram que o uso de uma abordagem híbrida, considerando conhecimento estatístico e lingüístico, leva a resultados mais precisos, quando comparados ao método de alinhamento de palavras mais utilizado atualmente. Constatou-se que a maioria dos erros de anotação encontrados são relacionados a características dos córpus paralelos utilizados, como a modificação de traduções e o uso de construções que dificilmente poderiam ser processadas automaticamente (gírias, por exemplo). Vale notar que o uso das listas de possíveis traduções extraídas de dicionários permitiu evitar muitos erros de anotação dessa natureza, diminuindo a cobertura do sistema, mas aumentado a sua precisão. Além disso, embora informação estatística seja utilizada, o sistema ainda é capaz de produzir anotações caso ela não esteja disponível, ou 
seja, caso seja considerada uma distribuição uniforme para todas as probabilidades de tradução. Essa característica é bastante relevante para a anotação de córpus pequenos, nos quais não há exemplos em número suficiente para gerar estatísticas de alinhamento confiáveis.

Apesar das anotações produzidas pelo sistema não alcançarem 100\% de precisão e, portanto, ainda requererem revisão manual para a utilização dos córpus anotados na geração de modelos de DLS, tais anotações certamente facilitam o processo de etiquetação: o sistema permite a anotação de grandes córpus paralelos em tempo bastante baixo, automaticamente eliminando casos potencialmente inadequados para servir como exemplos de desambiguação (seja pelos filtros de pré-processamento ou pela ausência de anotação) e agregando às unidades do inglês, que servirão efetivamente como exemplos de treinamento, não apenas a tradução do verbo em questão, mas as categorias gramaticais das palavras, seus lemas, e a posição do verbo em questão. Adicionalmente, a posição da tradução escolhida na unidade do português, bem como as palavras de tal unidade, são anotadas. A revisão manual, portanto, torna-se tarefa trivial, já que a anotação produzida pelo sistema facilita a visualização das traduções candidatas na sentença alvo e, em muitos casos, nenhuma alteração se faz necessária. O sistema foi utilizado para anotar vários subconjuntos dos córpus ilustrados na Tabela 4.2, os quais foram manualmente revisados para serem então utilizados em diferentes experimentos com o sistema de DLS proposto, a serem apresentados no Capítulo 6.

Por fim, vale notar que, apesar de ter sido aplicada para um pequeno conjunto de verbos, a abordagem pode ser estendida para conjuntos maiores de palavras e córpus de quaisquer gêneros e domínios. De fato, a abordagem pode ser considerada como uma solução básica, localizada, para o alinhamento de todas as palavras em córpus paralelos, desde que os recursos necessários sejam disponíveis para tais palavras. Em adição ao córpus paralelo, são necessários o dicionário eletrônico bilíngüe e uma ferramenta capaz de gerar dicionários de tradução, como a NATools. Os etiquetadores de categorias gramaticais e lematizadores permitem generalizar a análise, contudo, não são recursos imprescindíveis. Com relação à aplicação da abordagem para outras línguas, acredita-se que resultados similares seriam encontrados para pares de línguas relativamente próximas (tais como o inglês e português ou o espanhol) no que se refere à ordem das palavras nas sentenças.

No próximo capítulo será apresentada a abordagem proposta, que utiliza os córpus de exemplos criados segundo a metodologia descrita neste capítulo. 


\section{UMA ABORDAGEM HÍBRIDA RELACIONAL PARA A DESAMBI- GUAÇÃO LEXICAL DE SENTIDO}

Conforme evidenciado nos capítulos anteriores, a ambigüidade lexical de sentido representa um dos problemas mais graves para a TA. Apesar dos avanços na área de DLS, poucas pesquisas consideram tarefas multilíngues e esse problema ainda não é devidamente manipulado pelas ferramentas atuais de TA, sobretudo na tradução do inglês para o português.

O objetivo deste trabalho é justamente propor uma nova abordagem de DLS que possa ser aplicada à TA do inglês para o português, explorando, para tanto, características de vários dos trabalhos já propostos para o problema, mesmo em cenários monolíngues, e, em particular, buscando superar suas limitações. Conforme foi discutido nos capítulos anteriores, abordagens híbridas, i.e., baseadas em córpus de exemplos e conhecimento lingüístico, têm apresentado os melhores resultados. Contudo, tais abordagens utilizam um formalismo de representação e técnicas de modelagem limitados, ou seja, algoritmos de aprendizado de máquina baseados em representações vetoriais dos atributos. Isso dificulta a representação de conhecimento profundo, ou seja, que vai além de características extraídas de córpus, como bag-of-words e colocações, ou fornecidas por ferramentas superficiais de PLN, como etiquetadores gramaticais, e a utilização desse conhecimento no processo de indução dos modelos de DLS. Na abordagem híbrida proposta, essa limitação é superada por meio do uso de um formalismo baseado na lógica de primeira ordem, que permite a representação de diversas fontes de conhecimento (superficial e profundo) sobre os exemplos e as línguas fonte e alvo, e da técnica de Programação Lógica Indutiva (PLI), que possibilita o aprendizado de modelos de desambiguação bastante expressivos a partir dessa representação. Como na maioria das abordagens híbridas atuais, assume-se a DLS como um problema de classificação supervisionada, em que, a partir de um conjunto de exemplos de treinamento (e de conhecimento sobre eles), modelos de desambiguação são gerados, os quais podem então ser aplicados para classificar novos casos de ambigüidade. A hipótese defendida é que por meio do uso da PLI com o seu formalismo de representação expressivo e de uma variedade de fontes de conhecimento que possam ser automaticamente produzidas por meio de recursos já existentes, é possível gerar modelos de DLS que, quando comparados aos modelos produzidos por outros algoritmos de aprendizado tradicionalmente empregados para a DLS, são mais precisos e mais "interessantes”, sob o ponto de vista da aquisição de conhecimento, ou seja, expressam conhecimento potencialmente novo e que pode ser facilmente interpretado por humanos. A PLI é uma técnica que vem sendo aplicada com sucesso em outras tarefas de 
PLN, como a etiquetação gramatical, análise semântica, entre outras, mas não se tem conhecimento da sua utilização para a DLS.

Neste capítulo, primeiramente são brevemente discutidas as limitações das abordagens atuais de DLS, focalizando-se no formalismo e técnica de modelagem empregados (Seção 5.1). Em seguida, os principais conceitos da PLI são apresentados, juntamente com exemplos do seu uso para outras aplicações de PLN (5.2). A abordagem de proposta explorando a PLI para a geração de modelos de DLS é descrita na Seção 5.3, incluindo-se o seu escopo, fontes de conhecimento, arquitetura, detalhes sobre o sistema de PLI utilizado e uma forma alternativa do uso da PLI para a DLS.

\subsection{LIMITAÇÕES DAS ABORDAGENS HÍBRIDAS ATUAIS}

Conforme foi discutido no capítulo anterior, abordagens híbridas de DLS permitem combinar as vantagens das abordagens baseadas em conhecimento e em córpus, potencialmente resultando em sistemas mais abrangentes e precisos. De fato, uma vez que a DLS é uma tarefa semanticamente motivada, acredita-se que possa se beneficiar de uma abordagem profunda, dotada de conhecimento lingüístico substancial e, idealmente, de conhecimento de mundo, particularmente conhecimento relacional, tal como relações sintáticas e semânticas entre as palavras. Apesar da disponibilidade de conhecimento lingüístico em formato eletrônico que pode ser diretamente utilizado por aplicações de PLN, tais como a WordNet (Fellbaum, 1998), dicionários monolíngues e bilíngües, parsers, etc., a incorporação de certas formas de conhecimento em abordagens híbridas de DLS é dificultada pelas limitações das técnicas de modelagem que vêm sendo exploradas, em geral baseadas em representações vetoriais do tipo atributo-valor.

Conforme é ilustrado na Figura 5.1, vetores atributo-valor consistem de um conjunto $E$ de $N$ exemplos descritos por um conjunto $A$ de $M$ atributos representando determinadas propriedades e, no caso de aprendizado supervisionado, um atributo meta, ou classe, $C$. Cada elemento $e_{i j}$ refere-se ao valor do $j$-ésimo atributo para o $i$-ésimo exemplo. Cada atributo possui um "tipo" (o nome de tal atributo) e um único valor para um determinado exemplo.

\begin{tabular}{|l|rrrr|l|}
\cline { 2 - 6 } \multicolumn{1}{c|}{} & $\boldsymbol{A}_{\boldsymbol{I}}$ & $\boldsymbol{A}_{\mathbf{2}}$ & $\ldots$ & $\boldsymbol{A}_{\boldsymbol{M}}$ & \multicolumn{1}{c|}{$\boldsymbol{C}$} \\
\hline $\boldsymbol{E}_{\boldsymbol{I}}$ & $e_{11}$ & $e_{12}$ & $\ldots$ & $e_{1 M}$ & $C_{I}$ \\
$\boldsymbol{E}_{2}$ & $e_{21}$ & $e_{22}$ & $\ldots$ & $e_{2 M}$ & $C_{2}$ \\
$\ldots$ & $\ldots$ & $\ldots$ & $\ldots$ & $\ldots$ & $\ldots$ \\
$\boldsymbol{E}_{\boldsymbol{N}}$ & $e_{N 1}$ & $e_{N 2}$ & $\ldots$ & $e_{N M}$ & $C_{Y}$ \\
\hline
\end{tabular}

Figura 5.1: Representação utilizando-se vetores de atributos 
Portanto, vetores de atributos têm poder de expressividade equivalente ao da lógica proposicional, ou seja, permitem somente a representação de constantes e proposições atômicas com valor verdadeiro ou falso. Por exemplo, para representar o conhecimento nas sentenças (5.1), (5.2) e (5.3), as seguintes proposições, entre outras, poderiam ser utilizadas:

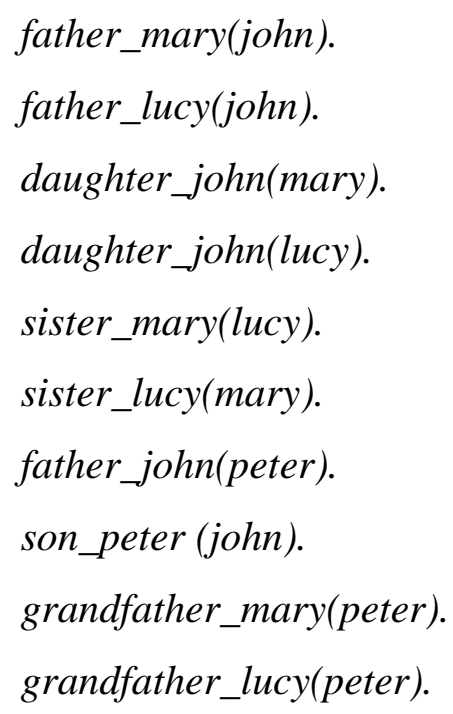

(5.1) John is Mary's father.

(5.2) John is Lucy's father.

(5.3) Peter is John's father.

Como é permitido apenas um argumento em uma dada proposição (i.e., as representações são atômicas), tais representações são bastante específicas. Portanto, a representação de conhecimento similar requer a especificação de novos predicados.

A representação proposicional é utilizada pelos algoritmos de aprendizado de máquina convencionalmente empregados para a DLS, tais como Nä̈ve Bayes, árvores de decisão, $S V M$, etc. Formalismos mais expressivos, tais como os baseados na lógica de primeira ordem, permitem a representação de variáveis e predicados n-ários, i.e., conhecimento relacional.

Nas abordagens híbridas de que se tem conhecimento, fontes de conhecimento profundo, tais como restrições de seleção, são pré-processadas para serem transformadas numa representação vetorial que possa ser manipulada pelos algoritmos de aprendizado de máquina, ou são usadas em etapas de pré-processamento, antes do aprendizado dos modelos, como filtros para eliminar um número de sentidos, como em (Stevenson \& Wilks, 2001). Como conseqüência, parte do conhecimento é perdido nessa transformação e tais fontes não interagem com o processo de aprendizado. Além disso, os modelos produzidos refletem somente o conhecimento superficial que é fornecido ao algoritmo de aprendizado. 
Outra limitação dos vetores atributo-valor é a necessidade de uma representação única para todos os exemplos: um atributo é criado para cada elemento do domínio (cada palavra na vizinhança da palavra ambígua, por exemplo) e a mesma estrutura é utilizada para caracterizar todos os exemplos. Isso geralmente resulta em uma representação bastante esparsa, pois os valores para muitos dos atributos serão nulos, dadas as diferenças entre os exemplos. Por exemplo, considere a estrutura bastante comum em que cada palavra na possível vizinhança da palavra ambígua nas sentenças de todos os exemplos do córpus constitui um atributo, cujo valor para um determinado exemplo deve ser o número de vezes em que tal palavra ocorre na sentença de tal exemplo. Certamente, muitas das palavras não ocorrerão nenhuma vez para muitos dos exemplos. Nesse caso, pode-se ainda argumentar que o valor "0" do atributo tem alguma semântica embutida. Vários outros tipos de argumentos, no entanto, simplesmente não podem ter seus valores determinados para certos exemplos porque são inexistentes em tais exemplos, ou porque não de dispõe de informação sobre tal atributo para tais exemplos. Por exemplo, um atributo para representar, como uma colocação, a primeira preposição após a palavra ambígua na sentença terá valores nulos nos exemplos nos quais não existe uma preposição na sentença após a palavra ambígua. O problema da esparsidade dos dados tornase ainda mais crítico à medida que conhecimento mais profundo é explorado e isso resulta em sérios problemas para o processo de aprendizado de máquina (Brown \& Kros, 2003). Por exemplo, a representação das relações sintáticas entre cada par de palavras relacionadas em uma sentença por meio da criação de atributos para cada possível relação irá resultar em muitos atributos com valores nulos, já que certas relações não ocorrem em muitas sentenças. Isso pode ser visualizado com duas sentenças bastante curtas, (5.4) e (5.5), e um subconjunto das possíveis relações, na Figura 5.2.

Por fim, uma desvantagem dos vetores atributo-valor é que atributos equivalentes podem precisar ser vinculados a identificadores distintos. Por exemplo, no caso da representação das relações sintáticas entre os elementos de uma sentença, nas sentenças nas quais um verbo tem mais de uma instanciação para um determinado papel sintático, tais como um sujeito composto, essa informação não pode ser representada por duas instanciações de um atributo sujeito-verbo, uma vez que cada atributo pode ter apenas um valor. Como ilustrado na Figura 5.2, dois atributos distintos são criados $\left(s u b j_{1}\right.$-verb $b_{1}, s u b j_{2}$-verb $\left.b_{1}\right)$, os quais serão tratados como diferentes formas de conhecimento pelos algoritmos de aprendizado.

(5.4) John and Anna gave Mary a big cake.

(5.5) Give me this watch now. 


\begin{tabular}{|c|c|c|c|c|c|c|}
\hline verb $_{1}$-subj $j_{1}$ & $\operatorname{verb}_{1}-\mathbf{s u b j}_{2}$ & $\operatorname{verb}_{1}-$ obj $_{1}$ & $\operatorname{verb}_{1}-o b j_{2}$ & $\operatorname{verb}_{1}-\bmod _{1}$ & $\operatorname{obj}_{1}-\bmod _{1}$ & ... \\
\hline give-john & give-anna & give-cake & & & cake-big & \\
\hline & & give-watch & give-me & give-now & watch-this & \\
\hline
\end{tabular}

Figura 5.2: Vetor atributo-valor para a representação de relações sintáticas

Conforme será ilustrado no restante deste capítulo, com um formalismo baseado na lógica de primeira ordem como o utilizado pela PLI, um predicado genérico pode ser criado para cada papel sintático, relacionando dois ou mais elementos, por exemplo, has_subject(verb, subject), que pode ter múltiplas instanciações: has_subject(give, john) e has_subject(give, anna), na sentença (5.4). Adicionalmente, cada exemplo é representado independentemente dos demais. Como conseqüência, o problema da esparsidade dos dados é reduzido. De fato, o formalismo utilizado pela Programação Lógica Indutiva é muito mais expressivo que os vetores atributo-valor, permitindo a representação de objetos estruturados, bem como a relação entre os objetos. Portanto, adicionalmente às proposições atômicas e factuais, conhecimento relacional pode ser representado por meio dos predicados n-ários e conhecimento condicional, ou seja, regras envolvendo constantes e variáveis podem ser utilizadas. Para representar o conhecimento das sentenças (5.1), (5.2) e (5.3), por exemplo, as seguintes cláusulas poderiam ser definidas:

father(john, mary).

father(john, lucy).

father(peter, john).

$\operatorname{sister}(X, Y)$ :- father $(Z, X)$, father $(Z, Y)$.

grandfather $(X, Y)$ :- father $(X, Z)$, father $(Z, Y)$.

Como se pode perceber, PLI provê um mecanismo adequado para manipular o problema da DLS. A técnica supera as limitações das técnicas proposicionais mencionadas acima, uma vez que prevê a inclusão de conhecimento de fundo (i.e., de domínio) de qualquer forma e utiliza uma linguagem de representação suficientemente expressiva para capturar relacionamentos contextuais. De maneira resumida, as vantagens da PLI sob outras técnicas de aprendizado de máquina podem ser sumarizadas pela superação de duas grandes limitações de tais técnicas (Cussens et al., 1997):

- O uso de um formalismo de representação limitado (lógica proposicional); e

- A dificuldade para usar conhecimento de fundo substancial no processo de aprendizado. 


\subsection{APRENDIZADO RELACIONAL E PROGRAMAÇÃO LÓGICA INDUTIVA}

A Programação Lógica Indutiva (PLI) (Muggleton, 1991) permite a construção de teorias baseadas em cláusulas de primeira ordem a partir de exemplos e de conhecimento de fundo, também representados por cláusulas de primeira ordem, sobre um determinado domínio. Para tanto, emprega técnicas das áreas de Aprendizado de Máquina Indutivo e da Programação Lógica. A relação com o Aprendizado de Máquina Indutivo diz respeito à meta de desenvolver técnicas e ferramentas para induzir hipóteses a partir de exemplos e sintetizar novos conhecimentos com base em experiências. A relação com a Programação Lógica, por sua vez, diz respeito ao formalismo de representação empregado, baseado na lógica de primeira ordem, com sua orientação semântica e suas técnicas bem definidas. Ao contrário da lógica computacional tradicional, que é baseada na inferência por dedução a partir de fórmulas providas por um usuário, a PLI investiga a indução como mecanismo de inferência, visando obter programas lógicos a partir de exemplos e de conhecimento de fundo. Com isso, a PLI permite a representação eficiente de conhecimento substancial sobre o problema, o que é usado durante o processo de aprendizado, e é capaz de produz modelos expressivos, refletindo tal conhecimento.

Fundamentalmente, a PLI cobre duas categorias de problemas de aprendizado: problemas preditivos e problemas descritivos. O problema preditivo caracteriza o uso mais clássico da PLI, visando ao aprendizado de descrições de conceitos na forma de regras de classificação. A PLI descritiva, por outro lado, visa o aprendizado de descrições sobre o conceito, sem o objetivo de classificação, as quais podem ser utilizadas para dar origem, por exemplo, a regras de associação. A abordagem de DLS proposta nesta tese faz uso, principalmente, da PLI preditiva. Portanto, as descrições a seguir são dadas em termos dessa categoria de PLI. Na Seção 5.3.4 é apresentada, também, uma proposta alternativa que faz uso de ambas, PLI preditiva e PLI descritiva.

Na PLI preditiva, essencialmente, dado um conjunto de exemplos de treinamento positivos (fatos verdadeiros) e negativos (fatos falsos) e conhecimento de fundo, ambos expressos em um formalismo de primeira ordem, o objetivo é encontrar uma hipótese com relação ao conhecimento de fundo e aos exemplos que, idealmente, seja completa (isto é, cubra todos os exemplos positivos) e consistente (isto é, não cubra exemplos negativos), ou seja, uma hipótese que seja uma generalização dos exemplos positivos. Formalmente (Muggleton, 1994): 


\section{Dados:}

- $\boldsymbol{E}$ - um conjunto finito de exemplos $\boldsymbol{E}=\boldsymbol{E}^{+} \cup \boldsymbol{E}^{-}$, descritos de acordo com uma linguagem de descrição de exemplos $\boldsymbol{L}_{\boldsymbol{E}}$, onde:

○ Exemplos Positivos. $\boldsymbol{E}^{+}=\left\{\boldsymbol{e}_{1}, \boldsymbol{e}_{2}, \ldots\right\}$ é um conjunto não vazio de cláusulas definidas $^{23}$, geralmente expressos por fatos ground, ou seja sem variáveis.

○ Exemplos Negativos. $\boldsymbol{E}^{-}=\left\{\boldsymbol{f}_{\mathbf{1}}, \boldsymbol{f}_{\mathbf{2}}, \ldots\right\}$ é um conjunto de cláusulas de Horn $^{24}$ (esse conjunto pode ser vazio).

- $\boldsymbol{B}$ - conhecimento de fundo sobre o domínio consistindo de um conjunto de cláusulas definidas $=\left\{\boldsymbol{C}_{1}, \boldsymbol{C}_{2}, \ldots.\right\}$, que podem expressar conhecimento intensional e extensional.

A meta é induzir uma hipótese (ou teoria) $\boldsymbol{H}$ com respeito a $\boldsymbol{E}$ e $\boldsymbol{B}$ tal que (idealmente) $\boldsymbol{B} \wedge \boldsymbol{H} \models \boldsymbol{E}^{+}$para todos os exemplos positivos em $\boldsymbol{E}^{+}$e $\boldsymbol{B} \wedge \boldsymbol{H} \not \models \boldsymbol{E}^{-}$para todos os exemplos negativos em $\boldsymbol{E}^{-}$. Certamente, tais restrições de total completude e consistência são muito rigorosas. Na prática, as seguintes condições devem ser satisfeitas para que $\boldsymbol{H}$ seja uma hipótese aceitável na PLI preditiva:

- Prior Satisfiability, i.e., $\boldsymbol{B}$ e $\boldsymbol{E}^{-}$são satisfazíveis ${ }^{25}: \boldsymbol{B} \cup \boldsymbol{E}^{-\not \neq} \square$.

- Posterior Satisfiability, i.e., $\boldsymbol{B}$ e $\boldsymbol{H}$ e $\boldsymbol{E}^{-}$são satisfazíveis: $\boldsymbol{B} \cup \boldsymbol{H} \cup \boldsymbol{E}^{-\not} \square$.

- Prior Necessity: $\boldsymbol{B} \not \models \boldsymbol{E}^{+}$.

- Posterior Sufficiency, i.e., $\boldsymbol{B}$ e $\boldsymbol{H}$ implicam logicamente todos os exemplos em $E^{+}: B \cup H \models e_{1} \wedge e_{2} \wedge \ldots$

A hipótese $\boldsymbol{H}$ é expressa por um programa lógico, ou seja, um conjunto de cláusulas de programa. Em geral, $\boldsymbol{H}$ também deve satisfazer certas restrições especificadas pelo usuário para delimitar o espaço de hipóteses. Essas restrições podem ser estabelecidas, dependendo do sistema de PLI, sobre a sintaxe (estrutura) das cláusulas (bias sintático) e / ou a semântica (comportamento ou significado) das cláusulas no espaço de busca (Muggleton \& De Raedt, 1994). É possível especificar também heurísticas, ou bias, para otimizar o processo

${ }^{23}$ Cláusulas de definidas são cláusulas de primeira ordem que devem conter, obrigatoriamente, um literal positivo (cabeça da regra).

${ }^{24}$ Cláusulas de Horn são cláusulas de primeira ordem que podem conter no máximo um literal positivo (cabeça da regra). Uma cláusula de Horn com exatamente um literal positivo é uma cláusula definida.

${ }^{25}$ Uma sentença é dita satisfatível se existe pelo menos um modelo para tal sentença, ou seja, se existe uma interpretação (um conjunto de fatos ground) que atribui um valor verdadeiro para tal sentença. 
de busca. De fato, segundo Nédellec et al. (1996), qualquer critério que influencie na escolha de uma hipótese pode ser chamado de bias, incluindo a linguagem na qual as hipóteses são descritas (por exemplo, via cláusulas de Horn, podendo conter certos predicados, com um determinado número máximo de literais no corpo - bias de linguagem), o procedimento de busca por hipóteses (por exemplo, busca exaustiva ou heurística - bias de busca), o critério de avaliação das hipóteses, ou seja, o critério de parada do sistema, que indica quando uma hipótese aceitável é encontrada, e que pode ser definido de acordo com a consistência e completude da hipótese (bias de validação).

O processo realizado para encontrar uma hipótese $\boldsymbol{H}$ é visto como um problema de busca em um espaço de hipóteses. Neste contexto, diferentes abordagens podem ser utilizadas para estruturar o espaço de busca, as quais podem ser classificadas como abordagens de "generalização", que iniciam a busca pelos exemplos de treinamento (hipóteses mais específicas) e procuram generalizar esses exemplos por meio de operadores de generalização, e abordagens de "especialização", que iniciam a busca a partir das descrições dos conceitos mais gerais e procuram especializar esses conceitos por meio de operadores de especialização.

A estruturação do espaço de busca consiste, em geral, da ordenação das hipóteses nesse espaço. Muggleton \& De Raedt (1994) descrevem diversas estratégias utilizadas pelos sistemas de PLI para prover tal ordenação. Geralmente, os sistemas de PLI fazem uso da ordenação baseada na relação subsunção- $\theta$. A subsunção- $\theta$ define que:

Uma cláusula $c_{1} \theta$-subsume uma cláusula $c_{2}$ se e somente se existe uma substituição $\theta$ tal que $c_{1} \theta \subseteq c_{2}$, ou seja, $c_{1}$ é uma generalização de $c_{2}$, e $c_{2}$ é uma especialização de $c_{1}$ sob subsunção- $\theta$.

Vale notar que uma substituição $\theta=\left\{V_{l} / \mathrm{t}_{1}, \ldots, V_{n} / t_{n}\right\}$ consiste da atribuição de termos $t_{i}$ a variáveis $V_{i}$. Assim, aplicar a substituição $\theta$ a um termo, átomo ou cláusula $F$ resulta na instanciação do termo, átomo ou cláusula $F \theta$ em que todas as ocorrências de variáveis $V_{i}$ são simultaneamente substituídas pelo termo $t_{i}$. Por exemplo, considere a cláusula $c$ :

$c=\operatorname{daughter}(X, Y) \leftarrow \operatorname{parent}(Y, X)$.

A aplicação da substituição $\theta=\{X /$ mary, Y/anna $\}$ a $c$ resulta em:

$\mathrm{c} \theta=$ daughter(mary, anna $) \leftarrow$ parent (anna, mary $\}$.

Considere, agora, a cláusula c': 
$c^{\prime}=$ daughter (mary, anna) $\leftarrow$ female(mary), parent(anna, mary), parent(anna, tom).

A cláusula $c \theta$-subsume c' considerando-se a substituição $\theta=\{X /$ mary, Y/anna $\}$.

Considere, por fim, a cláusula $c$ ' $=\operatorname{daughter}(X, Y) \leftarrow$ female $(X)$, $\operatorname{parent}(Y, X)$.

Diz-se que a cláusula c $\theta$-subsume c' ' considerando-se a substituição vazia, ou seja, a substituição $\theta=\varnothing$, já que $c$ é um subconjunto próprio de $c$ ".

A subsunção- $\theta$ introduz uma noção sintática de generalização: diz-se que $c$ é pelo menos tão geral quanto $c^{\prime}\left(c \leq c^{\prime}\right)$ se $c \theta$-subsume $c^{\prime}$. Uma cláusula $c$ é mais geral que uma cláusula $c^{\prime}\left(c<c^{\prime}\right)$ se $c \leq c^{\prime}$ é válido e o contrário, ou seja, $c^{\prime} \leq c$, não é válido. Neste caso, diz-se que c'é uma especialização ou um refinamento de $c$ e $c$ é uma generalização de c'.

Geralmente, os sistemas de PLI utilizam ambos operadores de generalização e especialização em diferentes etapas do processo de busca pela hipótese $\boldsymbol{H}$. O mecanismo básico de inferência do sistema de PLI preditivo utilizado neste trabalho induz teorias iterativamente de maneira bottom-up, batch (ou seja, não incremental, com todos os exemplos fornecidos de uma vez) e sem intervenção do usuário, até encontrar cláusulas que explicam todos os exemplos, por meio dos seguintes passos:

1. Um exemplo positivo (seed) do conjunto de treinamento é selecionado para ser generalizado, seguindo-se a ordem dos exemplos de treinamento.

2. A cláusula mais específica que cobre tal exemplo (bottom clause) é construída utilizando-se a técnica inverse entailment (Muggleton, 1995), que representa as fontes de conhecimento que dizem respeito a tal exemplo, de acordo com configurações que definem as fontes que podem fazer parte das cláusulas e de que maneira (definições intensionais / extensionais, constantes, variáveis de entrada ou saída) e com outras restrições de linguagem (como a profundidade das variáveis nas cláusulas, o número máximo possível de literais na cláusula, etc.), conforme será apresentado na Seção 5.3.3, gerando uma cláusula que usualmente contém muitos literais. A idéia é que tal cláusula deve cobrir somente o exemplo seed, ou seja, a bottom clause deve ser a cláusula mais específica que cobre tal exemplo. Esse passo é geralmente chamado de "saturação".

3. A generalização consistente mais compacta para a bottom clause é buscada no reticulado de cláusulas que subsumem tal cláusula e estão de acordo com as restrições de linguagem estabelecidas. A idéia é encontrar uma cláusula mais geral que explique, além do exemplo saturado, outros exemplos positivos. Para tanto, 
utiliza-se um operador de refinamento que constrói uma cláusula mais genérica adicionando gradualmente literais da bottom clause a ela. A busca pela melhor cláusula é determinada de acordo com uma estratégia de busca (best-first, por exemplo) e uma função de avaliação (por exemplo, número de exemplos positivos cobertos), conforme será apresentado na Seção 5.3.3. Esse passo é geralmente chamado de "redução".

4. A melhor cláusula encontrada é adicionada à teoria sendo construída e os exemplos cobertos por tal cláusula são removidos do conjunto de exemplos. Se tal conjunto ainda contiver exemplos, o algoritmo retorna ao passo 1.

Diz-se que uma cláusula ou regra "cobre" um exemplo se tal exemplo satisfaz todas as condições no corpo da regra e se a classe de tal exemplo é a mesma que a dada pela cabeça da regra. Se tal exemplo for positivo, diz-se que a regra cobre corretamente um exemplo. Caso contrário, ou seja, se o exemplo for negativo, diz-se que a regra cobre incorretamente um exemplo.

Intuitivamente, PLI tem grande aplicabilidade em várias tarefas de PLN, uma vez que tais tarefas são naturalmente caracterizadas pela necessidade de representação de conhecimento substancial sobre o domínio do problema, incluindo conhecimento relacional. Investigações sobre o uso da PLI para aplicações em PLN vêm sendo realizadas desde a segunda metade da década de 90 e incluem aprendizado de gramáticas estocásticas e etiquetação gramatical (Cussens et al. 1997; Cussens, 1997; Cussens \& Pulman, 2000a; Cussens \& Pulman, 2000b), parsers sintáticos do tipo shift-reduce e parsers semânticos (Mooney, 1997; Mooney, 2004), geração de tempo passado de verbos do inglês (Mooney \& Califf, 1995); extração de informações para o preenchimento de templates (Califf \& Mooney, 2003); extração de informações a partir de textos semi-estruturados (Ramakrishnan et al., 2007), entre outras. A avaliação de tais trabalhos mostra que a PLI apresenta resultados comparáveis ou superiores aos das técnicas estatísticas que representam o estado da arte para essas aplicações. Uma vantagem adicional da PLI diz respeito aos modelos simbólicos que são produzidos como saída, os quais podem ser facilmente interpretados por seres humanos, permitindo também o aprendizado de conhecimento novo, potencialmente útil para o entendimento da tarefa em questão. Apesar dessas vantagens, previamente a este trabalho, a PLI não havia sido aplicada, ainda, ao problema da DLS. Parte do motivo deve-se, por certo, à relativa complexidade inerente ao processo de especificação da tarefa como um problema de PLI. Primeiramente, para explorar o real potencial da PLI, a representação de conhecimento 
substancial sobre o domínio se faz necessária. De fato, não se espera que a PLI supere técnicas baseadas em vetores de atributos caso esta só faça uso de conhecimento superficial. Além disso, faz-se necessária a especificação cautelosa das fontes de conhecimento e das maneiras como tais fontes podem interagir. Stevenson \& Wilks (2001), por exemplo, mencionam que PLI estava entre as técnicas consideradas para a combinação de várias fontes de conhecimento profundo e superficial em sua abordagem de DLS, mas que ela não foi utilizada dada à complexidade para a definição do aparato necessário. De fato, segundo (Lavrac, 1998), grande parte do sucesso de abordagens utilizando PLI depende da seleção e formulação apropriada do conhecimento de fundo para ser utilizado no aprendizado. Por fim, apesar da disponibilidade de vários sistemas de PLI, a sua utilização não é trivial, se comparada aos diversos algoritmos estatísticos que assumem como entrada simplesmente vetores de atributos, em especial, os algoritmos providos por ambientes como o $\mathrm{Weka}^{26}$, em que dezenas de algoritmos podem ser utilizados a partir de um formato comum de entrada. No que segue, a abordagem proposta neste trabalho para a DLS utilizando-se PLI é descrita.

\subsection{ABORDAGEM PROPOSTA: O USO DE PLI PARA A DLS}

Nesta tese, investiga-se o uso da PLI para a tarefa de DLS. Primordialmente, propõe-se uma abordagem de DLS que faz uso da PLI preditiva para a indução de modelos de desambiguação a partir de um conjunto de fontes de conhecimento e exemplos de desambiguação. Como um objetivo secundário, estuda-se o uso da combinação de PLI preditiva e descritiva para a construção de atributos interessantes a serem usados por técnicas tradicionais de aprendizado de máquina, mais especificamente, SVMs, para a geração de modelos de DLS. Essas duas abordagens são descritas nas Seções 5.3.3 e 5.3.4. Primeiramente, são apresentados o escopo e as fontes de conhecimento exploradas em ambas as abordagens.

\subsubsection{Escopo}

Sistemas de DLS geralmente alcançam melhores resultados na desambiguação de substantivos que outras categorias gramaticais, como pode ser verificado pelos resultados das diversas edições do Senseval $^{27}$. Uma estratégica comum para a desambiguação de substantivos consiste da análise das palavras em um contexto amplo na vizinhança do

\footnotetext{
${ }^{26}$ http://www.cs.waikato.ac.nz/ml/weka/

${ }^{27}$ http://www.senseval.org/
} 
substantivo ambíguo, que podem ser representadas como bag-of-wods ou colocações. Neste trabalho, no entanto, focaliza-se em verbos, casos mais complexos e que requerem fontes de conhecimento específicas, em geral mais elaboradas que simples atributos contextuais. Por essa razão, acredita-se que a PLI é particularmente adequada neste caso. Conforme foi discutido no Capítulo 2, a desambiguação correta de verbos é altamente relevante para tarefas como a tradução automática, já que uma tradução inadequada pode modificar completamente o sentido da sentença e ainda influenciar negativamente na tradução de outras palavras, principalmente dos seus argumentos.

No Capítulo 6 serão descritos experimentos com diferentes conjuntos de verbos. Estes incluem os sete verbos inicialmente definidos a partir do estudo do problema da ambigüidade lexical apresentado no Capítulo 2 (come, get, give, go, look, make e take), os três verbos menos ambíguos adicionados posteriormente (ask, live e tell), os 32 verbos da terceira edição da competição Senseval (Mihalcea et al., 2004), e os 65 verbos da quarta edição dessa mesma competição (Pradhan et al., 2007). Adicionalmente, serão apresentados experimentos com os 35 substantivos da quarta edição do Senseval, uma vez que tais substantivos faziam parte do conjunto de palavras da tarefa lexical sample, à qual foram submetidos os resultados da abordagem proposta. Detalhes sobre cada um desses conjuntos de palavras serão apresentados no Capítulo 6.

\subsubsection{Fontes de conhecimento}

Para explorar o potencial da PLI para a DLS, uma importante tarefa consiste da identificação e aquisição de fontes de conhecimento relevantes para a DLS de verbos, em especial, para a aplicação de tradução, e também da especificação de uma representação adequada para tais fontes de conhecimento. Tomando como ponto de partida os estudos já existentes sobre fontes de conhecimento para a DLS monolíngue discutidos no Capítulo 3 (por exemplo, Stevenson \& Wilks, 2001; Lee \& Ng, 2002; Mohammad \& Pedersen, 2004; Agirre \& Stevenson, 2006), procurou-se primeiramente investigar se tais fontes de conhecimento eram também efetivas para verbos na tradução automática, utilizando-se algoritmos proposicionais tradicionalmente empregados para a DLS. Conforme descrito com detalhes em (Specia, 2005), nesses experimentos foram analisados o conjunto inicial de sete verbos altamente ambíguos, representados por um córpus de cerca de 200 sentenças para cada verbo extraídas do córpus Compara (cf. descrito no Capítulo 4), quatro algoritmos de aprendizado de máquina proposicionais (Naive Bayes, árvores de decisão, Memory-based e Support Vector Machines) 
e atributos representando diversas fontes de conhecimento superficial, já que fontes mais elaboradas não poderiam ser utilizadas com tais algoritmos.

Os atributos analisados incluem: (1) palavras de conteúdo em janelas de palavras de diversos tamanhos (e.g., \pm 5 ), representadas de acordo com suas posições relativas; (2) 10 colocações definidas por (Stevenson \& Wilks, 2001) (e.g.: primeiro adjetivo à esquerda do verbo ambíguo, etc.), mais uma colocação especialmente útil para verbos: a primeira preposição após o verbo ambíguo; (3) categorias gramaticais de palavras em janelas de diversos tamanhos; (4) palavras nos papéis de sujeito e objeto com respeito ao verbo ambíguo; (5) unigramas considerando-se diversos tamanhos de janelas (e.g., \pm 100 ). Os atributos foram testados individualmente e em combinações de dois e três atributos. Filtros de atributos eliminando valores pouco freqüentes, com três limites mínimos de freqüência distintos foram também investigados (cf. proposto por (Lee \& $\mathrm{Ng}, 2002)$ ).

Os resultados obtidos corroboram, para a tarefa em consideração, o que havia sido apontado por investigações de DLS monolíngue (Agirre \& Stevenson, 2006; Mohammad \& Pedersen, 2004): muito embora as melhores fontes de conhecimento variem de acordo com a palavra ambígua e o algoritmo empregado, em média, atributos representando a combinação de formas de conhecimento sintático local, mais especificamente, colocações e relações sintáticas, apresentaram os melhores resultados. Além disso, o uso de filtros de atributos eliminando valores que não ocorrem pelo menos 2 ou 3 vezes possibilitou uma melhoria significativa nos resultados para a maioria dos verbos e algoritmos. Com o uso de filtros, a combinação de unigramas, palavras de conteúdo e categorias gramaticais numa janela de \pm 5 palavras também apresentou bons resultados. Assim, todos esses atributos foram considerados relevantes.

Contudo, conforme foi discutido anteriormente, acredita-se que resultados mais efetivos podem ser obtidos com o uso de fontes de conhecimento mais elaboradas. Assim, fontes adicionais foram analisadas, com base principalmente nas fontes utilizadas como préprocessamento no trabalho de (Stevenson \& Wilks, 2001). É importante ressaltar que, muito embora a abordagem aqui proposta seja híbrida e, portanto, baseada também em conhecimento, o objetivo é a utilização de fontes de conhecimento que possam ser automaticamente produzidas por recursos ou ferramentas já existentes. A descrição do conjunto total de fontes escolhidas para a abordagem de DLS proposta é apresentada seguir, juntamente com os recursos ou ferramentas dos quais foram extraídas, e a especificação do seu formato de representação, utilizando-se a sintaxe de cláusulas lógicas do Prolog. Conforme será descrito no Capítulo 6, subconjuntos dessas fontes foram utilizados em 
diferentes experimentos de avaliação monolíngue e multilíngue, portanto, elas são apresentadas de maneira genérica, aqui. Para a ilustração desse formato, considere a sentença (5.6) e a representação de informações para a desambiguação do verbo come. É importante lembrar que, no caso das fontes de conhecimento envolvendo a representação de palavras da sentença fonte, tais palavras já haviam sido previamente lematizadas utilizando-se o parser Minipar.

(5.6) If there is such a thing as reincarnation, I would not mind coming back as a squirrel.

B. Bag-of-words. 5 unigramas, ou seja, palavras à direita e esquerda da palavra ambígua (excluindo-se stop words), extraídas do córpus e representadas por definições da forma has_bag(snt,word), onde snt simplesmente indica o identificador do exemplo em questão, por exemplo:

$$
\begin{aligned}
& \text { has_bag(snt 5_6, thing). }
\end{aligned}
$$

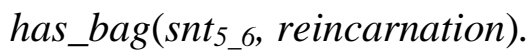

$$
\begin{aligned}
& \text { has_bag }\left(s n t_{5} 6 \text {, mind }\right) \text {. } \\
& \text { has_bag(snt } 5 \text {,6 squirrel). }
\end{aligned}
$$

$\mathbf{B}_{2}$. Bigramas freqüentes. Pares de palavras adjacentes em uma sentença (sem incluir a palavra ambígua) que ocorrem com uma freqüência mínima no córpus (pelo menos 10 vezes, por exemplo), representadas por definições do tipo has_bigram(snt, word 1 , word $_{2}$ ), por exemplo:

$$
\begin{aligned}
& \text { has_bigram }\left(\operatorname{snt}_{5 \_6}, \text { back, as }\right) . \\
& \text { has_bigram }\left(\operatorname{snt}_{5} 6,6 u c h, a\right) .
\end{aligned}
$$

B. POS. Etiquetas gramaticais de 5 palavras à direita e esquerda da palavra ambígua, extraídos do córpus por meio do uso do etiquetador gramatical Mxpost (Ratnaparkhi, 1996) e representadas por cláusulas do tipo has_pos(snt, word_position, pos), por exemplo:

$$
\begin{aligned}
& \text { has_pos(snt 5_6, 1st_word_left, } n n) . \\
& h a s \_p o s\left(s n t_{5} 6,1 s t \_w o r d \_r i g h t, r b\right) .
\end{aligned}
$$


B. Narrow context. Lemas de 5 palavras de conteúdo (i.e., verbos, substantivos e adjetivos) à direita e esquerda da palavra ambígua, extraídas do córpus, de acordo com as etiquetas de categorias gramaticais previamente atribuídas pelo Mxpost, e representadas por relações do tipo has_narrow(snt, word_position,word), por exemplo:

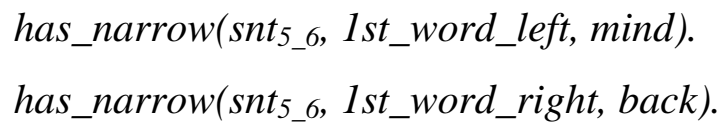

B5. Colocações. A palavra ambígua, propriamente dita, visando cobrir variações morfológicas que possam ser relevantes, e mais 11 colocações com respeito à tal palavra, extraídas do córpus de acordo com as suas posições e etiquetas gramaticais previamente atribuídas pelo Mxpost: $1^{\mathrm{a}}$ preposição à direita, $1^{\mathrm{o}}$ substantivo, $1^{\mathrm{o}}$ adjetivo e $1^{\mathrm{o}}$ verbo à direita e esquerda, $1^{\mathrm{a}} \mathrm{e}$ $2^{\mathrm{a}}$ palavras à direita e esquerda. As colocações são representadas utilizando-se definições da forma has_collocation(snt, collocation_type, collocation), por exemplo:

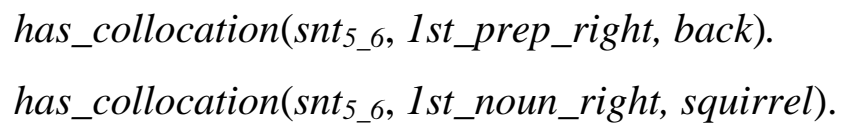

B. Relações sintáticas. Palavras em funções sintáticas relevantes relacionadas à palavra ambígua na sentença, obtidas com o uso do parser Minipar (Lin, 1993) e representadas por definições da forma has_rel(snt, type_rel, word). Caso a palavra ambígua seja um verbo, as são representados os elementos nas posições de sujeito e objeto de tal verbo ambíguo. Por outro lado, caso a palavra ambígua seja um substantivo, são representados o verbo do qual o substantivo é um objeto ou sujeito, ou o verbo que é modificado pelo substantivo, ou o sujeito ou objeto que são modificados por esse substantivo:

$$
\begin{aligned}
& \text { has_rel(snt } \left.5 \_6 \text {, subject, } i\right) . \\
& \text { has_rel(snt } 5 \text {,6 } \text { object, } n i l) \text {. }
\end{aligned}
$$

$\mathbf{B}_{7}$. Relações sintáticas freqüientes. Pares de palavras sintaticamente relacionadas na sentença que ocorrem no córpus com uma freqüência mínima (pelo menos 10 vezes), relacionadas por uma das seguintes relações (sem incluir a palavra ambígua): verbo-sujeito, verbo-objeto, verbo-modificador, sujeito-modificador e objeto-modificador. Esses pares são representados por fatos to tipo has_related_pair(snt, word 1 , word 2 ), por exemplo:

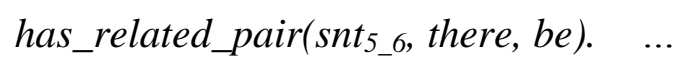


B. Sobreposição de definições. O sentido (ou tradução) que apresenta a maior taxa de sobreposição entre as palavras na sua definição (ou seja, glosa) em um dicionário (bilíngüe, no caso da tradução) e as palavras vizinhas à palavra ambígua na sua sentença, excluindo-se stop words de ambas as fontes, ou seja, o sentido que apresenta o maior número de palavras coincidentes nessas fontes. Essa informação corresponde a uma simplificação, proposta por Kilgarriff and Rosensweig (2000), para a medida inicialmente definida por Lesk (1986). Diferentes dicionários foram utilizados para os experimentos multilíngues e monolíngues: para experimentos multilíngues, foi empregado o dicionário Password (Parker \& Stahel, 1998), que contém definições em inglês para cada tradução das palavras no português. Para os experimentos com os dados do Senseval-3 e SemEval-1, o dicionário LDOCE (Procter, 1978) e as definições de sentido fornecidas pelos organizadores da tarefa foram utilizados, respectivamente. A sobreposição é primeiramente calculada, relativamente ao tamanho (em número de palavras) da sentença contendo o verbo e da(s) sentença(s) na glosa, e então representada por definições do tipo has_overlapping(snt, sense), por exemplo:

has_overlapping $\left(\right.$ snt $_{5}$ 6, voltar $)$.

B. Restrições de seleção. Restrições de seleção do verbo ambíguo, definidas em termos dos traços semânticos dos seus argumentos, ambos extraídos utilizando-se o LDOCE. No LDOCE, as entradas de cada sentido dos substantivos (ex., 0_1, 0_0 ${ }^{28}$ são descritas, entre outras informações, por códigos representando seus traços semânticos (35 categorias semânticas são utilizadas). Por exemplo, algumas entradas extraídas para os substantivos da sentença (3):

feature(reincarnation, 0_1, [abstract]).

feature(squirrel, O_0, [animal]).

Para cada sentido dos verbos o LDOCE também especifica o conjunto de restrições que devem ser satisfeitas pelos seus argumentos nos papéis de sujeito e objeto(s) para que tal sentido seja aplicável a uma dada interpretação. Por exemplo, algumas das restrições extraídas das entradas do LDOCE para come, são dadas a seguir. O primeiro elemento após o verbo indica o sentido do verbo, em seguida, são apresentadas as restrições impostas para o seu sujeito e objeto ([] indica que nenhuma restrição é imposta, enquanto nil indica que tal

\footnotetext{
${ }^{28}$ Os sentidos do LDOCE são definidos em dois diferentes níveis: homografia / homonímia (incluindo diferentes categorias gramaticais) e polissemia (sentidos). Assim, a notação ' 1 _3', por exemplo, indica o sentido ' 3 ' do homógrafo ' 1 '.
} 
argumento não é definido para a sentença, ou seja, o verbo é intransitivo e portanto a sentença não apresenta objeto).

restriction(come, 1_1, [animal, human], nil, 'to move towards the speaker or a particular place', 'Why don't you come when you know your dinner's ready? | The little girl came running to her mother for sympathy').

restrictions(come, 1_3, [abstract], nil, 'to arrive as expected or in the course of time', 'Uncle`s birthday is coming so we must remember to get him a present').

restriction(come, 1_4, [], nil ,'to reach', 'The water came (up) to my neck . | Her hair came (down) to her knees . | The floods came through to / as far as my garden').

restriction (come,1_5, [], nil, 'to exist in a particular place', 'In this list of goods the price comes next to the article').

Para tornar possível o uso de tal informação para a tarefa de DLS multilíngue, os códigos de sentido foram manualmente mapeados para as traduções correspondentes àqueles sentidos no português. Essa foi a única fonte de conhecimento que requereu intervenção manual, mas vale notar que o número de entradas para cada verbo no LDOCE é relativamente pequeno e, portanto, exigiu pouco tempo. Por exemplo, 165 entradas são disponíveis para o verbo come (das quais 142 são para expressões contendo tal verbo, sendo que muitas não foram utilizadas, pois são voltadas para descrever expressões idiomáticas e não definem restrições), que é o que possui o maior número de entradas, enquanto apenas seis entradas são dadas para o verbo ask. Após tal mapeamento, as restrições são representadas como:

restriction(come, [animal,human], nil, vir).

restriction(come, [abstract], nil, chegar).

restriction(come, [], nil, aparecer).

Nas tarefas de avaliação monolíngues, os sentidos do LDOCE foram automaticamente mapeados para os sentidos utilizados pela tarefa em questão (uma lista de mapeamentos entre tais sentidos e sentidos da WordNet foi definida na Universidade de Sheffield e mapeamentos da WordNet para outros repositórios de sentidos utilizados nas tarefas de avaliação foram disponibilizados pelos organizadores das competições). Para tornar a verificação das relações mais abrangente, relações de sinonímia e hiperonímia entre pares de palavras extraídas da WordNet foram utilizadas, por exemplo, synonym(reincarnation, rebirth). Assim, quando as restrições impostas pelo verbo não aparecem como traços semânticos na descrição das 
palavras nos papéis dos seus argumentos na sentença, verifica-se se outras palavras, potencialmente sinônimas ou hiperônimas de tais argumentos, contêm tais traços, satisfazendo portanto as restrições. Adicionalmente, a hierarquia de traços semânticos definida por Bruce \& Guthrie (1992) é utilizada para cobrir os casos em que as restrições estabelecidas pelo verbo são mais genéricas que os traços descrevendo seus argumentos. As restrições são verificadas utilizando-se as relações sintáticas de sujeito e objeto na sentença já identificadas pelo parser Minipar (fonte $\mathbf{B}_{\mathbf{6}}$ ), e então representadas por definições do tipo satisfy_restriction(sentence, rest_subject, rest_object), em que rest_subject e rest_object representam, respectivamente, uma lista de restrições, das quais pelo menos um é satisfeita pelo exemplo em questão. Por exemplo:

satisfy_restriction(snt $5 \_6$, [human], nil).

satisfy_restriction(snt 5_6 $_{\text {, }}[$ animal, human], nil).

As fontes de conhecimento descritas até então dizem respeito essencialmente à língua fonte e podem, portanto, ser utilizadas para ambas as tarefas de DLS multilíngue e monolíngue, bastando-se modificar a noção de "sentido" (traduções ou sentidos monolíngues) e os recursos de onde as informações são extraídas (dicionários monolíngues ou bilíngues, por exemplo). As fontes a seguir, no entanto, são voltadas especificamente para a tarefa multilíngue. $\mathbf{B}_{\mathbf{1 0}}$ refere-se a conhecimento extraído de dicionários bilíngües.

B $_{10}$. Expressões verbais. Phrasal verbs potencialmente ocorrendo na sentença, de acordo com uma lista de expressões dada por dicionários bilíngües (a mesma utilizada pelo sistema de etiquetação de exemplos descrito no Capítulo 4). Foram implementados procedimentos distintos para analisar o contexto do verbo ambíguo e identificar tais expressões (expressões separáveis e inseparáveis). Essa fonte foi utilizada apenas para os experimentos multilíngues, uma vez que os usos de verbos em expressões verbais não são considerados sentidos dos verbos nas tarefas monolíngues. A potencial existência ${ }^{29}$ de expressões verbais nos exemplos é representada por definições da forma has_expression(snt, verbal_expression), por exemplo: has_expression(sntt_6, “come back”).

$\mathbf{B}_{11}$ e $\mathbf{B}_{12}$ dizem respeito a conhecimento extraído do córpus paralelo de exemplos, considerando-se as sentenças do português (sem incluir a tradução da palavra ambígua) como

\footnotetext{
${ }^{29}$ Conforme foi mencionado no Capítulo 4, a presença de uma partícula após o verbo numa sentença não necessariamente indica o uso de tal verbo em uma expressão verbal.
} 
traduções parciais da sentença do inglês, ou seja, considerando-se o módulo de DLS em uso em um sistema de TA que primeiramente traduz todas as palavras não ambíguas da sentença, restando as palavras ambíguas para o módulo de DLS, que poderia então fazer uso das palavras já traduzidas como contexto da língua alvo. Poderia ser utilizado um sistema de TA "básico", que traduz apenas as palavras para as quais não houvesse ambigüidade.

Uma forma alternativa de utilização do contexto da língua alvo, que não a definição de atributos, é descrita em (Specia et al., 2006b; Specia et al., 2006c). Tal alternativa consiste na utilização da informação de freqüência de cada possível tradução da palavra ambígua juntamente com um contexto local, composto por diversas formas de colocações e bag-ofwords. A frequiência é dada por meio de buscas por queries consistindo dessas colocações e bag-of-words na web, utilizando-se a API do Google SOAP Search ${ }^{30}$. O ranking resultante de traduções, em ordem descendente de acordo com sua freqüência, é então empregado para reordenar múltiplas regras produzidas pelo sistema de PLI. Essa se mostrou uma alternativa útil, já que em muitos casso, entre as regras geradas pelo sistema, há múltiplas regras que cobrem um determinado exemplo, classificando-o com diferentes sentidos. Com essa informação de freqüência, a regra escolhida é a que classifica o exemplo de acordo com o sentido mais freqüente da palavra ambígua em questão na web, dado o seu contexto de ocorrência. Em experimentos com os sete verbos altamente ambíguos e um subconjunto de 50 sentenças por verbo extraídas do córpus Compara (Specia et al., 2006c), a precisão média dos modelos de DLS aumentou de $75 \%$ para $79 \%$, a partir do uso de colocações formadas por cada uma das possíveis traduções do verbo seguida de duas palavras a sua direita na sentença paralela em português. Uma desvantagem dessa abordagem é que a obtenção dessa informação é muito dispendiosa, pois um grande número de buscas se faz necessário, já que, para cada exemplo de um determinado verbo a ser classificado, uma query é criada para cada possível tradução daquele verbo (o verbo come, por exemplo, possui 226 possíveis traduções). Portanto, decidiu-se utilizar formas mais simples de contextos da língua alvo, i.e., $\mathbf{B}_{\mathbf{1 1}}$ e $\mathbf{B}_{\mathbf{1 2}}$, durante a geração dos modelos de DLS. No Capítulo 6 é apresentada uma estratégia simplificada de pós-processamento que considera a informação sobre a freqüência das possíveis traduções dada pelo córpus de treinamento para a reordenação de múltiplas regras cobrindo um dado exemplo, contudo, essa informação não é especifica para a desambiguação multilíngue.

\footnotetext{
${ }^{30} \mathrm{http}: / /$ code.google.com/apis/soapsearch/.
} 


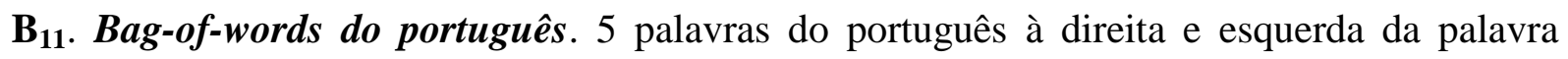
ambígua, extraídas da sentença do português no córpus paralelo de exemplos e representada utilizando-se definições do tipo has_bag_trns(snt, portuguese_word), por exemplo:

$$
\begin{aligned}
& \text { has_bag_trns( } \left.\operatorname{snt}_{5 \_6} \text {, coelho }\right) . \\
& \text { has_bag_trns }\left(\operatorname{snt}_{5 \_6}, \text { reincarnação }\right) \text {. }
\end{aligned}
$$

B $_{12}$. Colocações do português. 5 palavras do português à direita e à esquerda da palavra ambígua, de acordo com suas posições, extraídas da sentença do português no córpus paralelo de exemplos e representadas por cláusulas da forma has_narrow_trns(snt, word_position, portuguese_word), por exemplo:

$$
\begin{aligned}
& \text { has_narrow_trns }\left(\text { snt }_{5} \text {,6 }, 1 s t \_w o r d \_r i g h t, c o m o\right) \text {. } \\
& \text { has_narrow_trns }\left(\operatorname{snt}_{5} \_ \text {, } 2 n d \_w o r d \_r i g h t, u m\right) \text {. }
\end{aligned}
$$

Para a extração dessas fontes de conhecimento, o córpus de exemplos é primeiramente analisado utilizando-se o parser Minipar e anotado com etiquetas gramaticais utilizando-se o Mxpost. O parser é empregado para lematizar as palavras do inglês (com exceção da palavra alvo, cujas informações morfológicas são importantes) a serem utilizadas para as fontes $\mathrm{B}_{1}, \mathrm{~B}_{2}$ e $\mathrm{B}_{4}$, e para fornecer as relações sintáticas a serem utilizadas para as fontes $\mathrm{B}_{6}, \mathrm{~B}_{7}$ e $\mathrm{B}_{9}$. $\mathrm{O}$ Mxpost foi empregado para fornecer as etiquetas gramaticais utilizadas para a fonte $\mathrm{B}_{3} \mathrm{e}$ também para a extração de $\mathrm{B}_{5}$. Adicionalmente, ainda previamente à extração das fontes de conhecimento, com base nas etiquetas dadas pelo Mxpost, nomes próprios são substituídos por um único identificador (proper_noun) e pronomes são substituídos por identificadores correspondendo aos diferentes tipos de pronomes (relative_pronoun, demonstrative_pronoun, etc.). O processo de extração das fontes de conhecimento superficiais, principalmente as fornecidas pelo córpus, é bastante simples. Para outras fontes, no entanto, fez-se necessária a implementação de extratores mais complexos. Este é o caso, por exemplo, das restrições de seleção. Tais extratores foram implementados como regras Prolog genéricas (i.e., válidas para todos os verbos e exemplos), e fornecidos como conhecimento de fundo ao sistema de PLI para gerar os modelos de DLS. Assim, foram exploradas representações extensionais, i.e., fatos, geralmente referindo-se a fontes de conhecimento superficial, como bag-of-words, e representações condicionais e intensionais, ou seja, regras contendo variáveis para extração de definições sobre fontes de conhecimento profundo. 
Vale ressaltar que, conforme foi discutido no Capítulo 3, são poucos os trabalhos híbridos que utilizam uma combinação de várias fontes de conhecimento superficiais e profundas. Um exemplo representativo é a abordagem de Stevenson \& Wilks (2001). Nela, apenas um subconjunto das fontes exploradas aqui é utilizado. Por exemplo, relações interlexicais da WordNet não são consideradas para a verificação de restrições de seleção. Além disso, o uso de algumas das fontes monolíngues citadas aqui se dá de maneira diferente: etiquetas gramaticais são utilizadas como filtros para eliminar sentidos que só se aplicariam a determinadas categorias (a ambigüidade entre múltiplas categorias é considerada parte do problema de DLS), enquanto outras fontes são utilizadas como etiquetadores de sentido parciais, ou seja, fornecem um escore para cada sentido. Os escores de todas as fontes são combinados por meio de um algoritmo de aprendizado de máquina. Por outro lado, nos trabalhos puramente baseados em conhecimento que utilizam fontes profundas, como o de McRoy (1992), estas são manualmente especificadas, o que limita as abordagens em termos de abrangência. Neste trabalho, todas as fontes são automaticamente extraídas.

\subsubsection{PLI para a indução de modelos de DLS}

A abordagem proposta neste trabalho consiste no uso de um sistema de PLI, provido de um conjunto de fontes de conhecimento superficiais e profundas sobre exemplos de desambiguação, para a geração de modelos de DLS que possam ser utilizados para auxiliar o processo de escolha lexical na aplicação de tradução automática. Trata-se, portanto, do uso dos conceitos da PLI preditiva: classificadores simbólicos, na forma de um conjunto de regras, são gerados e podem ser aplicados para a classificação de novos casos de ambigüidade. Muito embora o foco seja a aplicação de TA, a abordagem é genérica o suficiente para ser utilizada para qualquer tarefa de DLS. Para tanto, pode ser personalizada em diversos aspectos, principalmente no que diz respeito ao repositório de sentidos (ou traduções), mas também com relação às fontes de conhecimento empregadas. Na Figura 5.3 é ilustrada a arquitetura geral da abordagem proposta.

Neste trabalho, foi utilizado o sistema de PLI Aleph (A Learning Engine for Proposing Hypotheses), um framework implementado em Prolog, com um mecanismo de inferência que pode ser personalizado em muitos aspectos (Srinivasan, 2000). Na Figura 5.3, os retângulos com bordas tracejadas representam as fontes de conhecimento descritas na Seção 5.3.2, extraídas do córpus de exemplos - com o uso de ferramentas de PLN, representados aqui como retângulos com bordas contínuas - e de diversos outros recursos, ilustrados por cilindros. Uma vez que todo o conhecimento sobre os exemplos é representado 
independentemente por cláusulas de programa, a representação dos exemplos, propriamente ditos, é bastante simplificada. Para os exemplos positivos, são especificadas cláusulas da forma sense(snt, sense), ou seja, cláusulas contendo o identificador para a instância e a sua classe, i.e., o sentido anotado para a palavra em questão ${ }^{31}$. Por exemplo, no caso da sentença (5.6), ilustrada na seção anterior, para o verbo come:

sense(snt 5 _6, voltar).

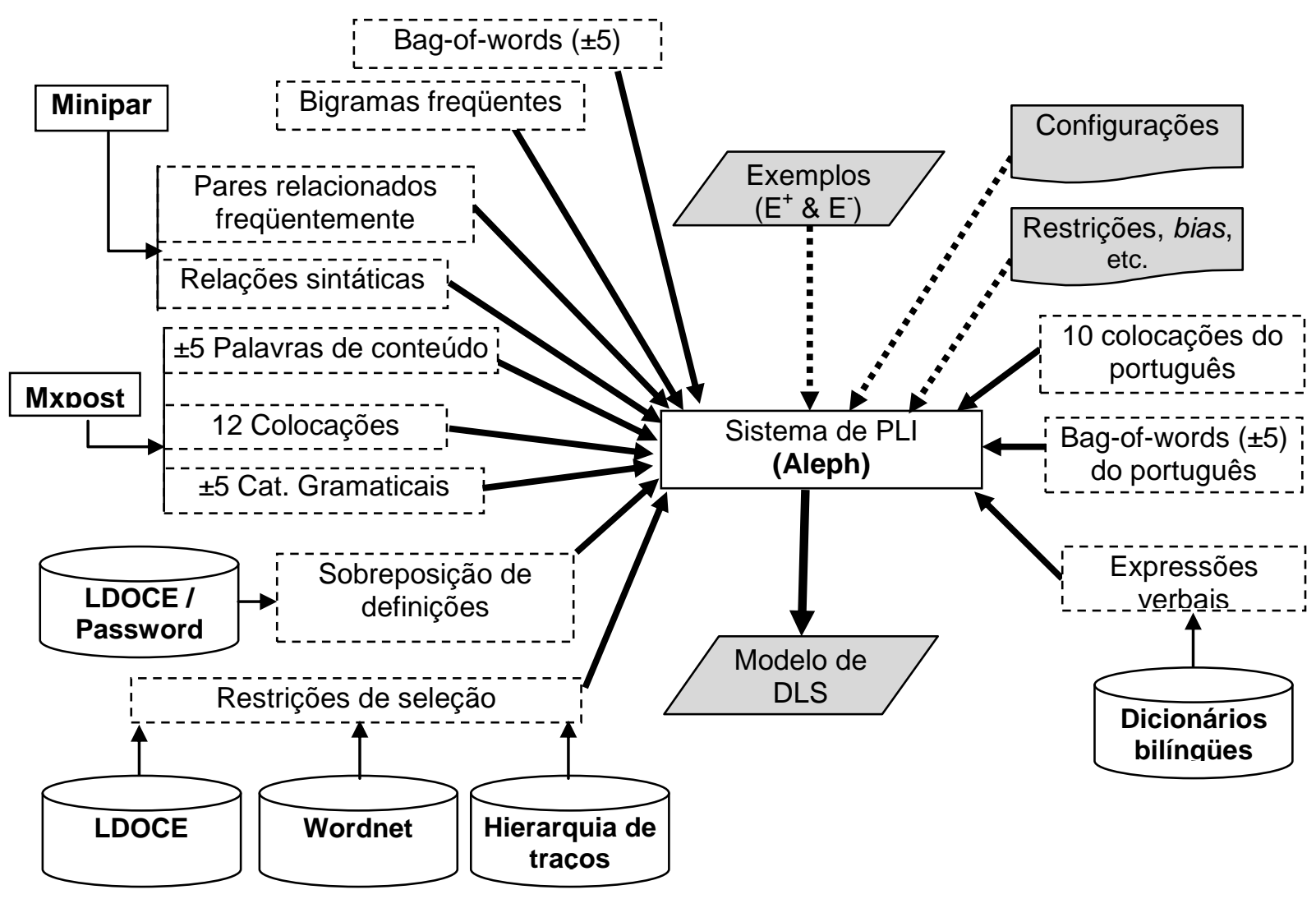

Figura 5.3: Arquitetura da abordagem de DLS proposta

Os exemplos negativos são gerados automaticamente como o complemento dos exemplos positivos, ou seja, dado um problema de DLS para uma determinada palavra $w$ com um conjunto $N$ de $n$ possíveis sentidos, para cada sentença $s n t_{i}$ no conjunto de treinamento de $w$, um exemplo negativo é criado para cada classe que não a classe real de tal sentença, ou seja, para as demais $n-1$ classes $^{32}$. Por exemplo, considerando-se que o verbo come possui o seguinte conjunto de sentidos $N=$ \{voltar, sair, chegar $\}$, no caso da sentença $s_{\text {t }} t_{5} 6$, cujo sentido é voltar, os seguintes exemplos negativos seriam criados:

\footnotetext{
${ }^{31}$ Os exemplos positivos são fornecidos ao sistema meio de um arquivo com extensão $f$.

${ }^{32}$ Os exemplos negativos são representados em um arquivo com extensão .n.
} 


$$
\begin{aligned}
& \text { sense(snt5_6, sair). } \\
& \text { sense(snt5_6, chegar). }
\end{aligned}
$$

Outra categoria de elementos de entrada do sistema consiste de uma série de configurações, as quais vão desde a especificação de opções gerais da PLI a parâmetros específicos do sistema Aleph. As opções gerais de PLI se resumem a: definições de modo e tipo e determinações. No sistema Aleph, definições de modo são especificadas utilizando-se a sintaxe mode(RecallNumber, PredicateMode) e consistem da especificação do predicado $\boldsymbol{p}$ a ser aprendido e dos predicados $\boldsymbol{q}$ que podem ser parte da definição de $\boldsymbol{p}$, e de como tais predicados podem ser instanciados:

modeh(RecallNumber, PredicateMode)

modeb(RecallNumber, PredicateMode)

Em ambos os casos, RecallNumber é um inteiro positivo que especifica o número máximo de soluções alternativas que podem ser usadas para instanciar o predicado em PredicateMode ou ‘*', que especifica que tal predicado pode ser instanciado qualquer número de vezes. PredicateMode é um predicado do tipo p(ModeType, ModeType,...) declarando o predicado $\boldsymbol{p}$ a aparecer na cabeça da cláusula a ser aprendida, juntamente com seu modo de instanciação (definição modeh) ou os predicados que podem aparecer no corpo dessa cláusula e seus modos de instanciação (definição modeb). ModeType especifica, para um dado argumento de um literal, qual o tipo esperado e se tal argumento é de entrada, saída, ou uma constante:

- $\quad+\mathbf{T}$ especifica que quando um literal com o símbolo de predicado $\mathbf{p}$ aparece em uma cláusula, o argumento correspondente deve ser uma variável de entrada do tipo $\mathbf{T}$. Uma variável de entrada do tipo $\mathbf{T}$ num literal $\mathbf{B}_{\mathbf{i}}$ do corpo da cláusula deve aparecer como uma variável de saída do mesmo tipo T em um literal do corpo que aparece antes de $\mathbf{B}_{\mathbf{i}}$, ou deve aparecer como variável de entrada do tipo $\mathbf{T}$ na cabeça da cláusula.

- -T especifica que o argumento é uma variável de saída do tipo T. Variáveis de saída do tipo T na cabeça da cláusula aparecem também como variáveis de saída do tipo $\mathbf{T}$ no corpo da cláusula.

- \#T especifica que o argumento é uma constante do tipo T. Apenas termos instanciados (ground) do tipo $\mathbf{T}$ podem ser utilizados para argumentos constantes. 
Pelo menos uma definição de modo deve ser declarada para cada fonte de conhecimento a ser utilizada. Múltiplas declarações podem ser feitas para a mesma fonte a aparecer no corpo das cláusulas (i.e., múltiplos modeb), com variações nos tipos e modos de instanciação. Alguns exemplos de definições de modo na abordagem proposta são:

$\therefore-\operatorname{modeh}(1$, sense(+snt, \#sense)).

$\therefore-$ modeb(12, has_collocation $(+$ snt,+ collococation_type, \# word $))$.

$\therefore-$ modeb(10, has_bag $(+$ snt, \#word $))$.

A primeira definição declara a cabeça das cláusulas da teoria: sense(snt, sense), que pode ser instanciada apenas uma vez (1) em cada cláusula (i.e., regra). As outras duas definições indicam que os literais has_collocation(snt, collocayion_type, word) e has_bag(snt,word), com no máximo 12 e 10 instanciações, respectivamente, podem aparecer no corpo da cláusulas da teoria.

Conforme foi ilustrado acima, as definições de modo também indicam o tipo $\mathrm{T}$ das variáveis utilizadas como argumentos dos predicados $\boldsymbol{p}$ e $\boldsymbol{q}$. A noção de tipos em PLI é uma noção fraca: um tipo é qualquer identificador atribuído pelo usuário a um elemento de conhecimento a ser utilizado nos predicados da teoria. Diferentes tipos são tratados distintamente e, portanto, tipos devem ser especificados para cada argumento de todos os predicados a serem incluídos na teoria sendo construída. Os tipos de cada argumento são declarados por definições da forma: type_name(value). Por exemplo, para as definições de modo acima, as seguintes declarações seriam necessárias:

$\operatorname{snt}(1)$.

$\operatorname{snt}(2)$.

$\operatorname{snt}(3)$.

...

collocation_type(1st_prep_right).

collocation_type(1st_noun_left).

word(if).

word(there).

word(was).

word(such). 
Nos exemplos, $\operatorname{snt}(X)$ especifica que $X$ possui o tipo snt, que deve ser usado para declarar todos os identificadores de sentenças. Já $\operatorname{word}(Y)$ serve para declarar todas as palavras $X$ que podem aparecer como argumentos em determinados predicados. Por fim, as declarações de determinações indicam quais dos predicados definidos podem ser usados para a construção da teoria, e são da forma: determination(Target/Arity, Background/Arity). O primeiro argumento especifica o nome e a aridade do predicado a ser aprendido, ou seja, o predicado que deve aparecer na cabeça das cláusulas. O segundo argumento indica o nome e a aridade dos predicados que podem aparecer no corpo de tais cláusulas. Normalmente, múltiplas declarações, incluindo o mesmo predicado como primeiro argumento, são criadas tendo as diversas fontes de conhecimento como segundo argumento, por exemplo:

$\therefore$-determination(sense/2, has_collocation/3).

$\therefore$ - determination(sense/2, has_bag/2).

$\cdots$

Por ser um framework para a experimentação com PLI, Aleph permite modificar o procedimento básico para a construção de teorias (cf. descrito na Seção 5.2) de várias maneiras, por meio de comandos específicos e um grande número de parâmetros (cerca de 75). As principais opções e parâmetros para este trabalho são:

- Modo de indução: no modo de indução default, descrito na Seção 5.2 (induce/0), a construção de cada cláusula bottom parte de um exemplo do conjunto de treinamento ainda não coberto por outra cláusula, respeitando-se a ordem em que os exemplos são dados. Todos os demais exemplos cobertos pela cláusula criada são então removidos do conjunto de treinamento, ou seja, nenhuma nova cláusula pode ser construída com base em tais exemplos. Assim, a ordem dos exemplos de treinamento tem um papel muito importante e alterações nessa ordem geralmente levam a mudanças significativas nas teorias induzidas $^{33}$. Aleph oferece outros métodos de indução, entre os quais, induce_max/0, no qual a ordem dos exemplos não é relevante. Em tal modo, todos os exemplos de treinamento são saturados e reduzidos, e apenas as melhores cláusulas a cada interação são mantidas. Outros modos incluem a indução de teorias incrementalmente (induce_incremental/0), à medida que os usuários fornecem exemplos e conhecimento de fundo, a indução de árvores de

\footnotetext{
${ }^{33} \mathrm{O}$ parâmetro samplesize pode ser utilizado para minimizar os efeitos da dependência da ordem dos exemplos na construção de cláusulas bottom como será descrito a seguir.
} 
decisão (induce_tree/0), a indução das restrições que são válidas de acordo com o conhecimento de fundo (induce_constraints/0), entre outros. Os principais modos de indução utilizados neste trabalho são induce/0 e induce_max/0.

- Estratégia de busca: a busca pela melhor cláusula para generalizar a cláusula bottom no passo de redução pode ser feita seguindo-se diferentes estratégias de busca, definidas pela instanciação do parâmetro search (set(search, Strategy)). As estratégias utilizadas neste trabalho incluem a ordenação das cláusulas de acordo com seu tamanho para a escolha das mais curtas ou mais longas ( $b f / d f)$, de acordo com seu número de literais, e a ordenação de acordo com as buscas heurísticas best-first e beam search (heuristic / ibs).

- Função de avaliação: além da estratégia de busca, a escolha da melhor cláusula para generalizar a cláusula bottom no passo de redução depende da utilidade de cada cláusula candidata, que é dada de acordo com um critério de avaliação. As opções de critérios são definidas pela instanciação do parâmetro Evalfn em set(evalfn, Evalfn). Os critérios mais relevantes incluem: accuracy, em que a utilidade da cláusula é definida como $P /(P+N)$, onde $P$ e $N$ são os números de exemplos positivos e negativos cobertos pela cláusula; compression, em que a utilidade é definida como $P-N-L+1$, onde $L$ é o número de literais na cláusula (cláusulas longas podem levar ao problema de overfitting); coverage, em que a utilidade é simplesmente definida como $P-N$; posonly, em que a utilidade da cláusula é calculada utilizando-se um escore bayesiano, de modo que exemplos negativos não se fazem necessários; entre outros. Todas essas opções foram avaliadas neste trabalho.

- Número de exemplos aleatórios: conforme mencionado, no processo default de indução, um exemplo é escolhido para dar origem à bottom clause a cada passo do processo, seguindo-se a ordem dos exemplos nos dados de treinamento. Isso impõe, portanto, um bias muito forte ao processo, que pode ser prejudicial caso a ordem dos exemplos não seja adequada. O parâmetro Size em set(samplesize, Size) permite minimizar os efeitos de uma escolha inapropriada no passo de saturação. Size define o número de tentativas de construção da cláusula bottom com exemplos aleatoriamente selecionados a serem feitas para a escolha do melhor exemplo. Cada exemplo dá origem a uma busca diferente no passo de redução e somente a melhor cláusula é adicionada à teoria. Esse parâmetro permite resultados similares aos do uso de induce_max, mas sem a necessidade 
de uma busca exaustiva por todas as possibilidades. No entanto, com o uso de samplesize as teorias resultantes de diversas execuções do sistema serão distintas, dado o critério de escolha aleatória.

- Mínimo de cláusulas positivas: set(minpos, $N$ ) define o número mínimo $N$ de exemplos positivos que devem ser cobertos por uma cláusula para que ela seja incluída na teoria. Isso ajuda a evitar overfitting e acelera o processo de busca, já que permite que o sistema encerre a busca por cláusulas melhores assim que uma cláusula cobrindo esse número mínimo de exemplos é encontrada.

- Precisão mínima: set(minacc, $P$ ) define a precisão mínima $P($ entre 0 e 1$)$ de uma cláusula para que ela seja incluída na teoria.

- Utilidade mínima: set(minscore, $U$ ) especifica a utilidade mínima $U$ de uma cláusula para que ela seja incluída na teoria. A noção de utilidade é definida de acordo com a função de avaliação escolhida.

- Tolerância a ruídos: set(noise, $N$ ) define o número máximo de exemplos negativos $N$ que podem ser cobertos por uma cláusula para que ela seja incluída na teoria. Esse parâmetro permite uma busca mais "realista", já que para a maioria dos problemas é impossível obter hipóteses totalmente consistentes, ou seja, que não cubram nenhum exemplo negativo.

- Tamanho das cláusulas: set(clauselength, $C$ ) define o número máximo $C$ de literais aceitável em uma cláusula para que ela seja incluída na teoria. Esse parâmetro pode ajudar a controlar o fenômeno de overfitting, que pode ser provocado por cláusulas muito longas.

- Profundidade das variáveis: $\operatorname{set}(i, I)$ define a profundidade máxima $I$ de variáveis nas cláusulas, ou seja, quantos níveis de compartilhamento de variáveis entre cláusulas. A profundidade de uma variável $v$ é ' 0 ', ou seja, $d(v)=0$, se tal variável aparece na cabeça da clausula. Caso contrário, a profundidade é definida recursivamente como $d(v)=\left(\max _{u \in U v} d(u)\right)+1$, sendo $U v$ o conjunto de variáveis nos átomos do corpo da cláusula contendo $v$ (Muggleton, 1995).

- Seleção de cláusulas "boas": set(good, true) faz com que o sistema armazene, a cada passo de busca, todas as cláusulas consideradas "boas", ou seja, as cláusulas que satisfazem o critério de utilidade definido pela escolha da função de avaliação evalfn e pelo parâmetro minscore. Esse parâmetro é importante para a construção de atributos a partir de cláusulas relevantes (Seção 5.3.4). 
De maneira similar, cerca de 75 parâmetros podem ser definidos pelo comando set(Parameter, Value). A lista completa de parâmetros pode ser consultada em (Srinivasan, 2000). Conforme será descrito no Capítulo 6, a análise de variações desses parâmetros é necessária para a obtenção de modelos otimizados para uma dada palavra ambígua.

Outro elemento (opcional) de entrada permitido pelo sistema Aleph consiste de regras definindo restrições que devem ser satisfeitas pelas cláusulas a serem incluídas na teoria. Por exemplo, podem ser especificadas restrições quanto à combinação de determinadas fontes de conhecimento no corpo das cláusulas, ao formato das regras, etc. As restrições são dadas por regras da forma:

false:-

Body.

em que Body é o conjunto de literais que especificam as condições que não devem ser violadas por cláusulas a serem incluídas na teoria. Outros comandos do Aleph, como hypothesis/3 e clause/2, são geralmente utilizados em tais regras para obter, respectivamente, a cláusula candidata sendo analisada pelo sistema e as cláusulas que já fazem parte da teoria sendo gerada. Uma restrição que se mostrou bastante útil neste trabalho é a que evita a geração de uma cláusula sem condições, ou seja, uma regra para classificar exemplos de acordo com um certo sentido independentemente das características de tal exemplo:

false:-

$$
\begin{aligned}
& \text { hypothesis(Head,Body,_), } \\
& \text { Body == true, !. }
\end{aligned}
$$

Essa restrição se faz necessária porque se pretende adicionar uma cláusula sem condições ao final de cada teoria, mas de forma controlada para que a sua classe corresponda à classe majoritária nos exemplos de treinamento. Assim, somente aqueles exemplos de teste que não forem cobertos por nenhuma outra regra serão classificados por essa regra default. Outro exemplo é uma restrição que evita a indução de uma segunda regra cobrindo um determinado exemplo, mas com uma classe distinta (o que poderia ser considerada uma contradição):

false:-

hypothesis(Head,Body,_),

clause(sense(A,B),Body),

$\operatorname{sense}(A, B) \backslash==$ Head, !. 
Além de restrições definidas dessa forma, outras maneiras de guiar o sistema durante a inferência de teorias incluem o uso de estratégias específicas de poda, definidas pelo usuário, visando à redução do espaço de busca por cláusulas, nos casos em que o usuário sabe, a priori, que certas cláusulas (envolvendo instanciações de determinadas fontes de conhecimento, por exemplo) não devem fazer parte da teoria final. Adicionalmente, funções de custo de cláusulas também podem ser definidas pelo usuário, as quais permitem a ordenação das cláusulas candidatas de acordo com critérios específicos. Essas especificações podem ser vistas como diversas formas de bias para guiar e minimizar o espaço de busca.

As configurações de parâmetros, declarações de modo e tipo, determinações e restrições são fornecidas, juntamente com o conhecimento de fundo, em um arquivo com extensão. $\boldsymbol{b}$.

Dados os elementos de entrada descritos acima, juntamente com os exemplos e demais formas de conhecimento de fundo, o mecanismo de inferência do sistema de PLI produz uma hipótese, formada por um conjunto de regras. Por exemplo, as regras na Figura 5.4 fazem parte da hipótese induzida para o verbo come em um dos experimentos a serem apresentados no Capítulo 6. As regras são apresentadas na ordem em que foram geradas e múltiplas regras contínuas com a mesma classe (ou seja, apontando para a mesma tradução) são agrupadas utilizando-se o marcador de disjunção “;”. A conjunção entre várias condições na mesma regra é representada por “,”.

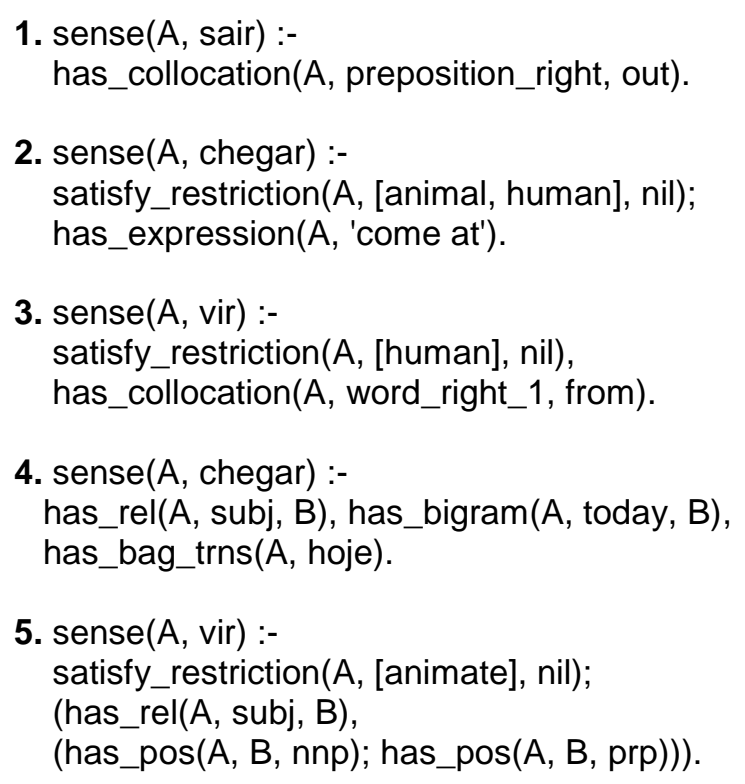

Figura 5.4: Exemplos de regras produzidas pelo Aleph para a desambiguação do verbo come 
A regra (1) define que a tradução do verbo come será "sair" se a primeira preposição à direita do verbo for out. A regra (2) verifica se os argumentos nos papéis de sujeito e objeto do verbo satisfazem as seguintes seleções de restrição: o sujeito possui os traços animal ou human, e não há objeto. Alternativamente, verifica se a sentença contém a expressão verbal come at. Em qualquer um dos casos, a tradução do verbo será "chegar". A regra (3) também testa as restrições de seleção dos argumentos do verbo: o sujeito deve possuir o traço human e o objeto é inexistente. Alternativamente, testa se a colocação correspondente à primeira palavra à direita do verbo é from. Em ambos os casos, a tradução é "vir". A regra (4) define que a tradução do verbo será "chegar" se o sujeito do verbo $(B)$ ocorrer freqüentemente (aqui, pelo menos 3 vezes) precedido da palavra today, e se a palavra "hoje" aparecer na parte da sentença já (parcialmente) traduzida para o português. Por fim, a regra (5) indica a tradução "vir" se o verbo possuir um sujeito com o traço animate e não possuir objeto (nil) ou se o sujeito do verbo $(B)$ for um nome próprio $(n n p)$ ou um pronome pessoal (prp). Exemplos adicionais de regras e as configurações e resultados dos experimentos realizados com a abordagem são apresentados no próximo capítulo.

Conforme foi apresentado nessa seção, sistemas de PLI e, em especial, o sistema Aleph, utilizado neste trabalho, permitem a customização do processo de indução de hipótese em diversos aspectos. Se por um lado essa característica pode ser vista como uma vantagem, já que permite grande flexibilidade, por outro lado, a otimização de parâmetros pode se tornar um problema. De fato, apesar de algumas opções serem intuitivas, o número de combinações é muito grande e a variação permitida em cada parâmetro inclui não apenas múltiplas opções, mas valores numéricos em $[0, \infty]$. A otimização de parâmetros é um requisito não apenas da PLI, mas de qualquer algoritmo de aprendizado. Contudo, no caso de algoritmos baseados em vetores de atributos, é possível utilizar métodos de otimização tradicionais (por exemplo, Hoste et al., 2002), que repetem experimentos por meio da variação sistemática de um pequeno número de parâmetros. Adicionalmente, pode-se contar com métodos auxiliares como os de seleção de atributos e exemplos representativos, que também já foram amplamente pesquisados. Neste trabalho, conforme será descrito na próxima seção, investigase uma maneira alternativa de explorar a PLI em que uma solução (em termos de acurácia) ótima não se faz necessária: a construção de atributos relevantes a partir de representações de exemplos e conhecimento de fundo (superficial e profundo), os quais podem então ser utilizados por algoritmos tradicionais de aprendizado de máquina, baseados em vetores de atributos. 


\subsubsection{PLI para a construção de atributos}

Conforme foi mencionado na Seção 5.2, funcionalmente, além de tarefas preditivas, ou seja, de classificação, como a que foi apresentada na seção anterior, a PLI pode ser também utilizada para tarefas descritivas. A PLI descritiva preocupa-se com a identificação de relacionamentos existentes entre as fontes de conhecimento e os exemplos, sem visar à discriminação de tais exemplos.

Essa modalidade da PLI foi investigada neste trabalho como um objetivo secundário, visando à construção de atributos relevantes a partir de fontes de conhecimento profundas, os quais podem então ser utilizados por algoritmos de aprendizado convencionais, baseados em vetores atributo-valor, como SVMs, para construir modelos de DLS (Figura 5.5). A intuição dessa abordagem é a suposição de que as instanciações mais relevantes do conhecimento de fundo profundo, que não poderia ser representado por vetores de atributos, podem ser identificadas pelo sistema de PLI. A partir dessas instanciações podem ser gerados atributos binários que representam um número significativamente reduzido do conjunto de todas as cláusulas e instanciações que poderiam ser derivadas a partir dos exemplos e conhecimento de fundo (e demais restrições discutidas anteriormente), tornando possível a representação desse conhecimento de maneira proposicional. Tais instanciações podem incluir conjunções de múltiplos literais.

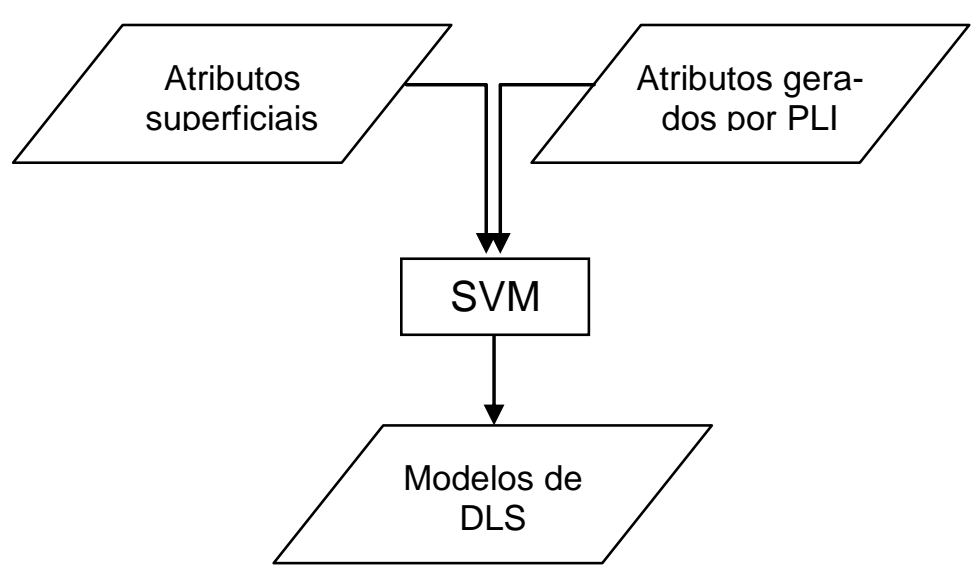

Figura 5.5: PLI para o aprendizado de atributos proposicionais

A idéia de identificar atributos relevantes utilizando-se representações na lógica de primeira ordem é muitas vezes chamada de propositionalization (e.g., Kramer et al., 2001), já que uma representação proposicional é produzida a partir de cláusulas de primeira ordem. Conceitualmente, a identificação de tais atributos envolve aspectos tanto da PLI preditiva quanto da PLI descritiva, e dá-se por meio de dois passos: (1) um passo de construção de atributos que identifica todos os atributos que são consistentes com as restrições definidas 
pelo conhecimento de fundo (essa é uma característica da PLI descritiva); e (2) um passo de seleção de atributos que mantém um subconjunto dos atributos construídos com base na sua utilidade para a classificação dos exemplos, definida de acordo com os parâmetros evalfn, minscore e good, que foram descritos na Seção 5.3.3 (essa é uma característica da PLI preditiva). No que segue, são apresentadas as especificações para a construção de atributos relevantes que refletem a combinação dessas suas categorias de PLI (as especificações foram adaptadas a partir de Muggleton \& De Raedt, 1994):

- $E-$ um conjunto finito de exemplos $=E^{+} \cup E^{-}$, onde:

○ Exemplos Positivos: $E^{+}=\left\{e_{1}, e_{2} \ldots\right\}$ é um conjunto não vazio de cláusulas definidas;

○ Exemplos Negativos: $E^{-}=\left\{\overline{e_{1}}, \overline{e_{2}} \ldots\right\}$ é um conjunto de cláusulas de Horn (este pode ser vazio).

- $B$ - conhecimento de fundo sobre o domínio consistindo de um conjunto finito de cláusulas definidas $=\left\{C_{1}, C_{2}, \ldots\right\}$.

- $\mathcal{H}$ é o conjunto finito de cláusulas, compostas de predicados, funções e constantes em $B \cup E ; F$ o conjunto de atributos construídos utilizando-se o conjunto de exemplos e $B$; e $\tau: \mathcal{H} \mapsto F$ é uma função que mapeia uma cláusula definida $h \in$ $\mathcal{H}$ para um atributo $f \in \mathcal{F}$.

- $F=\left\{f_{1}, f_{2} \ldots\right\} \subseteq F$ é a saída do algoritmo dados $B$ e $E$, que é aceitável para qualquer conjunto de hipóteses $H=\left\{h_{1}, h_{2} \ldots\right\} \subseteq \mathcal{H}$ se as seguintes condições são satisfeitas:

○ Posterior Sufficiency: $B \cup\left\{h_{1}\right\} \vDash e_{1} \vee e_{2} \vee \ldots$, onde $\left\{e_{1}, e_{2} \ldots\right\} \subseteq E^{+}$.

○ $f_{i}=\tau\left(h_{i}\right)$.

A principal diferença entre PLI preditiva, descritiva e essa combinação preditiva-descritiva está na condição Posterior Sufficiency. Para a construção de atributos, as cláusulas identificadas precisam cobrir um número mínimo de exemplos positivos. Esse não é o caso da PLI descritiva e é também insuficiente para a PLI preditiva.

Para explicar o significado de $\mathcal{H}, \mathcal{F}$ e $\tau$, assume-se que os valores binários FALSO e VERDADEIRO são representados por 0 e 1 ; os atributos $f_{i}$ são funções da forma $f_{i} X \mapsto\{0,1\}$; e os exemplos em $E$ são algum subconjunto da relação binária $X \times Y$, onde $X$ 
denota o conjunto de exemplos e $Y$ o conjunto de classes (sentidos). Exemplos positivos e negativos são representados pelo predicado sense: $X \times Y \mapsto\{0,1\}$ e cada $h_{i} \in \mathcal{H}$ é uma cláusula definida $\operatorname{sense}\left(X, y_{k}\right) \leftarrow c p_{i}(X)$, onde $X$ é uma variável e $\boldsymbol{y}_{\boldsymbol{k}}$ é alguma classe em $Y . c p_{i} X \mapsto\{0,1\}$ é um predicado contextual e corresponde a uma conjunção de literais que são avaliados como verdadeiro ou falso para um exemplo particular $\boldsymbol{x}$. A partir dessas descrições, dado $h_{i}: \operatorname{sense}\left(X, y_{k}\right) \leftarrow c p_{i}(X), f_{i}(x)=\tau\left(h_{i}\right)=1$ iff $c p_{i}(x)=1$ (ou 0 do caso contrário) .

Dados o conjunto de exemplos representados por identificadores de sentenças e suas classes (i.e., o sentido da palavra ambígua naquela sentença), o sistema para a construção de atributos que satisfaz minimamente a especificação definida acima procede como segue. Primeiramente, um conjunto de cláusulas $H$ é identificado para os exemplos, em que cada cláusula cobre pelo menos um exemplo positivo, dado $B$. A seguir, cada cláusula $h_{i}$ em $H$ é convertida em um atributo binário $f_{i}$ que assume o valor 1 para cada exemplo para o qual o corpo da cláusula é verdadeiro (ou 0 se o corpo é falso). Assim, o conjunto de cláusulas $H$ dá origem a um vetor de atributos binários para cada exemplo. Para ilustração, considere o atributo construído na Figura 5.6.

Cláusula:

$$
h_{1}=\operatorname{sense}(X, v o l t a r):-h a s_{-} \operatorname{expression}\left(X, \text { 'come back' }^{\prime}\right), h a s \_p o s\left(X, 4 t h \_w o r d \_r i g h t, n n\right) .
$$

Atributo:

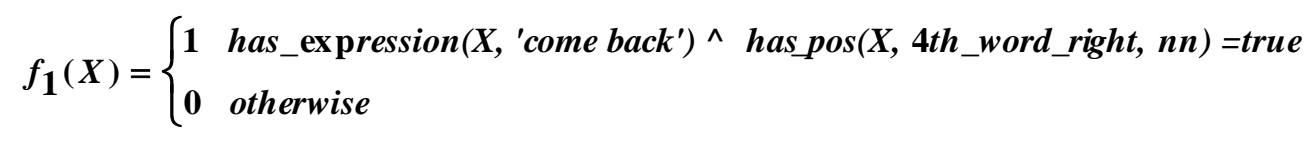

Figura 5.6: Exemplo de atributo binário construído a partir de uma cláusula que identifica o sentido do verbo come como "voltar" caso os predicados has_expression e has_pos sejam verdadeiros.

Os atributos construídos seguindo-se esse procedimento são utilizados, juntamente com um conjunto de atributos superficiais, para gerar modelos de DLS por meio de uma implementação de um algoritmo SVM, que tem mostrado resultados positivos em diversas abordagens de DLS em todas as edições da competição Senseval. Mais especificamente, o seguinte método é utilizado para a construção de um modelo de DLS para uma dada palavra ambígua: 
1. Com a finalidade de comparação, é gerado o melhor modelo possível utilizando-se o algoritmo SVM e fontes de conhecimento superficiais apenas, ou seja, aquelas que podem ser diretamente convertidas para uma representação vetorial.

2. São gerados no máximo $k$ (e.g., 5000) atributos utilizando-se o sistema de PLI provido de todas as fontes de conhecimento. Tais atributos são convertidos para atributos binários e instanciados a partir da representação relacional das fontes de conhecimento.

3. É gerado o melhor modelo possível utilizando-se o algoritmo SVM e os atributos superficiais (cf. passo 1) e os atributos produzidos no passo 2.

A superioridade do algoritmo SVM para a DLS, que já havia sido verificada em experimentos contrastivos com outros algoritmos proposicionais (Specia, 2005), é também comprovada nos experimentos que serão apresentados no Capítulo 6. No Capítulo 6, os modelos produzidos pelo SVM, seguindo-se o método apresentado acima, são também comparados aos modelos produzidos pelo sistema Aleph. Vale notar que os modelos produzidos pelo SVM e Aleph são de natureza distinta. Aleph produz modelos simbólicos, bastante expressivos, que podem ser facilmente interpretados e diretamente incorporados em aplicações baseadas em regras. Os modelos produzidos pelo SVM, por outro lado, resumem-se a vetores de atributos, com pesos específicos para cada atributo e classe, que representam hiper-planos separando o conjunto de exemplos de acordo com as classes de tais exemplos. Contudo, se o objetivo for simplesmente a classificação de novos casos, essa solução do tipo black-box pode apresentar resultados comparáveis aos do sistema Aleph, desde que dotada de atributos representando diferentes fontes de conhecimento superficiais e profundas, gerados utilizando-se PLI.

\subsubsection{Implementação}

A abordagem proposta consiste de três módulos principais: (a) o módulo para extrair e representar as fontes de conhecimento de acordo com o formalismo de primeira ordem; (b) o módulo de PLI para inferir os modelos de DLS; e (c) o módulo para avaliar tais modelos.

O módulo extrator das fontes de conhecimento consiste de um conjunto de scripts Perl e programas Prolog para, dado o córpus de exemplos de desambiguação (descrito no Capítulo 4), extrair as fontes contextuais (bag-of-words, bigramas, colocações, etc.) e acessar recursos lingüísticos (WordNet, dicionários, etc.) e processos externos para extrair as demais fontes (parser, etc.) e representá-las como cláusulas definidas, de acordo com as descrições ilustradas na Seção 5.3.2. 
Como módulo de PLI, é utilizado o mecanismo de inferência do sistema Aleph, versão 5, juntamente com o Yap Prolog versão 5.1.1 para Linux. Tal mecanismo de inferência foi personalizado de diversas maneiras, por meio das opções fornecidas como parâmetros e também da implementação de restrições, em Prolog, para a construção das teorias, conforme discutido na Seção 5.3.3.

Por fim, o módulo de avaliação é implementado como um conjunto de scripts Perl para, a partir dos modelos gerados pelo sistema Aleph, verificar a acurácia de cada regra e também do modelo completo para a classificação de todos os exemplos de teste, de acordo com a medida discutida na Seção 6.1.

\subsection{CONSIDERAÇÕES FINAIS}

Neste Capítulo foram discutidas as principais limitações das abordagens existentes para a DLS. A proposta de uma nova abordagem de DLS que visa superar tais limitações, principalmente no contexto da DLS multilíngue, foi então descrita. O desempenho dessa abordagem depende amplamente da identificação e especificação, de maneira adequada, das fontes de conhecimento relevantes para o problema, e de como tais fontes podem ser combinadas. A abordagem descrita utiliza um conjunto de diversas fontes, variando de fontes superficiais, extraídas de córpus, a fontes de natureza semântica, extraídas de recursos lingüísticos. A técnica de PLI é utilizada para permitir representar e incorporar tais fontes durante a construção de modelos de DLS e no aprendizado de atributos relevantes. Vale ressaltar que esta se trata da primeira proposta de aplicação da PLI para a tarefa de DLS. O sistema Aleph é empregado para a geração de modelos e atributos, dada a sua flexibilidade, que permite experimentos com diversas opções de PLI. No próximo capítulo, são descritos experimentos para avaliar a abordagem proposta em diversas tarefas de DLS. 





\section{AVALIAÇÃO DA ABORDAGEM DE DLS PROPOSTA}

Neste capítulo a abordagem de DLS apresentada no Capítulo 5 é avaliada em diversos cenários, incluindo-se tarefas multilíngues (Seção 6.2), para as quais tal abordagem foi inicialmente proposta, e também tarefas monolíngues (Seção 6.3), de modo a permitir a comparação com trabalhos correlatos. Adicionalmente à avaliação intrínseca, ou seja, à avaliação da tarefa per se, apresenta-se também experimentos de avaliação extrínseca dos modelos de DLS em um sistema estatístico de tradução automática (Seção 6.4). Primeiramente, no entanto, são discutidos diversos aspectos referentes ao processo de avaliação, como as métricas utilizadas, a ordem de aplicação das regras, etc. (Seção 6.1).

\subsection{CONSIDERAÇÕES GERAIS SOBRE A AVALIAÇÃO}

Nesta tese, segue-se o procedimento comum para a avaliação de abordagens de DLS conforme foi discutido na Seção 3.1. Considera-se, portanto, a medida "acurácia", que representa ambas as medidas precision e recall, já que a cobertura dos modelos apresentados é sempre completa. Vale notar que a acurácia para cada palavra, ou seja, a acurácia média para todos os exemplos da palavra, a ser apresentada nas seções a seguir, é calculada como a macro-média, ou seja, não se atribui pesos específicos para cada classe (sentido) de acordo com o número de exemplos de cada sentido, o que seria feito na micro-média. Assim, a acurácia de uma palavra word $_{j}$ consiste do somatório da acurácia de cada exemplo $\boldsymbol{e}_{i}$ de tal palavra dividido pelo número $|\boldsymbol{E}|$ total de exemplos de tal palavra, ou seja:

$$
a c c_{-} \text {word }_{j}=\frac{\sum_{i \in E} a c c_{-} \text {word }_{j-} e_{i}}{|E|}
$$

Por atribuir o mesmo peso para todos os sentidos, a macro-média não favorece sentidos mais comuns, ou seja, com mais exemplos (os quais teriam maior peso na micro-média). A medida macro-média é utilizada para calcular a acurácia média para todas as palavras. Essa medida é utilizada pelo sistema scorer nos exercícios de avaliação conjunta Senseval, e foi mantida neste trabalho para permitir a comparação com trabalhos avaliados em tais exercícios para tarefas monolíngues. Conforme foi discutido na Seção 3.1, o sistema scorer permite computar a macro-média de todas as palavras e exemplos de acordo com três diferentes níveis de refinamento: fine-grained, coarse-grained e mixed-grained. Os resultados apresentados nesta 
tese dizem respeito às distinções refinadas (fine-grained): a acurácia é computada contrastando-se o sentido previsto pelo sistema para um dado exemplo ao sentido(s) esperado(s). Isso resulta em "1" quando o sentido previsto é o mesmo que pelo menos um dos sentidos esperados, ou " 0 " no caso contrário, já que os modelos produzidos aqui geram apenas um sentido para cada exemplo. Não se dispõem, portanto, de uma hierarquia de sentidos.

Muito embora o sistema Aleph permita a avaliação das teorias geradas de acordo com um conjunto de exemplos de teste, a medida de acurácia calculada no Aleph não corresponde à noção de acurácia tradicionalmente utilizada para a avaliação de tarefas de DLS, ou seja, a acurácia macro-média. O cálculo da acurácia no sistema Aleph contrasta, para cada regra, a quantidade de exemplos positivos e negativos cobertos por tal regra: considera-se que um exemplo é coberto por uma regra se ambos o corpo (condições) e a cabeça (classe) da regra podem ser unificados com tal exemplo. Isso difere da medida de avaliação que foi implementada neste trabalho, em que dados apenas exemplos positivos, verifica-se se o corpo da regra pode ser unificado a cada exemplo e, em caso positivo, verifica-se se a cabeça da regra também unifica com tal exemplo, ou seja, se a classe predita pela regra é a classe real de tal exemplo, atribuindo-se um escore “1" em caso positivo, e " 0 " caso contrário. Neste trabalho, os exemplos negativos são automaticamente gerados e em número muito maior que os exemplos positivos (para cada exemplo positivo de uma dada palavra, $n-1$ exemplos negativos são criados, onde $n$ é o número de sentidos de tal palavra). Assim, a métrica utilizada pelo Aleph não fornece uma aproximação adequada à acurácia e não foi utilizada. De fato, exemplos negativos foram utilizados neste trabalho apenas para a geração de modelos, visando reduzir o espaço de busca, e não para a sua avaliação.

Por fim, vale notar que as regras produzidas pelo Aleph em um modelo podem ser aplicadas de diferentes maneiras para classificar novos exemplos e, conseqüentemente, avaliar a acurácia do modelo para tais exemplos. Na maioria dos experimentos descritos neste capítulo, a aplicação das regras segue a ordem na qual tais regras foram produzidas, como uma lista de decisões: a primeira regra é aplicada a todos os exemplos; aqueles cobertos (correta ou incorretamente) são removidos do conjunto de teste e o escore de acurácia média é atualizado de acordo com o novo número de exemplos cobertos corretamente. A segunda regra é então aplicada e o processo é repetido até que todas as regras sejam aplicadas ou todos os exemplos sejam cobertos. A última regra para cada verbo, que nem sempre é utilizada, consiste de uma regra default que classifica eventuais exemplos restantes, que não foram cobertos por outras regras, de acordo com o sentido majoritário nos exemplos de treinamento. 
A ordem em que as regras são geradas pode depender ou não da ordem dos exemplos de treinamento, de acordo com o método de indução utilizado (induce ou induce_max / induce_cover), ou do uso de parâmetro samplesize com valor maior que 0, conforme foi discutido na Seção 5.3.3. Sendo assim, o uso das regras na ordem em que são produzidas mostra-se uma opção viável. Contudo, verificou-se que em muitos casos múltiplas regras são geradas cobrindo um dado exemplo, possivelmente classificando-o com diferentes sentidos. Nesses casos, apenas a primeira regra é aplicada; as demais são ignoradas pra tal exemplo. Para verificar se tais regras adicionais poderiam, eventualmente, resultar em classificações mais precisas, foram realizados experimentos que consideram a reordenação das regras de acordo com a informação de freqüência dos sentidos no conjunto de exemplos de treinamento. Os resultados de tais experimentos para uma das bases de exemplos multilíngue serão apresentados na Seção 6.2.4.

Em grande parte dos experimentos descritos neste capítulo, a técnica de validação cruzada $n$-fold foi utilizada nos exemplos de treinamento para obter modelos otimizados de acordo com variações de opções e parâmetros. As escolhas que resultaram na melhor acurácia média nos exemplos de treinamento foram então selecionadas para gerar os modelos finais a serem avaliados no conjunto de teste.

\subsection{AVALIAÇÃO INTRÍNSECA - TAREFAS MULTILÍNGUES}

A desambiguação multilíngue de verbos constitui o foco deste trabalho. Portanto, foram realizados experimentos com diversos córpus de exemplos, parâmetros do sistema Aleph e processos de avaliação. Adicionalmente, foram realizados experimentos considerando-se PLI para o aprendizado de atributos, conforme foi discutido na Seção 5.3.4.

\subsubsection{Experimento 1 - Modelos de PLI para a desambiguação de 7 verbos (Specia, 2006)}

O primeiro experimento focaliza nos sete verbos mais ambíguos definidos como o escopo inicial desta tese (cf. Seção 2.4), representados por meio de um córpus de pouco menos de 200 sentenças extraídas do córpus Compara para cada verbo, cuja criação segue a metodologia descrita no Capítulo 4: o uso do sistema de anotação automática de etiquetas de sentido, seguido da revisão manual de tal anotação. Na Tabela 6.1 são ilustrados tais verbos, juntamente com o número de exemplos no córpus, o número de traduções distintas e o percentual de exemplos com a tradução mais freqüente. 
Tabela 6.1: Córpus utilizado no Experimento 1

\begin{tabular}{|l|r|r|r|}
\hline Verbo & \# exemplos & \multicolumn{1}{c|}{ \# traduções } & \% tradução mais frequente \\
\hline come & 183 & 11 & 50.3 \\
\hline get & 157 & 17 & 21 \\
\hline give & 180 & 5 & 88.8 \\
\hline go & 197 & 11 & 68.5 \\
\hline look & 191 & 7 & 50.3 \\
\hline make & 170 & 11 & 70 \\
\hline take & 142 & 13 & 28.5 \\
\hline
\end{tabular}

Para descrever tais exemplos, um subconjunto inicial das fontes de conhecimento descritas na Seção 5.3.2 foi utilizando, a saber, $\mathrm{B}_{1}$ (bag-of-words), $\mathrm{B}_{3}$ (etiquetas gramaticais), $\mathrm{B}_{5}$ (colocações), $\mathrm{B}_{6}$ (relações sintáticas de sujeito e objeto), $\mathrm{B}_{8}$ (sobreposição de definições), $\mathrm{B}_{9}$ (restrições de seleção) e $\mathrm{B}_{10}$ (expressões verbais). O sistema Aleph foi utilizado para a geração de modelos de DLS para cada um dos verbos considerando-se o modo default de indução de teorias, o que corresponde ao modo de aprendizado do sistema Progol (Muggleton, 1991). Foi utilizado, para tanto, o modo de indução induce e foram mantidas as configurações default, exceto pelos seguintes parâmetros definidos por declarações do tipo set(Parameter, Value):

- evalfn = posonly: somente exemplos positivos foram utilizados para 0 aprendizado.

- $\quad$ search = heuristic: a estratégia de busca heurística é utilizada.

- $\operatorname{minpos}=2$ : pelo menos 2 exemplos positivos devem ser cobertos por cada cláusula.

- samplesize $=1000$ : para minimizar o bias imposto pela ordem dos exemplos de treinamento.

Tais parâmetros e seus valores foram intuitivamente definidos e nenhuma estratégia de otimização de parâmetros foi utilizada. Outra simplificação importante diz respeito às definições de modo do sistema Aleph, ou seja, a especificação de quais cláusulas podem fazer parte da cabeça e corpo das regras (modificadores “+”, “_“ e “\#”, cf. Seção 5.3.3). Nessa etapa, as regras se restringem a definições extensionais, ou seja, sem variáveis:

$\therefore-\operatorname{modeh}(1$, sense $(+\operatorname{snt}$, \#sense $)$ ).

$\therefore-$ modeb(11, has_collocation(+snt, \#collocation_type, \#collocation)).

$\therefore-\operatorname{modeb}\left(*, h a s \_b a g(+s n t\right.$, \#word $\left.)\right)$.

$\therefore-\operatorname{modeb}(2$, has_rel(+snt, \#type_rel, \#word)).

$\therefore$ - modeb(1, has_expression (+snt, \#verbal_expression)).

$\therefore-\operatorname{modeb}(1$, satisfy_restriction(+snt, \#rest_subj, \#rest_obj)). 
:- modeb(10, has_pos(+snt, \#word_position, \#pos)).

:- modeb(1, has_overlapping(+snt, \#sense)).

Para a avaliação, apesar de o conjunto de exemplos ser bastante pequeno, não foi utilizada a técnica de validação cruzada uma vez que se pretendia comparar os resultados com outros experimentos considerando-se diferentes algoritmos, fontes de conhecimento e parâmetros. Assim, o conjunto de exemplos para cada verbo foi aleatoriamente dividido em $65 \%$ para treinamento e o restante para teste.

Para permitir a comparação com outras técnicas de aprendizado, foram selecionados dois algoritmos comumente empregados para a DLS monolíngue: árvores de decisão e SVMs, nas implementações fornecidas pelo ambiente $\mathrm{Weka}^{34}$ (J48 e SMO, respectivamente). Contudo, conforme foi discutido na Seção 5.1, uma vez que tais algoritmos são baseados em representações vetoriais do conhecimento sobre os exemplos, somente um subconjunto das fontes de conhecimento foi utilizado, mais especificamente, $\mathrm{B}_{1}, \mathrm{~B}_{3}, \mathrm{~B}_{5}, \mathrm{~B}_{6}$ e $\mathrm{B}_{8}$. Para tanto, essas fontes superficiais foram convertidas para uma representação vetorial. Por exemplo, no caso das colocações $\left(\mathrm{B}_{5}\right)$, um atributo é criado para cada tipo de colocação (e.g., col_1st_prep_right) e, para cada exemplo, é instanciado de acordo com o valor de tal colocação exemplo. Já no caso de unigramas $\left(\mathrm{B}_{1}\right)$, cada possível unigrama no conjunto de todos os exemplos é transformado em um atributo binário (e.g., reincarnation) e é instanciado, num dado exemplo, com o valor 1 (0) de acordo com a ocorrência (ou não) de tal palavra no exemplo. As demais fontes, ou seja, restrições de seleção e expressões verbais, não foram representadas, já que precisariam ser simplificadas. Por exemplo, um dado exemplo pode conter mais de uma possível expressão verbal ("come forth", "come forth with"), o que não poderia ser diretamente mapeado para um único atributo. Em experimentos posteriores tais fontes são pré-processadas para poderem ser representadas por vetores de atributos.

Os modelos produzidos pelo Aleph são aplicados seguindo-se a ordem na qual as regras foram geradas, com a inclusão da regra default ao final da teoria para a classificação de acordo com o sentido majoritário nos exemplos de treinamento. Vale notar que a regra default, na maioria dos verbos, é responsável pela classificação de um número pequeno de exemplos (de 1 a 6 exemplos). A acurácia média obtida para os exemplos de teste nos três algoritmos, juntamente com a baseline da tradução mais freqüente nos exemplos de treinamento aplicada aos exemplos de teste, é ilustrada na Tabela 6.2.

\footnotetext{
${ }^{34}$ http://www.cs.waikato.ac.nz/ ml/weka/
} 
Tabela 6.2: Acurácia obtida no Experimento 1

\begin{tabular}{|l|r|r|r|r|}
\hline \multicolumn{1}{|c|}{ Verbo } & \multicolumn{1}{c|}{ Baseline } & \multicolumn{1}{c|}{ J48 } & \multicolumn{1}{c|}{ SMO } & \multicolumn{1}{c|}{ Aleph } \\
\hline come & 0.55 & 0.55 & 0.60 & 0.82 \\
\hline get & 0.21 & 0.36 & 0.45 & 0.51 \\
\hline give & 0.98 & 0.88 & 0.88 & 0.96 \\
\hline go & 0.71 & 0.73 & 0.72 & 0.73 \\
\hline look & 0.60 & 0.66 & 0.84 & 0.83 \\
\hline make & 0.74 & 0.76 & 0.76 & 0.74 \\
\hline take & 0.13 & 0.35 & 0.41 & 0.66 \\
\hline Média & $\mathbf{0 . 5 6}$ & $\mathbf{0 . 6 1}$ & $\mathbf{0 . 6 7}$ & $\mathbf{0 . 7 5}$ \\
\hline
\end{tabular}

Como se pode verificar na Tabela 6.2, em média, a acurácia dos modelos produzidos pelo sistema Aleph é superior à acurácia dos outros dois algoritmos, os quais, por sua vez, superam a baseline da tradução mais freqüente. A diferença entre Aleph e J48 e a baseline é estatisticamente significante de acordo com Paired T-Test com $p<0.05$, enquanto a diferença entre Aleph e SMO é estatisticamente significante de acordo com o mesmo teste, mas com $p$ $<$ 0.10. Vale notar que, para todos os verbos, um número pequeno de regras foram produzidas, variando de 19 a 33. Diferentes fontes de conhecimento são utilizadas nas diversas regras dos modelos, o que indica que todas as fontes são potencialmente úteis para a desambiguação de verbos. Exemplos de regras geradas são ilustrados na Figura 6.1.

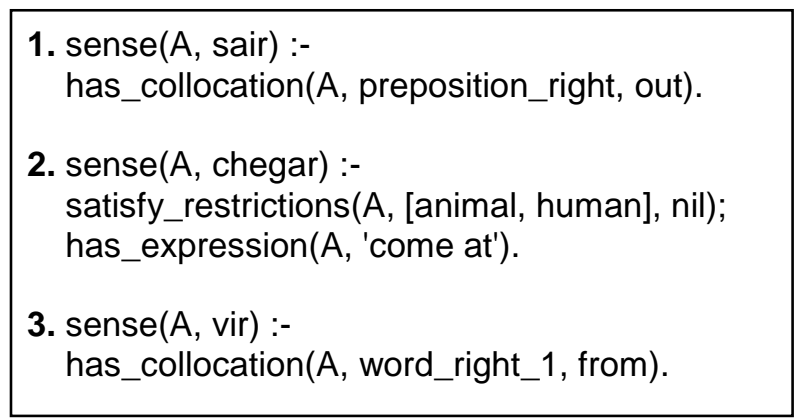

Figura 6.1: Exemplos de regras produzidas para o verbo come no Experimento 1

Uma investigação mais sistemática da relevância das fontes de conhecimento na acurácia dos modelos também foi realizada por meio da análise de diferentes combinações das fontes de conhecimento utilizadas. Como o número de combinações possíveis é muito grande, uma técnica comumente utilizada para análise da relevância das fontes de conhecimento (Agirre \& Stevenson, 2006) considera (1) cada fonte individualmente e (2) todas as fontes com exceção de uma determinada fonte. Aplicando-se essa técnica repetidamente para as sete fontes de conhecimento, os resultados mostraram que, individualmente, cada fonte de conhecimento tem acurácia bastante inferior à de qualquer combinação investigada. Da mesma forma, as demais combinações de fontes de conhecimento apresentaram acurácia significativamente inferior à obtida com a combinação de todas as fontes. 
No experimento descrito a seguir, os modelos iniciais são aperfeiçoados por meio da otimização de diferentes parâmetros do sistema Aleph. Adicionalmente, a comparação com outras técnicas de aprendizado de máquina é redefinida, de modo as fontes de conhecimento relacionais utilizadas no sistema Aleph sejam pré-processadas para serem também utilizadas com tais técnicas.

\subsubsection{Experimento 2 - Modelos de PLI otimizados para a desambiguação de 7 verbos (Specia et al., 2007a)}

No segundo experimento consideram-se os mesmos conjuntos de exemplos do Experimento 1 (cf. Tabela 6.1), e a mesma divisão entre treinamento e teste. Utiliza-se, no entanto, uma fonte de conhecimento adicional: narrow context $\left(\mathrm{B}_{4}\right)$. São mantidas as declarações de modo do Experimento 1, ou seja, somente definições extensionais são permitidas, com a inclusão da definição para a nova fonte de conhecimento:

:- modeb(10, has_narrow(+sent, \#position, \#word)).

Diferentemente do Experimento 1, exemplos negativos foram artificialmente gerados, conforme foi discutido na Seção 5.3.3, para permitir a utilização de outros métodos de avaliação de cláusulas baseados em proporções de exemplos positivos e negativos cobertos. Adicionalmente, os principais parâmetros do sistema Aleph, discutidos na Seção 5.3.3, foram otimizados a partir de um pequeno conjunto de opções intuitivamente definidas: a escolha entre os métodos de indução induce e induce_max, o método de busca (search), a função de avaliação (evalfn), o tamanho máximo das cláusulas (clauselength), o número mínimo de exemplos positivos cobertos (minpos) e a precisão mínima das cláusulas (minacc). Os valores para tais parâmetros foram obtidos por meio da técnica de validação cruzada com 10 subconjuntos (10-fold cross validation), ou seja, o conjunto de exemplos foi primeiramente dividido em 10 partes, e em 10 iterações modelos foram gerados para os $90 \%$ dos exemplos e testados nos $10 \%$ restantes. Os melhores valores médios de acurácia foram os seguintes: induce_max, search $=$ heuristic, evalfn $=$ coverage, clauselength $=8$, minpos $=2$ e minacc $=$ 0.8. Para os demais parâmetros, foram mantidos os valores default.

Para a avaliação dos modelos gerados, novamente, compara-se a sua acurácia à baseline do sentido mais frequiente e a outras técnicas de aprendizado, a saber, C4.5 (J48) e SVMs (SMO). Contudo, vale notar que, neste experimento, procurou-se utilizar todas as fontes de conhecimento fornecidas ao sistema Aleph também com as técnicas proposicionais. Para tanto, as fontes que não podiam ser diretamente representadas nos vetores de atributos 
foram pré-processadas, mais especificamente, $\mathrm{B}_{9}$ (restrições de seleção) e $\mathrm{B}_{10}$ (expressões verbais). Restrições de seleção são transformadas em atributos binários: para cada verbo, $n$ atributos binários são criados, cada atributo representando um dos $n$ sentidos (traduções) daquele verbo e sendo instanciado em um dado exemplo com " 1 " (“0”) quando a sentença do exemplo satisfaz (ou infringe) as restrições estabelecidas por tal sentido. Não se utiliza, durante o aprendizado, a informação sobre quais restrições são satisfeitas (ou infringidas). Assim, se um exemplo satisfaz diferentes conjuntos de restrições para o mesmo sentido, essa informação é perdida. Um determinado exemplo pode ter valores "1" para mais de um atributo, caso satisfaça restrições estabelecidas por diferentes sentidos do verbo, ou pode não ter nenhum valor "1". Essa simplificação não é ideal, pois como os sentidos dos verbos são, na verdade, as suas traduções para o português, em alguns casos, uma única tradução pode expressar sentidos diversos (cf. ilustrado na Seção 2.5). Portanto, a informação binária indicando simplesmente que as restrições para uma determinada tradução são satisfeitas pelo exemplo em questão pode dar origem a uma interpretação incorreta do exemplo. Idealmente, as restrições propriamente ditas deveriam ser representadas, como é feito na abordagem proposta com o uso de conhecimento de fundo. Contudo, isso não é possível na representação que utiliza vetores de atributos: diferentes atributos representando todas as combinações de traços semânticos (para sujeito e objeto) e sentidos poderiam ser criados, mas isso seria inviável e levaria ao problema da esparsidade dos dados. Além disso, a informação sobre a hierarquia dos traços semânticos não poderia ser utilizada.

Para a representação da fonte de conhecimento sobre expressões verbais, um único atributo é criado e instanciado com uma das possíveis expressões verbais existentes (se alguma) na sentença. Optou-se por essa representação, em vez da mesma utilizada para restrições de seleção, em que apenas a tradução da expressão existente na sentença seria representada, porque muitas das expressões possuem múltiplas traduções. Por exemplo, "take over" possui, entre outras, as seguintes traduções: “acompanhar", “assumir", "invadir". Perdese, portanto, a informação sobre as possíveis traduções das expressões existentes nas sentenças. Além disso, em alguns casos, mais de uma possível expressão pode ocorrer na sentença, por exemplo, a ocorrência de "come up with" em uma sentença pode representar a possível existência não somente da expressão "come up with", propriamente dita, mas também da expressão “come up”. Somente a primeira expressão (mais longa) encontrada é representada, neste caso "come up with".

As demais fontes utilizadas para os algoritmos proposicionais incluem $\mathrm{B}_{4}$ (narrow context) e as exploradas no Experimento 1, ou seja, $\mathrm{B}_{1}$ (bag-of-words), $\mathrm{B}_{3}$ (etiquetas 
gramaticais), $\mathrm{B}_{5}$ (colocações), $\mathrm{B}_{6}$ (relações sintáticas de sujeito e objeto), $\mathrm{B}_{8}$ (sobreposição de definições). Os resultados obtidos pelo sistema Aleph e pelos algoritmos J48 e SMO utilizando-se essas fontes de conhecimento são ilustrados, juntamente com a baseline da tradução mais frequiente, na Tabela 6.3 .

Tabela 6.3: Acurácia obtida no Experimento 2

\begin{tabular}{|l|r|r|r|r|}
\hline Verbo & Baseline & \multicolumn{1}{c|}{ J48 } & \multicolumn{1}{c|}{ SMO } & \multicolumn{1}{c|}{ Aleph } \\
\hline come & 0.55 & 0.53 & 0.62 & 0.87 \\
\hline get & 0.21 & 0.36 & 0.26 & 0.51 \\
\hline give & 0.98 & 0.96 & 0.98 & 0.98 \\
\hline go & 0.71 & 0.76 & 0.74 & 0.86 \\
\hline look & 0.60 & 0.57 & 0.79 & 0.83 \\
\hline make & 0.74 & 0.74 & 0.74 & 0.76 \\
\hline take & 0.13 & 0.31 & 0.44 & 0.63 \\
\hline Média & $\mathbf{0 . 5 6}$ & $\mathbf{0 . 6 0}$ & $\mathbf{0 . 6 5}$ & $\mathbf{0 . 7 8}$ \\
\hline
\end{tabular}

Como se pode perceber pela Tabela 6.3, a fonte de conhecimento adicional e a otimização de parâmetros levaram a uma melhoria de $3 \%$ (de $75 \%$ a $78 \%$ ) na acurácia média do sistema Aleph, se comparado ao Experimento 1. Contudo, o uso dessa fonte adicional e das duas fontes relacionais simplificadas não resultou em melhoria nos dois algoritmos proposicionais. De fato, a acurácia obtida é menor que a apresentada no Experimento 1: em média, diminuiu de $61 \%$ para $60 \%$, no J48, e de $67 \%$ para $65 \%$, no SMO. Acredita-se que isso se deve a ruídos eventualmente causados pela representação simplificada das duas fontes relacionais, bem como à esparsidade resultante dessa representação. No experimento descrito a seguir procurase minimizar a limitação causada pela representação das fontes relacionais em algoritmos proposicionais por meio do uso da PLI para construir atributos binários mais significativos, a serem utilizados pelo algoritmo SMO, que obteve acurácia significativamente superior à do $\mathrm{J} 48$.

\subsubsection{Experimento 3 - Modelos SVM com atributos PLI para a desambiguação de 7 verbos (Specia et al., 2007a)}

No Experimento 3, em vez de empregada para a geração de modelos de DLS, a PLI é utilizada para a indução de atributos interessantes a partir de representações relacionais. A idéia, descrita na Seção 5.3.4, é a de explorar um dos algoritmos proposicionais que vem sendo aplicado com sucesso para a DLS, a saber, SVMs, mas permitir que tal algoritmo faça uso de conhecimento derivado de fontes relacionais, a partir da representação apropriada desse conhecimento. Utiliza-se a mesma implementação de SVMs dos experimentos 
anteriores, isto é, SMO, fornecida pelo ambiente Weka, para o aprendizado dos modelos de desambiguação.

Partindo-se da mesma configuração e fontes de conhecimento do Experimento 2, o sistema Aleph é utilizado para gerar todas as cláusulas consideradas "boas" ou "úteis", que podem então ser transformadas em atributos binários. Para definir o critério de utilidade, é empregada a função de avaliação coverage (a utilidade é definida como a diferença entre o número de exemplos positivos e negativos cobertos $(P-N)$ ) e o parâmetro minscore instanciado com o valor "1", ou seja, para ser considerada "boa", a cláusula deve cobrir pelo menos dois exemplos positivos para cada exemplo negativo coberto, ou pelo menos um exemplo positivo, caso não cubra nenhum exemplo.

Mais especificamente, o seguinte método é utilizado para a construção de um modelo de DLS para uma dada palavra ambígua:

1. Com a finalidade de comparação, é gerado o melhor modelo possível utilizando-se o algoritmo SVM e as fontes de conhecimento superficiais $\mathrm{B}_{1}$ (bag-of-words), $\mathrm{B}_{3}$ (etiquetas gramaticais), $B_{5}$ (colocações), $B_{6}$ (relações sintáticas de sujeito e objeto) e $B_{8}$ (sobreposição de definições), as quais são transformadas em atributos proposicionais, conforme discutido na Seção 6.2.1. Novamente, foi utilizada a implementação do SVM linear fornecida pelo ambiente Weka, SMO. Na tentativa de melhorar os resultados do SMO, experimentou-se com uma técnica de seleção de atributos baseada em ganho de informação (InfoGain, também disponível no ambiente Weka) e diversos números de atributos a serem selecionados: 50, 100, 150, 200, 250, 500 e todos os atributos. O melhor desempenho medido nos dados de treinamento foi obtido com todos os atributos.

2. São gerados no máximo 5.000 atributos utilizando-se o sistema Aleph provido de todas as fontes de conhecimento. Tais atributos são convertidos para atributos binários e instanciados a partir da representação relacional das fontes de conhecimento. A otimização de parâmetros no sistema Aleph não é particularmente relevante, uma vez que não se pretende, aqui, analisar a acurácia dos modelos finais. Manteve-se, aqui, os parâmetros utilizados no Experimento 2, com a adição do parâmetro minscore, conforme foi mencionado anteriormente.

3. É gerado o melhor modelo possível utilizando-se o algoritmo SMO e os atributos superficiais (cf. passo 1) e os atributos produzidos pelo passo anterior. Como o número de atributos gerados no passo anterior é bastante grande, a seleção de atributos é especialmente importante. Foi utilizada a mesma técnica baseada em ganho de informação. Neste caso, a seleção de 500 atributos levou ao melhor desempenho nos dados de treinamento. 
Os resultados dos experimentos com o algoritmo SMO com e sem os atributos induzidos pelo sistema Aleph são ilustrados na Tabela 6.4, comparados à baseline do sentido mais freqüente e aos resultados do sistema Aleph no Experimento 2, conforme previamente ilustrados na Tabela 6.3. Vale notar que os resultados do algoritmo SMO com atributos superficiais diferem dos resultados do Experimento 2, já que aqui foram utilizadas apenas as fontes de conhecimento superficiais, em vez da simplificação das fontes relacionais realizadas no Experimento 2. Apesar da diferença ser pequena e não ser observada para todos os verbos, ela parece indicar que a representação proposicional de conhecimento relacional pela simplificação desse conhecimento, que é feita por grande parte dos trabalhos atuais de DLS, pode ser prejudicial para a acurácia dos modelos. Os resultados do SMO com atributos superficiais também diferem daqueles do Experimento 1, apesar de a média ser a mesma. Essa diferença pode ser explicada pelo uso da fonte de conhecimento adicional (narrow context $\left.\mathrm{B}_{4}\right)$.

Como se pode perceber pela Tabela 6.4, a adição de atributos induzidos pelo sistema Aleph no algoritmo SMO significativamente melhora a sua acurácia: de 0.67 para 0.73 , em média. A acurácia do sistema Aleph com todas as fontes de conhecimento é estatisticamente superior a da baseline e duas variações do algoritmo SMO (Paired T-Test, $\mathrm{p}<0.05$ ).

Tabela 6.4: Acurácia obtida no Experimento 3

\begin{tabular}{|l|r|r|r|r|}
\hline Verbo & Baseline & \multicolumn{2}{|c|}{$\begin{array}{c}\text { SMO - atributos } \\
\text { superficiais }\end{array}$} & \multicolumn{2}{c|}{$\begin{array}{c}\text { SMO - atributos } \\
\text { gerados por Aleph }\end{array}$} & Aleph \\
\hline come & 0.55 & 0.67 & 0.77 & 0.87 \\
\hline get & 0.21 & 0.32 & 0.41 & 0.51 \\
\hline give & 0.98 & 0.98 & 0.95 & 0.98 \\
\hline go & 0.71 & 0.72 & 0.79 & 0.86 \\
\hline look & 0.60 & 0.78 & 0.82 & 0.83 \\
\hline make & 0.74 & 0.75 & 0.75 & 0.76 \\
\hline take & 0.13 & 0.47 & 0.60 & 0.63 \\
\hline Média & $\mathbf{0 . 5 6}$ & $\mathbf{0 . 6 7}$ & $\mathbf{0 . 7 3}$ & $\mathbf{0 . 7 8}$ \\
\hline
\end{tabular}

Os experimentos a seguir concentram-se no uso de Aleph como indutor de modelos de DLS com diferentes córpus de exemplos. O uso de Aleph para o aprendizado de atributos é discutido novamente nos experimentos para a desambiguação monolíngue (Seção 6.3.2).

\subsubsection{Experimento 4 - Modelos de PLI para a desambiguação de 10 verbos (Specia et al., 2007b)}

Adicionalmente aos sete verbos altamente ambíguos endereçados pelos experimentos anteriores, o Experimento 4 cobre os três verbos menos ambíguos, acrescentados no processo de criação de córpus, conforme descrito na Seção 4.3. Além disso, o córpus utilizado neste 
experimento difere do que vinha sendo utilizado até então. O novo córpus foi criado utilizando-se o sistema proposto neste trabalho para a etiquetação de sentidos, seguida de revisão manual, conforme foi descrito na Seção 4.3.5. Este córpus possui 500 exemplos para cada verbo, extraídos de textos de diferentes gêneros e domínios (cf. Tabela 6.6, Seção 4.3.5). Os sentidos para cada verbo foram definidos como o conjunto de todas as possíveis traduções encontradas no córpus. Os números de possíveis traduções para cada verbo, bem como o percentual de exemplos contendo a tradução mais freqüente, são ilustrados na Tabela 6.5.

Tabela 6.5: Córpus utilizado no Experimento 4

\begin{tabular}{|l|r|r|}
\hline Verbo & \# traduções & \% tradução mais freqüente \\
\hline ask & 7 & 53 \\
\hline come & 29 & 36 \\
\hline get & 41 & 13 \\
\hline give & 22 & 72 \\
\hline go & 30 & 53 \\
\hline live & 8 & 66 \\
\hline look & 12 & 41 \\
\hline make & 21 & 70 \\
\hline take & 32 & 25 \\
\hline tell & 8 & 66 \\
\hline
\end{tabular}

O córpus de exemplos foi aleatoriamente dividido em $80 \%$ para treinamento e $20 \%$ para teste. As fontes de conhecimento utilizadas nesse experimento incluem, além de todas aquelas descritas nos experimentos anteriores, bigramas que ocorrem com alta frequiência no córpus $\left(\mathrm{B}_{2}\right)$, pares de palavras relacionadas sintaticamente e que ocorrem com alta frequiência no córpus $\left(\mathrm{B}_{7}\right)$, e duas fontes específicas para a tradução: bag-of-words do português $\left(\mathrm{B}_{11}\right)$ e narrow context do português $\left(\mathrm{B}_{12}\right)$. Os parâmetros do sistema Aleph são os utilizados no Experimento 2 (Seção 6.2.2): induce_max, search = heuristic, evalfn = coverage, clauselength $=8$, minpos $=2$ e minacc $=0.8$. Contudo, aqui se utilizam declarações de modo que permitam explorar a capacidade de PLI de manipulação de conhecimento intensional. Para tanto, utilizam-se variáveis nessas declarações, permitindo-se diferentes modos de instanciação. A seguir, são ilustradas as declarações para as novas fontes de conhecimento utilizadas aqui, bem como exemplos de declarações com variáveis, as quais são representadas pelos sinais de “+” (variáveis de entrada) e “-” (variáveis de saída), conforme foi descrito na Seção 5.3.3:

$\therefore-\operatorname{modeb}\left(10, h a s \_b a g \_t r a n s(+s n t\right.$, \#word_pt $\left.)\right)$.

$\therefore-$ modeb(10, has_narrow_trans(+snt, \#position, \#word_pt)).

$\therefore-$ modeb(*, has_bigram(+snt, \#word, \#word)).

$\therefore-$ modeb(*, has_related_pair(+snt, \#word, \#word)). 


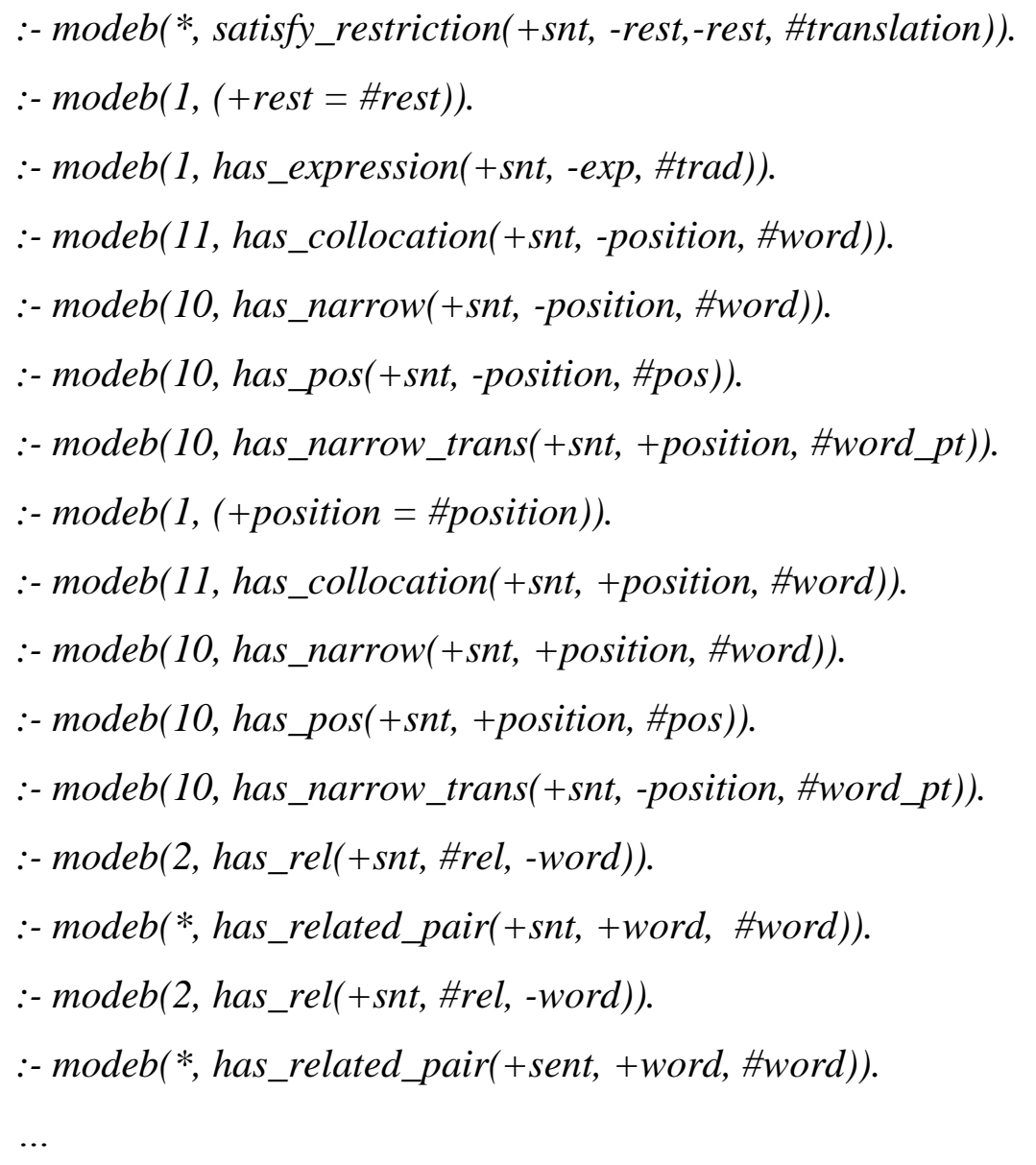

Para a avaliação dos modelos gerados, novamente, compara-se a sua acurácia à baseline do sentido mais freqüente e a outras técnicas de aprendizado, C4.5 (J48), SVMs (SMO) e, adicionalmente, Naïve Bayes, que também é comumente utilizado em abordagens de DLS. Utilizam-se todas as fontes de conhecimento para ambos o sistema Aleph e os algoritmos proposicionais. As fontes superficiais são diretamente convertidas para uma representação vetorial, enquanto que, das fontes profundas, $\mathrm{B}_{9}$ (restrições de seleção) e $\mathrm{B}_{10}$ (expressões verbais) são transformadas de acordo com o procedimento descrito na Seção 6.2.2, e as novas fontes utilizadas aqui, i.e., $\mathrm{B}_{2}$ (bigramas) e $\mathrm{B}_{7}$ (pares de palavras relacionadas sintaticamente) são convertidas em atributos binários: um atributo é criado para cada bigrama e par relacionado sintaticamente e é instanciado com " 1 ” (“0”) caso o bigrama / par relacionado ocorra na sentença (ou não ocorra). Na Tabela 6.6 é apresentada a acurácia obtida pelos modelos produzidos pelo Aleph e pelos demais algoritmos, juntamente com a baseline da tradução mais freqüente. Adicionalmente, na última coluna da Tabela 6.6 é ilustrada a acurácia obtida pelos modelos de PLI considerando-se a aplicação das regras diferente da que vinha sendo feita até então. Conforme foi discutido na Seção 6.1, em muitos casos múltiplas regras são geradas cobrindo um dado exemplo, classificando-o com diferentes sentidos. Aqui, 
em vez de aplicar a primeira regra encontrada, tais regras são reordenadas de acordo com a informação de freqüência dos sentidos no conjunto de exemplos de treinamento. Antes de aplicar uma regra, para cada exemplo, verificam-se todas as regras que cobrem tal exemplo e, caso existam regras para diferentes sentidos, reordenam-se tais regras de acordo com a probabilidade (prior) de cada sentido no córpus de treinamento, neste caso, dada pela frequiência de ocorrência de cada sentido no córpus. Assim, regras para sentidos mais freqüentes passam a ter prioridade de aplicação.

Tabela 6.6: Acurácia obtida no Experimento 4

\begin{tabular}{|l|r|r|r|r|r|r|}
\hline Verbo & Baseline & \multicolumn{1}{|c|}{ J48 } & \multicolumn{1}{c|}{$\begin{array}{l}\text { Naïve } \\
\text { Bayes }\end{array}$} & \multicolumn{1}{c|}{ SMO } & \multicolumn{1}{c|}{ Aleph } & \multicolumn{1}{c|}{$\begin{array}{c}\text { Aleph } \\
\text { reordenação } \\
\text { de regras }\end{array}$} \\
\hline ask & 0.68 & 0.68 & 0.82 & 0.88 & 0.92 & 0.90 \\
\hline come & 0.46 & 0.57 & 0.61 & 0.68 & 0.73 & 0.74 \\
\hline get & 0.03 & 0.25 & 0.46 & 0.47 & 0.49 & 0.43 \\
\hline give & 0.72 & 0.71 & 0.74 & 0.74 & 0.74 & 0.74 \\
\hline go & 0.49 & 0.61 & 0.66 & 0.66 & 0.66 & 0.63 \\
\hline live & 0.71 & 0.72 & 0.64 & 0.73 & 0.87 & 0.85 \\
\hline look & 0.48 & 0.69 & 0.81 & 0.83 & 0.93 & 0.90 \\
\hline make & 0.64 & 0.62 & 0.60 & 0.64 & 0.68 & 0.68 \\
\hline take & 0.14 & 0.41 & 0.50 & 0.51 & 0.59 & 0.55 \\
\hline tell & 0.65 & 0.67 & 0.66 & 0.68 & 0.82 & 0.74 \\
\hline Média & $\mathbf{0 . 5 0}$ & $\mathbf{0 . 5 9}$ & $\mathbf{0 . 6 5}$ & $\mathbf{0 . 6 8}$ & $\mathbf{0 . 7 4}$ & $\mathbf{0 . 7 2}$ \\
\hline
\end{tabular}

A acurácia dos modelos de PLI é claramente superior à baseline da tradução mais freqüente e é também significativamente superior à acurácia dos modelos gerados por outros algoritmos: em todos os casos, a diferença é estatisticamente significante (Paired T-Test com p < 0.05). Vale notar que, aqui, a técnica de seleção de atributos foi utilizada com os algoritmos J48, Naïve Bayes e SMO, com diferentes possíveis números de atributos, visando otimizar seus resultados. Os melhores resultados obtidos, ilustrados na tabela, correspondem à seleção de 50 atributos. Os modelos aplicados considerando-se a reordenação das regras de acordo com a freqüência de suas classes não resultaram em melhorias na acurácia com relação à aplicação das regras seguindo-se a sua ordem de produção. De fato, a informação geral de freqüência, sem considerar os contextos dos exemplos a serem classificados, parece não trazer benefício. Esses resultados podem ser contrastados com aqueles citados na Seção 5.3.2, em que informações de freqüência sobre o contexto da língua alvo implicam melhorias significativas na acurácia dos modelos. Assim, essa estratégia de reordenação não foi utilizada em experimentos posteriores. Conforme esperado, a acurácia dos modelos é maior para os verbos menos ambíguos no córpus, ou seja, com um número menor de possíveis traduções: ask (7), live (8), tell (8) e look (12). 
Os modelos produzidos pelo sistema de PLI são relativamente compactos, contendo de 50 a 96 regras cada modelo. Novamente, tais modelos parecem explorar todas as fontes de conhecimento. Algumas das regras produzidas para o verbo ask são ilustradas na Figura 6.2.

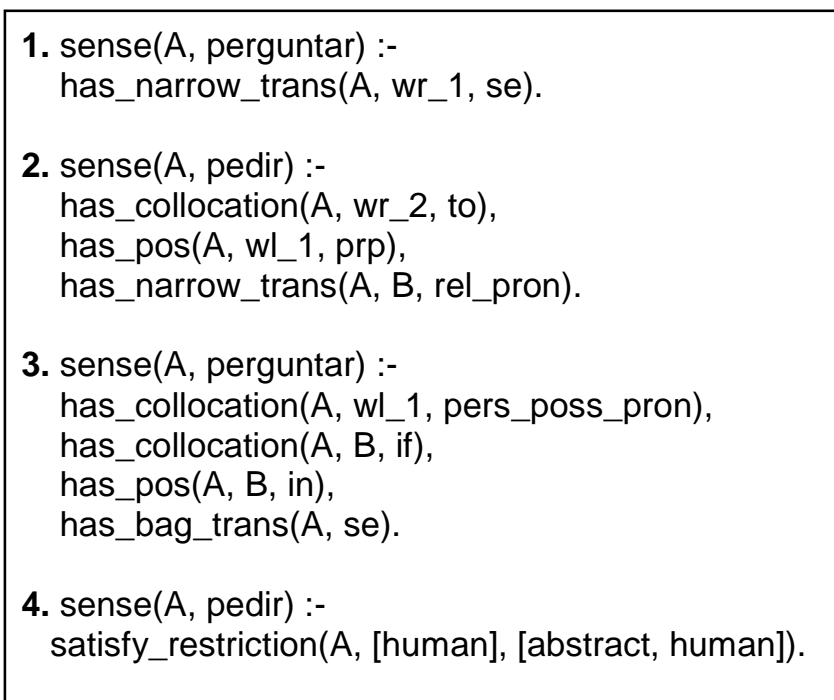

Figura 6.2: Exemplos de regras produzidas no Experimento 4 para a desambiguação do verbo ask

Como se pode notar na Regra 2 da Fig. 6.2, por exemplo, variáveis são utilizadas nos predicados. Neste caso, a regra define que a tradução do verbo ask será "pedir", caso a segunda palavra à direita do verbo seja to e a categoria gramatical da primeira palavra à esquerda do verbo seja um pronome (prp) e exista um pronome relacional (rel_pron) em qualquer lugar na vizinhança do verbo. Como a posição do pronome relacional não é especificada, essa fonte funciona de maneira similar à bag-of-words. Essa regra cobriria sentenças do tipo "She asked him to say that he was happy". A Regra 3 também utiliza variáveis. Ela define que a tradução do verbo ask será "perguntar" se a primeira palavra à esquerda do verbo seja um pronome pessoal ou possessivo (pers_poss_pron), e a sentença contenha a palavra if numa posição $B$, que é etiquetada como uma preposição (in) e, por fim, caso o contexto já traduzido para o português possua a palavra "se" em qualquer posição.

\subsection{AVALIAÇÃO INTRÍNSECA - TAREFAS MONOLÍNGUES}

Nos diversos experimentos descritos na Seção 6.2, a abordagem proposta foi comparada a outros algoritmos de aprendizado de máquina utilizando-se as mesmas fontes de conhecimento, ou um subconjunto dessas fontes. Como não há na literatura outros trabalhos utilizando o mesmo córpus inglês-português, ou mesmo trabalhos com outros córpus voltados para a tarefa de desambiguação multilíngues para esse par de línguas, experimentos com um 
córpus padrão para a desambiguação multilíngue não foram possíveis. Por outro lado, como a abordagem proposta pode ser facilmente adaptada para novas aplicações, é possível comparála com abordagens monolíngues utilizando-se conjuntos de dados padrão e repositórios de sentido monolíngues. Nesta seção são descritos experimentos com conjuntos de exemplos que vêm sendo utilizados em exercícios de avaliação conjunta de DLS. Assim, a abordagem proposta é comparada a outras abordagens que podem ser completamente distintas, em termos não apenas de algoritmos de aprendizado, mas de fontes de conhecimento, estratégias de desambiguação, etc. Os conjuntos de exemplos são voltados para a desambiguação na língua inglesa.

\subsubsection{Experimento 5 - Modelos de PLI para a desambiguação de 32 verbos do Senseval-3 (Specia et al., 2007a)}

No Experimento 5, modelos de desambiguação utilizando-se o sistema Aleph são gerados para o conjunto de 32 verbos da tarefa Lexical Sample com distinções refinadas da terceira edição da competição Senseval (Senseval-3): activate, add, appear, ask, begin, climb, decide, eat, encounter, expect, express, hear, lose, mean, miss, note, operate, play, produce, provide, receive, remain, rule, smell, suspend, talk, treat, use, wash, watch, win, e write. O número de exemplos para cada verbo varia de 26 / 14 a 265 / 133 (média de 123.5 / 61.8) nos exemplos de treinamento / teste. Tais exemplos são divididos em 66\% para treinamento e o restante para teste. Conforme é ilustrado na Tabela 6.7, o número de sentidos varia de acordo com o verbo, de 3 a 10 (média de 6.06 sentidos) e a acurácia média da baseline do sentido mais freqüente é de 55\%. Os sentidos utilizados para a anotação dos exemplos são extraídos do WordSmith, mas um mapeamento entre estes e os sentidos da WordNet é fornecido. Esse mapeamento é importante porque permite uma segunda conversão, entre os sentidos da WordNet e do dicionário LDOCE, do qual são extraídas as informações sobre restrições de seleção. Assim, conforme foi discutido na Seção 5.3.2, não é necessária nenhuma intervenção manual para a extração das fontes de conhecimento. Esse mapeamento também foi utilizado para automatizar a extração da informação de sobreposição de definições: as sentenças usadas nas definições e exemplos no dicionário LDOCE serviram como contexto a ser comparado com a sentença contendo o verbo a ser desambiguado.

Como se trata da desambiguação monolíngue, algumas das fontes de conhecimento descritas na Seção 5.3.2 não se aplicam a essa tarefa. Não se pode utilizar o contexto da tradução e expressões verbais, já que o repositório de sentidos dos verbos no Senseval-3 não 
inclui os usos dos verbos em expressões verbais. Mais especificamente, as fontes utilizadas neste experimento são: $\mathrm{B}_{1}$ (bag-of-words), $\mathrm{B}_{3}$ (etiquetas gramaticais), $\mathrm{B}_{4}$ (narrow context), $\mathrm{B}_{5}$ (colocações), $B_{6}$ (relações sintáticas de sujeito e objeto), $B_{8}$ (sobreposição de definições) e $B_{9}$ (restrições de seleção). O mesmo procedimento descrito na Seção 6.2.2 para a otimização de um conjunto reduzido de parâmetros foi realizado. Os melhores valores médios de acurácia obtidos foram os seguintes: induce_max, search $=$ heuristic, evalfn $=$ coverage, clauselength $=8$, minpos $=2$ e minacc $=1$. Para os demais parâmetros, foram mantidos os valores default . As declarações de modo e determinações são similares às utilizadas no Experimento 1 (Seção 6.2.1), ou seja, prevêem cláusulas extensionais apenas. A acurácia dos modelos de PLI para cada verbo é ilustrada na Tabela 6.7, na próxima seção, juntamente com a acurácia de modelos gerados utilizando-se SVMs e atributos aprendidos pelo sistema Aleph. O número de regras geradas pelo Aleph é pequeno, variando de 8, para palavras com menos exemplos, como use, a 98, para palavras com muitos exemplos, como ask. Alguns exemplos de regras induzidas nesse experimento monolíngue para o verbo appear são ilustrados na Figura 6.3.

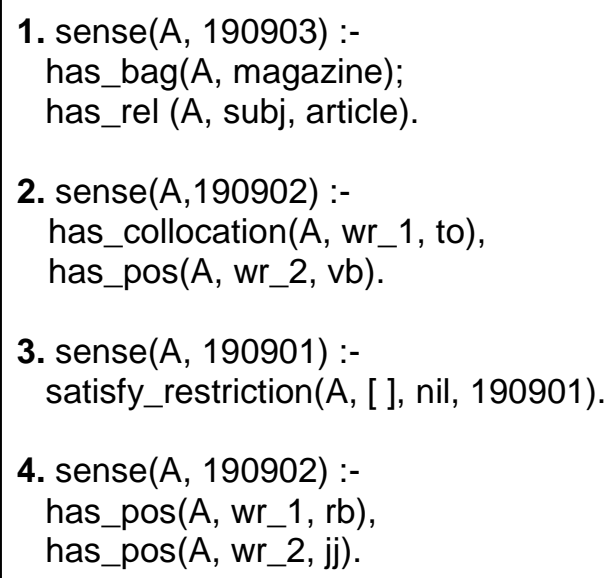

Figura 6.3: Exemplos de regras produzidas no Experimento 5 para o verbo appear

Os sentidos utilizados na regra, conforme o repositório fornecido pelos organizadores da tarefa, são:

- 190901: "appear, arise, emerge, show", "to come into view; become visible".

- 190902: “appear, look, seem", "to seem: 'He appears smart, but I have doubts"”.

- 190903: "appear, come_out", "to come before the public, as a book or performer".

Na Figura 6.3, a Regra 1, por exemplo, define que o sentido de appear será "to come before the public, as a book or performer" caso a palavra magazine apareça em qualquer posição na sua vizinhança, e o seu sujeito seja article. 
Nessa tarefa, conforme mencionado, também foi possível comparar a acurácia dos modelos gerados pelo sistema Aleph à acurácia de outras abordagens testadas utilizando-se o mesmo conjunto de exemplos e o mesmo método de avaliação. Foram considerados todos os trabalhos de aprendizado supervisionado reportando resultados especificamente para o conjunto de 32 verbos. Todos foram publicados nos anais do Workshop Senseval-3 (Mihalcea et al., 2004). Os resultados para a modalidade de distinções de sentido refinadas, isto é, considerando-se como correto apenas o sentido refinado exato da palavra na sentença, são ilustrados na Tabela 6.8, na próxima seção, juntamente com a acurácia de modelos gerados utilizando-se SVMs e atributos aprendidos pelo sistema Aleph. As abordagens Syntalex-1 a Syntalex-4, descritas em (Mohammad \& Pedersen, 2004), utilizam uma combinação de árvores de decisão (bagged decision trees), com o algoritmo C4.5. A combinação de árvores de decisão consiste em treinar o algoritmo C4.5 10 vezes, em 10 subconjuntos do conjunto de exemplos de treinamento. Para classificar um exemplo, os escores dados por cada modelo são somados e o maior escore é considerado. Syntalex-1 explora como atributos etiquetas gramaticais da palavra ambígua e de seus vizinhos imediatos. Syntalex-2 utiliza categorias gramaticais de um contexto maior na sentença: a palavra ambígua e duas palavras à direita e à esquerda, enquanto Syntalex-3 utiliza bigramas e etiquetas gramaticais do contexto local como no Syntalex-1. Por fim, Syntalex-4 utiliza os mesmos atributos que Syntalex-3, mas como a combinação de árvores de decisão é feita de modo que para um sentido ser escolhido, todas as árvores precisam atribuir escores altos para tal sentido.

CLaC1 e CLaC2 são descritos em (Lamjiri et al., 2004). CLaC1 utiliza um algoritmo Naïve Bayes com um contexto de palavras de conteúdo, cujo tamanho varia em uma janela dinamicamente ajustada ao redor da palavra ambígua. CLaC2 utiliza um algoritmo de entropia máxima (maximum entropy) com um conjunto de colocações, etiquetas gramaticais da palavra ambígua e do seu contexto imediato, e a categoria semântica mais genérica do primeiro substantivo à direita e esquerda da palavra ambígua, obtida percorrendo-se todos os hiperônimos da palavra ambígua na WordNet.

O último sistema testado, MC-WSD, descrito em (Ciaramita \& Johnson, 2004), utiliza um multi-class averaged perceptron com um componente treinado e nas glosas da WordNet e outro nos atributos dos exemplos fornecidos pelo Senseval, explorando um conjunto bastante rico de atributos: categorias gramaticais de \pm 3 palavras, bag-of-words, unigramas, bigramas, relações sintáticas, número de argumentos esperados pelo verbo e categorias sintáticas desses argumentos, juntamente com algumas características morfológicas da palavra ambígua. Para cada sentido de cada palavra ambígua, o primeiro componente utiliza as glosas da WordNet 
para definir exemplos de treinamento adicionais por meio da extração de synsets similares aos synsets contendo o sentido em questão (utilizando-se as relações e hierarquia da WordNet).

Dessas sete abordagens, os modelos baseados em PLI são ultrapassados apenas pelo MC-WSD. Isso mostra que, muito embora a abordagem tenha sido proposta para a desambiguação multilíngue, ela alcança desempenho comparável ao do estado da arte na área. Uma melhoria nesse desempenho foi alcançada com experimentos posteriores, conforme será descrito na Seção 6.3.3. A seguir, são apresentados os experimentos com esse mesmo conjunto de exemplos utilizando-se a abordagem alternativa para a exploração de PLI, ou seja, o uso de PLI para o aprendizado de atributos relevantes, que também resulta numa melhoria significativa na performance obtida aqui.

\subsubsection{Experimento 6 - Modelos SVM com atributos PLI para a desambiguação de 32 verbos do Senseval-3 (Specia et al., 2007a)}

Seguindo-se a metodologia descrita na Seção 6.2.3, a PLI é empregada, aqui, para a geração atributos interessantes, dadas as mesmas fontes de conhecimento e configurações e do Experimento 5, com a adição do parâmetro minscore instanciado com o valor "1". Esse parâmetro define que, para ser considerada "boa", a cláusula deve cobrir pelo menos dois exemplos positivos para cada exemplo negativo coberto, ou pelo menos um exemplo positivo, caso não cubra nenhum exemplo negativo. Novamente, modelos básicos foram gerados utilizando-se o algoritmo SMO e as fontes de conhecimento superficiais, ou seja, $\mathrm{B}_{1}$ (bag-ofwords), $\mathrm{B}_{3}$ (etiquetas gramaticais), $\mathrm{B}_{4}$ (narrow context), $\mathrm{B}_{5}$ (colocações), $\mathrm{B}_{6}$ (relações sintáticas de sujeito e objeto) e $\mathrm{B}_{8}$ (sobreposição de definições), todas transformadas em atributos proposicionais. 150 atributos foram selecionados por meio da técnica de seleção de atributos baseada em ganho de informação InfoGain.

Para o aprendizado de atributos utilizando-se o sistema Aleph provido de todas as fontes de conhecimento, no máximo 5.000 cláusulas "boas" foram selecionadas, convertidas para atributos binários e instanciadas. Os modelos que utilizam o algoritmo SMO com os atributos superficiais e os produzidos por Aleph foram então gerados. Aqui, a técnica de seleção de atributos com 250 atributos resultou na melhor performance.

Os resultados desse experimento para cada um dos 32 verbos, bem como os resultados obtidos pelos modelos de PLI descritos na seção anterior (6.3.1), são apresentados na Tabela 6.7, juntamente com o número de sentidos de cada verbo no conjunto de exemplos (treinamento e teste) e a baseline do sentido mais freqüente. 
Tabela 6.7: Acurácias obtidas nos Experimentos 5 e 6

\begin{tabular}{|c|c|c|c|c|c|}
\hline Verbo & \# sentidos & Baseline & $\begin{array}{c}\text { SMO - } \\
\text { atributos } \\
\text { superficiais }\end{array}$ & Aleph & $\begin{array}{c}\text { SMO - atributos } \\
\text { gerados por } \\
\text { Aleph }\end{array}$ \\
\hline activate & 5 & 0.825 & 0.851 & 0.526 & 0.833 \\
\hline$a d d$ & 6 & 0.466 & 0.824 & 0.733 & 0.824 \\
\hline appear & 4 & 0.439 & 0.682 & 0.878 & 0.712 \\
\hline ask & 7 & 0.294 & 0.532 & 0.405 & 0.500 \\
\hline begin & 5 & 0.597 & 0.571 & 0.558 & 0.740 \\
\hline climb & 6 & 0.552 & 0.716 & 0.597 & 0.835 \\
\hline decide & 4 & 0.677 & 0.774 & 0.774 & 0.774 \\
\hline eat & 6 & 0.884 & 0.884 & 0.837 & 0.872 \\
\hline encounter & 5 & 0.508 & 0.739 & 0.677 & 0.723 \\
\hline expect & 4 & 0.744 & 0.756 & 0.795 & 0.923 \\
\hline express & 5 & 0.691 & 0.673 & 0.709 & 0.727 \\
\hline hear & 6 & 0.406 & 0.531 & 0.656 & 0.656 \\
\hline lose & 9 & 0.528 & 0.583 & 0.556 & 0.583 \\
\hline mean & 8 & 0.525 & 0.775 & 0.550 & 0.700 \\
\hline miss & 6 & 0.333 & 0.367 & 0.566 & 0.333 \\
\hline note & 3 & 0.388 & 0.582 & 0.821 & 0.880 \\
\hline operate & 3 & 0.167 & 0.722 & 0.833 & 0.778 \\
\hline play & 10 & 0.462 & 0.539 & 0.462 & 0.538 \\
\hline produce & 6 & 0.521 & 0.638 & 0.755 & 0.670 \\
\hline provide & 5 & 0.826 & 0.899 & 0.884 & 0.898 \\
\hline receive & 6 & 0.889 & 0.889 & 0.925 & 0.889 \\
\hline remain & 4 & 0.786 & 0.843 & 0.800 & 0.871 \\
\hline rule & 3 & 0.400 & 0.667 & 0.866 & 0.833 \\
\hline smell & 7 & 0.389 & 0.796 & 0.685 & 0.778 \\
\hline suspend & 8 & 0.359 & 0.609 & 0.609 & 0.578 \\
\hline talk & 10 & 0.726 & 0.740 & 0.739 & 0.739 \\
\hline treat & 9 & 0.281 & 0.404 & 0.578 & 0.474 \\
\hline use & 5 & 0.714 & 0.857 & 0.928 & 0.928 \\
\hline wash & 10 & 0.676 & 0.706 & 0.618 & 0.735 \\
\hline watch & 6 & 0.745 & 0.745 & 0.764 & 0.745 \\
\hline win & 6 & 0.421 & 0.526 & 0.474 & 0.605 \\
\hline write & 7 & 0.261 & 0.522 & 0.565 & 0.348 \\
\hline Média & 6.06 & 0.550 & 0.686 & 0.692 & 0.720 \\
\hline
\end{tabular}

Como ilustrado na Tabela 6.7, tanto SMO com atributos superficiais, quanto Aleph e SMO com atributos gerados pelo Aleph superam significativamente a baseline no sentido mais freqüente (Paired T-Test, p < 0.01). Os resultados de SMO com a adição de atributos induzidos pelo sistema Aleph são significativamente melhores que a acurácia do SMO com atributos superficiais (Paired T-Test, $\mathrm{p}<0.05$ ), e são comparáveis aos dos modelos gerados pelo sistema Aleph. Surpreendentemente, não parece haver diferença estatística significativa entre os modelos gerados pelo sistema Aleph e os modelos gerados por SMO com atributos superficiais apenas. Acredita-se que isso possa ser decorrente do processo de seleção de atributos utilizado para o SMO com atributos superficiais. Adicionalmente, apenas declarações extensionais são permitidas no sistema Aleph. Na próxima seção são apresentados resultados de experimentos voltados para a melhoria da performance dos 
modelos de PLI no mesmo conjunto de dados, utilizando-se, por exemplo, fontes de conhecimento adicionais e declarações intensionais. Vale notar também que algumas das fontes de conhecimento propostas não foram utilizadas para essa tarefa de desambiguação monolíngue, o que pode ter resultado na degradação do desempenho do algoritmo de PLI, que depende fortemente de fontes de conhecimento expressivas.

Na Tabela 6.8, a acurácia média dos modelos produzidos pelo sistema Aleph e pelo SMO com o uso de atributos de PLI é comparada à acurácia de sistemas participantes da competição Senseval-3 que reportaram resultados especificamente para o conjunto de 32 verbos. Tais sistemas foram descritos na Seção 6.3.1. SMO com o uso de atributos gerados por PLI obtém acurácia média comparável à do melhor sistema, MC-WSD. A diferença entre as acurácias do MC-WSD e dos modelos SMO com atributos gerados pelo Aleph não é estatisticamente significante, enquanto a diferença para os demais sistemas é significativa.

Tabela 6.8: Acurácias médias dos Experimentos 5 e 6 e de outros participantes do Senseval-3

\begin{tabular}{|l|r|}
\hline \multicolumn{1}{|c|}{ Sistema } & Acurácia média \\
\hline MC-WSD & 0.725 \\
\hline SMO + atributos PLI & 0.720 \\
\hline Aleph & 0.692 \\
\hline Syntalex-3 & 0.676 \\
\hline Syntalex-1 & 0.670 \\
\hline CLaC1 & 0.670 \\
\hline Syntalex-2 & 0.665 \\
\hline CLaC2 & 0.660 \\
\hline Syntalex-4 & 0.653 \\
\hline Baseline & 0.550 \\
\hline
\end{tabular}

\subsubsection{Experimento 7 - Modelos otimizados de PLI para a desambiguação de 32 verbos do Senseval-3 (Specia et al., 2007b)}

O Experimento 7 é voltado para a otimização dos resultados obtidos no Experimento 5, ou seja, dos modelos de PLI para a desambiguação monolíngue dos 32 verbos Senseval-3. As fontes de conhecimento utilizadas aqui são: $\mathrm{B}_{1}$ (bag-of-words), $\mathrm{B}_{2}$ (bigramas), $\mathrm{B}_{3}$ (etiquetas gramaticais), $\mathrm{B}_{4}$ (narrow context), $\mathrm{B}_{5}$ (colocações), $\mathrm{B}_{6}$ (relações sintáticas de sujeito e objeto), $\mathrm{B}_{7}$ (pares de palavras relacionadas sintaticamente), $\mathrm{B}_{8}$ (sobreposição de definições) e $\mathrm{B}_{9}$ (restrições de seleção). A otimização de parâmetros resultou nas mesmas escolhas utilizadas no Experimento 5 (Seção 6.3.1), enquanto que as definições de modo e determinações são as mesmas definidas para o Experimento 4 (Seção 6.2.4), excetuando-se aquelas referentes às fontes de conhecimento multilíngues, e permitindo definições intensionais. A acurácia média obtida para os modelos resultantes, 0.72 , conforme é ilustrado na Tabela 6.9, é a mesma que 
obtida pelo algoritmo SMO com o auxílio de atributos gerados por PLI (cf. Tabela 6.7), e é comparável à acurácia do melhor sistema participante da competição Senseval-3 para o mesmo conjunto de verbos, i.e., MC-WSD (0.725). Para a grande maioria dos verbos (com exceção de sete: encounter, expect, note, operate, provide, treat e write), a acurácia da nova configuração superou significativamente a obtida no Experimento 5.

Tabela 6.9: Acurácia obtida no Experimento 7

\begin{tabular}{|l|r|r|}
\hline \multicolumn{1}{|c|}{ Verbo } & Baseline & Aleph \\
\hline activate & 0.825 & 0.851 \\
\hline add & 0.466 & 0.796 \\
\hline appear & 0.439 & 0.880 \\
\hline ask & 0.294 & 0.428 \\
\hline begin & 0.597 & 0.620 \\
\hline climb & 0.552 & 0.716 \\
\hline decide & 0.677 & 0.790 \\
\hline eat & 0.884 & 0.897 \\
\hline encounter & 0.508 & 0.539 \\
\hline expect & 0.744 & 0.731 \\
\hline express & 0.691 & 0.782 \\
\hline hear & 0.406 & 0.688 \\
\hline lose & 0.528 & 0.556 \\
\hline mean & 0.525 & 0.700 \\
\hline miss & 0.333 & 0.733 \\
\hline note & 0.388 & 0.716 \\
\hline operate & 0.167 & 0.556 \\
\hline play & 0.462 & 0.539 \\
\hline produce & 0.521 & 0.766 \\
\hline provide & 0.826 & 0.870 \\
\hline receive & 0.889 & 0.926 \\
\hline remain & 0.786 & 0.943 \\
\hline rule & 0.400 & 0.900 \\
\hline smell & 0.389 & 0.764 \\
\hline suspend & 0.359 & 0.594 \\
\hline talk & 0.726 & 0.740 \\
\hline treat & 0.281 & 0.386 \\
\hline use & 0.714 & 0.929 \\
\hline wash & 0.676 & 0.677 \\
\hline watch & 0.745 & 0.843 \\
\hline win & 0.421 & 0.590 \\
\hline write & 0.261 & 0.435 \\
\hline Média & $\mathbf{0 . 5 5 0}$ & $\mathbf{0 . 7 2 0}$ \\
\hline
\end{tabular}

Como nos demais experimentos, o número de regras produzidas é relativamente pequeno: de 6 a 88. Alguns exemplos de regras produzidas na tarefa monolíngue para o verbo expect são ilustrados na Figura 6.4. 


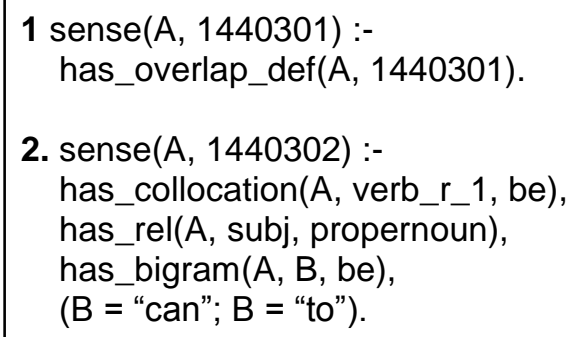

Figura 6.4: Exemplos de regras produzidas no Experimento 7 para o verbo expect

Os sentidos utilizados na regra, conforme o repositório fornecido pelos organizadores da tarefa, são:

- 1440301: "expect, communicate, convey", "to hope for or look forward to with some reason to believe in fulfillment: 'I expect him at noon'; 'I expect success'”.

- 1440302: "expect, guess, presume, reckon”, “(informal) to guess or suppose: 'I expect you would like a drink of water after such hard"”.

Na Figura 6.4, a Regra 1, define que o sentido de expect será "to hope for or look forward to with some reason to believe in fulfillment" caso a maior sobreposição de palavras na sentença em questão ocorra com a definição desse sentido. Já a Regra 2 estabelece que o sentido do verbo expect será "to guess or suppose" caso o primeiro verbo à sua direita seja be, o seu sujeito seja um nome próprio e uma palavra $B$ ocorra freqüentemente à esquerda de be (como um bigrama), a qual pode ser instanciada com can ou to. Essa última regra cobriria casos como "John expects to you be at home at 6:00".

Esses novos resultados são bastante encorajadores, pois mostram que, mesmo para tarefas monolíngues, tanto a principal abordagem proposta nesta tese quanto a abordagem alternativa se equiparam, em termos de acurácia, à abordagem que obteve o melhor desempenho na edição mais atual da competição Senseval até então. Uma nova edição foi realizada recentemente e, conforme será descrito nas próximas duas seções, resultados de ambas as abordagens foram submetidos à competição como dois sistemas distintos.

\subsubsection{Experimento 8 - Modelos de PLI para a desambiguação de 100 palavras do SemEval-1 (Specia et al., 2007c)}

Muito embora a abordagem de DLS proposta focalize na desambiguação de verbos, experimentos considerando a desambiguação de substantivos também foram realizados, com 
o objetivo de avaliar a performance da abordagem na edição mais recente da competição Senseval, agora chamada SemEval. Na presente edição do SemEval, SemEval-2007 ${ }^{35}$, a tarefa Lexical Sample consiste de 100 palavras, 65 verbos e 35 substantivos. Exemplos contendo essas palavras foram extraídos dos córpus WSJ Penn Treebank II e Brown. O número de exemplos de treinamento / teste varia de $19 / 2$ a 2,536 / 541 (média = 222.8 / 48.5). Os sentidos dos exemplos foram anotados de acordo com etiquetas OntoNotes (Hovy et al., 2006), com distinções menos refinadas que aquelas utilizadas na WordNet. Assim, a tarefa é definida como de coarse-grained disambiguation, muito embora o número de possíveis sentidos de algumas das palavras seja tão grande como na tarefa com distinções refinadas nas edições anteriores da competição. O número de sentidos varia de 1 a 13 (média = 3.68) para diferentes palavras nos exemplos de treinamento e teste. Conforme ilustrado na Tabela 6.10, 12 palavras ocorrem com apenas um sentido nos exemplos de treinamento. Os organizadores da tarefa argumentam que as palavras não ambíguas não foram descartadas por fazerem parte do córpus que já havia sido utilizado para outras tarefas que não a DLS.

As fontes de conhecimento utilizadas neste experimento são todas as disponíveis para a desambiguação monolíngue, no entanto, como determinadas fontes são válidas apenas para a desambiguação de verbos, estas não foram utilizadas para substantivos. Mais especificamente, as seguintes fontes foram utilizadas para a desambiguação de verbos: $\mathrm{B}_{1}$ (bag-of-words), $\mathrm{B}_{2}$ (bigramas), $\mathrm{B}_{3}$ (etiquetas gramaticais), $\mathrm{B}_{4}$ (narrow context), $\mathrm{B}_{5}$ (colocações), $\mathrm{B}_{6}$ (relações sintáticas de sujeito e objeto), $\mathrm{B}_{7}$ (pares de palavras relacionadas sintaticamente), $\mathrm{B}_{8}$ (sobreposição de definições), $\mathrm{B}_{9}$ (restrições de seleção) e $\mathrm{B}_{10}$ (expressões verbais). Para a desambiguação de substantivos foram utilizadas as fontes $\mathrm{B}_{1}, \mathrm{~B}_{2}, \mathrm{~B}_{3}, \mathrm{~B}_{4}, \mathrm{~B}_{5}$, $\mathrm{B}_{6}, \mathrm{~B}_{7}$ e $\mathrm{B}_{8} . \mathrm{B}_{1}-\mathrm{B}_{7}$ foram extraídas da mesma maneira que nos experimentos anteriores. A informação sobre a sobreposição de definições $\left(\mathrm{B}_{8}\right)$ foi extraída considerando-se o repositório de sentidos fornecido pelos organizadores da tarefa como contexto das definições dos sentidos. Tal repositório assemelha-se a um dicionário: para cada sentido de uma dada palavra, são fornecidas uma definição curta e exemplos de uso. As palavras na definição e exemplos de cada sentido foram comparadas às palavras na sentença ambígua para calcular a taxa de sobreposição. Esse repositório de sentidos também fornece um mapeamento de cada sentido para os sentidos correspondentes da WordNet. Na maior parte dos casos, um sentido OntoNotes é mapeado para um grupo de sentidos da WordNet, apesar de existirem também alguns mapeamentos um-para-um. Esse mapeamento, juntamente com o mapeamento de

\footnotetext{
${ }^{35}$ (http://nlp.cs.swarthmore.edu/semeval/)
} 
sentidos da WordNet para os sentidos do LDOCE (cf. descrito na Seção 6.3.1), foi utilizado para a definição das restrições de seleção dos verbos $\left(\mathrm{B}_{9}\right)$, as quais são originalmente especificadas utilizando-se os sentidos do LDOCE. Por fim, a informação sobre expressões verbais $\left(\mathrm{B}_{10}\right)$ foi extraída com base no mesmo recurso, ou seja, o repositório de sentidos fornecido pelos organizadores da tarefa. Em tal repositório, caso um dado sentido represente o uso do verbo como uma expressão verbal, tal expressão é fornecida na definição do sentido. Por exemplo, a definição na Figura 6.5 é dada para o primeiro sentido do verbo turn:

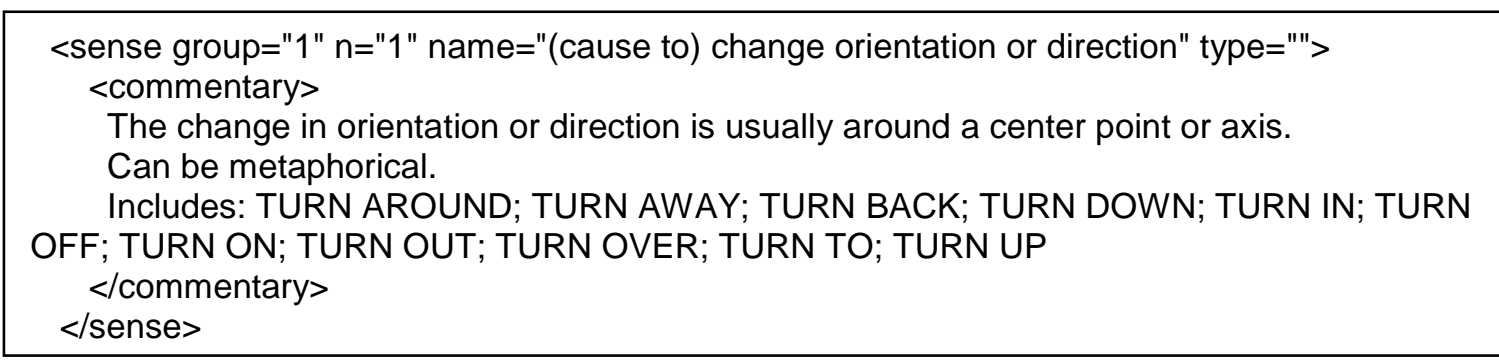

Figura 6.5: Exemplo de definição de sentido no SemEval-2007 contendo expressões verbais

Em alguns casos, um sentido é criado especialmente para um grupo de expressões verbais (em geral, com sentidos WordNet distintos). Por exemplo, conforme é ilustrado na Figura 6.6, o sentido "9" é criado para representar um conjunto de expressões verbais para o verbo work. Assim, a lista de expressões verbais e seus sentidos, para cada verbo, foi extraída desse repositório.

A configuração dos parâmetros utilizados é a mesma do Experimento 5 (Seção 6.3.1), enquanto que as definições de modo e determinações são as definidas no Experimento 4 (Seção 6.2.4), excetuando-se as referentes às fontes de conhecimento multilíngues. A acurácia média obtida foi de 0.851. Esse resultado supera significativamente (Paired T-Test com $\mathrm{p}<$ 0.01) a baseline do sentido mais freqüente (0.787) e é comparável à acurácia obtida pelos modelos SMO com o auxílio de atributos gerados por Aleph (0.857), descritos na próxima seção. No quadro geral da competição, que contou com 15 sistemas participantes, o sistema descrito nesta seção, intitulado USP-IBM-1, ocupa a quinta posição (cf. Tabela 6.12, na próxima seção). Os números de regras induzidas para diferentes palavras, excluindo-se aquelas com apenas um sentido, varia de 5, para palavras com poucos sentidos e exemplos, como approve, a 140, para palavras com muitos exemplos e mais sentidos, como say, que possui 2.161 exemplos de treinamento. Os modelos de PLI produzidos para os verbos são similares aos ilustrados na outra tarefa monolíngue anteriormente analisada, com os dados do 
Senseval-3 (cf. Figuras 6.3 e 6.4). Na Figura 6.7 são ilustrados alguns exemplos de regras induzidas para o substantivo authority.

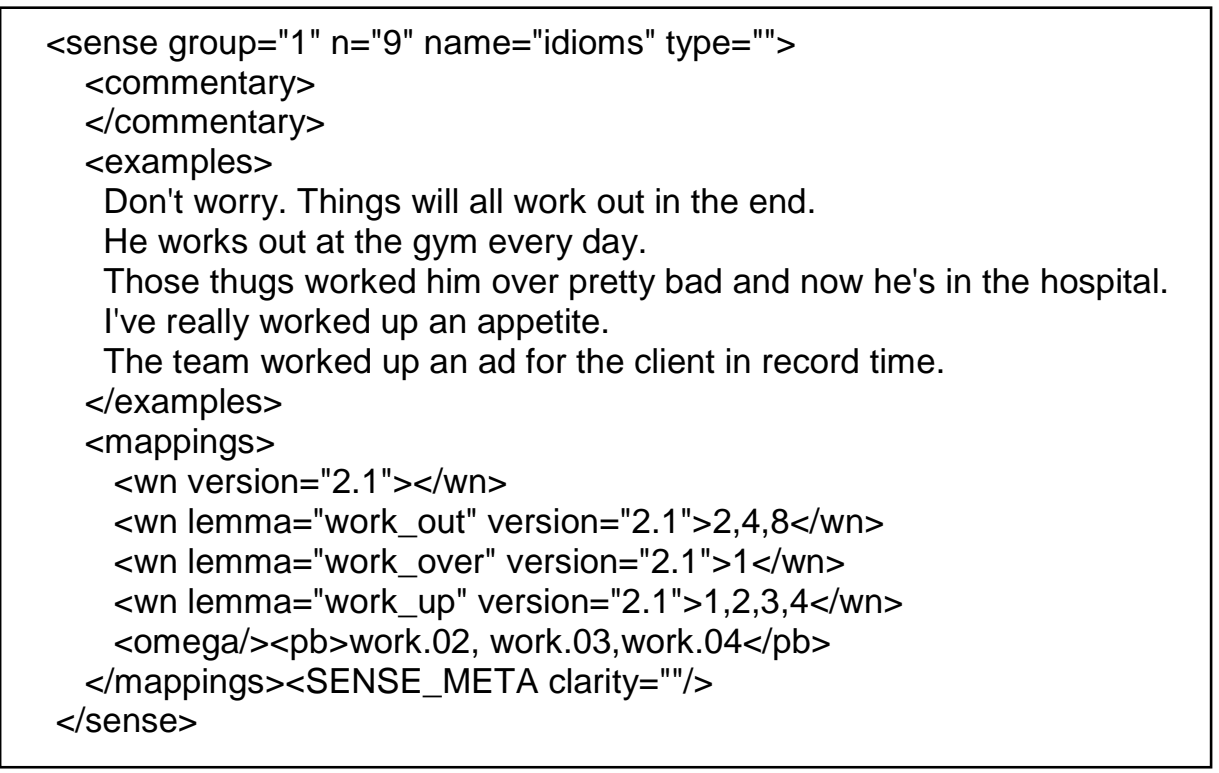

Figura 6.6: Exemplo de definição de sentido no SemEval-2007 específica para expressões verbais

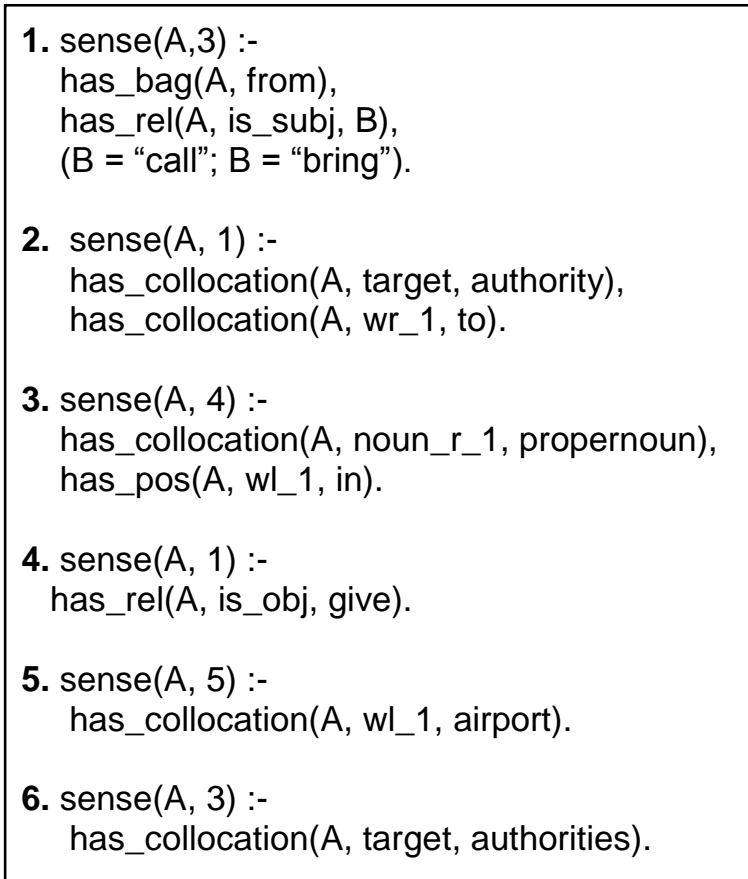

Figura 6.7: Exemplos de regras produzidas no Experimento 8 para o substantivo authority

Os sentidos utilizados na regra, conforme o repositório fornecido pelos organizadores da tarefa, são:

- 1: "power to give orders, official state of power".

- 3: "officials who have specific powers". 
- 4: "knowledgeable source, expert" group".

- 5: "a government agency with specific power".

Na Figura 6.7, a Regra 1, por exemplo, define que o sentido da palavra authority será "officials who have specific powers" caso a sentença contenha a palavra from na vizinhança da palavra, e tal palavra seja o sujeito de um verbo $B$, que pode ser instanciado com call ou bring. A Regra 2 estabelece que o sentido do verbo authority será "power to give orders, official state of power" caso a forma morfológica da palavra seja authority e a primeira palavra à sua direita seja to.

\subsubsection{Experimento 9 - Modelos SVM com atributos PLI para a desambiguação de 100 palavras do SemEval-1 (Specia et al., 2007c)}

O Experimento 9 refere-se aos mesmos dados do Experimento 8, mas aqui se utiliza o algoritmo SMO com atributos induzidos por PLI. Novamente, SMO utiliza fontes de conhecimento superficiais - $\mathrm{B}_{1}$ (bag-of-words), $\mathrm{B}_{3}$ (etiquetas gramaticais), $\mathrm{B}_{4}$ (narrow context), $\mathrm{B}_{5}$ (colocações), $\mathrm{B}_{6}$ (relações sintáticas de sujeito e objeto), $\mathrm{B}_{8}$ (sobreposição de definições) - juntamente com no máximo 500 atributos gerados pelo sistema Aleph, com base nas mesmas configurações utilizadas no Experimento 8, adicionalmente ao parâmetro minscore instanciado com o valor "1". Para a seleção dos melhores atributos no SMO, a técnica de validação cruzada $n$-fold ( $\operatorname{com} n=3$ ) foi utilizada nos dados de treinamento para determinar o melhor número de atributos a serem selecionados com a técnica InfoGain. Foram testadas várias porcentagens $(1 / 64, \ldots, 1 / 2)$, o que resultou em números distintos sendo selecionados para diferentes palavras ambíguas. A acurácia média obtida por esse sistema, submetido como USP-IBM-2, foi de 0.857, que significativamente supera (Paired T-Test com $\mathrm{p}<0.01)$ a baseline do sentido mais freqüente (0.787) e é comparável à acurácia obtida pelos modelos de PLI (0.851, conforme descrito na Seção 6.3.4). Esse sistema ocupou a quarta colocação na competição, conforme ilustrado na Tabela 6.12. Descartando-se empates, o sistema IBM-USP-2 supera o IBM-USP-1 para 31 das palavras, mas a diferença, em média, não é significante. As acurácias de ambos os Experimentos 8 e 9 para cada palavra, agrupadas de acordo com suas categorias gramaticais, são ilustradas nas Tabelas 6.10 e 6.11 .

Tabela 6.10: Acurácias obtidas para os 65 verbos dos Experimentos 8 e 9

\begin{tabular}{|l|r|r|r|r|}
\hline \multicolumn{1}{|c|}{ Verbo } & \# sentidos & \multicolumn{1}{|c|}{ Baseline } & \multicolumn{1}{c|}{ Aleph } & $\begin{array}{c}\text { SMO - atributos } \\
\text { gerados por Aleph }\end{array}$ \\
\hline affect & 1 & 1.000 & 1.000 & 1.000 \\
\hline allow & 2 & 0.971 & 0.971 & 0.971 \\
\hline
\end{tabular}




\begin{tabular}{|c|c|c|c|c|}
\hline announce & 2 & 1.000 & 1.000 & 1.000 \\
\hline approve & 2 & 0.917 & 0.917 & 0.917 \\
\hline ask & 6 & 0.517 & 0.793 & 0.776 \\
\hline attempt & 1 & 1.000 & 1.000 & 1.000 \\
\hline avoid & 1 & 1.000 & 1.000 & 1.000 \\
\hline begin & 4 & 0.563 & 0.708 & 0.688 \\
\hline believe & 2 & 0.782 & 0.836 & 0.855 \\
\hline build & 3 & 0.739 & 0.761 & 0.609 \\
\hline buy & 5 & 0.761 & 0.804 & 0.826 \\
\hline care & 3 & 0.286 & 0.429 & 0.429 \\
\hline cause & 1 & 1.000 & 1.000 & 1.000 \\
\hline claim & 3 & 0.800 & 0.800 & 0.800 \\
\hline come & 10 & 0.233 & 0.488 & 0.605 \\
\hline complain & 2 & 0.857 & 0.857 & 0.857 \\
\hline complete & 2 & 0.938 & 0.938 & 0.938 \\
\hline contribute & 2 & 0.500 & 0.722 & 0.667 \\
\hline describe & 3 & 1.000 & 1.000 & 1.000 \\
\hline disclose & 1 & 0.929 & 0.929 & 0.929 \\
\hline do & 4 & 0.902 & 0.902 & 0.934 \\
\hline end & 4 & 0.524 & 0.810 & 0.905 \\
\hline enjoy & 2 & 0.571 & 0.786 & 0.500 \\
\hline estimate & 1 & 1.000 & 1.000 & 1.000 \\
\hline examine & 3 & 1.000 & 1.000 & 1.000 \\
\hline exist & 2 & 1.000 & 1.000 & 1.000 \\
\hline explain & 2 & 0.889 & 0.889 & 0.889 \\
\hline express & 1 & 1.000 & 1.000 & 1.000 \\
\hline feel & 3 & 0.686 & 0.824 & 0.745 \\
\hline find & 5 & 0.821 & 0.857 & 0.893 \\
\hline fix & 5 & 0.500 & 0.500 & 0.500 \\
\hline go & 12 & 0.459 & 0.705 & 0.656 \\
\hline grant & 2 & 0.800 & 0.800 & 0.800 \\
\hline hold & 9 & 0.375 & 0.458 & 0.542 \\
\hline hope & 1 & 1.000 & 1.000 & 1.000 \\
\hline improve & 1 & 1.000 & 1.000 & 1.000 \\
\hline join & 4 & 0.389 & 0.611 & 0.389 \\
\hline keep & 8 & 0.563 & 0.575 & 0.638 \\
\hline kill & 4 & 0.875 & 0.875 & 0.875 \\
\hline lead & 6 & 0.385 & 0.333 & 0.692 \\
\hline maintain & 2 & 0.900 & 0.900 & 1.000 \\
\hline need & 2 & 0.714 & 0.821 & 0.893 \\
\hline negotiate & 1 & 1.000 & 1.000 & 1.000 \\
\hline occur & 3 & 0.864 & 0.909 & 0.955 \\
\hline prepare & 2 & 0.778 & 0.833 & 0.889 \\
\hline produce & 3 & 0.750 & 0.727 & 0.727 \\
\hline promise & 2 & 0.750 & 0.875 & 0.875 \\
\hline propose & 2 & 0.857 & 0.857 & 0.857 \\
\hline prove & 3 & 0.318 & 0.500 & 0.591 \\
\hline purchase & 1 & 1.000 & 1.000 & 1.000 \\
\hline raise & 8 & 0.147 & 0.441 & 0.265 \\
\hline recall & 3 & 0.867 & 0.867 & 0.867 \\
\hline receive & 2 & 0.958 & 0.958 & 0.958 \\
\hline regard & 3 & 0.714 & 0.929 & 0.857 \\
\hline remember & 2 & 1.000 & 1.000 & 1.000 \\
\hline remove & 1 & 1.000 & 1.000 & 1.000 \\
\hline replace & 2 & 1.000 & 1.000 & 1.000 \\
\hline report & 3 & 0.914 & 0.914 & 0.914 \\
\hline rush & 2 & 1.000 & 1.000 & 1.000 \\
\hline say & 5 & 0.987 & 0.985 & 0.985 \\
\hline
\end{tabular}




\begin{tabular}{|l|r|r|r|r|}
\hline see & 6 & 0.444 & 0.389 & 0.537 \\
\hline set & 9 & 0.286 & 0.500 & 0.571 \\
\hline start & 6 & 0.447 & 0.500 & 0.553 \\
\hline turn & 13 & 0.387 & 0.516 & 0.548 \\
\hline work & 8 & 0.558 & 0.674 & 0.651 \\
\hline Média & $\mathbf{3 . 5 3 8}$ & $\mathbf{0 . 7 6 2}$ & $\mathbf{0 . 8 1 7}$ & $\mathbf{0 . 8 2 8}$ \\
\hline
\end{tabular}

Tabela 6.11: Acurácias obtidas para os 35 substantivos dos Experimentos 8 e 9

\begin{tabular}{|c|c|c|c|c|}
\hline Substantivo & \# sentidos & Baseline & Aleph & $\begin{array}{l}\text { SMO - atributos } \\
\text { gerados por Aleph }\end{array}$ \\
\hline area & 3 & 0.703 & 0.730 & 0.676 \\
\hline authority & 4 & 0.238 & 0.714 & 0.619 \\
\hline base & 5 & 0.100 & 0.850 & 0.500 \\
\hline bill & 3 & 0.755 & 0.961 & 0.961 \\
\hline capital & 4 & 0.965 & 0.965 & 0.947 \\
\hline carrier & 8 & 0.714 & 0.714 & 0.714 \\
\hline chance & 4 & 0.400 & 0.667 & 0.600 \\
\hline condition & 2 & 0.765 & 0.824 & 0.559 \\
\hline defense & 7 & 0.286 & 0.381 & 0.429 \\
\hline development & 3 & 0.621 & 0.690 & 0.793 \\
\hline drug & 2 & 0.870 & 0.826 & 0.783 \\
\hline effect & 3 & 0.767 & 0.900 & 0.933 \\
\hline exchange & 5 & 0.738 & 0.885 & 0.852 \\
\hline future & 3 & 0.863 & 0.925 & 0.973 \\
\hline hour & 4 & 0.896 & 0.813 & 0.833 \\
\hline job & 3 & 0.821 & 0.846 & 0.897 \\
\hline management & 2 & 0.711 & 0.822 & 0.733 \\
\hline move & 4 & 0.979 & 0.979 & 0.979 \\
\hline network & 3 & 0.909 & 0.855 & 0.891 \\
\hline order & 7 & 0.912 & 0.912 & 0.912 \\
\hline part & 4 & 0.662 & 0.930 & 0.972 \\
\hline people & 4 & 0.904 & 0.930 & 0.957 \\
\hline plant & 2 & 0.984 & 0.984 & 0.984 \\
\hline point & 9 & 0.813 & 0.920 & 0.913 \\
\hline policy & 2 & 0.974 & 0.974 & 0.872 \\
\hline position & 7 & 0.467 & 0.556 & 0.533 \\
\hline power & 3 & 0.277 & 0.574 & 0.809 \\
\hline president & 3 & 0.729 & 0.921 & 0.972 \\
\hline rate & 2 & 0.862 & 0.876 & 0.814 \\
\hline share & 2 & 0.971 & 0.971 & 0.970 \\
\hline source & 5 & 0.371 & 0.629 & 0.629 \\
\hline space & 5 & 0.786 & 0.929 & 0.929 \\
\hline state & 3 & 0.792 & 0.792 & 0.833 \\
\hline system & 5 & 0.486 & 0.600 & 0.671 \\
\hline value & 3 & 0.983 & 0.966 & 0.915 \\
\hline Média & 3.94 & 0.809 & 0.882 & 0.882 \\
\hline
\end{tabular}

Comparando-se as acurácias médias para verbos e substantivos, pode-se perceber que os modelos de DLS alcançam acurácia superior para substantivos, os quais são geralmente mais facilmente distinguíveis dados os seus contextos. De fato, acredita-se que resultados ainda superiores poderiam ter sido alcançados aqui, para substantivos, caso fontes de conhecimento 
especialmente voltadas para a desambiguação dessa categoria gramatical tivessem sido definidas.

A acurácia baixa dos modelos de PLI e SMO utilizando atributos gerados por PLI para certas palavras pode ser consequiência de características dos dados. Em particular, a distribuição de sentidos é bastante acentuada em muitos casos, com diferentes tendências nos conjuntos de treinamento e teste. Por exemplo, no caso de to care, o sentido majoritário nos exemplos de treinamento é "1" (78.3\%), enquanto que nos exemplos de teste o sentido majoritário é " 2 " (71\%). Em casos como esse, muitos dos exemplos de teste não são classificados pelas regras produzidas pelo Aleph, já que o número de exemplos de treinamento para os sentidos em questão é insuficiente, e o uso da regra default para classificar tais exemplos de acordo com o sentido majoritário dos exemplos de treinamento resulta em erro, uma vez que tal sentido não se aplica à maioria dos exemplos de teste. Isso se estende aos modelos gerados pelo SMO: atributos que seriam relevantes aos exemplos de teste não são construídos ou não são escolhidos no processo de seleção de atributos nos dados de treinamento. Uma vez que tanto Aleph quanto SMO só permitem a classificação de exemplos com uma dada classe quando se dispõe de exemplos de treinamento para tal classe, um problema adicional é que algumas palavras possuem, nos exemplos de teste, sentidos que não aparecem nos exemplos de treinamento. Esse é o caso, por exemplo, dos verbos occur (dois sentidos nos exemplos de treinamento, três nos exemplos de teste). A grande variedade de sentidos associada a poucos exemplos de treinamento também é um dos motivos para a baixa acurácia dos sistemas em alguns casos. Por exemplo, hold possui nove sentidos nos 129 exemplos de treinamento, sendo que oito desses sentidos ocorrem nos apenas 24 exemplos de teste. Similarmente, come possui 10 sentidos nos 183 exemplos de treinamento, sendo que nove desses sentidos aparecem nos 43 exemplos de teste.

Tabela 6.12: Acurácias dos sistemas participantes da tarefa Lexical Sample no SemEval-2007

\begin{tabular}{|l|l|r|}
\hline \multicolumn{1}{|c|}{ Sistema } & Classificador utilizado & Acurácia \\
\hline NUL-ML & SVM & 88.7 \\
\hline UBC-ALM & SVD+k-NN & 86.9 \\
\hline I2R & Baseado em grafos & 86.4 \\
\hline USP-IBM-2 & SVM + ILP & $\mathbf{8 5 . 7}$ \\
\hline USP-IBM-1 & ILP & $\mathbf{8 5 . 1}$ \\
\hline KU & Probabilístico & 85.1 \\
\hline OE & Naive Bayes + SVM & 83.8 \\
\hline VUTBR & Naive Bayes & 80.3 \\
\hline UBC-ZAS & SVD + k-NN & 79.9 \\
\hline ITC-irst & SVM & 79.6 \\
\hline Baseline & - & 78.0 \\
\hline USYD & SVM & 74.3 \\
\hline UMND1 & Não-supervisionado & 53.8 \\
\hline
\end{tabular}




\begin{tabular}{|l|l|r|}
\hline Tor & Não-supervisionado & 52.1 \\
\hline USYD $^{*}$ & SVM & - \\
\hline ITC $^{*}$ & SVM & - \\
\hline
\end{tabular}

A Tabela 6.12 mostra também os classificadores utilizados por cada um dos outros sistemas competidores. Detalhes sobre tais classificadores, bem como sobre os atributos utilizados em todos os trabalhos podem ser encontrados nos anais do SemEval-2007 (Agirre et al., 2007).

\subsection{AVALIAÇÃO EXTRÍNSECA}

Por serem simbólicos, os modelos de DLS produzidos pela abordagem proposta poderiam ser diretamente integrados a sistemas de TA baseados em regras: o conjunto de regras de DLS para um dado item lexical seria disparado quando da existência de múltiplas traduções possíveis para tal item no sistema de TA. Contudo, como não se dispunha de um sistema completo de TA inglês-português para realizar a integração do módulo de DLS, optou-se por um sistema estatístico de TA e uma metodologia que não requer a alteração de tal sistema, já que atua sob seus resultados intermediários. Essa escolha permite também comparar a metodologia de avaliação proposta com outros trabalhos que vêm sendo propostos recentemente para a integração de sistemas de DLS e TA estatística.

Conforme foi discutido no Capítulo 2, apenas recentemente experimentos sobre a utilidade de módulos de DLS em sistemas de TA começaram a ser realizados, em particular, no contexto de sistemas estatísticos. Os resultados dos experimentos de integração propostos até o momento (Carpuat and Wu, 2005; Vickrey et al., 2005; Carpuat and Wu, 2006; Carpuat and $\mathrm{Wu}, 2007$; Chan et al., 2007) variam de negativos ou neutros a significativamente positivos. Muito embora diferenças consideráveis possam ser encontradas nos sistemas de TA e DLS testados, bem como no modo como foram integrados, acredita-se que tais experimentos desenvolvem soluções limitadas ou redefinem a tarefa de DLS, tornando-a uma tarefa distinta.

As limitações, encontradas especialmente nas primeiras abordagens propostas, incluem o conjunto restrito de fontes de conhecimento superficiais explorado pelo sistema de DLS, o modo como o repositório de sentidos é adquirido (sentidos monolíngues mapeados para traduções, ou traduções extraídas unicamente a partir do alinhamento automático de palavras), e o modo como a integração é realizada (substituição da escolha do sistema de TA por aquela do sistema de DLS). 
Nas abordagens mais recentes (Carpuat \& Wu, 2007; Chan et al., 2007), pode ser observada a redefinição da tarefa de desambiguação lexical: não se considera um repositório pré-definido de sentidos e a unidade básica de desambiguação é uma "subfrase", em vez de uma palavra. Essas abordagens parecem se mostrar apropriadas para a tradução de línguas fonte como o chinês, nas quais a definição de "palavra" difere daquela convencionalmente utilizada nas línguas indo-européias. De fato, ambos os trabalhos utilizando tal noção são voltados para a tradução do chinês para o inglês. Contudo, essa abordagem requer a simplificação da tarefa de DLS, especialmente no que diz respeito às fontes de conhecimento que podem ser exploradas. Uma vez que as unidades de desambiguação não são subfrases lingüisticamente motivadas, mas sim quaisquer subconjuntos de palavras contíguas, certas fontes não podem ser extraídas, por exemplo, relações sintáticas ou restrições de seleção entre a subfrase ambígua e as demais frases ou palavras na sentença. Adicionalmente, tal abordagem aumenta consideravelmente a complexidade do módulo de DLS, uma vez que todas as subfrases são consideradas semanticamente ambíguas, muito embora muitas não requeiram desambiguação semântica, por exemplo, aquelas envolvendo apenas itens lexicais funcionais. A esparsidade dos dados é também um problema em tais abordagens, haja vista que uma grande quantidade de exemplos se faz necessária para produzir modelos de desambiguação úteis para todas as possíveis combinações de palavras, principalmente no trabalho de Carpuat \& Wu, em que subfrases de até seis palavras são consideradas. Por fim, acredita-se que apenas as traduções propostas pelo módulo de alinhamento de palavras no sistema estatístico de TA não são suficientes. Traduções raras são pouco prováveis e, portanto, dificilmente serão encontradas. De fato, conforme ilustrado em Specia et al. (2005b), para a tradução de certas palavras, em especial, dos verbos analisados neste trabalho, ferramentas como o GIZA++ não apresentam desempenho satisfatório. Traduções extras, fornecidas pelo módulo de DLS, poderiam melhorar a cobertura para traduções pouco freqüentes, já que módulos de DLS necessitam de menos exemplos de treinamento.

Dadas essas limitações, acredita-se que o problema da integração de módulos de DLS em sistemas de TA estatísticos de modo que tais sistemas possam se beneficiar de modelos ricos e expressivos de DLS, sem serem sobrecarregados durante o seu treinamento, ainda precisa ser investigado. A seguir, são discutidos experimentos com dois métodos simples e eficientes de integração da abordagem de DLS proposta em um sistema estatístico de TA, bem como de uma abordagem alternativa de DLS (probabilística). Diferentemente das primeiras abordagens propostas para a integração, os métodos explorados aqui utilizam repositórios de sentidos multilíngues e um vasto conjunto de fontes de conhecimento sobre a 
língua fonte e também sobre a língua alvo. Adicionalmente, diferentemente das abordagens mais recentes de integração, a DSL é endereçada no seu sentido tradicional, ou seja, a desambiguação de palavras de conteúdo potencialmente ambíguas.

\subsubsection{Modelos de DLS}

Duas categorias de modelos de DLS foram utilizadas na integração com um sistema de TA: (a) os modelos simbólicos produzidos pelo sistema Aleph, de acordo com a arquitetura apresentada na Seção 5.3, que corresponde à principal abordagem proposta deste trabalho e gera como saída uma única classe (tradução) para cada exemplo de teste; e (b) modelos gerados por SVMs a partir da simplificação de algumas das fontes de conhecimento, conforme descrito na Seção 6.2.4, e do algoritmo LibSVM (Chang \& Lin, 2001), uma implementação de SVMs que gera, como saída para cada exemplo de teste, um ranking probabilístico de escores para todas as classes. Essa segunda categoria de modelos foi escolhida porque, dado que o sistema de DLS não é 100\% preciso, acredita-se que se deve levar em consideração não apenas a classe mais provável, mas um subconjunto contendo todas as classes com probabilidade superior a um determinado limite, levando em conta a "incerteza" do processo de classificação do sistema de DLS. Entre vários algoritmos probabilísticos testados, LibSVM foi o que obteve maior acurácia. O desempenho obtido pelo LibSVM para cada um dos 10 verbos é ilustrado na Tabela 6.13. A acurácia média, 69\%, apesar de inferior à obtida pelos modelos de PLI (74\%), é consideravelmente superior à baseline do sentido mais freqüente $(50 \%)$.

Tabela 6.13: Acurácia do algoritmo LibSVM com fontes de conhecimento simplificadas para os 10 verbos

\begin{tabular}{|l|r|r|}
\hline Verbo & Baseline & LibSVM \\
\hline ask & 0.68 & 0.83 \\
\hline come & 0.46 & 0.54 \\
\hline get & 0.03 & 0.40 \\
\hline give & 0.72 & 0.88 \\
\hline go & 0.49 & 0.71 \\
\hline live & 0.71 & 0.81 \\
\hline look & 0.48 & 0.80 \\
\hline make & 0.64 & 0.69 \\
\hline take & 0.14 & 0.53 \\
\hline tell & 0.65 & 0.67 \\
\hline Média & $\mathbf{0 . 5 0}$ & $\mathbf{0 . 6 9}$ \\
\hline
\end{tabular}

\subsubsection{Sistema de TA: Microsoft Treelet}

O sistema estatístico de TA proposto por Quirk et al. (2005) é utilizado para os experimentos. Esse sistema, denominado Microsoft Treelet, é baseado em frases sintaticamente motivadas. 
Durante o treinamento, sentenças paralelas são primeiramente alinhadas por palavras utilizando-se GIZA++. Um parser produz então estruturas sintáticas de dependência para a sentença de entrada, da qual são extraídas sub-árvores (treelets), que constituirão as unidades básicas de tradução. As dependências sintáticas de tais sub-árvores são projetadas na sentença paralela da língua alvo por meio de um conjunto de heurísticas de projeção. Um conjunto de nove funções estatísticas é então utilizado para compor os modelos de tradução e da língua alvo, incluindo a contagem de palavras, de frases, alinhamento de palavras, ordenação de subárvores, etc. Para traduzir uma nova sentença, após a análise e projeção sintática, as possíveis traduções $t$ da sentença recebem um escore de acordo com a combinação linear das funções estatísticas, ou seja, a soma do resultado de cada uma dessas funções:

$$
\operatorname{score}(t)=\sum_{j} \lambda_{j} f_{j}(t)
$$

onde $\lambda_{j}$ representa os pesos do modelo e $f_{j}(t)$ é o valor da função $j$ (modelo) para a tradução candidata $t$. Os pesos de cada função são determinados utilizando-se a técnica MERT (Minimum Error Rate Training) (Och, 2003), ou seja, a partir da maximização da medida BLEU para um subconjunto dos exemplos de treinamento (conjunto de desenvolvimento).

\subsubsection{Métodos de integração}

Os métodos de integração propostos utilizam a técnica $n$-best reranking de Och et al. (2004), na qual novas funções são combinadas ao modelo linear original do sistema de TA, chamado de baseline, para selecionar a tradução candidata com o maior escore em uma lista de $n$-best candidatas, a partir da otimização dos pesos das funções (nova e existentes) utilizando-se MERT em um conjunto de desenvolvimento. Na lista $n$-best do sistema Treelet, cada sentença candidata possui valores específicos para as nove funções já existentes, os quais são multiplicados pelo peso de cada uma dessas funções (que é o mesmo para todas as candidatas) e somados para determinar o escore da sentença. A idéia, portanto, é adicionar uma nova função correspondendo à saída dos modelos de DLS ao conjunto de funções do sistema e reestimar os pesos de todas as funções de acordo com a otimização da medida BLEU realizada pelo MERT para então reordenar tal lista, conforme ilustrado na Figura 6.8.

Conforme argumentado por Och e seus colegas, a técnica $n$-best reranking permite a experimentação rápida com funções de qualquer natureza na TA estatística, incluindo-se funções referentes a dependências de longa distância, que seriam complexas e custosas de incluir em sistemas de TA de outra maneira. A limitação da técnica $n$-best reranking é que sentenças com as variações necessárias precisam estar disponíveis na lista de n-best 
candidatas, já que essa é a única informação proveniente do sistema de TA utilizada para a reordenação. Neste caso, escolhas lexicais correspondendo às predições do sistema de DLS precisam estar contidas na lista $n$-best. Dependendo da característica a ser adicionada, mesmo listas com um grande número de traduções candidatas podem não conter as candidatas necessárias. Para superar tal limitação, uma adaptação desse método é proposta, na qual novas sentenças candidatas são "artificialmente" geradas quando não são encontradas na lista de candidatas as variações necessárias. Dois métodos são, portanto, avaliados: (a) n-best reranking padrão e (b) n-best reranking de uma lista expandida com candidatas artificiais. Uma abordagem similar para $n$-best reranking foi aplicada por Toutanova \& Suzuki (2007) para incorporar marcadores de caso na tradução do inglês para o japonês.

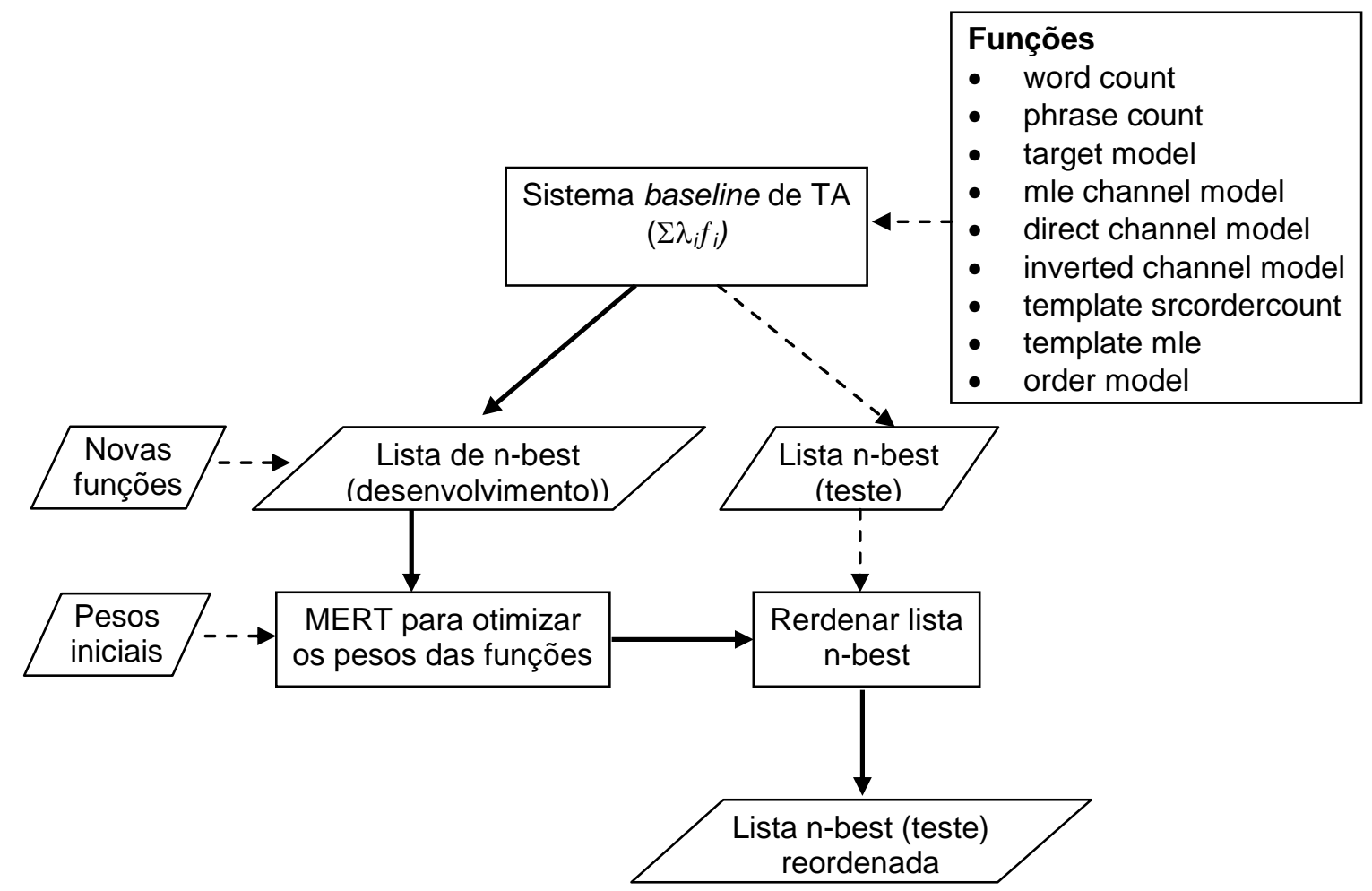

Figura 6.8: Técnica $n$-best reranking para a adição de funções a um sistema básico de TA

\subsubsection{Método 1: $n$-best reranking padrão}

Neste método, uma função correspondendo à classe (tradução) indicada pelo modelo de DLS encontrada na sentença candidata é adicionada às nove funções já existentes no sistema de TA. O valor dessa função é o logaritmo da probabilidade (em $[0,1])$ da tradução encontrada na sentença candidata, conforme indicado pelo modelo de DLS. No caso dos modelos simbólicos, tais probabilidades se limitam a "1", quando a tradução encontrada na sentença é a indicada pelo módulo de DLS, ou “0” (com um critério de suavização), caso contrário. 
Para definir tal valor, para cada sentença candidata para uma dada palavra ambígua, percorre-se a lista de possíveis traduções fornecidas pelo modelo de DLS com probabilidades superiores a um determinado limite para verificar se tal candidata contém uma das possíveis traduções em uma posição que é alinhada (ainda que parcialmente) àquela da palavra ambígua na sentença fonte. As variações morfológicas das possíveis traduções são consideradas por meio da expansão dessa lista de traduções com suas variações fornecidas por um léxico enumerativo do português (Nunes et al., 1996). Se nenhuma das possíveis traduções é encontrada na sentença, a probabilidade " 0 " (com um critério de suavização) é atribuída à função na sentença candidata. Os valores das outras funções do sistema básico de TA permanecem os mesmos.

Após a atribuição do valor para a nova função em cada sentença candidata na lista $n$ best do conjunto de exemplos de desenvolvimento, a técnica MERT é utilizada para estimar os pesos de todos os atributos. O mesmo procedimento de atribuição de valores para a nova função é realizado para a lista $n$-best do conjunto de exemplos de teste. Essa lista é então reordenada de acordo com os pesos estimados no conjunto de desenvolvimento. A sentença candidata no topo da lista reordenada é escolhida como a tradução para a sentença fonte.

\subsubsection{Método 2: $n$-best reranking de uma lista expandida}

Durante os experimentos com o primeiro método de avaliação, percebeu-se que, em muitos casos, determinadas traduções das palavras ambíguas indicadas pelos modelos de DLS, incluindo as mais prováveis, não estavam presentes na lista $n$-best (mesmo para $n=1.000$ ). Isso ocorre porque o sistema de TA pode não dispor de exemplos de treinamento em número suficiente para identificar tais traduções. Para incluir essas traduções na lista $n$-best, para cada sentença candidata distinta nessa lista, foram geradas até $m$ outras candidatas, onde $m$ corresponde ao número de traduções dadas pelo modelo de DLS para a sentença de teste em questão com uma probabilidade superior a um certo limite.

Para verificar se as candidatas originais contêm uma das $m$ possíveis traduções, o procedimento descrito para o Método 1 (Seção 6.4.3.1) foi utilizado. Caso a candidata contenha uma das possíveis traduções ou qualquer verbo numa posição alinhada à da palavra ambígua na sentença fonte, $m$ - 1 cópias dessa candidata são geradas substituindo-se tal verbo por cada uma das $m$ - 1 demais possíveis traduções - a menos que estas já estejam na lista $n$ best ou $n$-best expandida. As variações morfológicas do verbo encontrado na sentença candidata original são utilizadas para flexionar as possíveis traduções dadas pelo modelo de DLS (sempre no infinitivo) a serem atribuídas às novas candidatas, novamente, utilizando-se 
o léxico do português. A suposição de que a sentença candidata deve possuir pelo menos um verbo na posição alinhada à da palavra ambígua na sentença fonte mostra-se aceitável para o par de línguas inglês-português, já que, na maioria dos casos, verbos são traduzidos por verbos ou expressões verbais. Se nenhum verbo é encontrado em tal posição, a candidata original é mantida, mas não são geradas novas candidatas a partir dela. Uma variação desse método em que qualquer palavra encontrada em tal posição é substituída pelas possíveis traduções foi também analisada, mas os resultados foram inferiores. Acredita-se que as novas candidatas, nesse caso, representavam dados espúrios, uma vez que palavras de categorias gramaticais distintas são simplesmente substituídas por verbos na sua forma infinitiva.

A lista $n$-best expandida para cada sentença de teste contém, portanto, no máximo $n+(n * m)$ sentenças candidatas, ou seja, todas as candidatas originais e mais as candidatas artificialmente geradas para cada original. $m$ é geralmente baixo, uma vez que apenas um pequeno subconjunto de possíveis traduções possui uma probabilidade acima do limite considerado (0.1). No caso dos modelos simbólicos de DLS, $m$ assume, no máximo, o valor “1” e portanto a expansão pode consistir, no máximo, da duplicação da lista original.

O valor da nova função é atribuído da mesma maneira que no Método 1, tanto para as candidatas originais quanto para as novas candidatas. Contudo, aqui os valores de três outras funções são re-calculados nas novas sentenças candidatas, uma vez que eles podem mudar em tais sentenças: modelo da língua alvo (language model) e modelos de alinhamento direito e inverso de palavras (direct e reverse word-alignment). Os valores das demais funções não são alterados, seja porque permanecem os mesmos ou porque seriam muito complexos para recalcular (por exemplo, phrase translation probability).

Novamente, o conjunto de exemplos de desenvolvimento é utilizado para a otimização dos pesos das funções via MERT, os quais são então utilizados para reordenar as candidatas para cada sentença de teste na lista $n$-best expandida.

Vale notar que, em ambos os métodos, a acurácia média dos modelos de DLS (69\% e 74\%) pode ser considerada relativamente baixa. Contudo, no caso dos modelos SVM, não apenas a tradução mais provável é utilizada nos métodos de integração, mas sim um subconjunto de todas as traduções possíveis. Isso permite minimizar os efeitos de escolhas inadequadas por parte do sistema de DLS. 


\subsubsection{Experimentos e resultados}

Os experimentos com os dois métodos de integração foram realizados com o conjunto de 10 verbos ambíguos e o córpus de 500 sentenças por verbo descrito anteriormente neste Capítulo (400 para treinamento e 100 para teste), considerando-se as duas variações de modelos de DLS apresentadas na Seção 6.4.1.

O conjunto de treinamento para o sistema de TA consiste de um super-conjunto dos exemplos de treinamento do sistema de DLS, extraído das mesmas fontes. No total, tal córpus contém cerca de 700.000 pares de sentenças (643.000 do Europarl, 31.000 da Bíblia, 19.000 do Compara, e 6.000 das diversas outras fontes). O conjunto de desenvolvimento para estimar os pesos originais das funções no modelo linear consiste de um subconjunto dos exemplos de treinamento contendo 4.000 sentenças. Já o conjunto de desenvolvimento para estimar os novos pesos das funções consiste dos mesmos 4.000 exemplos de treinamento do sistema de DLS. Os exemplos de teste, por sua vez, são os mesmos utilizados no sistema de DLS, ou seja, 100 sentenças para cada verbo, totalizando 1.000 exemplos. Definiu-se empiricamente $n$ = 100 para a geração das listas $n$-best e o limite inferior de " 0.1 ” para a seleção das possíveis traduções indicadas pelos modelos probabilísticos de DLS.

A avaliação das traduções resultantes foi realizada considerando-se uma única referência, fornecida pelo córpus paralelo de teste. As 700.000 sentenças em português do córpus paralelo de treinamento são utilizadas para o treinamento de um modelo baseado em trigramas da língua alvo. Os resultados para os dois métodos de integração e as duas variações de modelos de DLS, em termos da medida BLEU, são ilustrados na Tabela 6.14.

Tabela 6.14: Escores BLEU para os dois métodos de integração e variações de modelos de DLS

\begin{tabular}{|l|l|l|l|}
\hline Modelo de DLS & Baseline & Método 1 & Método 2 \\
\cline { 1 - 3 } PLI & \multirow{2}{*}{0.3248} & 0.3404 & 0.3404 \\
\cline { 1 - 1 } \cline { 3 - 4 } SVM & & 0.3500 & 0.3500 \\
\hline
\end{tabular}

Baseline indica o escore BLEU obtido pelo sistema de TA, antes da inclusão da nova função para a DLS. Ambos os modelos de DLS levaram a uma melhoria nesse escore, a qual é estatisticamente significante em ambos os casos (Paired T-Test, $\mathrm{p}<0.05$ ). Como se previa, o ranking probabilístico de classes gerado pelo algoritmo SVM resultou em melhores escores. Diferentemente do que se esperava, contudo, o segundo método de integração não levou à melhoria na medida BLEU. Analisando-se as listas $n$-best originais e expandidas, percebeu-se que, de fato, a lista expandida contém muitas das traduções prováveis que não estavam presentes na lista original e diferentes sentenças são finalmente escolhidas como a tradução 
mais provável nos diferentes métodos de integração. Embora investigações mais aprofundadas ainda precisem ser realizadas, acredita-se que isso pode ser devido à necessidade de alteração de outras funções do modelo quando da geração das novas traduções candidatas, ou mesmo a deficiências da medida BLEU, que não reflete apropriadamente modificações lexicais como as realizadas pelo método de integração.

Para ilustrar a influência da nova função adicionada ao sistema de TA no cálculo dos pesos das demais funções via MERT, na Tabela 6.15 são ilustrados os pesos inicias e reestimados para as nove funções originais, mais a função referente aos modelos de DLS. Como se pode perceber, os pesos de muitas das outras funções diminuíram, enquanto a função relativa aos modelos de DLS recebeu pesos positivos: 0.379 e 2.445 , respectivamente, nos dois métodos.

Tabela 6.15: Pesos de todas as funções no modelo linear de TA antes e depois da inclusão da função de DLS

\begin{tabular}{|l|r|r|r|}
\hline \multirow{2}{*}{ Função } & \multirow{2}{*}{ Antes } & \multicolumn{2}{c|}{ Depois } \\
\cline { 3 - 4 } & & \multicolumn{1}{c|}{ Método 1 } & \multicolumn{1}{c|}{ Método 2 } \\
\hline dls & - & 0.379 & 2.445 \\
\hline word count & 2.649 & 1.463 & 1.342 \\
\hline phrase count & -1.563 & -2.585 & -4.143 \\
\hline target model & 1 & 1 & 1 \\
\hline mle channel model & 1.623 & 1.776 & 1.626 \\
\hline direct channel model & -0.230 & -0.217 & -0.134 \\
\hline inverted channel model & 0.196 & 0.216 & 0.276 \\
\hline template mle & 0.756 & 0.756 & 1.073 \\
\hline template src order count & -0.467 & -1.791 & -1.473 \\
\hline order model & -0.062 & -0.061 & -0.209 \\
\hline
\end{tabular}

Considera-se, em geral, que os resultados desses experimentos preliminares com a integração de modelos de DLS em sistemas de TA sejam bastante promissores. Pretende-se realizar experimentos adicionais para analisar, manualmente, as modificações na lista reordenada de traduções candidatas, bem como para investigar as diferenças entre os dois métodos propostos para a integração.

\subsection{CONSIDERAÇÕES FINAIS}

Neste capítulo foram apresentados diversos experimentos com a abordagem de DLS proposta nesta tese, bem como com um método alternativo para o uso de PLI para a DLS. Para tarefas multilíngues, PLI consistentemente supera os resultados de outros algoritmos de aprendizado de máquina com as mesmas fontes de conhecimento. Quando comparado a outras abordagens totalmente distintas (em termos de métodos e algoritmos de aprendizado, fontes de conhecimento, etc.) para tarefas monolíngues, as abordagens de PLI obtém resultados 
comparáveis ao estado da arte para verbos, e levemente inferiores para substantivos. Vale notar que as fontes de conhecimento exploradas aqui foram especificamente definidas para verbos e, portanto, uma degradação relativa na acurácia quando da desambiguação de substantivos era previsível.

Em geral, acredita-se que os resultados obtidos são bastante positivos, especialmente no cenário multilíngue, considerando-se que (1) os verbos endereçados são altamente ambíguos, (3) algumas traduções ocorrem com frequiência muito baixa no córpus (por exemplo, apenas um ou dois exemplos são encontrados para algumas traduções), e (2) o córpus de exemplos foi automaticamente anotado e, portanto, traduções sinônimas foram usadas para anotar diferentes ocorrências do mesmo sentido em muitos casos, mas essas contam como diferentes sentidos para o mecanismo de inferência. Como a avaliação é automática, não se identificam os casos em que uma tradução sinônima à tradução esperada é utilizada. Portanto, acredita-se que uma estratégia de avaliação menos restritiva poderia levar a acurácias ainda mais altas. Pode-se notar, nos diversos experimentos, o efeito do nível de ambigüidade nos resultados. Os três verbos menos ambíguos introduzidos posteriormente, juntamente com outros verbos com relativamente menos sentidos, sempre obtêm resultados superiores.

Uma vantagem clara dos modelos gerados por PLI está na sua natureza simbólica e altamente expressiva. Tais modelos podem reproduzir qualquer forma de conhecimento de fundo utilizando conjuntos de regras que efetuam testes em conjunções de predicados, referentes a diferentes tipos de conhecimento, os quais podem incluir variáveis (declarações intensionais). Isso vale também para o uso de PLI para a construção de atributos, já que estes são derivados das cláusulas geradas por PLI. Muito embora não se tenha realizado uma análise sistemática sobre a qualidade do conhecimento aprendido, expresso por esses modelos, acredita-se que muitas das cláusulas geradas representam conhecimento interessante, potencialmente novo, para a tarefa de DLS.

De modo geral, os resultados para ambas as tarefas multilíngues e monolíngues confirmam a hipótese levantada no Capítulo 1, de que PLI dotada de fontes de conhecimento superficiais e profundas é capaz de gerar modelos expressivos, que combinam e integram as diversas fontes de conhecimento, e que atingem desempenho melhor ou comparável ao dos sistemas que representam o estado-da-arte em DLS. Os resultados de um experimento de avaliação extrínseca corroboram também a hipótese de que os modelos gerados de acordo com a abordagem proposta podem auxiliar no processo de escolha lexical em sistemas de TA. 


\section{CONCLUSÕES, CONTRIBUIÇÕES E TRABALHOS FUTUROS}

Esta tese focalizou na proposta e desenvolvimento de uma nova abordagem para a desambiguação lexical de sentido voltada para a tradução automática, com aplicação na tradução do inglês para o português. Como a DLS é uma tarefa semanticamente motivada, acredita-se que uma abordagem efetiva requer conhecimento substancial sobre as línguas envolvidas. Contudo, as abordagens atuais utilizam formalismos proposicionais, que não permitem a representação de certas formas de conhecimento. Assim, a hipótese desse trabalho era de que uma abordagem híbrida, baseada tanto em conhecimento lingüístico quanto em conhecimento contextual fornecido por exemplos de desambiguação, utilizando uma linguagem de representação e técnica de modelagem mais expressivas que as abordagens existentes, bem como fontes de conhecimento e estratégias específicas para a desambiguação multilíngue, poderia levar a modelos bastante expressivos, com resultados precisos, bem como ser facilmente estendida para conjuntos maiores de palavras ambíguas, para textos de qualquer gênero e domínio.

Experimentos com diversas tarefas de DLS multilíngue do inglês para o português mostraram que, de fato, os resultados de tal abordagem são superiores aos obtidos por abordagens com algoritmos de aprendizado de máquina tradicionalmente empregados para a DLS. Uma acurácia média máxima de $78 \%$ foi obtida em experimentos com os 7 verbos altamente ambíguos que definiram o escopo inicial do trabalho, descritos por um córpus de aproximadamente 200 sentenças por verbo, de um único domínio (livros de ficção). Uma acurácia média máxima de $74 \%$ foi obtida em novos experimentos com o córpus de 500 sentenças de vários gêneros e domínios para um conjunto de 10 verbos. Experimentos comparativos com o mesmo córpus e técnicas proposicionais de aprendizado tradicionalmente empregadas para gerar modelos de DLS (a saber, Naive Bayes, árvores de decisão e Support Vector Machines), utilizando-se uma representação simplificada das fontes de conhecimento, mostraram que a abordagem proposta supera significativamente as demais (acurácias máxima de $67 \%$ para o primeiro córpus e $68 \%$ para o segundo).

Experimentos adicionais com tarefas monolíngues, realizados com bases de dados padrão para a avaliação comparativa da DLS do inglês, simplesmente removendo-se as fontes de conhecimento específicas para a tradução, mostraram resultados comparáveis aos das abordagens que representam o estado-da-arte na DLS de verbos, foco da abordagem proposta. A acurácia média obtida para os 32 verbos da tarefa de desambiguação do inglês do exercício de avaliação conjunta Senseval-3 foi de $72 \%$, a mesma que a do sistema melhor colocado. A 
acurácia média obtida para a DLS de 50 verbos e 50 substantivos na última edição desse exercício (SemEval-2007) foi de 85.1\%, inferior a apenas três das 16 abordagens competidoras. Vale notar que a abordagem não foi alterada para incluir outras fontes de conhecimento monolíngues, ou específicas para substantivos.

Adicionalmente à acurácia dos modelos resultantes, é importante ressaltar que tais modelos são bastante expressivos, explorando as diversas fontes de conhecimento utilizadas no processo de aprendizado, possivelmente com relações entre elas, por meio do uso de variáveis.

Outro uso da técnica de PLI também foi investigado nesta tese. Mais especificamente, empregou-se tal técnica para a indução de uma forma proposicional de atributos, a partir da representação relacional das fontes de conhecimento. Esses atributos foram então usados para a geração de modelos de desambiguação com um algoritmo proposicional de aprendizado, a saber, SVM. Tal estratégia também apresenta resultados bastante satisfatórios, comparáveis aos dos modelos relacionais, tanto para a tarefa multilíngue, com o primeiro córpus de exemplos de 200 sentenças para cada um dos 7 verbos (acurácia média de 73\%), quanto para a tarefa monolíngue com os 32 verbos do Senseval-3 e as 100 palavras do SemEval-2007 (acurácias médias de $72 \%$ e $85.7 \%$, respectivamente).

Acredita-se que tais resultados positivos obtidos com o uso de PLI devem-se em grande parte ao conjunto variado e substancial de fontes de conhecimento exploradas, as quais foram facilmente representadas por meio do formalismo de representação da lógica de primeira ordem e utilizadas por meio da técnica de modelagem da Programação Lógica Indutiva. As mesmas fontes foram exploradas pela variação da abordagem utilizando-se SVMs e atributos selecionados por meio da PLI. Desse modo, as acurácias médias das duas abordagens investigadas são geralmente comparáveis. A escolha da abordagem mais adequada depende, basicamente, da natureza dos modelos esperados: simbólicos ou numéricos.

Experimentos preliminares de avaliação da abordagem proposta, bem como de uma abordagem simplificada utilizando SVMs, no contexto da tradução automática estatística do inglês para o português mostraram uma melhoria significativa na qualidade das traduções resultantes. Isso evidencia a eficácia dos modelos produzidos e também a relevância das fontes de conhecimento exploradas, já que modelos gerados utilizando-se diferentes algoritmos e tais fontes levaram a resultados positivos. A incorporação do módulo de DLS resultante em sistemas de TA baseados em regras, apesar de não ter sido investigada, seria bastante direta, já que os modelos resultantes consistem de um conjunto de regras. A 
incorporação em sistemas estatísticos de TA, por outro lado, se mostrou mais viável para modelos probabilísticos de DLS.

No que se refere à generalização dos resultados para um conjunto mais amplo de palavras, a limitação da abordagem proposta diz respeito à necessidade de córpus de exemplos etiquetados com os sentidos de tais palavras. Contudo, um sistema de etiquetação automática de sentidos foi proposto para facilitar tal tarefa. Esse sistema, que se baseia em heurísticas como a posição das possíveis traduções com relação à posição da palavra fonte e em estatísticas de córpus, possui precisão satisfatória para o par de línguas em questão, ou seja, inglês-português, uma vez que tais línguas são relativamente próximas, mas a revisão manual das anotações realizadas ainda se faz necessária. As fontes de conhecimento utilizadas, por sua vez, podem ser automaticamente extraídas de recursos lexicais e córpus.

\subsection{CONTRIBUIÇÕES}

A principal contribuição deste trabalho consiste da proposta e desenvolvimento da nova abordagem para a desambiguação lexical de sentido voltada para a TA do inglês para o português. Essa tarefa incluiu:

- O estudo inédito sobre o uso de um método genuinamente híbrido para o problema da ambigüidade lexical de sentido, já que os demais trabalhos de DLS baseados em córpus não fazem uso de conhecimento lingüístico profundo durante o processo de aprendizado, dadas as limitações do formalismo de representação e técnica de modelagem empregados.

- O estudo inédito sobre a utilização da Programação Lógica Indutiva para a tarefa de DLS. Muito embora a PLI já tenha sido utilizada para outras tarefas de PLN, com resultados promissores, esse é o primeiro trabalho a empregar tal técnica especificamente para a DLS, uma tarefa semanticamente motivada e que, portanto, tem grande potencial de se beneficiar com a PLI.

- A investigação de fontes de conhecimento relevantes para a DLS no contexto da TA de verbos do inglês para o português, em especial, de fontes específicas para a TA (o contexto da tradução).

- O projeto e implementação de mecanismos automatizados para a extração e representação dessas diversas fontes a partir do córpus de exemplos e de recursos lingüísticos. 
- O projeto e implementação, por fim, de um módulo computacional de DLS para auxiliar no processo de escolha lexical nos casos de ambigüidade na TA do inglês para o português.

Outras contribuições desta tese incluem:

- O estudo, baseado na língua em uso, do problema da ambigüidade lexical de sentido na TA do inglês para o português. Outros estudos sobre problemas da TA inglês-português foram realizados (por exemplo, o ambiente de avaliação $\mathrm{EVAL}^{36}$ ), contudo, o foco desses estudos não foi a ambigüidade lexical de sentido. Além disso, a maior parte desses estudos considera apenas o português europeu.

- O estudo das diferenças entre a DLS monolíngue e multilíngue, em particular, no que se refere ao repositório de sentidos. A maioria das abordagens atuais é voltada para a DLS monolíngue e, portanto, utiliza repositórios de sentido monolíngues. Mesmo entre as abordagens multilíngues, muitas utilizam sentidos monolíngues, os quais são mapeados para traduções na língua alvo. Contudo acredita-se que essa solução não é adequada para a DLS na TA.

- O projeto e implementação de uma metodologia para a criação automática de córpus de exemplos anotados com os sentidos das palavras ambíguas. Os córpus resultantes de tal implementação foram disponibilizados para uso.

- A investigação e implementação de métodos para a integração do módulo de DLS em um sistema estatístico de TA do inglês para o português.

\subsection{TRABALHOS FUTUROS}

Por se tratar da primeira abordagem de DLS a utilizar uma linguagem de representação e técnica de modelagem baseadas na lógica de primeira ordem, acredita-se que vários aspectos ainda possam ser explorados. Em especial, pretende-se explorar a variação da técnica de Programação Lógica Indutiva, chamada Probabilistic Inductive Logic Programming ou Statistical Relational Learning, que utiliza um modelo probabilístico para descrever as cláusulas de entrada e permite a geração de cláusulas com probabilidades associadas a elas (De Raedt \& Kersting, 2003). Como conseqüência, a contribuição da abordagem proposta em sistemas estatísticos de TA poderia ser avaliada mais adequadamente.

\footnotetext{
${ }^{36} \mathrm{http}: / /$ poloclup.linguateca.pt/ferramentas/eval/index.html
} 
Outra linha de investigação que se pretende explorar diz respeito a uma avaliação mais qualitativa dos resultados, tanto intrínseca, da DLS propriamente dita, como extrínseca, no contexto da TA. A avaliação intrínseca consistiria da análise manual das soluções propostas pelo sistema de DLS, com base nos contextos das sentenças fonte e / ou alvo (fornecidas pelo córpus paralelo). Já a avaliação extrínseca consistiria da comparação entre as traduções realizadas pelo sistema de TA e as traduções produzidas a partir da introdução do módulo de DLS. De fato, as medidas de avaliação automáticas geralmente utilizadas, incluindo BLEU, empregada nesta tese, são reconhecidamente inadequadas para a avaliação de modificações em sistemas básicos de TA para o tratamento de fenômenos lexicais como a ambigüidade, já que privilegiam a fluência da tradução, em detrimento da sua adequação.

Ainda no que diz respeito à avaliação, pretende-se investigar a contribuição da abordagem proposta em outros sistemas estatísticos de TA, em especial, o sistema Moses (Koehn et al., 2007), e também em sistemas de TA baseado em regras, categoria de sistema para o qual a abordagem de DLS foi inicialmente proposta.

Por fim, pretende-se estender a abordagem proposta para novos conjuntos de palavras, principalmente para palavras de outras categorias gramaticais. Para tanto, um passo importante consistirá da identificação e extração das fontes de conhecimento apropriadas para tais categorias gramaticais. Principalmente para a desambiguação de substantivos, acredita-se que a web poderia ser explorada como uma rica fonte de conhecimento, fornecendo colocações e outras estatísticas de córpus. 





\section{REFERÊNCIAS}

Agirre, E, Màrquez, L., Wicentowski, R. (2007). Proceedings the 4th International Workshop on Semantic Evaluations (SemEval-2007), Prague.

Agirre, E. and Edmonds, P. (eds) (2006). Word Sense Disambiguation: Algorithms and Applications, Springer.

Agirre, E. and Stevenson, M. (2006). Knowledge Sources for Word Sense Disambiguation. In E. Agirre and P. Edmonds (eds), Word Sense Disambiguation: Algorithms, Applications and Trends, Springer.

Agirre, E. and Lacalle, O. L. (2007). UBC-ALM: Combining k-NN with SVD for WSD. 4th International Workshop on Semantic Evaluations (SemEval-2007), Prague, pp. 342-345.

Agirre, E. and Martínez, D. (2000). Exploring Automatic Word Sense Disambiguation with Decision Lists and the Web. COLING Workshop on Semantic Annotation and Intelligent Content. Saarbrücken.

Agirre, E. and Martínez, D. (2004). Unsupervised WSD Based on Automatically Retrieved Examples: The Importance of Bias. 2004 Conference on Empirical Methods in Natural Language Processing (EMNLP-2004), Barcelona, pp. 25-32.

Agirre, E. and Rigau, G. (1996). Word Sense Disambiguation Using Conceptual Density. 16th International Conference on Computational Linguistics (COLING-1996). Copenhagen, pp. 16-22.

ALPAC (1966). Languages and machines: computers in translation and linguistics. A report by the Automatic Language Processing Advisory Committee, Division of Behavioral Sciences, National Academy of Sciences, National Research Council. Washington, D.C. Publication 1416, 124p.

Alves, I. M. R. (2002). Tradutores Automáticos e Ambigüidade: Uma Abordagem Crítica. Trabalho de Conclusão de Curso, Universidade do Vale do Rio dos Sinos - UNISINOS, São Leopoldo.

Arnold, D.J., Balkan, L., Humphreys, R.L., Meijer, S., Sadler, L. (1993). Machine Translation: An Introductory Guide. Blackwells-NCC, London.

Atkins, S. (1992). Tools for corpus-aided lexicography: the HECTOR project. Acta Linguistica Hungarica 41(1992-93):5-72.

Atkins, S. and Fillmore, C. (1994). Starting Where the Dictionaries Stop: The Challenge of Corpus Lexicography. In B. Atkins \& A. Zampolli (eds), Conceptual approaches to the lexicon. Oxford University Press, Oxford.

Baker, K. L., Franz, A.M., Jordan, P. W., Mitamura, T., Nyberg, E. H. (1994). Coping with Ambiguity in a Large-Scale Machine Translation System. 15th International Conference on Computational Linguistics (COLING-1994), Kyoto, pp. 90-94.

Banerjee, S. and Pedersen, T. (2002). An adapted Lesk algorithm for word sense disambiguation using WordNet. Third International Conference on Intelligent Text Processing and Computational Linguistics (CICLing-2002), Mexico City, pp.136-145.

Bar-Hillel, Y. (1960). The Present Status of Automatic Translation of Languages. Advances in Computers. Academic Press, New York, 1:91-163.

Beale, S. (1997). HUNTER-GATHERER: Applying Constraint Satisfaction, Branch-and-Bound and Solution Synthesis to Computational Semantics. PhD Thesis, Language Technologies Institute, Carnegie Mellon University.

Bentivogli, L., Forner, P., Pianta, E. (2004). Evaluating Cross-Language Annotation Transfer in the MultiSemCor Corpus. 20th International Conference on Computational Linguistics (COLING2004), Geneva, pp. 364-370. 
Berger, A. L., Della, S. A., Della, V. J. (1996). A maximum entropy approach to natural language processing. Computational Linguistics, 22(1):39-71.

Black, E. (1988). An Experiment in Computational Discrimination of English Word Senses. IBM Journal of Research and Development, 32(2), pp. 185-194.

Blei, D. M., Ng, A. Y., Jordan, M. I. (2003). Latent Dirichlet Allocation. Journal of Machine Learning Research, 3:993-1022.

Boguraev, B. (1979). Automatic Resolution of Linguistic Ambiguities. Report 11, Computer Laboratory, University of Cambridge, Cambridge.

Borba, F. S. (1996). Uma Teoria de Valências para o Português. Ática, São Paulo.

Bordag, S. (2006). Word Sense Induction: Triplet-Based Clustering and Automatic Evaluation. 11th Conference of the European Chapter of the Association for Computational Linguistics (EACL2006), Trento, pp. 137-144.

Boyd-Graber, J., Blei, D., Zhu, X. (2007). A Topic Model for Word Sense Disambiguation. Joint Conference on Empirical Methods in Natural Language Processing and Computational Natural Language Learning (EMNLP-CoNLL-2007), Prague, pp. 1024-1033.

Bräscher, M. (2002). A Ambigüidade na Recuperação da Informação. DataGramaZero - Revista de Ciência da Informação, 3(1).

Brill, E. (1992). A Simple Rule-based Part-of-speech Tagger. 3rd Conference on Applied Natural Language Processing, Morgan Kaufmann, San Mateo, pp. 152-155.

Brill, E. (1995). Transformation Error-Driven Learning and Natural Language Processing: A Case Study in Part-of-Speech Tagging, Computational Linguistics, 21(4):543-565.

Briscoe, T. (1991). Lexical Issues in Natural Language Processing. In E. Klein and F. Veltman (eds), Symposium on Natural Language and Speech, Springer-Verlag, Berlin, pp. 39-68.

Brody, S., Navigli, R., Lapata, M. (2006). Ensemble Methods for Unsupervised WSD. 44th Annual Meeting of the Association for Computational Linguistics \& 21st International Conference on Computational Linguistics (COLING-ACL-2006), Sydney, pp. 97-104.

Brown, M. L. and Kros, J. F (2003). Data Mining and the Impact of Missing Data. Industrial Management and Data Systems, 103(8): 611-621.

Brown, P.F., Della Pietra, S.A., Della Pietra, V.J., Mercer, R.L. (1991). Word Sense Disambiguation Using Statistical Methods. 29th Annual Meeting of the Association for Computational Linguistics (ACL-1991), Berkley, pp. 264-270.

Bruce, R. and Guthrie, L. (1992). Genus disambiguation: A study in weighted performance. 14th Conference on Computational Linguistics (COLING-1992), Nantes, pp. 1187-1191.

Bruce, R. and Wiebe, J. (1994). Word-sense disambiguation using decomposable models. 32nd Annual Meeting of the Association. for Computational Linguistics (ACL-1994), Las Cruces, pp.139-145.

Brun, C. (2000). A Client/Server Architecture for Word Sense Disambiguation. 17th Conference on Computational Linguistics (COLING-2000), Saarbrucken, pp. 132-138.

Burchfield, R. (1971) (ed.). The Oxford English Dictionary. Oxford University Press.

Burnard, L. (2000). Reference Guide for the British National Corpus (World Edition). Oxford University Press.

Cabezas, C. and Resnik, P. (2005). Using WSD Techniques for Lexical Selection in Statistical Machine Translation. UMIACS Technical Report UMIACS-TR-2005-42, July. 
Cai, J. F., Lee, W. S., The, Y. W. (2007a). Improving Word Sense Disambiguation Using Topic Features. Joint Conference on Empirical Methods in Natural Language Processing and Computational Natural Language Learning (EMNLP-CoNLL-2007), Prague, pp. 1015-1023.

Cai, J. F., Lee, W. S., The, Y. W. (2007b). NUS-ML: Improving Word Sense Disambiguation Using Topic Features. 4th International Workshop on Semantic Evaluations (SemEval-2007), Prague, pp. 249-252.

Califf, M. E. and Mooney, R.J. (2003). Bottom-Up Relational Learning of Pattern Matching Rules for Information Extraction. Journal of Machine Learning Research, 4:177-210.

Carletta, J. (1996). Assessing Agreement on Classification Tasks: the Kappa Statistic, Computational Linguistics, 22(2):249-254.

Carlson, A .J., Cumby, C. M., Rizzolo, N.D., Rosen, J. L., Roth, D. (1999). SNoW User Manual. Computer Science Department, University of Illinois, Urbana-Champaign (http://12r.cs.uiuc.edu/ cogcomp/software/snow-userguide/ [01/04/2004]).

Carpuat, M, Shen, Y. Yu, X., Wu, D. (2006). Toward Integrating Word Sense and Entity Disambiguation into Statistical Machine Translation. Third International Workshop on Spoken Language Translation (IWSLT-2006), Kyoto, pp. 37-44.

Carpuat, M. and Wu, D. (2007). Improving Statistical Machine Translation using Word Sense Disambiguation. 2007 Joint Conference on Empirical Methods in Natural Language Processing and Computational Natural Language Learning (EMNLP-CoNLL-2007), Prague, pp. 61-72.

Carpuat, M. and Wu, D. (2005a). Word sense disambiguation vs. statistical machine translation. 43rd Annual Meeting of the Association for Computational Linguistics (ACL-2005), Ann Arbor, pp. 387394.

Carpuat, M. and Wu, D. (2005b). Evaluating the word sense disambiguation performance of statistical machine translation. Second International Joint Conference on Natural Language Processing (IJCNLP-2005), Jeju Island, Korea, pp. 122-127.

Carpuat, M. Su, W. and Wu, D. (2004). Augmenting ensemble classification for Word Sense Disambiguation with a kernel PCA model. 3rd International Workshop on the Evaluation of Systems for the Semantic Analysis of Text (Senseval-3), Barcelona, pp. 88-92.

Caseli, H. M., Silva, A. M. P., Nunes, M.G.V. (2004). Evaluation of Methods for Sentence and Lexical Alignment of Brazilian Portuguese and English Parallel Texts. 7th Simpósio Brasileiro de Inteligência Artificial (SBIA), São Luiz, pp. 184-193.

Chan, Y. S., Ng, H. T., Chiang, D. (2007). Word sense disambiguation improves statistical machine translation. 45th Annual Meeting of the Association for Computational Linguistics (ACL-2007), Prague, pp. 33-40.

Chang, C-C., Lin, C-J. (2001). LIBSVM: a library for support vector machines. Software available at http://www. csie.ntu.edu.tw/cjlin/libsvm.

Chapman, R. (1977). Roget's International Thesaurus, $4^{\text {th }}$ ed., Harper and Row, New York.

Chatterjee, N., Goyal, S., and Naithani, A. (2005). Pattern Ambiguity and its Resolution in English to Hindi Translation. Recent Advances in Natural Language Processing (RANLP-2005), Borovets, pp. $152-156$.

Ciaramita, M. and Johnson, M. (2004). Multi-component Word Sense Disambiguation. 3rd International Workshop on the Evaluation of Systems for the Semantic Analysis of Text (Senseval-3), Barcelona, pp. 97-100.

Cole, R. A., Mariani, J., Uszkoreit, H., Zaenen, A., Zue, V. (1996). Survey of the State of the Art in Human Language Technology. Cambridge University Press, Cambridge. 
Copeland, C., Durand, J., Krauwer, S., Maegaard, B. (1991). The Eurotra Formal Specifications. Studies in Machine Translation and Natural Language Processing, 2, Commission of European Communities.

Cottrell, G. W. (1989). A Connectionist Approach to Word Sense Disambiguation, Research Notes in Artificial Intelligence, Morgan Kaufmann, San Mateo.

Cottrell, G. W. and Small, S. L. (1983). A Connectionist Scheme for Modeling Word Sense Disambiguation. Cognition and Brain Theory, 6:89-120.

Cowie, J., Guthrie, J.A., Guthrie, L. (1992). Lexical Disambiguation Using Simulated Annealing. 4th International Conference on Computational Linguistic (COLING-1992), Nantes, pp. 359-365.

Cucerzan, S. and Yarowsky, D. (2002). Augmented Mixture Models for Lexical Disambiguation. 2002 Conference on Empirical Methods in Natural Language Processing (EMNLP-2002), Philadelphia, pp. 33-40.

Cussens, J. (1997). Part-of-Speech Tagging Using Progol. 7th International Workshop on Inductive Logic Programming (ILP-1997), Prague, LNAI 1297, Springer-Verlag, pp. 93-108.

Cussens, J., Page, D., Muggleton, S. Srinivasan, A. (1997). Using Inductive Logic Programming for Natural Language Processing. Workshop on Empirical Learning of Natural Language Tasks, Prague, pp. 25-34.

Cussens, J. and Pulman, S. (2000a). Experiments in Inductive Chart Parsing. 1st Workshop on Learning Language in Logic, Bled, Slovenia, pp. 72-83.

Cussens, J. and Pulman, S. (2000b). Incorporating Linguistics Constraints into Inductive Logic Programming. 4th Conference on Computational Natural Language Learning and 2nd Learning Language in Logic Workshop (CoNLL-LLL-2000), Lisbon, pp. 184-193.

Daelemans, W., Zavrel, J., Van Der Sloot, K., Van Den Bosch, A. (1998). TiMBL: Tilburg Memory Based Learner. Technical Report 98-03, Tilburg.

Dagan, I. and Itai, A. (1994). Word Sense Disambiguation Using a Second Language Monolingual Corpus. Computational Linguistics, 20:563-596.

Dagan, I., Itai, A., Schwall, U. (1991). Two Languages are More Informative than One. 29th Annual Meeting of the Association for Computational Linguistics (ACL-1991), Berkeley, pp. 130-137.

Dagan, I., Marcus, S., Markovitch, S. (1993). Contextual Word Similarity and Estimation from Sparse Data. 31st Annual Meeting of the Association for Computational Linguistics (ACL-1993), Columbus, pp. 164-171.

De Raedt, L. and Kersting, K. Probabilistic Logic Learning (2003). ACM-SIGKDD Explorations: Special issue on Multi-Relational Data Mining, 5(1):31-48.

Decadt, B., Hoste, V., Daelemans, W. (2004). GAMBL, Genetic Algorithm Optimization of MemoryBased WSD. 3rd International Workshop on the Evaluation of Systems for the Semantic Analysis of Text (Senseval-3), Barcelona, pp. 108-112.

Dempster, A., Laird, N., and Rubin, D. (1977). Maximum Likelihood from Incomplete Data via the EM Algorithm. Journal of the Royal Statistical Society, Series B, 39(1):1-38.

Diab, M. and Resnik, P. (2002). An Unsupervised Method for Word Sense Tagging using Parallel Corpora. 40th Annual Meeting of the Association for Computational Linguistics (ACL-2002), Philadelphia, pp. 255-262.

Dias-da-Silva, B. C. (1996). A Face Tecnológica dos Estudos da Linguagem: O Processamento Automático das Línguas Naturais. Tese de Doutorado, Faculdade de Ciências e Letras de Araraquara, Universidade Estadual Paulista, Araraquara. 
Dihn, D., Kiem, H., Hovy, E. (2003). BTL: a Hybrid Model for English-Vietnamese Machine Translation. 9th Machine Translation Summit, New Orleans, pp. 23-27.

Dini, L., Di Tomaso, V., Segond, F. (1998). Word sense disambiguation with functional relations. 1st International Conference on Language Resources and Evaluation (LREC), Granada, pp. 11891196.

Dolan, W. (1994). Word Sense Ambiguation: Clustering Related Senses. 32nd Annual Meeting of the Association for Computational Linguistics (ACL-1994), New Mexico, pp. 712-716.

Dorr, B. J. and Katsova, M. (1998). Lexical Selection for Cross-Language Applications: Combining LCS with WordNet. 3rd Conference of the Association for Machine Translation in the Americas (AMTA-1998), Langhorne, pp. 438-447.

Dorr, J. B. (1993). Machine Translation: A View from the Lexicon. The MIT Press, Cambridge.

Dostert, L. E. (1955). The Georgetown-I.B.M. experiment. Locke, W.N. and Booth, A.D. (eds.) Machine translation of languages. Cambridge, MIT Press, pp.124-135.

Duda, O. R. and Hart, P.E. (1973). Pattern Classification and Scene Analysis. Wiley, New York.

EAGLES Lexicon Interest Group (1998). Preliminary Recommendations on Semantic Encoding. Interim Report (http://www.ilc.cnr.it/EAGLES96/rep2/rep2.html [01/04/2004]).

Edmonds, P. and Cotton, S. (2001). Senseval-2: Overview. 2nd International Workshop on Evaluating Word Sense Disambiguation Systems (Senseval-2), Pennsylvania, pp. 1-5.

Egedi, D., Palmer, M., Park, H. S., Joshi, A. K. (1994). Korean to English Translation Using Synchronous TAGs. 1st Conference of the Association for Machine Translation in the Americas (AMTA-1994), Maryland, pp. 48-55.

Escudero, G., Màrquez, L., Rigau, G. (2000a). Naive Bayes and Exemplar-Based Approaches to Word Sense Disambiguation Revisited. 14th European Conference on Artificial Intelligence (ECAI2000), Berlin, pp. 421-425.

Escudero, G., Màrquez, L., Rigau, G. (2000b). Boosting Applied to Word Sense Disambiguation. 12th European Conference on Machine Learning (ECML-2000), Barcelona, pp. 129-141.

Escudero, G., Màrquez, L., Rigau, G. (2000c). A Comparison between Supervised Learning Algorithms for Word Sense Disambiguation. Fourth Conference on Computational Language Learning and Second Learning Language in Logic Workshop (CoNLL-LLL-2000), Lisbon, pp. 3136.

Escudero, G., Màrquez, L., Rigau, G. (2001). Using LazyBoosting for Word Sense Disambiguation. 2nd International Workshop on Evaluating Word Sense Disambiguation Systems (Senseval-2), Toulouse.

Fellbaum, C. (1998). WordNet: An Electronic Lexical Database. MIT Press, Massachusetts.

Fernández, J., Castilho, M., Rigau, G., Atserias, J., Turmo, J. (2004). Automatic Acquisition of Sense Examples using ExRetriever. International Conference on Language Resources and Evaluation (LREC-2004), Lisbon, pp. 25-28.

Fernandez-Amoros, D., Gonzalo, J., Verdejo, F. (2001). The Role of Conceptual Relations in Word Sense Disambiguation. International Conference on Application of Natural Language to Information Systems (NLDB-2001), Madrid, pp. 87-98.

Flanagan, M. and McClure, S. (2002). SYSTRAN and the Reinvention of MT. IDCBulletin \#26459 Jan 2002 (http://www.systransoft.com/IDC/26459.html [10/03/2004]).

Florian, R., Cucerzan, S., Schafer, C., Yarowsky, D. (2002). Combining Classifiers for Word Sense Disambiguation. Natural Language Engineering, Cambridge University Press, Cambridge, 1(1):114. 
Fossey, M. F., Pedrolongo, T., Martins, R. T., Nunes, M. G. V. (2004). Análise Comparativa de Tradutores Automáticos Inglês-Português, Série de Relatórios do NILC, NILC-TR-04-04, São Carlos, Março, 18p.

Frankenberg-Garcia, A. and Santos, D. (2003). Introducing COMPARA: the Portuguese-English Parallel Corpus. Corpora in translator education, pp. 71-87.

Francis, W. M. and Kucera, H. (1979). Brown Corpus - Manual of Information. Department of Linguistics, Brown University (http://helmer.aksis.uib.no/icame/brown/bcm.html [03/04/2004]).

Freund, Y. and Schapire, R.E. (1996). Experiments with a New Boosting Algorithm. 13th International Conference on Machine Learning, pp. 148-156.

Fujii, A., Inui, K., Tokunaga, T., Tanaka, H. (1998). Selective Sampling for Example-based Word Sense Disambiguation. Computational Linguistics, 24(4): 573-598.

Gaizauskas, R., Wakao, T., Humphreys, K., Cunningham, H., Wilks, Y. (1996). Description of the LaSIE System as Used for MUC-6. 6th Message Understanding Conference, Morgan Kaufmann, San Mateo, pp. 207-220.

Gajek, O. (1991). The METAL system. Communications of the ACM, 34(9):46-47.

Gale, W. A. and Church, K. W. (1991). A Program for Aligning Sentences in Bilingual Corpora. 29th Annual Meeting of the Association for Computational Linguistics (ACL-1991), Berkeley, 177-184.

Gale, W. A., Church, K. W., Yarowsky, D. (1992a). Estimating Upper and Lower Bounds on the Performance of Word Sense Disambiguation Programs. 30th Annual Meeting of the Association for Computational Linguistics (ACL-1992), Newark, pp. 249-25.

Gale, W. A, Church, K. W., Yarowsky, D. (1992b). One Sense Per Discourse. 4th DARPA Speech and Natural Language Workshop, Pacific Grove, pp. 233-237.

Gale, W. A., Church, K. W. Yarowsky, D. (1992c). A Method for Disambiguating Word Senses in a Large Corpus. Computers and the Humanities, 26:415-439.

Gale, W. A. and Church, K.W. (1993). A Program for Aligning Sentences in Bilingual Corpora. Computational Linguistics, 19:75-102.

Galley, M. and McKeown, K. (2003). Improving word sense disambiguation in lexical chaining. 18th International Joint Conference on Artificial Intelligence (IJCAI-2003), Acapulco, pp.1486-1488.

Germann, U., Jahr, M., Knight, K., Marcu, D., Yamada, K. (2001). Fast decoding and optimal decoding for machine translation. 39th Annual Meeting of the Association for Computational Linguistics (ACL-2001), Toulouse, pp. 228 - 235.

Goodman, K. and Nirenburg, S. (1991). The KBMT Project: A case study in Knowledge-Based Machine Translation. Morgan Kaufmann Publishers, California.

Greghi, J. G., Martins, R. T., Nunes, M. G. V. (2002). DIADORIM: A Lexical Database for Brazilian Portuguese. 3rd International Conference on Language Resources and Evaluation, Las Palmas de Gran Canaria, pp. 1346-1350.

Grozea, C. (2004). Finding optimal parameter settings for high performance word sense disambiguation. 3rd International Workshop on the Evaluation of Systems for the Semantic Analysis of Text (Senseval-3), Barcelona, pp. 125-128.

Guthrie, J., Guthrie, L., Wilks, Y., Aidinejad, H. (1991). Subject-Dependent Co-Occurrence and Word Sense Disambiguation. 29th Annual Meeting of the Association for Computational Linguistics (ACL-1991), Berkeley, pp. 146-152.

Hawkins, P. (1999). DURHAM: A Word Sense Disambiguation System. PhD thesis, Laboratory for Natural Language Engineering, Department of Computer Science, University of Durham, Durham. 
Hayes, P. J. (1976). A Process to Implement Some Word Sense Disambiguation. Working Paper 23, Institut pour les Etudes Sémantiques et Cognitives, Universitè de Genève, Gèneve.

Hearst, M. (1991). Noun Homograph Disambiguation using Local Context in Large Text Corpora. 7th Annual Conference of the UW Centre for the New OED and Text Research: Using Corpora, Oxford, pp. 1-22

Hirst, G. (1987). Semantic Interpretation and the Resolution of Ambiguity. Studies in Natural Language Processing. Cambridge University Press, Cambridge.

Hoste, V., Hendrickx, I., Daelemans, W., van den Bosch, A. (2002). Parameter Optimization for Machine-Learning of Word Sense Disambiguation. Natural Language Engineering, Cambridge University Press, 8:311-325.

Hovy, E. H., Marcus, M. Palmer, S. Pradhan, L. Ramshaw, and R. Weischedel. (2006). OntoNotes: The $90 \%$ Solution. Human Language Technology / North American Association of Computational Linguistics Conference (HLT-NAACL 2006), New York, pp. 57-60.

Hutchins, W. J. and Somers, H. L. (1992). An Introduction to Machine Translation. Academic Press, Great Britain.

Ide, N. (1999). Parallel Translations as Sense Discriminators. SIGLEX-99 Workshop on Standardizing Lexical Resources, Maryland, pp. 52-61.

Ide, N. and Véronis, J. (1998). Word Sense Disambiguation: The State of the Art. Computational Linguistics, 24(1).

Ide, N., Erjavec, T., Tufi, D. (2002). Sense Discrimination with Parallel Corpora. ACL-2002 Workshop on Word Sense Disambiguation: Recent Successes and Future Directions, Philadelphia, pp. 54-60.

Jackendoff, R. (1990). Semantic Structures. The MIT Press, Cambridge.

Jiang, J. and Conrath, D. (1997). Semantic similarity based on corpus statistics and lexical taxonomy. 10th International Conference on Research in Computational Linguistics, Taiwan, pp. 19-33.

Jurafsky, D. and Martin, J. H. (2000). Speech and Language Processing: An introduction to Natural Language Processing, Computational Linguistics and Speech Recognition. Prentice-Hall, New Jersey.

Karov, Y. and Edelman, S. (1998). Similarity-based Word Sense Disambiguation. Computational Linguistics, 24(1):41-59.

Katz, J. J., Fodor, J. A. (1963). The Structure of a Semantic Theory. Language, 39:170-210.

Kilgarriff, A. (1992). Polysemy. PhD Thesis, University of Sussex, UK.

Kilgarriff, A. (1997a). I Don't Believe in Word Senses. Computers and the Humanities, 31(2):91-113.

Kilgarriff, A. (1997b). What is Word Sense Disambiguation Good For? NLP Pacific Rim Symposium1997, Phuket, pp. 209-214.

Kilgarriff, A. and Rosenzweig, J. (2000). English Senseval: Report and Results. 2nd International Conference on Language Resources and Evaluation (LREC-2000), Athens, pp. 1239-1244.

Kilgarriff, A., Palmer, M. (2000). Introduction to the Special Issue on Senseval. Computers and the Humanities, 34(1-2):1-13, Kluwer Academic Publishers, The Netherlands.

Klavans, J. and Kan, M. (1998). Role of Verbs in Document Analysis. 36th Annual Meeting of the Association for Computational Linguistics (ACL-1998), Montreal, pp. 680-686.

Koehn, P. (2002). Europarl: A Multilingual Corpus for Evaluation of Machine Translation. (http://www.isi.edu/ koehn/publications/europarl/ [01/12/2003]).

Koehn, P., Och, F. J., Marcu, D. (2003). Statistical phrase based translation. Human Language 
Technology and North American Chapter of the Association for Computational Linguistics (HLTNAACL-2003), Edmonton, pp. 48-54.

Koehn, P., Hoang, H., Birch, A., Callison-Burch, C., Federico, M., Bertoldi, N., Cowan, B., Shen, W, Moran, C., Zens, R., Dyer, C., Bojar, O., Constantin, A., Herbst, E. (2007). Moses: Open Source Toolkit for Statistical Machine Translation. 45th Annual Meeting of the Association for Computational Linguistics (ACL-2007), demonstration session, Prague.

Kramer, S., Lavrac, N., Flach, P. (2001). Propositionalization Approaches to Relational Data Mining. Relational Data Mining, S. Dzeroski and N. Lavrac (eds), Springer, pp. 262-291.

Krovetz, R. (1998). More than One Sense Per Discourse. Research Memorandum, NEC Research Institute, Princeton.

Lamjiri, A., Demerdash, O., Kosseim, F. (2004). Simple Features for Statistical Word Sense Disambiguation. 3rd International Workshop on the Evaluation of Systems for the Semantic Analysis of Text (Senseval-3), Barcelona, pp. 133-136.

Lavrac, N. (1998). Computational Logic and Machine Learning: A Roadmap for Inductive Logic Programming. Technical Report, Jozef Stefan Institute, Ljubljana, Slovenia.

Leacock, C., Chodorow, M., Miller, G. A. (1998). Using Corpus Statistics and WordNet Relations for Sense Identification. Computational Linguistics, 24(1):147-165.

Leacock, C., Towell, G., Voorhees, E. M. (1993). Corpus-Based Statistical Sense Resolution. ARPA Human Language Technology Workshop, Morgan Kaufmann Publishers, San Francisco, pp. 260265.

Lee, H. (2002). Classification Approach to Word Selection in Machine Translation. 5th Conference of the Association for Machine Translation in the Americas (AMTA-2002), Tiburon, pp. 114-123.

Lee, Y. K., Ng, H. T., Chia, T. K. (2004). Supervised Word Sense Disambiguation with Support Vector Machines and Multiple Knowledge Sources. 3rd International Workshop on the Evaluation of Systems for the Semantic Analysis of Text (Senseval-3), Barcelona, pp. 137-140.

Lee, Y. K. and Ng, H. T. (2002). An Empirical Evaluation of Knowledge Sources and Learning Algorithms for Word Sense Disambiguation. 2002 Conference on Empirical Methods in Natural Language Processing (EMNLP-2002), Philadelphia, pp. 41-48.

Leffa, V. J. (1995). Resolução da Ambigüidade Lexical na Tradução Automática de Textos: um Estudo Exploratório. I Encontro do CelSul, Florianópolis, pp. 33.

Leffa, V. J. (1998). Textual constraints in L2 lexical disambiguation. System, Great Britain, 26(2):183194.

Lesk, M. (1986). Automated Sense Disambiguation Using Machine-readable Dictionaries: How to Tell a Pine Cone from an Ice Cream Cone. 1986 ACM SIGDOC Conference, Toronto, pp. 24-26.

Lin, D. (1993). Principle-based Parsing without Overgeneration. 31st Annual Meeting of the Association for Computational Linguistics (ACL-1993), Columbus, pp. 112-120.

Lin, D. (2004). A Path-based Transfer Model for Machine Translation. 20th International Conference on Computational Linguistics (COLING-2004), Geneva, pp. 625-630.

Lyons, J. (1977). Semantics. Cambridge University Press, Cambridge.

Maegaard, B. (2001). Machine Translation. In E. Hovy, N. Ide, R. Frederking, J. Mariani, and A. Zampolli (eds), Multilingual Information Management: Current Levels and Future Abilities. Insituti Editoriali e Poligrafici Internazionali, Pisa.

Manning, C. D. and Schütze, H. (2001). Foundations of Statistical Natural Language Processing. The MIT Press, Cambridge. 
Martínez D. and Agirre E. (2000). One Sense per Collocation and Genre/Topic Variations. Joint SIGDAT Conference on Empirical Methods in Natural Language Processing and Very Large Corpora, Hong Kong, pp. 207-215.

Masterman, M. (1957). The Thesaurus in Syntax and Semantics. Mechanical Translation, 4:1-2.

Masterman, M. (1961). Semantic Message Detection for Machine Translation Using an Interlingua. International Conference on Machine Translation of Languages and Applied Language Analysis, London, pp. 437-475.

McCarthy, D. (1997). Word Sense Disambiguation for the Acquisition of Selectional Restrictions. ACL/EACL Workshop on Automatic Information Extraction and Building of Lexical Semantic Resources, Madrid, pp. 52-60.

McCarthy, D., Koeling, R., Weeds, J., Carroll, J. (2004a). Finding predominant senses in untagged text. 42nd Annual Meeting of the Association for Computational Linguistics (ACL-2004), Barcelona, pp. 280-287

McCarthy, D., Koeling, R., Weeds, J., Carroll, J. (2004b). Using automatically acquired predominant senses for word sense disambiguation. 3rd International Workshop on the Evaluation of Systems for the Semantic Analysis of Text (Senseval-3), Barcelona, pp. 151-154.

McRoy, S. (1992). Using Multiple Knowledge Sources for Word Sense Discrimination. Computational Linguistics, 18(1):1-30.

Mihalcea, R. (2002). Bootstrapping Large Sense Tagged Corpora. 3rd International Conference on Language Resources and Evaluation (LREC-2002), Las Palmas, Spain.

Mihalcea, R. (2004). Co-training and Self-training for Word Sense Disambiguation. 8th Conference on Natural Language Learning (CoNLL-2004), Boston, pp. 33-40.

Mihalcea, R. and Moldovan, D. I. (1999a). A Method for Word Sense Disambiguation of Unrestricted Text. 37th Annual Meeting of the Association for Computational Linguistics (ACL-1999), Maryland, pp. 152-158.

Mihalcea, R. and Moldovan D. I. (1999b). An Automatic Method for Generating Sense Tagged Corpora. 16th National Conference on Artificial intelligence (AAAI-99), Orlando, pp. 461-466.

Mihalcea, R. and Moldovan, D. I. (2001). Automatic Generation of a Coarse Grained WordNet. NAACL Workshop on WordNet and Other Lexical Resources, Pittsburgh, pp. 35-41.

Mihalcea, R. and Edmonds, P. (2004). Proceedings of Senseval-3: 3rd International Workshop on the Evaluation of Systems for the Semantic Analysis of Text, Barcelona.

Mihalcea, R. and Ehsanul, F. (2004). Sense-Learner: Minimally Supervised Word Sense Disambiguation for All Words in Open Text. 3rd International Workshop on the Evaluation of Systems for the Semantic Analysis of Text (Senseval-3), Barcelona, pp. 155-158.

Mihalcea, R., Chklovski, T., Kilgariff, A. (2004). The Senseval-3 English Lexical Sample Task. 3rd International Workshop on the Evaluation of Systems for Semantic Analysis of Text (Senseval-3), Barcelona, pp. 25-28.

Miháltz, M. (2005). Towards A Hybrid Approach to Word-Sense Disambiguation in Machine Translation. RANLP-2005 Workshop on Modern Approaches in Translation Technologies, Borovets.

Miller, G. A., Chorodow, M., Landes, S., Leacock, C, Thomas, R.G. (1994). Using a Semantic Concordancer for Sense Identification. ARPA Human Language Technology Workshop, Washington, pp. 240-243.

Mitamura, T. (1999). Controlled Language for Multilingual Machine Translation. 7th Machine Translation Summit, Singapore. 
Mohammad, S. and Pedersen, T. (2004). Complementarity of Lexical and Simple Syntactic Features: The SyntaLex Approach to Senseval-3. 3rd International Workshop on the Evaluation of Systems for the Semantic Analysis of Text (Senseval-3), Barcelona, pp. 159-162.

Monard, M. C. and Baranauskas, J. A. (2003). Conceitos sobre Aprendizado de Máquina. In S.O. Rezende (org.), Sistemas Inteligentes: Fundamentos e Aplicações, Manole, Barueri, pp. 89-114.

Montcheuil, G. M., El-Bèze, M. Chen, B., Kraif, O. (2004). Using a Word Sense Disambiguation System for Translation Disambiguation: the LIA-LIDILEM Team Experiment. 3rd International Workshop on the Evaluation of Systems for the Semantic Analysis of Text (Senseval-3), Barcelona, pp. 175-178.

Montoyo, A., Romero, R., Vazquez, S., Calle, M., and Soler, S. (2002). The Role of WSD for Multilingual Natural Language Applications. Text, Speech and Dialogue (TSD-2002), Brno, pp. 41-48.

Mooney, R. J. (2004). Learning Semantic Parsers: An Important But Under-Studied Problem. AAAI Spring Symposium on Language Learning: An Interdisciplinary Perspective, Stanford, pp. 39-44.

Mooney, R. J. and Califf, M. E. (1995). Induction of First-Order Decision Lists: Results on Learning the Past Tense of English Verbs. Journal of Artificial Intelligence Research, 3:1-24.

Mooney, R. J. (1996). Comparative Experiments on Disambiguating Word Senses: An Illustration of the Role of Bias in Machine Learning. 1996 Conference on Empirical Methods in Natural Language Processing (EMNLP-1996), Somerset, New Jersey, pp. 82-91.

Mooney, R. J. (1997). Inductive Logic Programming for Natural Language Processing. 6th International Inductive Logic Programming Workshop, Stockholm, LNAI 1314, Springer-Verlag, pp. 3-24.

Muggleton, S. (1991). Inductive Logic Programming. New Generation Computing, 8(4):295-318.

Muggleton, S. (1994). Inductive Logic Programming: derivations, successes and shortcomings. SIGART Bulletin 5(1):5-11.

Muggleton, S. (1995). Inverse Entailment and Progol. New Generation Computing, 13:245-286.

Muggleton, S. and De Raedt, L. (1994). Inductive logic programming: Theory and methods. Journal of Logic Programming, 19-20:629-679.

Nadas, A., Nahamoo, D., Picheny, M.A., Powell, J. (1991). An iterative 'flip-flop' approximation of the most informative split in the construction of decision trees. International Conference on Acoustics, Speech, and Signal Processing, Toronto, pp. 565-568.

Navigli, R. (2006a). Online Word Sense Disambiguation with Structural Semantic Interconnections. 11th Conference of the European Association for Computational Linguistics (EACL-2006), Trento, pp. 107-110.

Navigli, R. (2006b). Meaningful Clustering of Senses Helps Boost Word Sense Disambiguation Performance. 44th Annual Meeting of the Association for Computational Linguistics and 21st International Conference on Computational Linguistics (COLING-ACL 2006), Sydney, pp.105112.

Navigli, R. and Velardi, P. (2005). Structural Semantic Interconnections: A Knowledge-Based Approach to Word Sense Disambiguation. IEEE Transactions on Pattern Analysis and Machine Intelligence (PAMI), 27(7):1075-1086.

Nédellec, C., C. Rouveirol, H. Adé, F. Bergadano, and B. Tausend (1996). Declarative bias in ILP. In L. De Raedt (ed.), Advances in Inductive Logic Programming, Volume 32 of Frontiers in Artificial Intelligence and Applications, IOS Press, pp. 82-103. 
Ng, H. T. (1997a). Exemplar-Based Word Sense Disambiguation: Some Recent Improvements. 1997 Conference on Empirical Methods in Natural Language Processing (EMNLP-1997), Providence, pp. 208-213.

Ng, H. T. (1997b). Getting Serious about Word Sense Disambiguation. SIGLEX Workshop on Tagging Text with Lexical Semantics: Why, What, and How?, Washington, pp. 1-7.

$\mathrm{Ng}, \mathrm{H} . \mathrm{T}$. and Lee, H. B. (1996). Integrating Multiple Knowledge Sources to Disambiguate Word Senses: An Exemplar-Based Approach. 34th Annual Meeting of the Association for Computational Linguistics (ACL-1996), Somerset, New Jersey, pp. 40-47.

Ng, H. T., Wang, B., Chan, Y. S. (2003). Exploiting Parallel Texts for Word Sense Disambiguation: An Empirical Study. 41st Annual Meeting of the Association for Computational Linguistics (ACL2003), Sapporo, pp. 455-462.

Ng, H. T. and Zelle, J. (1997). Corpus-Based Approaches to Semantic Interpretation in Natural Language Processing. AI Magazine, 18(4):45-64.

Niu, Z., Ji, D., Tan, C. (2007). I2R: Three Systems for Word Sense Discrimination, Chinese Word Sense Disambiguation, and English Word Sense Disambiguation. 4th International Workshop on Semantic Evaluations (SemEval-2007), Prague, pp. 177-182.

Nunes, M. G. V. et al. (1996). The design of a Lexicon for Brazilian Portuguese: Lessons learned and Perspectives. II Encontro para o Processamento Computacional da Língua Portuguesa Escrita e Falada (Propor-1996), Curitiba, pp. 61-70.

Och, F. J. (2003). Minimum error rate training in statistical machine translation. 41st Annual Meeting of the Association for Computational Linguistics (ACL-2003), Sapporo, pp. 160-167.

Och, F. J. and Ney, H. (2003). A Systematic Comparison of Various Statistical Alignment Models, Computational Linguistics, 29(1):19-51.

Och, F. J., Gildea, D., Khudanpur, S., Sarkar, A., Yamada, K., Fraser, A., Kumar, S., Shen, L., Smith, D., Eng, K., Jain, V., Jin, Z., Radev, D. (2004). A Smorgasbord of Features for Statistical Machine Translation. Human Language Technology and North American Chapter of the Association for Computational Linguistics (HLT-NAACL-04), Boston, pp. 161-168.

Oliveira Jr., O. N., Marchi, A. R., Martins, M. S., Martins, R. T. (2000). A Critical Analysis of the Performance of English-Portuguese-English MT Systems. V Encontro para o Processamento Computacional da Língua Portuguesa Escrita e Falada (Propor-2000), Atibaia, pp. 85-92.

Paliouras, G., Karkaletsis, V., Androutsopoulos, I., Spyropoulos, C. D. (2000). Learning Rules for Large-Vocabulary Word Sense Disambiguation: a Comparison of Various Classifiers. 2nd International Conference on Natural Language Processing (NLP-2000), Patra, Lecture Notes in Artificial Intelligence, Springer, pp. 383-394.

Paliouras, G., Karkaletsis, V., Spyropoulos, C. D. (1999). Learning Rules for Large-Vocabulary Word Sense Disambiguation. 16th International Joint Conference on Artificial Intelligence (IJCAI-1999), Morgan Kaufmann Publishers, San Francisco, pp. 674-679.

Palmer, M. (1998). Are WordNet sense distinctions appropriate for computational lexicons? SIGLEX/ Senseval Workshop on Word Sense Disambiguation, Brighton.

Pantel, P., Lin, D. (2002). Discovering Word Senses from Text. ACM SIGKDD Conference on Knowledge Discovery and Data Mining, Edmonton, pp. 613-619.

Papineni, K., Roukos, S., Ward, T. and Zhu, W. J. (2002). BLEU: a method for automatic evaluation of machine translation. 40th Annual Meeting of the Association for Computational Linguistics, Philadelphia (ACL-2002), pp. 311-318. 
Park, S., Zhang, B., Kim, Y. T. (2003). Word Sense Disambiguation by Learning Decision Trees from Unlabeled Data. Applied Intelligence, 19, Kluwer Academic Publishers, The Netherlands, pp. 2738.

Parker, J. and Stahel, M. (1998). Password: English Dictionary for Speakers of Portuguese. Martins Fontes, São Paulo.

Patrick, A. B. (1985). An Exploration of Abstract Thesaurus Instantiation. M.Sc.Thesis, University of Kansas, Kansas.

Patwardhan, S., Banerjee, S., Pedersen, T. (2003). Using measures of semantic relatedness for word sense disambiguation. 4th International Conference on Intelligent Text Processing and Computational Linguistics (CICLing-2003), Mexico City, pp. 241-257.

Patwardhan, S., Banerjee, S., Pedersen, T. (2005). SenseRelate::TargetWord - A Generalized Framework for Word Sense Disambiguation. 20th National Conference on Artificial Intelligence (AAAI-2005), Pittsburgh, PA. pp. 1692-1693.

Patwardhan, S., Banerjee, S., Pedersen, T. (2007). UMND1: Unsupervised Word Sense Disambiguation Using Contextual Semantic Relatedness. 4th International Workshop on Semantic Evaluations (SemEval-2007), Prague, pp. 390-393.

Pedersen, B. S. (1997). Lexical Ambiguity in Machine Translation: Expressing Regularities in the Polysemy of Danish Motion Verbs. PhD Thesis, Center for Sprogteknologi, Copenhagen.

Pedersen, T. (2000). A Simple Approach to Building Ensembles of Naive Bayesian Classifiers for Word Sense Disambiguation. 1st Conference of the North American Chapter of the Association for Computational Linguistics and 6th Conference on Applied Natural Language Processing (NAACLANLP-2000), Seattle, pp. 63-69.

Pedersen, T. (2002a). A Baseline Methodology for Word Sense Disambiguation. 3rd International Conference on Intelligent Text Processing and Computational Linguistics (CICLing-2002), LNCS 2276, Mexico City, pp. 126-135.

Pedersen, T. (2002b). Evaluating the Effectiveness of Ensembles of Decision Trees in Disambiguating Senseval Lexical Samples. SIGLEX / Senseval Workshop on Word Sense Disambiguation: Recent Successes and Future Directions, Philadelphia, pp. 81-87.

Pedersen, T. and Bruce, R. (1997). Distinguishing Word Senses in Untagged Text. 1997 Conference on Empirical Methods in Natural Language Processing (EMNLP-1997), Providence, pp. 197-207.

Pedersen, T. and Bruce, R. (1998). Knowledge Lean Word-Sense Disambiguation. 15th National Conference on Artificial Intelligence (AAAI-1998), Providence, pp. 800-805.

Pedersen, T. and Kulkarni, A. (2006). Selecting the "Right" Number of Senses Based on Clustering Criterion Functions. 11th Conference of the European Chapter of the Association for Computational Linguistics (EACL-2006), Trento, pp. 111-114.

Pedersen, T., Patwardhan, S., Michelizzi, J. (2004). WordNet::Similarity - Measuring the Relatedness of Concepts. 19th National Conference on Artificial Intelligence (AAAI-2004), San Jose, CA, pp. 1024-1025.

Pereira, F., Tishby, N., Lee, L. (1993). Distributional Clustering of English Words. 31st Annual Meeting of the Association for Computational Linguistics (ACL-1993), Ohio, pp. 183-190.

Peters, W., Peters, I., Vossen, P. (1998). Automatic Sense Clustering in EuroWordNet. 1st Conference on Language Resources and Evaluation (LREC-1998), Granada.

Pierce, J. R. and Carroll, J. B. (1966). Language and Machines - Computers in Translation and Linguistics. ALPAC report, National Academy of Sciences, National Research Council, Washington, D.C. (Publication 1416) 124p. (available from http://darwin.nap.edu/books/ARC000005/html) 
Pradhan, S., Loper, E., Dligach, D., Palmer, M. (2007). English Lexical Sample, SRL and all Words. 4th International Workshop on Semantic Evaluations (SemEval-2007), Prague, pp. 93-98.

Procter, P. (ed). (1978). Longman Dictionary of Contemporary English. Longman Group, Essex.

Pustejovsky, J. (1995). The Generative Lexicon. The MIT Press, Cambridge.

Quillian, M. R. (1961). A Design for an Understanding Machine. Colloquium of Semantic problems in natural language. King's College, Cambridge University, Cambridge.

Quinlan, J. R. (1988). C4.5 - Programs for Machine Learning. Morgan Kaufmann.

Quirk, C., Menezes, A., Cherry, C. (2005). Dependency Treelet Translation: Syntactically Informed Phrasal SMT. 43rd Annual Meeting of the Association for Computational Linguistics (ACL-2005), Ann Arbor, pp. 271-279.

Ramakrishnan, G., Joshi, S., Balakrishnan, S., Srinivasan, A. (2007). Using ILP to Construct Features for Information Extraction from Semi-Structured Text. International Conference on Inductive Logic Programming (ILP-08), Oregon.

Ramakrishnan, G., Prithviraj, B. and Bhattacharya, P. (2004). A gloss-centered algorithm for disambiguation. The Third International Workshop on the Evaluation of Systems for the Semantic Analysis of Text (Senseval-3), Barcelona, pp. 217-221

Rapp, R. (2004). Utilizing the One-Sense-Per-Discourse Constraint for Fully Unsupervised Word Sense Induction and Disambiguation. 4th International Conference on Language Resources and Evaluation (LREC-2004), Lisbon, pp. 951-954.

Ratnaparkhi, A. (1996). A Maximum Entropy Part-Of-Speech Tagger. 1996 Conference on Empirical Methods in Natural Language Processing (EMNLP-1996), Pennsylvania, pp. 133-142.

Rehfeldt, G. K. (1980). Polissemia e Campo Semântico: Estudo Aplicado aos Verbos de Movimento. Editora da Universidade Federal do Rio Grande do Sul, Porto Alegre.

Resnik, P. (1995a). Disambiguating Noun Groupings with Respect to WordNet Senses. 3rd Workshop on Very Large Corpora, Cambridge, pp. 54-68.

Resnik, P. (1995b). Using Information Content to Evaluate Semantic Similarity in a Taxonomy. 14th International Joint Conference on Artificial Intelligence (IJCAI-1995), Montreal, pp. 448-453.

Resnik, P. (1997). Selectional Preferences and Sense Disambiguation. ACL-SIGLEX Workshop on Tagging Text with Lexical Semantics: Why, What and How? Washington, pp. 52-57.

Resnik, P. and Yarowsky, D. (1997a). Evaluating Automatic Semantic Taggers. ACL-SIGLEX Workshop Tagging Texts with Lexical Semantics: Why, What and How? Washington, pp. 91.

Resnik, P. and Yarowsky, D. (1997b). A Perspective on Word Sense Disambiguation Methods and their Evaluating. ACL-SIGLEX Workshop Tagging Texts with Lexical Semantics: Why, What and How? Washington, pp. 79-86.

Rivest, R. L. (1987). Learning Decision Lists. Machine Learning, 2(3):229-246.

Schütze, H. (1992). Dimensions of Meaning. Supercomputing-1992, IEEE Computer Society Press, Washington, pp. 787-796.

Schütze, H. (1998). Automatic Word Sense Discrimination. Computational Linguistics, 24(1):97-124.

Schütze, H. and Pedersen, J. (1995). Information Retrieval Based on Word Senses. 4th Annual Symposium on Document Analysis and Information Retrieval, Las Vegas.

Simões, A. M. and Almeida, J. J. (2003). NATools - A Statistical Word Aligner Workbench. Procesamiento del Lenguaje Natural, 31:217-224. 
Small, S. L. (1980). Word-expert Parsing, a Theory of Distributed Word-based Natural Language Based Understanding. Technical Report 954, Department of Computer Science, University of Maryland, Maryland.

Snow, R., Prakash, S., Jurafsky, D., Ng, A. Y. (2007). Learning to Merge Word Senses. Joint Conference on Empirical Methods in Natural Language Processing and Computational Natural Language Learning (EMNLP-CoNLL-2007), Prague, pp. 1005-1014.

Sparck-Jones, K. and Galliers, J. R. (1996). Evaluating Natural Language Processing Systems: an Analysis and Review. Springer-Verlag.

Specia, L. and Nunes, M. G. V. (2004a). A Ambigüidade Lexical de Sentido na Tradução do Inglês Para o Português - Um Recorte de Verbos Problemáticos. Série de Relatórios do ICMC-USP (NILC-TR-04-01). São Carlos, Março, 30p.

Specia, L. and Nunes, M. G. V. (2004b). Desambiguação Lexical Automática de Sentido: Um Panorama. Série de Relatórios do ICMC-USP (NILC-TR-04-08). São Carlos, Agosto, 117p.

Specia, L. (2005). Knowledge sources for disambiguating highly ambiguous verbs in machine translation. Student Session of the 17th European Summer School in Logic, Language and Information (ESSLLI-2005), Edinburgh, pp. 330-341.

Specia, L., Oliveira-Netto, S., Nunes, M. G. V., Stevenson, M. (2005a). An Automatic Approach to Create a Sense Tagged Corpus for Word Sense Disambiguation in Machine Translation. 2nd Meaning Workshop (Meaning-2005), Trento, pp. 31-36.

Specia, L., Nunes, M. G. V., Stevenson, M. (2005b). Exploiting Parallel Texts to Produce a Multilingual Sense-tagged Corpus for Word Sense Disambiguation. Recent Advances on Natural Language Processing (RANLP-2005), Borovets, pp. 525-531.

Specia, L. (2006). A Hybrid Relational Approach for WSD - First Results. COLING-ACL-2006 Student Research Workshop, Sydney, pp. 55-60.

Specia, L., Nunes, M. G. V., Ribeiro, G. C., Stevenson, M. (2006a). The Need for ApplicationDependent WSD Strategies: a Case Study in MT. 7th Workshop on Computational Processing of Written and Spoken Portuguese (Propor-2006), LNAI 3960, Itatiaia, pp. 233-237.

Specia, L., Nunes, M. G. V., Stevenson, M. (2006b). Translation Context Sensitive WSD. 11th Annual Conference of the European Association for Machine Translation (EAMT-2006), Oslo, pp. 227232.

Specia, L.; Nunes, M. G. V. (2006c). Exploiting the Translation Context for Multilingual WSD. 9th International Conference on Text, Speech and Dialogue (TSD-2006), LNAI 4188, Brno, pp. 269276.

Specia, L., Nunes, M. G. V., Srinivasan, A., Ramakrishnan, G. (2007a). Word Sense Disambiguation using Inductive Logic Programming. Selected papers from the 16th International Conference on Inductive Logic Programming (ILP-2006), LNCS 4455, pp. 409-423.

Specia, L., Nunes, M. G. V., Stevenson, M. (2007b). Learning Expressive Models for Word Sense Disambiguation. 45th Annual Meeting of the Association for Computational Linguistics (ACL2007), Prague, pp. 41-48.

Specia, L., Nunes, M. G. V., Srinivasan, A., Ramakrishnan, G. (2007c). USP-IBM-1 and USP-IBM-2: The ILP-based Systems for Lexical Sample WSD in SemEval-2007. 4th International Workshop on Semantic Evaluations (SemEval-2007), Prague, pp. 442-445.

Srinivasan, A. (2000). The Aleph Manual. Technical Report, Computing Laboratory, Oxford University. Available from http://web.comlab.ox.ac.uk/oucl/research/areas/ machlearn/Aleph/aleph_toc.html.

Stevenson, M. (2003). Word Sense Disambiguation: The Case for Combining Multiple Knowledge 
Sources. CSLI Publications, Stanford, CA.

Stevenson, M. and Wilks, Y. (1999). Combining Weak Knowledge Sources for Sense Disambiguation. International Joint Conference on Artificial Intelligence, Stockholm, pp. 884-888.

Stevenson, M. and Wilks, Y. (2000). Large Vocabulary Word Sense Disambiguation. Y. Ravin and C. Leacock (eds.), Polysemy: Theoretical and Computational Approaches, Oxford University Press, Oxford, pp. 161-177.

Stevenson, M. and Wilks, Y. (2001). The Interaction of Knowledge Sources for Word Sense Disambiguation. Computational Linguistics, 27(3):321-349.

Stokoe, C., Oakes, M. P., Tait, J. (2003). Word Sense Disambiguation in Information Retrieval Revisited. ACM Special Interest Group on Information Retrieval, Toronto, pp. 159-166.

Sussna, M. (1993). Word Sense Disambiguation for Free-text Indexing Using Massive Semantic Network. 2nd International Conference on Information and Knowledge Base Management, Virginia, pp. 67-74.

Tillmann, C., Vogel, S., Ney, H. and Zubiaga, A. (1997). A DP-based search using monotone alignments in statistical translation. 35th Annual Meeting of the Association for Computational Linguistics and 8th European Chapter of the Association for Computational Linguistics (ACLEACL-1997), Madrid, pp. 313-320.

Toutanova, K. and Suzuki, H. (2007). Generating Case Markers in Machine Translation. Human Language Technology and North American Chapter of the Association for Computational Linguistics (HLT-NAACL-07), Rochester, pp. 49-56.

Towell, G. and Voorhees, E. M. (1998) Disambiguating Highly Ambiguous Words. Computational Linguistics, 24(1):125-145.

Ullmann, (1964). Semântica: uma Introdução à Ciência do Significado. Fundação Calouste Gulbenkian, Lisboa.

Véronis, J. (1998). A Study of Polysemy Judgements and Inter-annotator Agreement. Programme and Advanced Papers of the Senseval Workshop, Herstmonceux Castle pp. 2-4.

Véronis, J. and Ide, N. M. (1990). Word Sense Disambiguation with Very Large Neural Networks Extracted from Machine Readable Dictionaries. 13th International Conference on Computational Linguistics (COLING-1990), Helsinki pp. 398-394.

Vickrey, D., Biewald, L., Teyssier, M. and Koller, D. (2005). Word-Sense Disambiguation for Machine Translation. Human Language Technology Conference and Conference on Empirical Methods in Natural Language Processing (HLT-EMNLP-2005), Vancouver, pp. 771-778.

Vogel, S., Och, F. J., Tillmann, C., Nießen, S., Sawaf, H., Ney, H. (2000). Statistical Methods for Machine Translation. In Verbmobil: Foundations of Speech-to-Speech Translation, Springer Verlag, Berlin, pp. 377-393.

Vogel, S., Zhang, Y., Huang, F., Tribble, A., Venugopal, A., Zhao, B., Waibel, A. (2003). The CMU Statistical Machine Translation System. 9th Machine Translation Summit, Phuket.

Voorhees, E. M. (1993). Using WordNet to disambiguate word senses for text retrieval. 16th Annual International ACM SIGIR Conference on Research and Development in Information Retrieval, Pittsburgh, PA., pp. 171-180.

Vossen, P. (1998). EuroWordNet: Building a Multilingual Database with WordNets for European Languages. The ELRA Newsletter, 3(1).

Waltz, D. L. and Pollack, J. B. (1985). Massively Parallel Parsing: A Strongly Interactive Model of Natural Language Processing. Cognitive Science, 9:51-74. 
Weaver, W. (1949). Translation. W. N. Locke and A.D. Booth (ed.), Machine Translation of Languages: Fourteen Essays. The MIT Press, Cambridge, pp. 15-23.

Wilcoxon, F. (1945). Individual comparisons by ranking methods. Biometrics, 1:80-83.

Wilks, Y. (1975). A Preferential, Pattern-seeking, Semantics for Natural Language Inference. Artificial Intelligence, 6:53-74.

Wilks, Y. (1997). Senses and Texts. Computers and the Humanities, 31(2).

Wilks, Y. and Stevenson, M. (1996). The Grammar of Sense: Using Part-of-speech Tags as a First Step in Semantic Disambiguation. Technical Report CS-96-05, University of Sheffield. Also published in the Journal of Natural Language Engineering, 4(1):1-9, 1998.

Wilks, Y. and Stevenson, M. (1997a). Sense Tagging: Semantic Tagging with a Lexicon. SIGLEX Workshop "Tagging Text with Lexical Semantics: What, why and how". Washington, pp. 47-51.

Wilks, Y. and Stevenson, M. (1997b). Combining Independent Knowledge Sources for Word Sense Disambiguation. Recent Advances in Natural Language Processing (RANLP-2003), Tzigov Chark, pp. 1-7.

Wilks, Y. and Stevenson, M. (1998). Word Sense Disambiguation Using Optimised Combinations of Knowledge Sources. 17th International Conference on Computational Linguistics (COLING1998), Montreal, pp. 1398-1402.

Wilks, Y., Fass, D., Guo, C-M., McDonald, J. E., Plate, T., Slator, B. M. (1990). Providing Machine Tractable Dictionary Tools. Journal of Machine Translation, 5 (2):99-151.

Wu, D. (1997). Stochastic inversion transduction grammars and bilingual parsing of parallel corpora. Computational Linguistics, 23(3):377-403.

Yamada, K. and Knight, K. (2001). A syntax-based statistical translation model. 39th Annual Meeting of the Association for Computational Linguistics and 10th Conference of the European Chapter of the Association for Computational Linguistics (ACL-EACL-2001), Toulouse, pp. 523-530.

Yarowsky, D. (1992). Word-Sense Disambiguation Using Statistical Models of Roget's Categories Trained on Large Corpora. 14th International Conference on Computational Linguistics (COLING1992), Nantes, pp. 454-460.

Yarowsky, D. (1993). One Sense Per Collocation. ARPA Human Language Technology Workshop, Princeton, pp. 266-271.

Yarowsky, D. (1994). Decision Lists for Lexical Ambiguity Resolution: Application to Accent Restoration in Spanish and French. 32nd Annual Meeting of the Association for Computational Linguistics (ACL-1994), Las Cruces, pp. 88-95.

Yarowsky, D. (1995). Unsupervised Word Sense Disambiguation Rivaling Supervised Methods. 33rd Annual Meeting of the Association for Computational Linguistics (ACL-1995), Cambridge, MA, pp. 189-196.

Yarowsky, D. (2000). Hierarchical Decision Lists for Word Sense Disambiguation. Computers and the Humanities, 34(1-2), Kluwer Academic Publishers, The Netherlands, pp. 179-186.

Yarowsky, D., Cucerzan, S., Florian, R., Schafer, C. and Wicentowski, R. (2002). Combining Classifiers for word sense disambiguation. Natural Language Engineering, 8(4): 327-341.

Zavaglia, C. (2002). Análise da Homonímia no Português: Tratamento Semântico com Vistas a Procedimentos Computacionais. Tese de Doutorado, Faculdade de Ciências e Letras de Araraquara, Universidade Estadual Paulista, Araraquara.

Zhu, J. and Hovy, E. (2007). Active Learning for Word Sense Disambiguation with Methods for Addressing the Class Imbalance Problem. 45th Annual Meeting of the Association of Computational Linguistics (ACL-2007), Prague, pp. 783-790. 
Zinovjeva, N. (2000). Learning Sense Disambiguation Rules for Machine Translation. Master's Thesis in Language Engineering. Department of Linguistics, Uppsala University. 